Hugo Puertas de Araújo

\title{
Simulação e Caracterização de Diodos Controlados por Porta Visando a Fabricação de Sensores de Radiação Luminosa
}

Dissertação apresentada à Escola Politécnica da Universidade de São Paulo para obtenção do título de Mestre em Engenharia Elétrica.

São Paulo, 2000 


\section{Hugo Puertas de Araújo}

Engenheiro Eletricista; Escola Politécnica da USP, 1997

\section{Simulação e Caracterização de Diodos Controlados por Porta Visando a Fabricação de Sensores de Radiação Luminosa}

Dissertação apresentada à Escola Politécnica da Universidade de São Paulo para obtenção do título de Mestre em Engenharia Elétrica.

Área de Concentração:

Microeletrônica

Orientador:

Sebastião Gomes dos Santos Filho 
Araújo, Hugo Puertas de

Simulação e caracterização de diodos controlados por porta visando a fabricação de sensores de radiação luminosa. São Paulo, 2000.

$163 p$.

Dissertação (Mestrado) - Escola Politécnica da Universidade de São Paulo. Departamento de Engenharia Eletrônica.

1. Diodo controlado por porta 2. Sensores de radiação luminosa I. Universidade de São Paulo. Escola Politécnica. Departamento de Engenharia Eletrônica II. $\mathrm{t}$ 
Este trabalho é dedicado à minha família sem o apoio da qual eu não teria chegado até aqui. 


\section{AGRADECIMENTOS}

Ao amigo e orientador Prof. Dr. Sebastião Gomes dos Santos Filho, por sua orientação e real interesse no trabalho desenvolvido.

Agradeço também aos colegas e amigos do Grupo de Superfícies, Interfaces e Deposição Eletroquímica (GSIDE) do LSI-EPUSP pelos incentivos e discussões proveitosas.

Ao prof. Dr. João Antônio Martino, por ceder amostras de transistores nMOS usadas na medida de $\mathrm{s}_{0}$.

Ao Conselho Nacional de Pesquisa e Desenvolvimento $(\mathrm{CNPq})$ pelo financiamento do presente trabalho. 


\section{Sumário}

Lista de figuras

Lista de tabelas

Lista de símbolos

Resumo

Abstract

1 - Introdução 1

1.1 - Sensores de radiação luminosa ...........................................................1

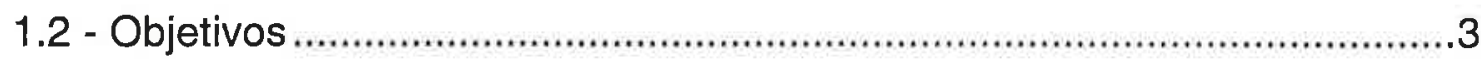

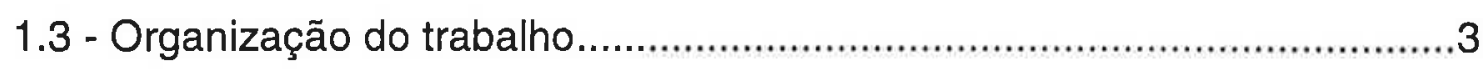

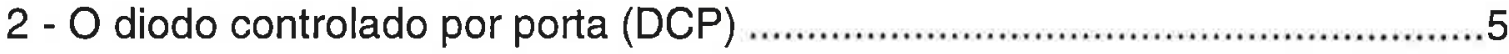

2.1 - Efeitos de campos superficiais em junções PN ................................6

2.2 - Região de carga espacial superficial em condições de não-equilíbrio sob

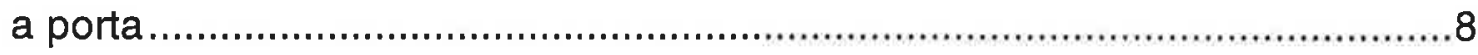

2.3 - A corrente reversa em DCP's ......................................................... 14

2.3.1 - Melhorias no modelo básico ..................................................18

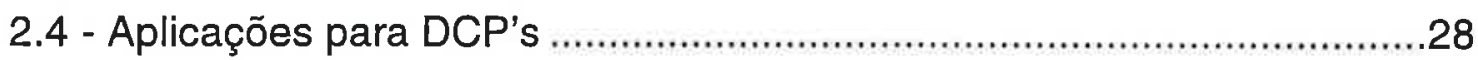

3 - Projeto de uma pastilha-teste (Chip-test) para DCP's ............................33

3.1 Etapas de processo e conjunto de máscaras ......................................33

3.2 Descrição dos dispositivos escolhidos para a pastilha-teste ....................36

4 - Procedimentos experimentais ......................................................53

4.1 - Processo de fabricação .............................................................53

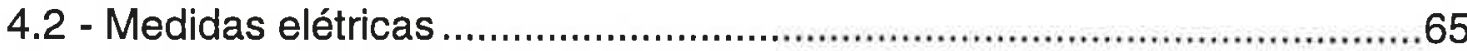

4.2.1 - Determinação da concentração de substrato..................................65

4.2.2 - Determinação da velocidade de recombinação superficial .............65 
5 - Apresentação e discussão dos resultados .68

5.1 - Simulações .68

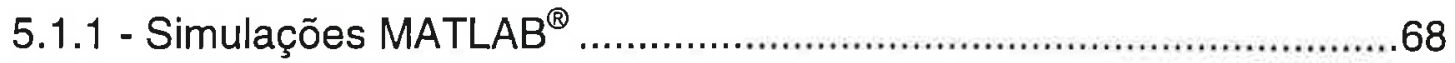

5.1.2 - Simulações elétricas .....................................................................92

5.2 - Medidas experimentais em alguns dispositivos implementados ..........107

5.2.1 - Caracterização das lâminas de processo (P1, N1, EN1 e EN3) ....107

5.2.2 - Caracterização do transistor 117

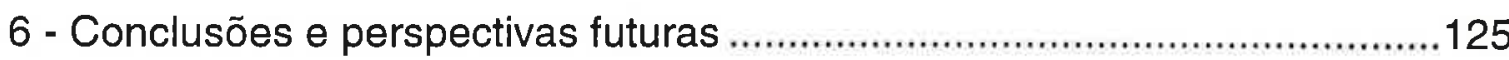

6.1 - Conclusões

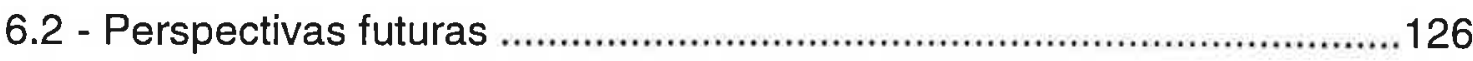

Anexo A - Conceitos básicos sobre ondas eletromagnéticas, faixas de energia e absorção de radiação 127

A.1 - Natureza das ondas eletromagnéticas .............................................130

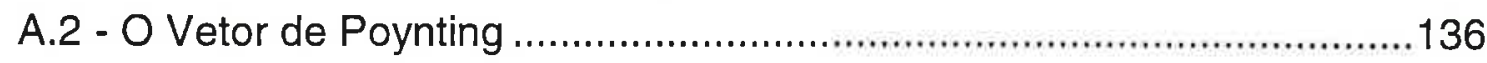

A.3 - Níveis de energia em um átomo e num sólido..................................137

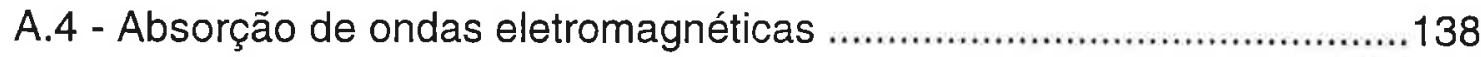

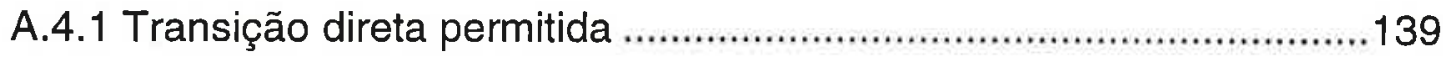

A.4.2 Transição indireta entre vales indiretos ……………………...........140

A.4.3 Transições entre prolongamentos de banda .................................141

A.4.4 Absorção fundamental em presença de campo elétrico forte ..........142

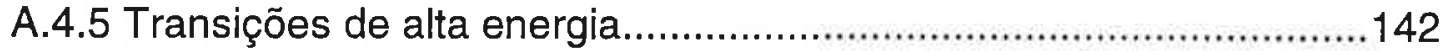

A.4.6 Transições entre bandas e níveis de impureza ...............................142

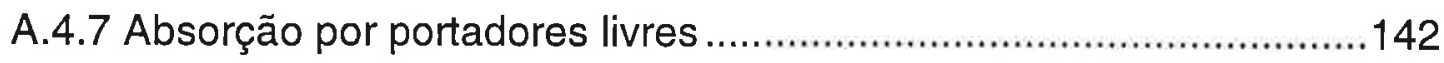

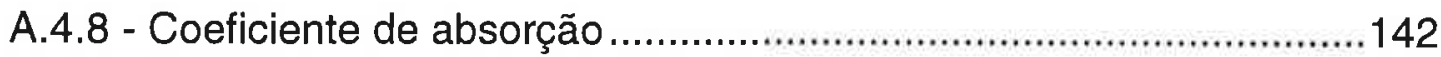

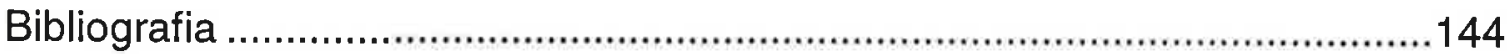


Apêndice A - Propriedades físicas do Silício

Apêndice B - Constantes físicas

Apêndice $\mathrm{C}$ - Identidades vetoriais 


\section{Lista de figuras}

Fig. 1-1: Espectro eletromagnético 2

Fig. 2-1: a) Estrutura ideal de um DCP; b) Detalhe da junção. ...........................5

Fig. 2-2: Junção em equilíbrio térmico. ............................................................

Fig. 2-3: Junção reversamente polarizada. ………….......................................7

Fig. 2-4: Curva $C x V$ em baixa freqüência, parametrizada pela tensão de junção. 14

Fig. 2-5: Dependência da corrente reversa com a tensão de polarização de porta em DCP's. 15

Fig. 2-6: Corrente reversa e capacitância em função do potencial de porta. ....18 Fig. 2-7: Nível de quase-Fermi nas direções $y$ (a) e $x$ (b) segundo Grove e Fitzgerald. 19

Fig. 2-8: Nível de quase-Fermi na direção y em duas condições: (a) nível de $F_{n}$ abaixo de $E_{i}$ (b) nível de $F_{n}$ cruzando $E_{i}$ 20

Fig. 2-9: Simbologia adotada .21

Fig. 2-10: "Regiões mortas" dentro da região de depleção de um DCP. .22

Fig. 2-11: Variação de $\gamma$ em função da posição de $F_{N}$ dentro da faixa proibida.

Fig. 2-12: Velocidade de recombinação superficial como função do comprimento efetivo do canal. .28

Fig. 2-13: Corrente reversa versus tensão reversa para um $D C P P^{+} N$ [GROV'67] 29

Fig. 2-14: Estudo da tensão de ruptura em junções metalúrgicas e induzidas. 29 
Fig. 2-15: Montagem utilizada para estabilização de nós capacitivos de células de memória. .30

Fig. 2-16: Curva $I x V$ de um DCP pulsado via resistor. 31

Fig. 3-1: Representação esquemática dos processos implementados na fabricação de DCP's. Em cinza temos $\mathrm{SiO}_{2}$ (o cinza escuro é o óxido de porta), em lilás $\mathrm{Si}_{3} \mathrm{~N}_{4}$, em vermelho Si-poli, em verde junções, e em azul o $\mathrm{Ni}$ 35

Fig. 3-2: Disposição dos dispositivos na pastilha-teste. .38

Fig. 3-3: Capacitor MOS em planta (a) e em perfil vertical (b). 39

Fig. 3-4: Diodo de junção em planta (a) e em perfil vertical (b) 40

Fig. 3-5: Diodo Schottky em planta (a) e em perfil vertical (b) e diodo de junção "serpentina" (c).... 40

Fig. 3-6: Cascatas de transistores. (a) $L$ variável, (b) $Z$ variável. 41

Fig. 3-7: Inversor nMOS. 42

Fig. 3-8: Estruturas Kelvin e van der Pauw. (a) Si-poli, (b) Difusão e (c) Alumínio. .43

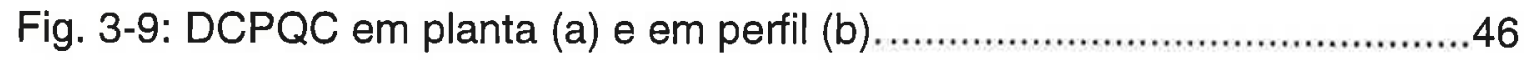

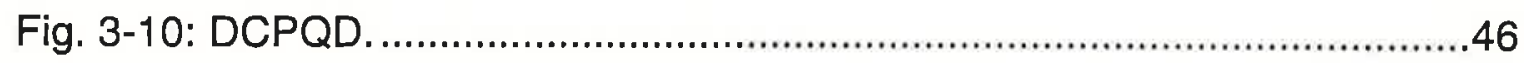

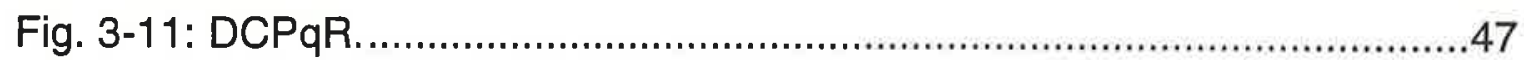

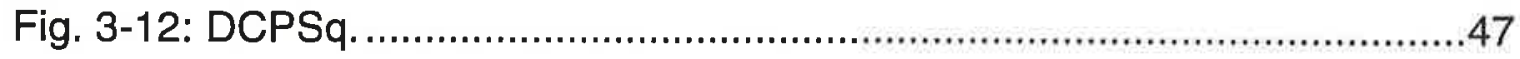

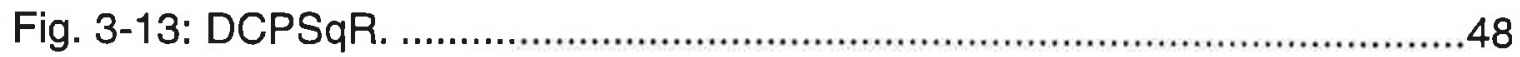

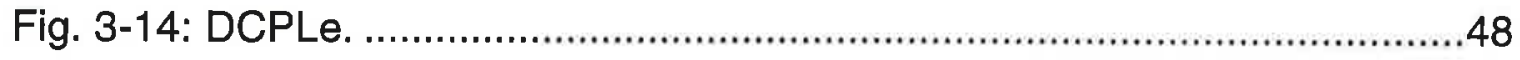

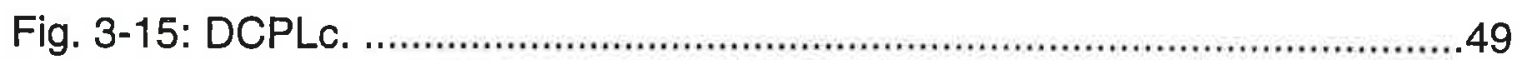

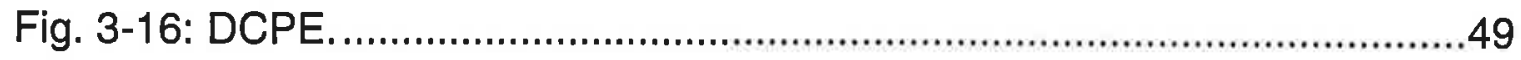

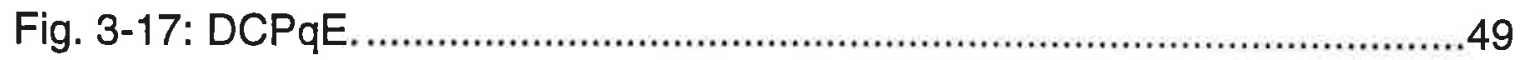


Fig. 3-18: DCP4P 50

Fig. 3-19: DCPS4P 50

Fig. 3-20: DCPCF (a) e DCPcf em detalhe (b). 51

Fig. 3-21: DCPFF e DCPff em detalhe. 52

Fig. 4-1: Obtenção, por clivagem, de 2 lâminas de processo a partir de uma lâmina de $100 \mathrm{~mm}$. .55

Fig. 4-2: Perfil térmico do processo de RTP. .58

Fig. 4-3: Representação esquemática dos processos implementados na fabricação de DCP's. Em cinza temos $\mathrm{SiO}_{2}$ (o cinza escuro é o óxido de porta), em lilás $\mathrm{Si}_{3} \mathrm{~N}_{4}$, em vermelho Si-poli, em verde junções, e em azul o $\mathrm{Ni}$. 64

Fig. 4-4: Característica $\mathrm{I}_{\text {rev }} \mathrm{XV}$ porta evidenciando os três regimes de operação: acumulação, depleção e inversão .66

Fig. 5-1: Junção $N^{+} P$ sob iluminação. 69

Fig. 5-2: Componente de base, $J_{\text {base }} \times$ Energia, parametrizada em $W$ para $x_{j}=$ $0,1 \mu \mathrm{m} \quad\left(S_{p}=5 \cdot 10^{6} \mathrm{~cm} / \mathrm{s}\right)$ .75

Fig. 5-3: Componente de base, $J_{\text {base }} \times$ Energia, parametrizada em $W$ para $x_{j}=$ $0,5 \mu \mathrm{m}\left(S_{p}=5 \cdot 10^{6} \mathrm{~cm} / \mathrm{s}\right)$ .75

Fig. 5-4: Componente da corrente de depleção, $J_{d p} x$ Energia parametrizada em $W \mathrm{p} / x_{j}=0,1 \mu \mathrm{m}\left(S_{p}=5 \cdot 10^{6} \mathrm{~cm} / \mathrm{s}\right)$ .76

Fig. 5-5: Componente da corrente de depleção, $J_{d p} x$ Energia parametrizada em

$$
W \mathrm{p} / x_{j}=0,5 \mu \mathrm{m}\left(S_{p}=5 \cdot 10^{6} \mathrm{~cm} / \mathrm{s}\right)
$$
.76

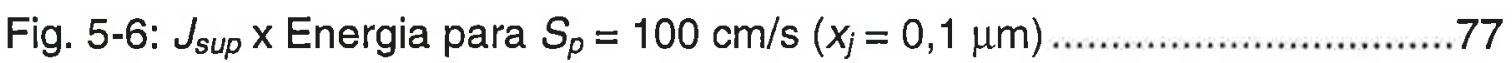

Fig. 5-7: $J_{\text {sup }} \times$ Energia para $S_{p}=5 \cdot 10^{6} \mathrm{~cm} / \mathrm{s}\left(x_{j}=0,1 \mu \mathrm{m}\right) \ldots \ldots \ldots \ldots \ldots \ldots \ldots \ldots \ldots \ldots \ldots \ldots \ldots \ldots \ldots \ldots . . .77$ 


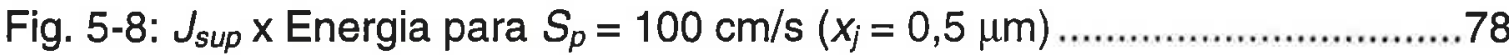

Fig. 5-9: $J_{\text {sup }} \times$ Energia para $S_{p}=5 \cdot 10^{6} \mathrm{~cm} / \mathrm{s}\left(x_{j}=0,5 \mu \mathrm{m}\right) \ldots \ldots \ldots \ldots \ldots \ldots \ldots \ldots . \ldots . \ldots \ldots$

Fig. 5-10: $R E \times$ Energia para $W=2 \mu \mathrm{m} . S_{p}=5 \cdot 10^{6} \mathrm{~cm} / \mathrm{s}$ e $S_{n}=5 \cdot 10^{8} \mathrm{~cm} / \mathrm{s}, x_{j}=$ $0,1 \mu \mathrm{m}$ 81

Fig. 5-11: $R E$ x Energia para $W=10 \mu \mathrm{m} . S_{p}=5 \cdot 10^{6} \mathrm{~cm} / \mathrm{s}$ e $S_{n}=5 \cdot 10^{8} \mathrm{~cm} / \mathrm{s}, x_{j}=$ $0,1 \mu \mathrm{m}$ 81

Fig. 5-12: $R E \times$ Energia para $W=2 \mu \mathrm{m} . S_{p}=100 \mathrm{~cm} / \mathrm{s}$ e $S_{n}=5 \cdot 10^{8} \mathrm{~cm} / \mathrm{s}, x_{j}=$ $0,1 \mu \mathrm{m}$ .82

Fig. 5-13: $R E \times$ Energia para $W=10 \mu \mathrm{m} . S_{p}=100 \mathrm{~cm} / \mathrm{s}$ e $S_{n}=5 \cdot 10^{8} \mathrm{~cm} / \mathrm{s}, x_{j}=$ $0,1 \mu \mathrm{m}$ .82

Fig. 5-14: $R E x$ Energia para $W=2 \mu \mathrm{m} . S_{p}=100 \mathrm{~cm} / \mathrm{s}$ e $S_{n}=100 \mathrm{~cm} / \mathrm{s}, x_{j}=0,1$ $\mu \mathrm{m}$ .83

Fig. 5-15: $R E \times$ Energia para $W=10 \mu \mathrm{m} . S_{p}=100 \mathrm{~cm} / \mathrm{s}$ e $S_{n}=100 \mathrm{~cm} / \mathrm{s}, x_{j}=$ $0,1 \mu \mathrm{m}$ .83

Fig. 5-16: Rendimento total $x W$ para $x_{j}=0,1$ e $0,5 \mu \mathrm{m} .\left(S_{p}=5 \cdot 10^{6}\right.$ e $S_{n}=5 \cdot 10^{8}$ $\mathrm{cm} / \mathrm{s})$ .85

Fig. 5-17: Rendimento total $x W$ para $x_{j}=0,1$ e $0,5 \mu \mathrm{m} . \quad\left(S_{p}=5 \cdot 10^{6}\right.$ e $S_{n}=5 \cdot 10^{8}$ $\mathrm{cm} / \mathrm{s})$ .85

Fig. 5-18: Rendimento para 694, 532 e $458 \mathrm{~nm}$ 87

Fig. 5-19: Rendimento x comprimento de onda para $W=0,1 \mu \mathrm{m}$ .88

Fig. 5-20: Rendimento x comprimento de onda para $W=1,0 \mu \mathrm{m}$ 89

Fig. 5-21: Rendimento $x$ comprimento de onda para $W=20,0 \mu \mathrm{m}$ 89

Fig. 5-22: Convenção adotada no software DCPSim. .93

Fig. 5-23: Fluxograma do software DCPSim 96 
Fig. 5-24: Campo elétrico $\times$ Profundidade para $V_{\text {inicial }}=-3,0 \mathrm{~V}$ e $\Delta V=0,0 \mathrm{~V}$.....97

Fig. 5-25: Potencial $x$ Profundidade para $V_{\text {inicial }}=-3,0 \mathrm{~V}$ e $\Delta V=0,0 \mathrm{~V}$ .97

Fig. 5-26: Concentração de portadores $x$ Profundidade para $V_{\text {inicial }}=-3,0 \mathrm{~V}$ e $\Delta V$ $=0,0 \mathrm{~V}$ .98

Fig. 5-27: Campo elétrico $x$ Profundidade para $V_{\text {inicial }}=-3,0$ V e $\Delta V=-10,0$ V..99

Fig. 5-28: Potencial $x$ Profundidade para $V_{\text {inicial }}=-3,0 \mathrm{~V}$ e $\Delta V=-10,0 \mathrm{~V}$ .99

Fig. 5-29: Concentração de portadores $x$ Profundidade para $V_{\text {inicial }}=-3,0 \mathrm{~V}$ e $\Delta V$ $=-10,0 \mathrm{~V}$ .100

Fig. 5-30: Campo elétrico $x$ Profundidade para $V_{\text {inicial }}=-20,0$ V e $\Delta V=-15,0 \mathrm{~V}$ 101

Fig. 5-31: Potencial $x$ Profundidade para $V_{\text {inicial }}=-20,0$ V e $\Delta V=-15,0$ V .......102 Fig. 5-32: Concentração de portadores $x$ Profundidade para $V_{\text {inicial }}=-20,0 \mathrm{~V}$ e $\Delta V=-15,0 \mathrm{~V}$ 102

Fig. 5-33: Largura da região de depleção para vários valores de $V_{\text {inicial }} \times \Delta V .104$ Fig. 5-34: Largura da região de depleção $\mathrm{x}$ amplitude de degrau. Note que $W$ satura para $V_{\text {inicial }} \geq \Delta V$. 105

Fig. 5-35: Queda da largura da região de depleção devido à inversão de superfície, sem degrau aplicado 105

Fig. 5-36: Aumento da largura da região de depleção em função de $V_{\text {inicial }}$ para $\Delta V$ de $-15,0 \mathrm{~V}$ .106

Fig. 5-37: Curva $I x V$ de diodo - lâmina N1 ................................................108

Fig. 5-38: Detalhe da região exponencial - lâmina N1 ....................................109

Fig. 5-39: Curva do diodo - lâmina P1 ........................................................110

Fig. 5-40: Detalhe da região exponencial - lâmina P1 
Fig. 5-41: Curva de diodo - Lâmina EN1 .......................................................112

Fig. 5-42: Detalhe da região exponencial - lâmina EN1 .................................112

Fig. 5-43: Curva de diodo - lâmina EN3 ………..........................................113

Fig. 5-44: Detalhe da região exponencial - lâmina EN3 ……...........................114

Fig. 5-45: Filme de níquel sobre um dispositivo em EN3 (20X) .....................115

Fig. 5-46: Filme de níquel sobre um dispositivo em EN3 (50X) .....................115

Fig. 5-47: Filme de níquel sobre um dispositivo em N1 (20X) ......................115

Fig. 5-48: Filme de níquel sobre um dispositivo em N1 (50X) ......................116

Fig. 5-49: Montagem utilizada para o levantamento da curva $I_{D S} \times V_{G S} \ldots \ldots \ldots \ldots . .118$

Fig. 5-50: Curva $I_{D S} \times V_{G S}$ na região triodo...................................................118

Fig. 5-51: Montagem empregada para o levantamento da curva $I x V$ do diodo

Fig. 5-52: Característica IxV do diodo de dreno ..........................................119

Fig. 5-53: Detalhe da região direta da curva da figura 5-40 …......................120

Fig. 5-54: Curva $I X V$ para tensão de porta variando de $-1,0 \mathrm{~V}$ a $1,0 \mathrm{~V}$............121

Fig. 5-55: Montagem empregada para a determinação de $s_{0} \ldots \ldots \ldots \ldots \ldots \ldots \ldots \ldots . . .123$

Fig. 5-56: Corrente de dreno versus tensão de porta ...................................123

Fig. A-1: Funções de distribuição de probabilidade em energia para: $T=50 \mathrm{~K}$.

$E_{F}=0,5 \mathrm{eV}$

Fig. A-2: Funções de distribuição de probabilidade em energia para $T=650 \mathrm{~K}$. $E_{F}=0,5 \mathrm{eV}$ 129

Fig. A-3: Onda eletromagnética se propagando na direção $z$. 130

Fig. A-4: Campo elétrico para uma onda eletromagnética em meio de condutividade não nula propagando-se na direção $x$ 
Fig. A-5: Variação dos coeficientes $n$ e $k$ em função de $\sigma$ para $\omega=1 \cdot 10^{5} \mathrm{rad} / \mathrm{s}$

Fig. A-6: Formação da estrutura de bandas no diamante como função da separação entre os átomos. 137

Fig. A-7: Diagrama de bandas de energia para Ge (a), silício (b) e GaAs (c).140 Fig. A-8: Transição indireta 141

Fig. A-9: Formação de prolongamentos das bandas de energia 141

Fig. A-10: Coeficiente de absorção para Ge, silício e GaAs 143 


\section{Lista de tabelas}

Tab. 3-1: Dados de máscara dos capacitores MOS projetados .........................39

Tab. 3-2: Classificação e parâmetros de máscaras dos DCP's escolhidos ......44

Tab. 4-1: Dados das lâminas de processo .....................................................54

Tab. 4-2: Condições de implantação e recozimento de dopantes simulados no SUPREM 3 61

Tab. 5-1: Valor do coeficiente de absorção para vários comprimentos de onda

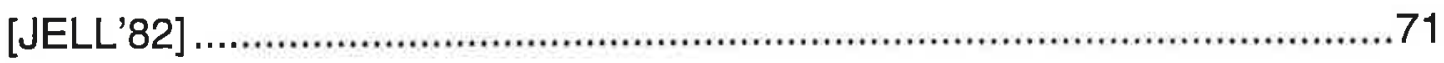

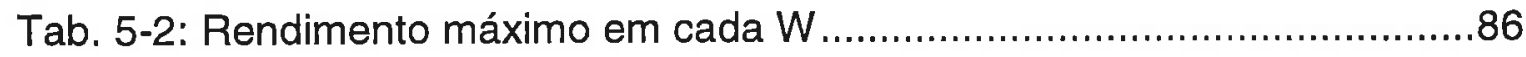

Tab. 5-3: Faixa utilizável para os três comprimentos de onda selecionados ....88

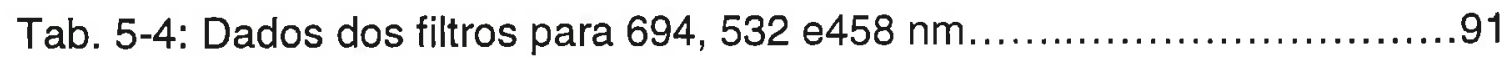

Tab. 5-5: Valor de W, em $\mu \mathrm{m}$, como função do potencial de polarização e da amplitude do degrau. Estruturas em inversão ou depleção profunda .......103

Tab. 5-6: Características da lâminas de processo ...........................116

Tab. A-1: Interações e partículas mediadoras ………….................................127 


\section{Lista de símbolos}

\begin{tabular}{|c|c|c|}
\hline$A_{M J}$ & $\cdots$ & Área da junção metalúrgica \\
\hline$A_{S}$ & $\cdots$ & Área sob a porta MOS \\
\hline$C$ & $\cdots$ & Capacitância por unidade de área \\
\hline$C_{S}^{A F}$ & $\cdots$ & Capacitância associada à região de depleção em altas frequiências \\
\hline$C_{s}^{B F}$ & $\cdots$ & Capacitância associada à região de depleção em baixas freqüências \\
\hline$c_{n s}$ & $\cdots$ & Coeficiente de captura para elétrons na superfície \\
\hline$C_{o x}$ & $\cdots$ & Capacitância do óxido por unidade de área \\
\hline$c_{p s}$ & $\cdots$ & Coeficiente de captura para lacunas na superfície \\
\hline$C_{S}$ & $\cdots$ & Capacitância associada à região de depleção \\
\hline$c_{s}$ & $\cdots$ & Coeficiente de captura na superfície \\
\hline$D$ & $\cdots$ & Coeficiente de difusão \\
\hline$D_{n}$ & $\cdots$ & Coeficiente de difusão para elétrons \\
\hline$D_{p}$ & $\cdots$ & Coeficiente de difusão para lacunas \\
\hline$E$ & $\cdots$ & Campo elétrico \\
\hline$E_{i}$ & $\cdots$ & Nível intrínseco \\
\hline$E_{T}$ & $\cdots$ & Nível de energia para as "armadilhas" \\
\hline$F$ & $\cdots$ & Fluxo incidente de fótons \\
\hline$f$ & $\cdots$ & Freqüência da onda eletromagnética \\
\hline$F_{n}$ & $\cdots$ & Nível de quase-Fermi para elétrons \\
\hline$F_{p}$ & ... & Nível de quase-Fermi para lacunas \\
\hline$G$ & $\cdots$ & Taxa de geração óptica \\
\hline$G_{B}$ & $\cdots$ & Taxa de geração no substrato \\
\hline$G_{n}$ & ... & Taxa de geração óptica para elétrons \\
\hline
\end{tabular}


$G_{p} \quad \ldots \quad$ Taxa de geração óptica para lacunas

$G_{S} \quad \ldots$ Taxa de geração na superfície

$h \quad$... Passo para a resolução da equação de Poisson

$H^{\prime} \quad$... Comprimento da lâmina a partir do fim da região de depleção

$I_{0} \quad \ldots \quad$ Corrente reversa na junção

$I_{D} \quad \ldots \quad$ Corrente de dreno

$I_{D S} \quad \ldots \quad$ Corrente entre dreno e fonte

$I_{g e n, F I G} \quad \ldots \quad$ Corrente de geração associada à junção induzida

$I_{g e n, M J} \quad \ldots \quad$ Corrente de geração associada à junção metalúrgica

$I_{g e n, S} \quad \ldots \quad$ Corrente de geração associada à superfície junto à junção PN

$I_{R} \quad \ldots \quad$ Corrente reversa na junção

$I_{y} \quad$... Corrente ao longo do canal

$J_{0} \quad \ldots \quad$ Densidade de corrente reversa na junção

$J_{\text {base }} \quad \ldots \quad$ Densidade de corrente gerada na região quase-neutra de base

$J_{d p} \quad \ldots \quad$ Densidade de corrente gerada na região de depleção

$J_{n} \quad \ldots \quad$ Densidade de corrente de elétrons

$J_{p} \quad \quad \ldots \quad$ Densidade de corrente de lacunas

$J_{\text {sup }} \quad$... Densidade de corrente gerada na região quase-neutra de superfície

$J_{T} \quad \quad \ldots \quad$ Densidade total de corrente gerada por incidência de fótons

$k \quad \quad \ldots \quad$ Constante de Boltzmann

$L \quad \quad \ldots \quad$ Comprimento do canal

$L_{D} \quad \ldots \quad$ Comprimento intrínseco de Debye

$L_{S} \quad \quad \quad \ldots$ Comprimento efetivo de canal para a condição de regime de operação dominado pela superfície 
$\dot{L}_{s} \quad \ldots$ Comprimento efetivo de canal para a condição de regime de operação dominado pela superfície quando usamos $s_{0}$ ao invés de $s_{0}$

$L_{W} \quad$... Comprimento efetivo de canal para a condição de regime de operação dominado por substrato

$n$

... Concentração de elétrons

$n_{1} \quad \ldots \quad$ Concentração de elétrons normalizada com $n_{i}$

$n_{l s} \quad \ldots \quad$ Concentração de elétrons na superfície normalizada com $n_{i}$

$N_{A} \quad \ldots \quad$ Concentração de impurezas aceitadoras

$N_{B} \quad$... Concentração de substrato

$N_{D} \quad$... Concentração de impurezas doadoras

$n_{i} \quad \ldots \quad$ Concentração intrínseca de portadores

$n_{p} \quad \ldots$ Concentração de elétrons no lado $\mathrm{P}$

$n_{s} \quad \ldots$ Concentração de elétrons na superfície

$N_{S S} \quad \ldots \quad$ Densidade de estados interfaciais

$N_{s t} \quad \ldots \quad$ Densidade de estados de "armadilhas" na superfície

$N_{t} \quad$... Densidade de estados de "armadilhas"

$N_{T S} \quad \ldots \quad$ Densidade de estados na região central da faixa proibida

p $\quad$... Concentração de lacunas

$p_{1} \quad \ldots$ Concentração de lacunas normalizada $\operatorname{com} n_{i}$

$p_{l s} \quad \ldots$ Concentração de lacunas na superfície normalizada com $n_{i}$

$p_{n} \quad \quad \ldots \quad$ Concentração de lacunas no lado $\mathrm{N}$

$p_{n o} \quad \ldots$ Concentração de lacunas no lado $\mathrm{N}$ em equilíbrio térmico

$p_{s} \quad \ldots$ Concentração de lacunas na superfície

$q \quad \ldots \quad$ Carga eletrônica 
$Q_{n} \quad \ldots \quad$ Carga relativa à camada de inversão

$Q_{o x} \quad$... Carga no óxido por unidade de área

$Q_{s} \quad \quad \ldots \quad$ Carga no semicondutor

$Q_{s s} \quad \ldots \quad$ Carga efetiva no óxido

$R \quad$... Reflectância do material

$R E \quad \quad \ldots \quad$ Resposta espectral

$R_{Q} \quad$... Resistência por quadrado

$s_{0} \quad \ldots \quad$ Velocidade de recombinação superficial aparente

$s_{0}^{\prime} \quad \ldots \quad$ Velocidade de recombinação superficial real

$S_{n} \quad \ldots \quad$ Velocidade de recombinação na extremidade da região quase-neutra do lado $\mathrm{N}$

$S_{p} \quad \ldots \quad$ Velocidade de recombinação na extremidade da região quase-neutra do lado $\mathrm{P}$

$t \quad \quad \ldots \quad$ Espessura da lâmina

T $\quad$... Temperatura absoluta

$u \quad \ldots \quad$ Potencial normalizada com a tensão térmica

$u_{F} \quad \ldots \quad$ Potencial de Fermi normalizado com a tensão térmica

$U_{F I J} \quad \ldots \quad$ Taxa de geração no substrato associada à junção induzida sob a porta

$U_{M J} \quad$... Taxa de geração no substrato associada à junção metalúrgica

$u_{S} \quad \ldots \quad$ Potencial de superfície normalizado com a tensão térmica

$U_{S} \quad$... Taxa de geração no substrato associada à superfície

$V_{D} \quad \ldots \quad$ Tensão de dreno

$V_{D S} \quad \ldots \quad$ Tensão entre dreno e fonte

$V_{\text {final }} \quad \ldots$ Tensão atingida na porta após a aplicação de degrau de tensão 


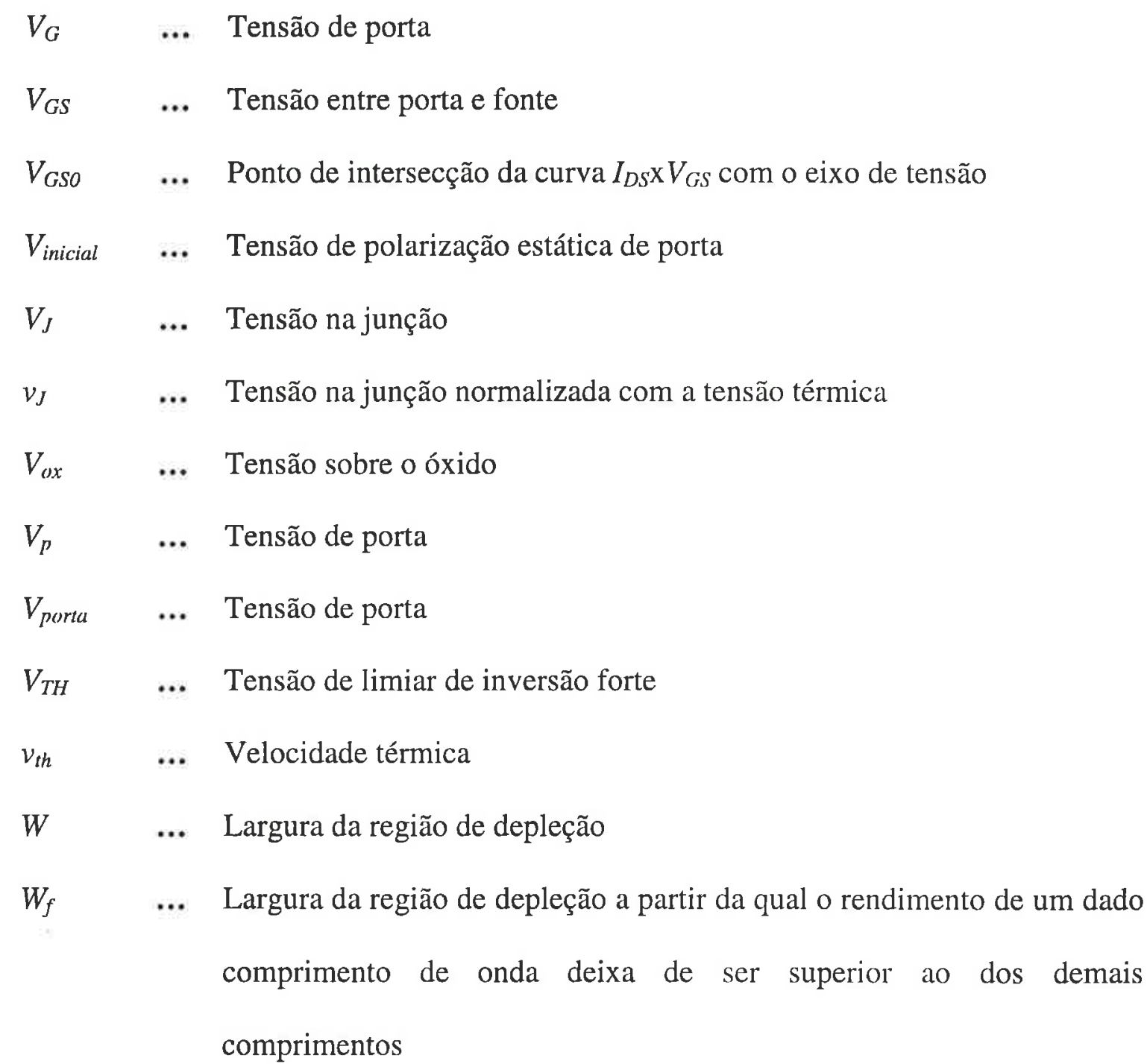

$W_{i} \quad$... Largura da região de depleção a partir da qual o rendimento de um dado comprimento de onda é superior ao dos demais comprimentos

$\begin{array}{lll}W_{u} & \ldots & \text { Largura útil da região de depleção } \\ x & \ldots & \text { Coordenada espacial perpendicular ao canal do dispositivo } \\ x_{d} & \ldots & \text { Largura da região de depleção } \\ x_{d m a x} & \ldots & \text { Largura máxima da região de depleção } \\ x_{i} & \ldots & \text { Ponto de intersecção do nível de quase-Fermi com o nível intrínseco } \\ x_{j} & \ldots & \text { Profundidade de junção } \\ x_{o x} & \ldots & \text { Espessura do óxido de porta }\end{array}$


$y \quad \quad \ldots \quad$ Coordenada espacial paralela ao canal do dispositivo

Z $\quad$... Largura do canal

$\alpha \quad \quad \ldots \quad$ Coeficiente de absorção

$\gamma \quad \ldots \quad$ Velocidade de recombinação superficial normalizada com relação à

Velocidade de recombinação superfícial para superfície depletada

$\Delta V \quad$... Amplitude do degrau de tensão aplicado à porta

$\varepsilon_{0} \quad$... Permissividade do vácuo

$\varepsilon_{S i} \quad$... Permissividade do silício

$\lambda \quad \ldots \quad$ Comprimento de onda

$\mu \quad \ldots \quad$ Mobilidade dos portadores no canal

$\bar{\mu}_{n} \quad \ldots \quad$ Mobilidade média para elétrons

$\eta \quad \ldots$ Concentração de elétrons na superfície normalizada com $n_{I}$ ou rendimento de conversão de fluxo luminoso para corrente elétrica

$\eta_{a z u l} \quad \ldots \quad$ Rendimento para o comprimento de onda de $458 \mathrm{~nm}$

$\eta_{i} \quad \ldots \quad$ Fator de idealidade

$\eta_{\text {máx }} \quad \ldots \quad$ Rendimento máximo

$\eta_{\text {verde }} \quad \ldots \quad$ Rendimento para o comprimento de onda de $532 \mathrm{~nm}$

$\eta_{\text {vermelho }} \quad \ldots \quad$ Rendimento para o comprimento de onda de $694 \mathrm{~nm}$

$\xi \quad \ldots$ Comprimento na direção $y$ normalizado com $L$

$\rho \quad \ldots \quad$ Densidade de carga volumétrica

$\sigma \quad \quad \ldots \quad$ Secção cruzada de captura efetiva

$\sigma_{S} \quad \ldots \quad$ Secção cruzada de captura efetiva na superfície

$\tau_{0} \quad \ldots \quad$ Tempo de vida médio em equilíbrio térmico 
$\tau_{n 0} \quad \ldots \quad$ Tempo de vida médio em equilíbrio térmico para elétrons

$\tau_{p o} \quad \ldots$ Tempo de vida médio em equilíbrio térmico para lacunas

$\varphi \quad \quad \ldots$ Concentração de lacunas na superfície normalizada com $n_{i}$

$\phi \quad$... Potencial

$\phi_{F} \quad \ldots \quad$ Potencial do nível de Fermi

$\phi_{F n} \quad \ldots \quad$ Potencial de Fermi para elétrons

$\phi_{F p} \quad \ldots \quad$ Potencial de Fermi para lacunas

$\phi_{M S} \quad \ldots$ Diferença de potencial entre a função trabalho do metal e o nível de Fermi do semicondutor

$\phi_{s} \quad \quad \quad \ldots \quad$ Potencial de superfície

$\psi \quad$... Potencial elétrico 


\section{Resumo}

O presente trabalho faz inicialmente uma revisão da básica a respeito de diodos controlados por porta ressaltando o método criado por Grove, e corrigido por Pierret, para a determinação da velocidade de recombinação superficial, parâmetro esse, importante na análise do desempenho do dispositivo frente a situações que tendem a degradar o funcionamento do mesmo.

Em seguida, propomos a utilização de DCP's como sensores de radiação luminosa e possivelmente como sensor de cores. Para tanto, simulamos o comportamento de uma junção PN sob iluminação quando variamos a extensão da região de depleção associada à mesma.

De acordo com essas simulações, observamos que o rendimento de conversão da energia luminosa para elétrica, em função do comprimento de onda da luz incidente, apresenta dependência com relação a extensão da região de carga espacial. Essa característica pode vir a ser usada, futuramente, na deteç̧ão seletiva de comprimentos de onda, e portanto, permitindo a discriminação de cores.

A variação da largura da região de depleção nas proximidades de uma junção PN pode ser conseguida, numa estrutura do tipo DCP, através dì aplicação em sua porta, de pulsos de amplitude e inclinação adequadas, de forma a levá-lo a operar em depleção profunda.

Nessas condições, o valor máximo da largura da região de depleção é maior do que o seu valor máximo estacionário, podendo chegar a até 3 vezes o mesmo, conforme foi constatado por simulação, através de um software por nós desenvolvido, para uma estrutura MOS pulsada. 
Tal simulação forneceu-nos o campo e potencial elétricos e a concentração de portadores em função da profundidade através da resolução da equação de Poisson com condições de contorno adequadas.

Dados os resultados obtidos nas simulações, a próxima etapa foi a elaboração de máscaras litográficas para construir diodos controlados por porta com diferentes geometrias, algumas sugeridas pela literatura, outras desenvolvidas para esse trabalho. Tais máscaras foram confeccionadas pelo CTI em Campinas e foram desenhadas através do software Microeletrônica de Etienne Sicard da universidade de Toulouse.

Utilizamos as máscaras fabricadas para construir uma pastilha-teste preliminar com os diodos controlados por porta propostos. Infelizmente, nesta única corrida, tivemos curto-circuito entre porta e substrato e apenas as junções PN funcionaram a contento. Obtivemos diodos com fator de idealidade de $\sim 1,4$ e densidade de corrente reversa, no melhor dos casos, igual a $1,23 \cdot 10^{4} \mathrm{nA} / \mathrm{cm}^{2}$ para áreas de $(1000 \times 1000) \mu \mathrm{m}^{2}$.

Por outro lado, como não conseguimos DCP's funcionando, utilizamos transistores nMOS convencionais, fornecidos pelo Prof. João Antonio Martino, para medir a velocidade de recombinação superficial, $s_{0}$, que resultou em $5,5 \cdot 10^{6} \mathrm{~cm} / \mathrm{s}$, segundo o método proposto por Pierret. 


\section{Abstract}

This work presents a basic review about gate-controlled diodes (GCD) mainly on the method, created by Grove and corrected by Pierret, for measuring the surface recombination velocity that is an important parameter on the analysis of device performance.

In the sequence, we propose the use of GCD's as light radiation sensors and, probably as color sensors. To do so, we have simulated the behavior of a PN junction under ilumination, varying the depletion region lenght.

The simulations revealed that the luminous to electrical energy conversion depends on the lenght of the spatial charge region. This could be used, in the future, on the selective wavelenght detection, alloying color discrimination.

The variation of the depletion region length in the vicinity of a PN junction can be done, in a GCD structure, by applying in its gate, a set of electrical pulses with the right characteristics, in order to drive it to the deep depletion mode.

In these conditions, the maximum lenght of the depletion region is larger than its steady state value, reaching as much as 3 times that value, as could be determined by means of simulation of a pulsed MOS structure, in a specific software developed for that purpose.

This software give us the electric field and potencial and the carrier concentration against depth into the silicon by solving the Poisson equation with the right boundary conditions. Keeping these results in mind, the next step was the project of the lithographic masks in order to explore some different geometries, some of them suggested by the literature, others developed in this work. The fabrication of those masks were done by CTI in Campinas e were designed with the software Microeletrônica by Etienne Sicard from the university of Toulouse. 
We have used the masks to manufacture a preliminary chip test which included gate-controled diodes. Unfortunately, in this unique run, "short circuits" between gate and bulk has occurred and only the PN junctions worked as expected. We have obtained diodes with ideality factor of $\sim 1.4$ and reverse current density of $1.23 \cdot 10^{4} \mathrm{nA} / \mathrm{cm}^{2}$ in the best case for junction areas of $(1000 \times 1000) \mu \mathrm{m}^{2}$.

On the other hand, as we have not got gate-controlled diodes which were working, we have used conventional nMOS transistors borrowed by Prof. João Antonio Martino. Surface recombinantion velocity $s_{0}$ was measured in these nMOS transistors and resulted in $5.5 \cdot 10^{6} \mathrm{~cm} / \mathrm{s}$, according to the method proposed by Pierret. 


\section{1 - Introdução}

Sensores de radiação luminosa, dependendo da faixa espectral de detecção, encontram inúmeras utilizações hoje em dia, desde a medicina até aplicações aeroespaciais ([AUDE'89], [KOLT'88], [LARI'68], [SNOW'67], [SZE'94], [YATE'92], [ZIOC'91]).

Dentro desse contexto, novos tipos de sensores podem representar novas áreas de pesquisa e até possibilitar estudos básicos dos fenômenos envolvidos nos processos de absorção de radiação eletromagnética pelos materiais semicondutores.

Propomos nesse trabalho, a utilização, como sensor de radiação luminosa, de um dispositivo que até então tem sido usado principalmente como elemento de caracterização no estudo da superfície de semicondutores. Trata-se do Diodo Controlado por Porta (DCP).

Pretendemos mostrar, ao longo desse trabalho, que a possibilidade de se variar a extensão da região de carga espacial do diodo controlado por porta (DCP) pode ser utilizada para a detecção seletiva do comprimento de onda da luz incidente no mesmo.

\section{1 - Sensores de radiação luminosa}

Sensores de radiação luminosa são aqueles que convertem a energia presente nas radiações luminosas em outra forma útil de energia, por exemplo, a energia elétrica.

Há vários tipos de sensores, como aqueles que variam a sua resistência elétrica com a incidência de radiação, outros variam a corrente gerada através de seus terminais, etc.

Esse trabalho tem como um de seus objetivos propor a utilização de DCP's como sensores de radiação, cujo princípio de funcionamento é a variação da corrente 
gerada entre seus terminais como função da absorção de fótons incidentes conforme veremos em detalhe no capítulo 2.

No DCP, há um limite inferior em energia que pode ser medido ou acusado pelo mesmo. Tal limite é dado pela largura, em energia, da faixa proibida ( $g a p$ ) do material. Assim sendo, para cada material, somente os comprimentos de onda com energia superior ao gap do material pode ser medida, já que para energias menores o particular material é transparente. A figura 1-1 ilustra todo o espectro eletromagnético com suas correspondentes energias.
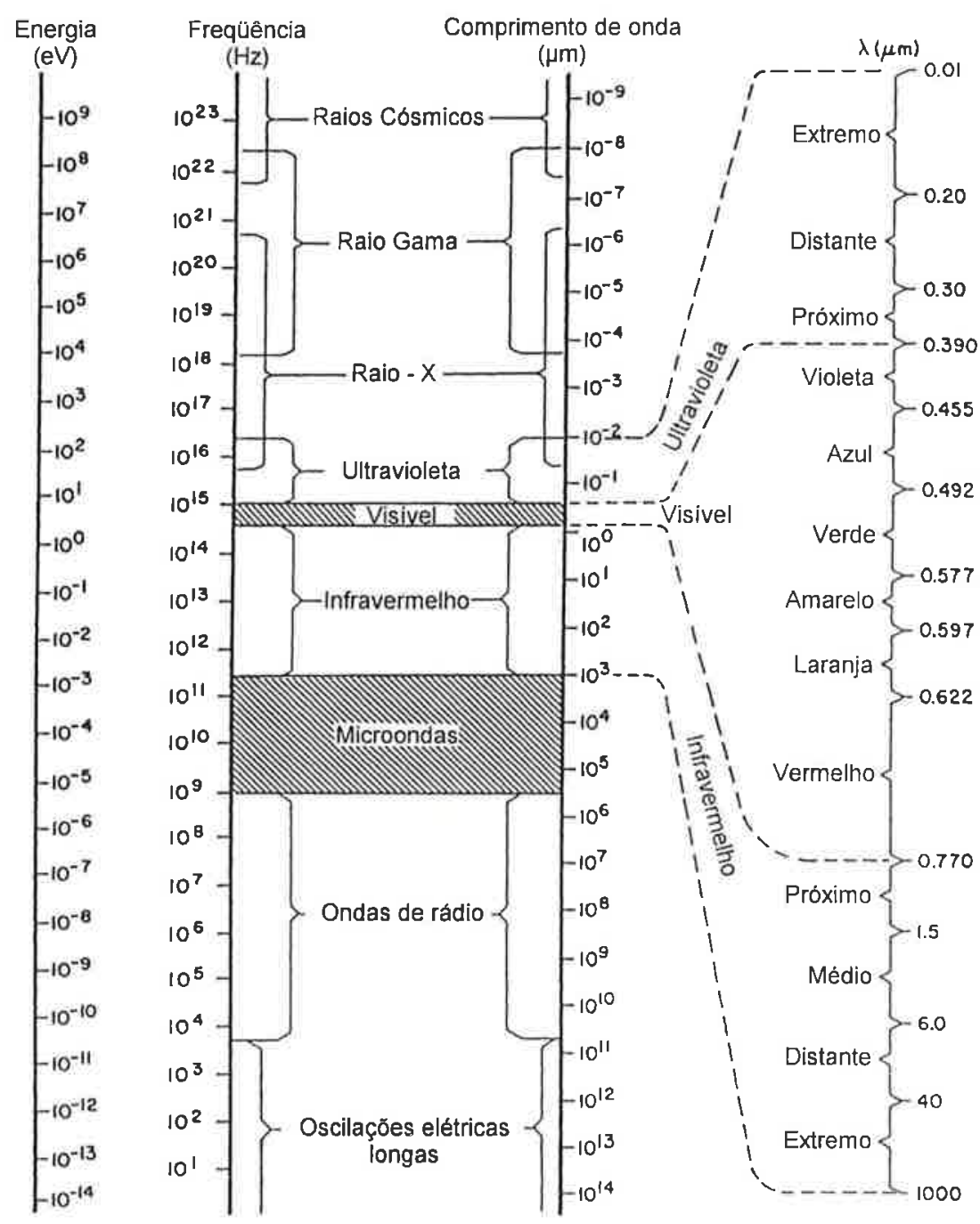

Fig. 1-1: Espectro eletromagnético 
Para o caso do silício, dado que sua faixa proibida tem largura de aproximadamente $1,1 \mathrm{eV}$ na temperatura ambiente, significa que o mesmo pode ser empregado como sensor desde o infravermelho próximo ( $\mathrm{f} \geq 10^{14} \mathrm{~Hz}$, veja figura 1-1).

A absorção da radiação luminosa dá-se através dos processos de geração de pares elétron-lacuna (veja o anexo A), sendo que o mecanismo de geração de corrente será melhor detalhado no capítulo 2.

\section{2 - Objetivos}

O presente trabalho tem por objetivos:

a) Simulação da faixa de resposta espectral do diodo controlado por porta;

b) Simulação numérica do comportamento em regime quase-estacionário (depleção profunda) do diodo controlado por porta, tendo como resultado os perfis e profundidade de campo e potencial elétricos e cálculo da corrente na junção;

c) Projeto de um conjunto de máscaras para a construção do DCP;

d) Projeto de processos construtivos que visem obter DCP's de características desejadas;

e) Propor o uso do DCP como sensor de radiação luminosa.

\section{3 - Organização do trabalho}

Neste capítulo primeiro apresentamos a introdução e os objetivos do trabalho.

A organização dos capítulos seguintes está detalhada a seguir.

O capítulo segundo procura estabelecer as bases físicas do funcionamento de diodos controlados por porta, que são os dispositivos de interesse no presente trabalho. É dada ênfase especial à técnica de medida da velocidade de recombinação superficial, dado que a mesma é um importante parâmetro indicativo das condições obtidas em um 
processo construtivo ou dos possíveis danos causados à superfície do semicondutor devido à incidência de radiações.

O capítulo terceiro trata do projeto das máscaras utilizadas para a construção dos chips a serem ensaiados. Foi dada ênfase às geometrias projetadas e aos dados de máscara quais sejam, áreas e capacitâncias calculadas para os diferentes dispositivos.

No capítulo quatro são apresentados os procedimentos experimentais e os processos construtivos levados a efeito para a obtenção dos dispositivos, bem como as técnicas de medidas elétricas empregadas.

O capítulo cinco apresenta os resultados obtidos por simulação, onde procurouse avaliar o comportamento de uma junção PN sob iluminação para diferentes extensões da região de depleção e também o comportamento de um capacitor MOS submetido a pulsos de tensão de forma a levá-lo a operar em depleção profunda. Também, são apresentados alguns resultados de medidas elétricas em DCP's.

Finalmente o capítulo seis traz as conclusões alcançadas ao longo desse trabalho bem como algumas perspectivas futuras relacionadas ao tema. 


\section{2 - O diodo controlado por porta (DCP)}

Desde o surgimento do transistor e mormente do transistor de efeito de campo tipo MOS, ficou patente a influência que o estado da superfície do semicondutor exerceria sobre o comportamento global do dispositivo nele implementado ([GROV'67], [NICO'82], [SZE'83]).

A partir daí a comunidade científica começou a direcionar esforços no sentido de compreender de que forma ocorria essa influência e como poderiam ser minimizados os seus efeitos negativos.

É nesse contexto que surge o diodo controlado por porta (DCP) como uma ferramenta de análise de superfície, onde se procurou estender a já bem conhecida teoria sobre estruturas MOS para condições de não-equilíbrio, nas cercanias de junções polarizadas.

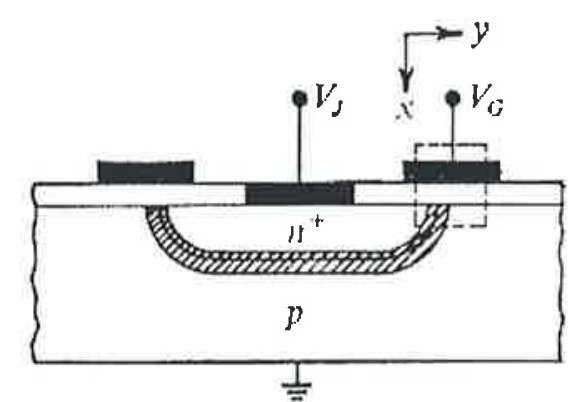

(a)

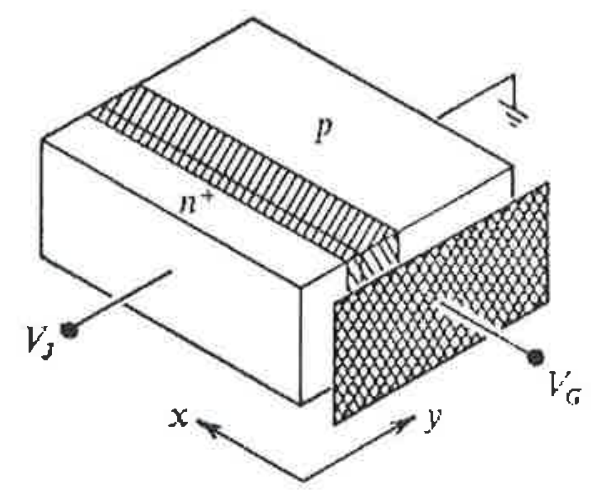

(b) 
Um diodo controlado por porta, doravante DCP, é uma estrutura que engloba em silício, ao mesmo tempo, uma junção PN e um capacitor MOS que a envolve, conforme mostrado na figura $2-1$.

Ao longo do tempo outras aplicações foram sugeridas para DCP's como algumas de que vamos tratar mais adiante, mas primeiramente vamos nos deter apenas sobre a física do dispositivo.

\section{1 - Efeitos de campos superficiais em junções PN}

Toda a discussão a seguir basear-se-á na figura 2-1, ou seja, para substratos tipo $\mathrm{P}$ e difusão $\mathrm{N}$ muito mais dopada do que o lado P. No entanto, o que for aqui dito é igualmente válido para substratos tipo $\mathrm{N}$ bastando apenas algumas alterações em símbolos e sinais.

Quando aplicamos um potencial nulo na junção (equilíbrio térmico) e também no terminal de porta (veja figura 2-2), teremos um encurvamento das faixas de energia unicamente na direção y que é devida à presença da junção metalúrgica.

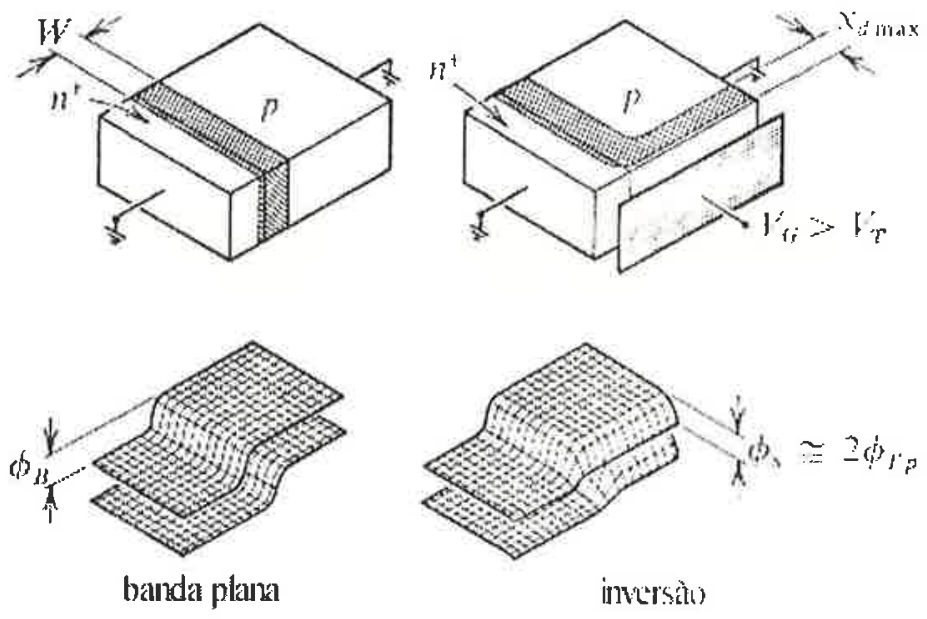

Fig. 2-2: Junção em equilíbrio térmico 
Mas ao aplicarmos uma tensão ao terminal de porta (fig. 2-2), o mesmo induzirá uma depleção de portadores na região do canal, o que se traduz num encurvamento do diagrama de faixas de energia também na direção $x$.

A região de depleção induzida por campo, como já é sabido do estudo de capacitores MOS, atinge uma extensão máxima quando a superfície começa a entrar em inversão ([SZE'81], [NICO'82]).

Em estruturas DCP, no entanto, o início da inversão, e portanto o potencial de superfície, é função da tensão aplicada à junção, como se pode ver na figura 2-3.

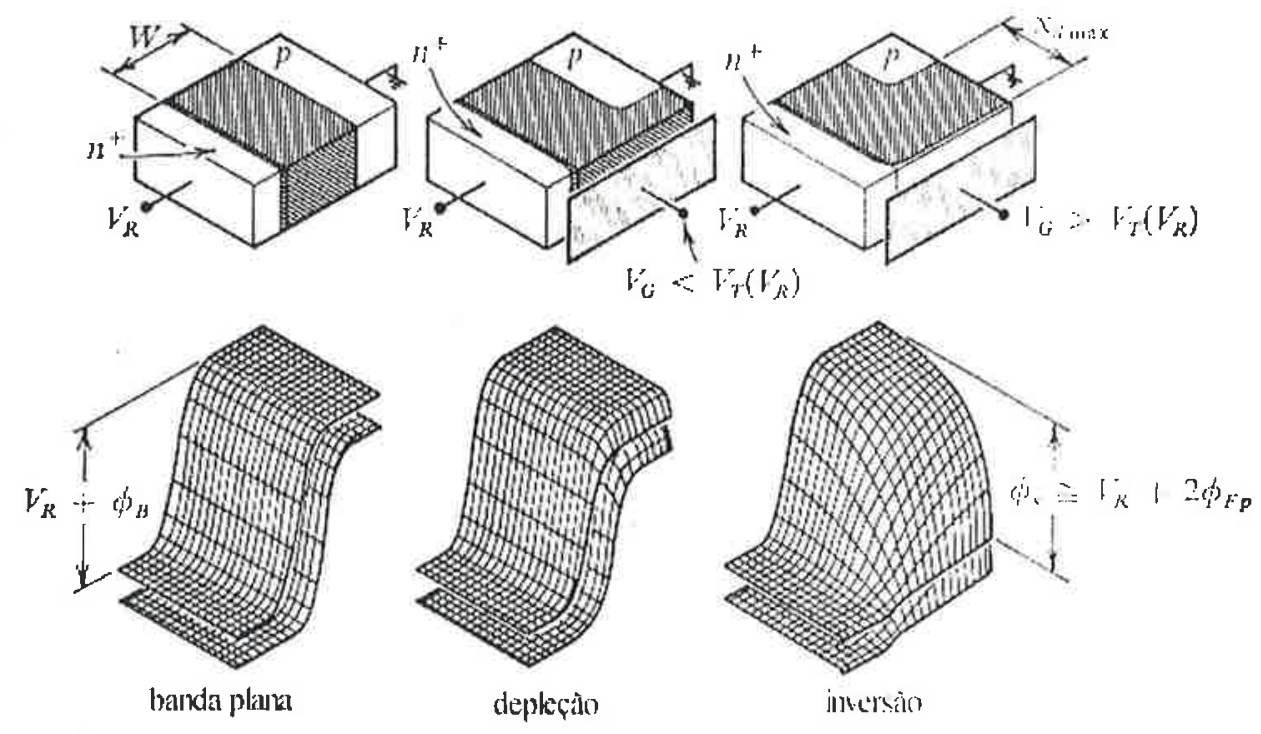

Fig. 2-3: Junção reversamente polarizada

O potencial de superfície no caso exposto na figura 2-3 pode ser dado aproximadamente por:

$$
\phi_{S} \cong 2 \cdot \phi_{F}+V_{J}
$$

onde $V_{J}$ é a tensão de junção e $\phi_{F}$ é o potencial de Fermi, que para o nosso estudo é igual ao nível de quase-Fermi para os majoritários ([GROV'67], [GROV'66]). 
Os encurvamentos de faixas de energia aos quais temos nos referido até agora, nada mais são do que acúmulos e depleções de cargas que podem ser contabilizados, como de fato é feito no próximo item.

\section{2 - Região de carga espacial superficial em condições de não-equilíbrio sob a porta}

Primeiramente, vamos assumir, a título de simplificação, que fora das condições de equilíbrio térmico, a variação de potencial ao longo da direção y (veja fig. 2-1) seja desprezível, o que nos faz considerar apenas o encurvamento de faixas de energia normal à superfície sobre a qual está a porta.

Nessas condições, a carga total induzida no semicondutor é dada por:

$$
Q_{S} \equiv \int_{0}^{\infty} \rho(x) d x
$$

onde,

$$
\rho=q \cdot\left(p-n+N_{D}-N_{A}\right)=-\varepsilon_{S i} \cdot \varepsilon_{0} \cdot \frac{d^{2} \phi}{d x^{2}}
$$

As concentrações $p$ e $n$ podem ser quantificadas como segue [GROV'66]:

$$
\begin{aligned}
& p=n_{i} \cdot \exp \left[\frac{q \cdot\left(\phi_{F p}-\phi\right)}{k \cdot T}\right] \\
& n=n_{i} \cdot \exp \left[\frac{q \cdot\left(\phi-\phi_{F n}\right)}{k \cdot T}\right]
\end{aligned}
$$

Temos ainda que, para manter a condição de neutralidade de cargas num substrato tipo P, é válida a relação [GROV'66]: 


$$
N_{A}-N_{D}=2 \cdot n_{i} \cdot \sinh \left(\frac{q \cdot \phi_{F}}{k \cdot T}\right)
$$

A partir da equação 2.2-1, podemos calcular $Q_{S}$ substituindo $2.2-4,2.2-3$ (a) e 2.2-3 (b) em 2.2-2, o que nos leva à seguinte equação [GROV'66]:

$$
\begin{aligned}
Q_{S} & =-2 \cdot q \cdot n_{i} \cdot L_{D} \cdot\left[\exp \left(u_{F}-u_{S}\right)-\exp \left(u_{F}\right)+\right. \\
& \left.+\exp \left(u_{S}-u_{F}-v_{J}\right)+2 \cdot u_{S} \cdot \sinh \left(u_{F}\right)\right]^{1 / 2}
\end{aligned}
$$

onde:

$$
\begin{gathered}
u_{S}=\frac{q \cdot \phi_{S}}{k \cdot T} \\
u_{F}=\frac{q \cdot \phi_{F}}{k \cdot T} \\
v_{J}=\frac{q \cdot V_{J}}{k \cdot T} \\
L_{D}=\left(\frac{k \cdot T}{q} \cdot \frac{\varepsilon_{S i} \varepsilon_{0}}{2 \cdot q \cdot n_{i}}\right)^{1 / 2}
\end{gathered}
$$

sendo $L_{D}$ definido como o comprimento intrínseco de Debye [GROV'66].

A carga total induzida no silício dada pela equação $2.2-5$, é composta por uma parcela devida ao acúmulo de minoritários abaixo da porta e outra parcela devida à depleção dos portadores móveis deixando um região de carga espacial, o que pode ser traduzido na seguinte equação:

$$
Q_{S} \equiv Q_{n}-q \cdot\left(N_{A}-N_{D}\right) \cdot x_{d}
$$


onde $x_{d}$ é a largura da camada de depleção e $Q_{n}$ é a parcela devida à camada de inversão.

A parcela $Q_{n}$ pode ser quantificada como segue:

$$
Q_{n} \equiv-q \cdot \int_{0}^{x_{i}} n(x) d x=-q \int_{u_{s}}^{u_{F}} \frac{n(u) d u}{d u / d x}
$$

onde $x_{i}$ é o ponto onde o nível intrínseco intercepta o nível de quase-Fermi para lacunas.

A equação de $Q_{n}$ pode ser desenvolvida para resultar na equacão 2.2-13 a seguir.

$$
\begin{gathered}
Q_{n}=-q \cdot n_{i} \cdot L_{D} \cdot \exp \left(-v_{J}\right) \cdot \int_{u_{F}}^{u_{F}} \frac{\exp \left(u-u_{F}\right) d u}{\exp \left(u_{F}-u\right)-\exp \left(u_{F}\right)+\exp \left(u-u_{F}-v_{J}\right)-} \\
\frac{-\exp \left(-u_{F}-v_{J}\right)+2 \cdot u \cdot \sinh \left(u_{F}\right)}{}
\end{gathered}
$$

Agora, se fizermos uma aproximação de depleção, ou seja, se na equação de Poisson original (equação 2.2-2) desprezarmos o efeito dos portadores móveis $p$ e $n$, teremos que a distribuição de potencial dentro do silício obedece a uma relação parabólica do tipo (veja [GROV'66]):

$$
\phi(x)=\phi_{s} \cdot\left(1-\frac{x}{x_{d}}\right)^{2}
$$

onde $\phi_{S}$, ou potencial de superfície, será dado por: 


$$
\phi_{S}=\frac{q \cdot\left(N_{A}-N_{D}\right) \cdot x_{d}^{2}}{2 \cdot \varepsilon_{S i} \varepsilon_{0}}
$$

Note-se que a aproximação de depleção só é válida enquanto não houver inversão forte de superfície. Nessa condição, a carga total no silício é dada quase que exclusivamente pela região de carga espacial.

No limite de inversão forte, podemos dizer que concentração de portadores minoritários na superfície iguala-se à de majoritários no substrato de silício. Isso implica dizer que, para substrato $P$ :

$$
n_{s}=N_{A}-N_{D}
$$

Levando-se a equação 2.2-16 à 2.2-3 (b), temos que:

$$
\phi_{s}(i n v)=\phi_{F n}+\frac{k \cdot T}{q} \cdot \ln \left(\frac{N_{A}-N_{D}}{n_{i}}\right)
$$

A equação 2.2-17 substituída na equação 2.2-4 e considerando $\phi_{F n}=\phi_{F p}+V_{J}$ resulta:

$$
\phi_{S}(i n v)=V_{J}+2 \cdot \phi_{F p}
$$

A equação da largura máxima da região de depleção como função do potencial de superfície é dada por [GROV'66]:

$$
x_{d \max }=\left[\frac{2 \cdot \varepsilon_{S i} \varepsilon_{0} \cdot\left(V_{J}+2 \cdot \phi_{F}\right)}{q \cdot\left(N_{A}-N_{D}\right)}\right]^{1 / 2}
$$


Fazendo-se o balanço total de cargas, a condição de neutralidade exige que

$$
Q_{o x}+Q_{S S}+Q_{S}=0
$$

onde

$$
Q_{o x}=V_{o x} \cdot C_{u x}
$$

é a parcela de carga devida à tensão e capacitância no óxido. Q QsS é a carga efetiva no óxido e $Q_{S}$ é a carga no silício.

A tensão de porta pode ser descrita como:

$$
V_{P}=V_{o x}+\phi_{S}+\phi_{M S}
$$

Substituindo $V_{o x}=Q_{o x} / C_{o x}=-\left(Q_{S S}+Q_{S}\right) / C_{o x}$ em 2.2-22 (a) resulta:

$$
V_{P}-\phi_{M S}+\frac{Q_{S S}}{C_{o x}}=\phi_{S}-\frac{Q_{S}}{C_{a x}}
$$

Considerando a aproximação de depleção para $Q_{S}$ e $\phi_{S}$, resulta [GROV'66]:

$$
V_{P}-\phi_{M S}+\frac{Q_{S S}}{C_{o x}}=\frac{q \cdot\left(N_{A}-N_{D}\right) \cdot x_{d}^{2}}{2 \cdot \varepsilon_{S i} \varepsilon_{0}}+\frac{q \cdot\left(N_{A}-N_{D}\right) \cdot x_{d}}{C_{a x}}
$$

Substituindo a equação 2.2-19 na equação $2.2-23$, obtemos uma expressão para a tensão de porta necessária para ocorrer inversão forte na superfície $\left(V_{P}=V_{T H}\right)$.

$$
V_{T H}\left(V_{J}\right)-\phi_{M S}+\frac{Q_{S S}}{C_{o x}}=V_{J}+2 \cdot \phi_{F} \pm \frac{1}{C_{o x}} \cdot\left[2 \cdot \varepsilon_{S i} \varepsilon_{0} \cdot q \cdot\left(N_{A}-N_{D}\right) \cdot\left(V_{J}+\phi_{F}\right)\right]^{1 / 2}
$$


$\mathrm{Na}$ equação 2.2-24, o sinal positivo é usado quando o substrato for tipo $\mathrm{P}$ e o negativo para tipo $\mathrm{N}$.

Dado que $C_{S}$ é a capacitância associada à região de depleção no silício e que a mesma é dada pela relação [GROV'66]:

$$
C_{s}=-\frac{d Q_{S}}{d \phi_{S}}
$$

Podemos agora expressar a capacitância em baixas e altas freqüências para a região de depleção [GROV'66], respectivamente, como:

$$
\begin{gathered}
C_{S}^{B F}=\varepsilon_{S i} \varepsilon_{0} \cdot \frac{q \cdot\left(p_{S}-n_{S}+N_{D}-N_{A}\right)}{Q_{S}} \\
C_{S}^{A F}=\frac{\varepsilon_{S i} \varepsilon_{0}}{x_{d}}
\end{gathered}
$$

Também é possível encontrar uma expressão para a largura da região de depleção como função da tensão de junção isolando $x_{t l}$ na equação $2.2-23$ resultando em:

$$
x_{d}=\frac{\varepsilon_{S i}}{\varepsilon_{o x}} \cdot x_{o x} \cdot\left\{\left[1+\frac{2 \cdot \varepsilon_{o x}^{2} \cdot \varepsilon_{0} \cdot\left(V_{P}-\phi_{M S}+Q_{S S} / C_{o x}\right)}{\varepsilon_{S i} \cdot x_{o x}^{2} \cdot q \cdot\left(N_{A}-N_{D}\right)}\right]^{1 / 2}-1\right\}
$$

onde $x_{o x}$ é a espessura do óxido de porta.

Das relações anteriores, também podemos obter uma equação para a capacitância de porta de baixa freqüência na região de depleção como segue: 


$$
\frac{C}{C_{o x}}=\left[1+\frac{2 \cdot \varepsilon_{o x}^{2} \varepsilon_{0}}{\varepsilon_{S i} \cdot x_{o x}^{2} \cdot q \cdot\left(N_{A}-N_{D}\right)} \cdot\left(V_{P}-\phi_{M S}+\frac{Q_{S S}}{C_{o x}}\right)\right]^{1 / 2}
$$

No gráfico mostrado na figura 2-4 podemos ver o comportamento das curvas $C x V$ em baixa frequiência em função do potencial de junção nas regiões de acumulação, depleção e inversão. Nesta figura observa-se que quanto mais negativo é o potencial de junção (substrato P), maior a extensão da região de depleção na curva $C x V$ de baixa frequiência.

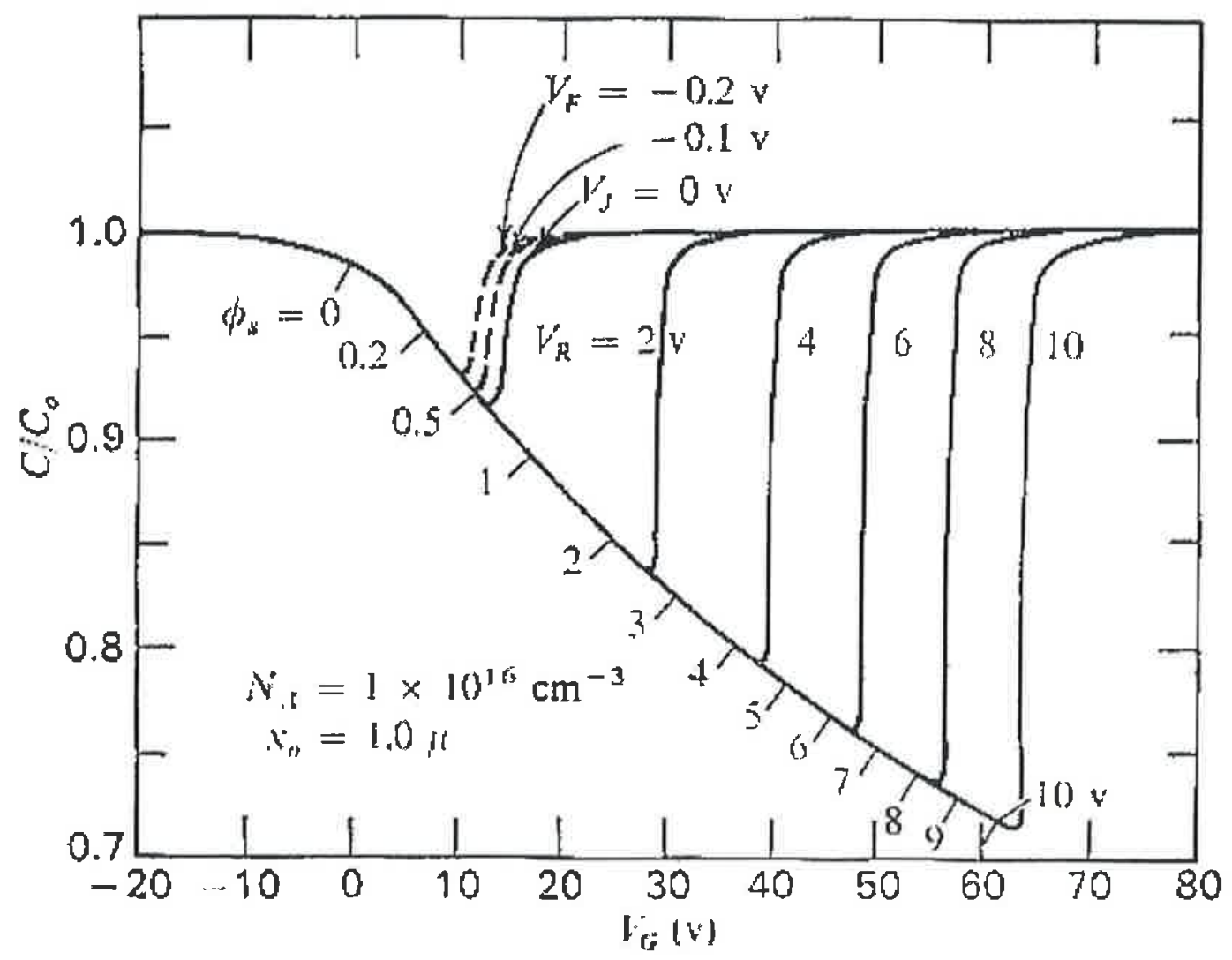

Fig. 2-4: Curva $C x V$ em baixa freqüência, parametrizada pela tensão de junção

\section{3 - A corrente reversa em DCP's}

A corrente reversa em DCP's é devida à geração de portadores em centros de geração do tipo Shockley-Read-Hall que se encontram dentro da região de depleção e 
também em centros interfaciais rápidos na superfície do semicondutor, na interface $\mathrm{Si}$ $\mathrm{SiO}_{2}$.

Devido às características desse dispositivo, a corrente reversa é extremamente dependente da tensão de polarização de porta, e portanto, ao estado da superfície ao longo do canal.

Assim é que podemos definir três regimes básicos de operação, como se pode ver na figura 2-5 a seguir: acumulação, depleção e inversão superficial.

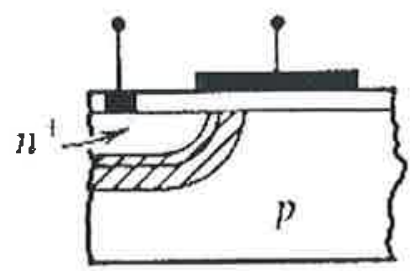

(a)

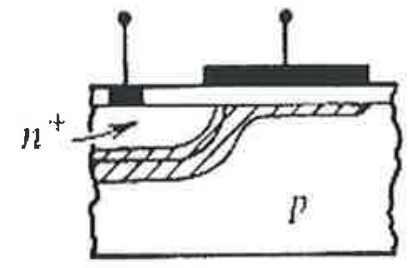

(b)

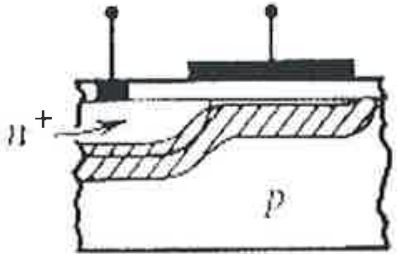

[c]

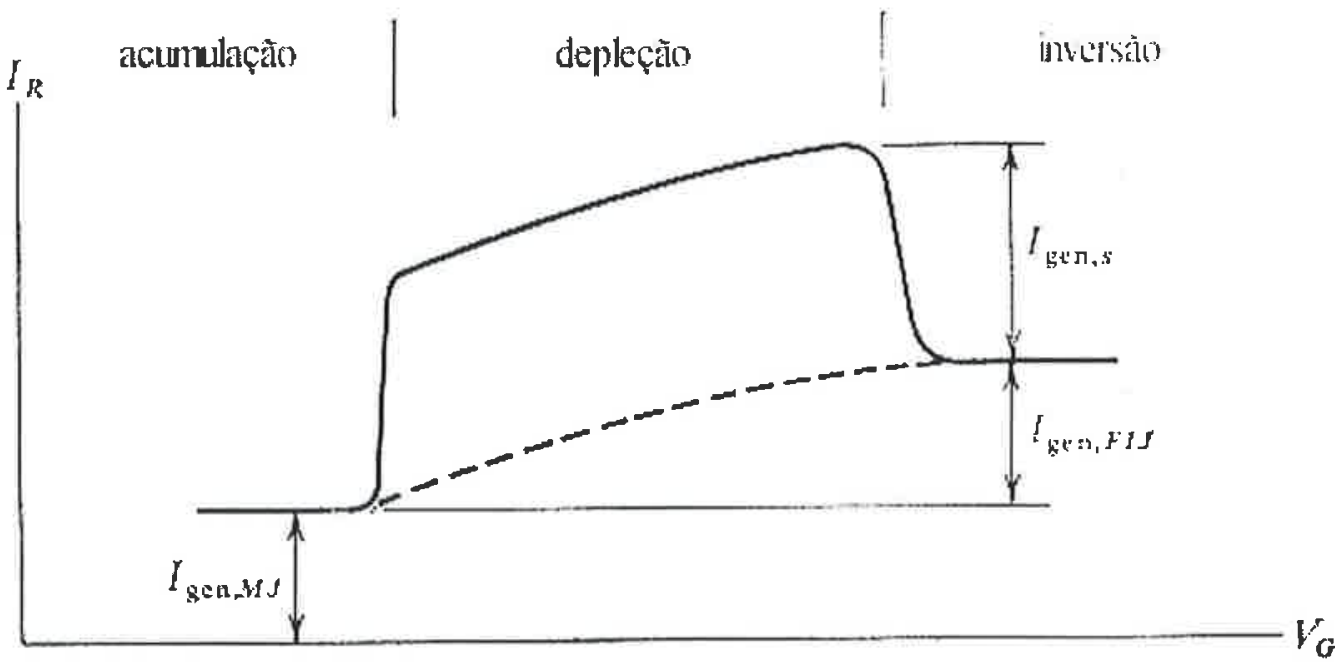

Fig. 2-5: Dependência da corrente reversa com a tensão de polarização de porta em DCP's

Em acumulação, temos apenas a região de depleção associada à junção metalúrgica, e portanto somente os centros SRH aí presentes contribuirão com 
portadores para a corrente reversa. Essa parcela sempre existe e é constante, sendo representada no gráfico da figura 2-5 pela parcela $I_{g e n, M J}$.

Quando atingimos o regime de depleção, acrescentamos mais duas componentes à corrente reversa total. São elas as componentes devidas aos centros de geração no corpo do semicondutor que se encontrem dentro da região de depleção induzida pelo potencial de porta e a parcela relativa à geração nos estados rápidos interfaciais.

O acréscimo dessas duas novas parcelas responde pela variação de corrente observada quando entramos em regime de depleção.

A componente de corrente superficial, $I_{Y, e n, S}$, é independente do potencial de porta sendo proporcional apenas à velocidade de recombinação superficial, mas a

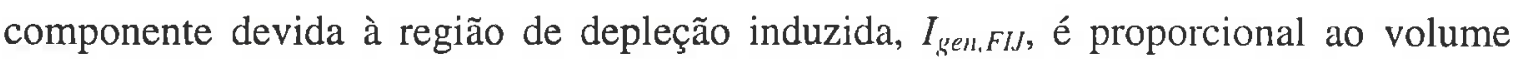
depletado, o qual, por sua vez, depende do potencial de porta de acordo com a equação 2.2-28. Isso faz com que a corrente reversa aumente com o aumento do potencial de porta no regime de depleção.

Finalmente, quando atingimos a inversão de superfície, os centros aí presentes são preenchidos pelos portadores vindos do substrato. Isso anula a componente devida à superfície junto à junção.

Por outro lado, como a região de depleção atinge aí a sua expansão máxima, também a componente proporcional à mesma atinge um patamar estável. A partir daí a corrente reversa total passa novamente a ser constante com relação ao potencial aplicado à porta do dispositivo.

A corrente reversa total é composta por três componentes que podem ser assim equacionadas:

$$
I_{g e n, M J}=q \cdot U_{M J} \cdot W \cdot A_{M J}
$$




$$
\begin{gathered}
I_{g e n, F I J}=q \cdot U_{F I J} \cdot x_{d m a ́ x} \cdot A_{S} \\
I_{g e n, S}=q \cdot U_{S} \cdot A_{S}
\end{gathered}
$$

onde $W$ é a largura da região de depleção da junção metalúrgica, $x_{\text {tlmáx }}$ é a largura máxima da região de depleção induzida embaixo do óxido, $A_{M J}$ é a área da junção metalúrgica, $A_{S}$ é a área sob a porta do DCP, $U_{M J}$ e $U_{F I J}$ são taxas de geração no corpo do semicondutor por unidade de volume e $U_{S}$ é a taxa de geração por unidade de área superficial.

Agora, se tomarmos

$$
\begin{gathered}
U_{M J}=U_{F I J}=U=\sigma \cdot v_{t l} \cdot N_{t} \cdot n_{i}=\frac{n_{i}}{\tau_{0}} \\
U_{S}=\sigma_{S} \cdot v_{t h} \cdot N_{s t} \cdot n_{i}=n_{i} \cdot s_{0}
\end{gathered}
$$

onde $\sigma$ é a secção cruzada de captura efetiva, $v_{t / h}$ é a velocidade térmica e $N_{t}$ é a densidade de estados de armadilhas (traps). O subscrito "s" indica "de superfície" nos símbolos das equações acima.

A partir das relações acima, podemos finalmente escrever as equações para cada uma das componentes da corrente reversa total.

$$
\begin{gathered}
I_{g e n, M J}=q \cdot \frac{n_{i} \cdot W \cdot A_{M J}}{\tau_{0 M J}} \\
I_{g e n, F I J}=q \cdot \frac{n_{i} \cdot x_{\text {Unüx }} \cdot A_{S}}{\tau_{0 F I J}} \\
I_{g e n, S}=q \cdot n_{i} \cdot s_{0} \cdot A_{S}
\end{gathered}
$$

Portanto, podemos extrair a velocidade de recombinação superficial através da medida de $I_{g e n, S}$ (veja figura 2-5) e da equação 2.3-8. 
A figura 2-6 ilustra as curvas $C x V$ de baixa freqüência e as curvas $I_{R} \times V_{G}$ parametrizadas em função da tensão reversa aplicada na junção para um diodo controlado por porta típico [GROV'66].
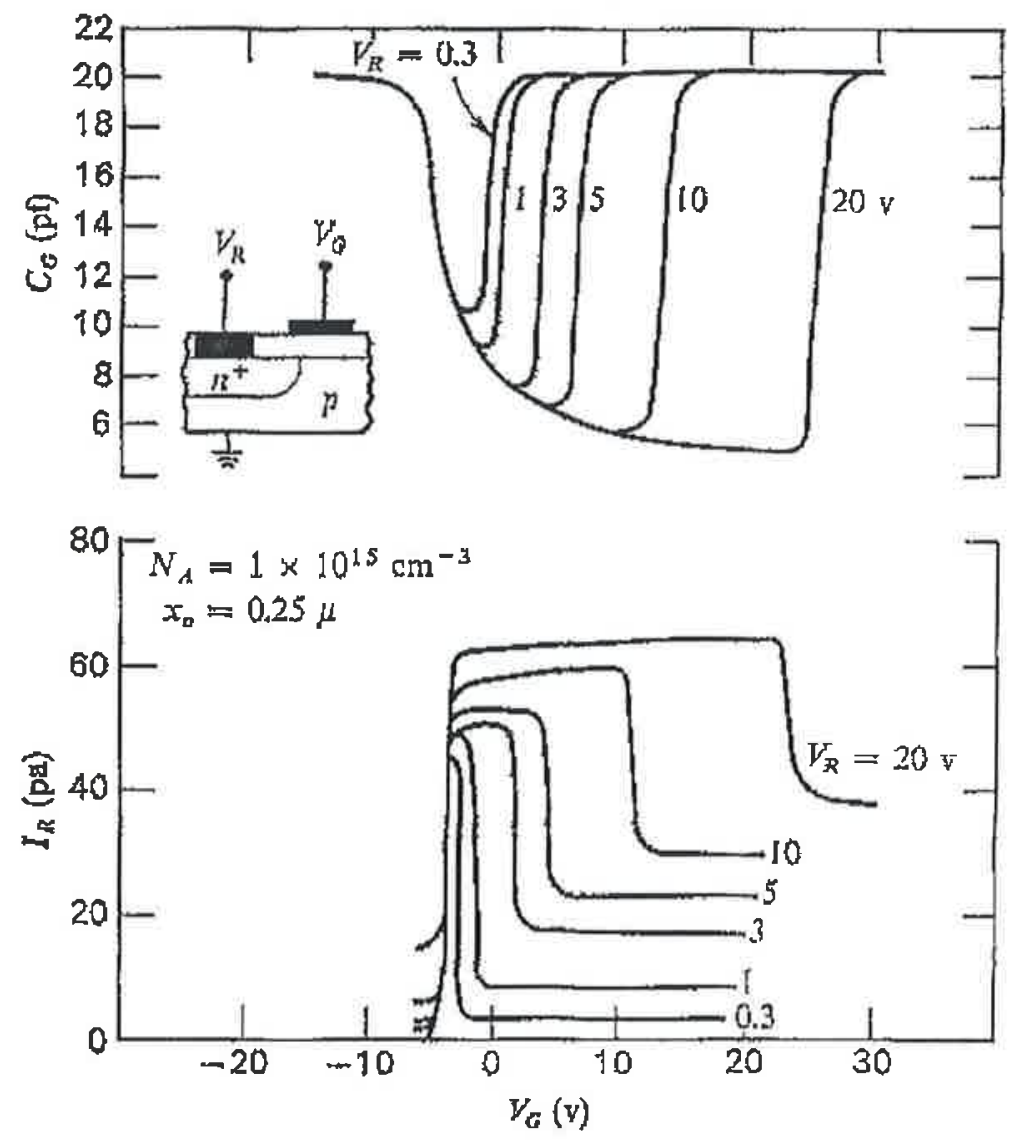

Fig. 2-6: Corrente reversa e capacitância em função do potencial de porta [GROV'66]

\subsection{1 - Melhorias no modelo básico}

Toda discussão até aqui no item 2.3 baseou-se na admissão de uma hipótese simplificadora: o nível de quase-Fermi para os minoritários é constante ao longo do canal do dispositivo, o que implica dizer que não há passagem significativa de corrente sob a porta do mesmo. 
O nível de detalhamento do modelo de Grove e Fitzgerald [GROV'66, GROV'67] foi suficientemente acurado para a descrição do comportamento da capacitância do DCP em alta e baixa freqüência, daí o fato dos autores (Grove e Fitzgerald) não terem se ocupado de um possível aprimoramento.

No entanto, Pierret [PIER'74], percebeu que apesar desse modelo levar a bons resultados quanto ao modelamento da capacitância, o mesmo conduzia a valores muito menores do que deveria ser para a velocidade de recombinação superficial $\left(s_{0}\right)$ quando a mesma era calculada conforme descrito na seção 2.3. Foi então proposto um novo modelo [PIER'74] que considerava a variação do nível ${ }^{1}$ de quase-Fermi na superfície do DCP.

As figuras 2-7 e 2-8 a seguir, mostram os modelos de Grove e Fitzgerald (com nível de quase-Fermi constante ao longo do canal) e Pierret (com nível de quase-Fermi variável ao longo do canal).

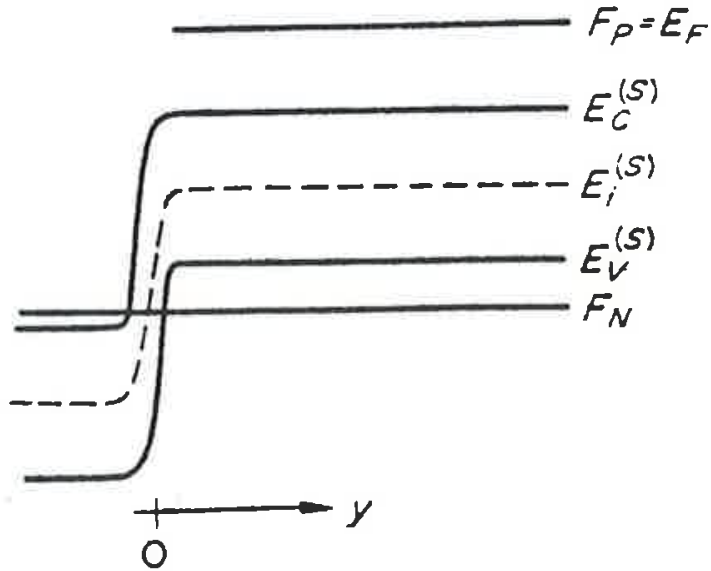

(a)

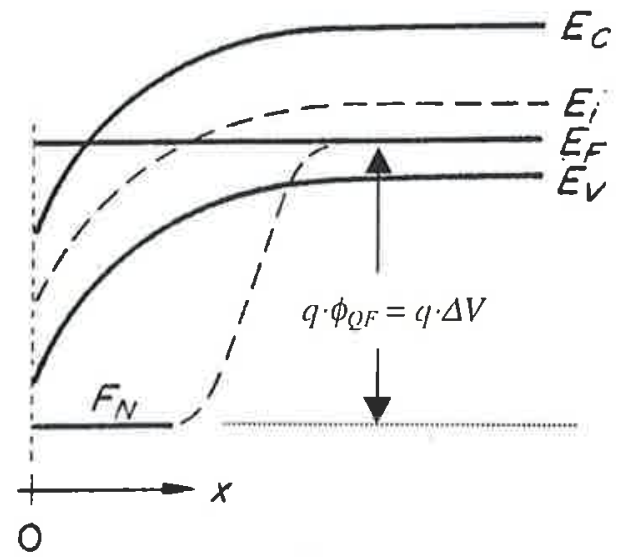

(b)

Fig. 2-7: Nível de quase-Fermi nas direções y (a) e $x$ (b) segundo Grove e Fitzgerald [PIER'74] 


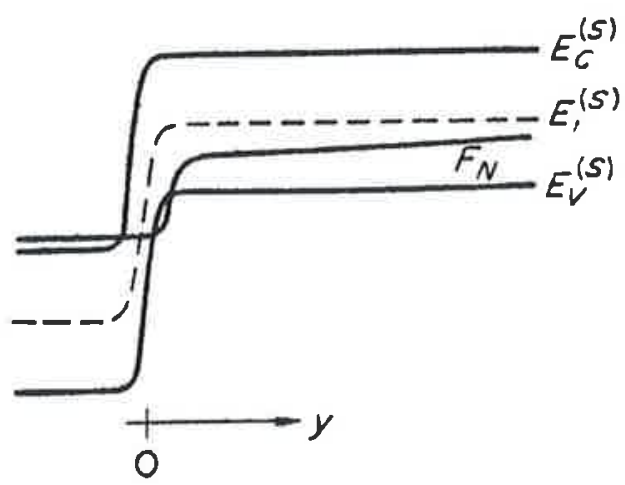

(a)

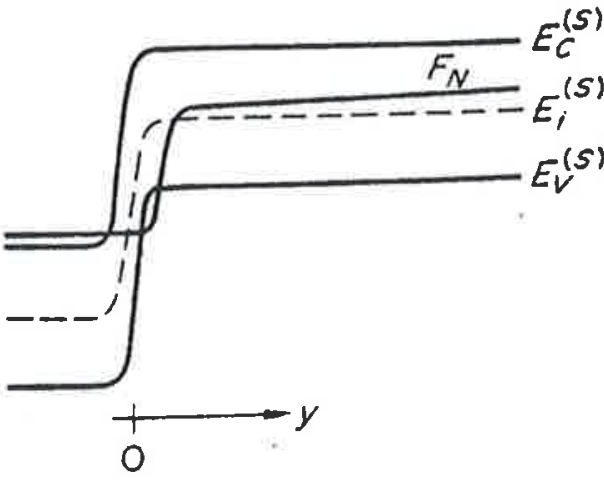

(b)

Fig. 2-8: Nível de quase-Fermi na direção y em duas condições: (a) nível de $F_{n}$ abaixo de $E_{i}$; (b) nível de $F_{n}$ cruzando $E_{l}$ [PIER'74]

Na figura 2-7 (a) vemos a variação do diagrama de faixas de energia ao longo do canal. Nesse modelo, o nível de quase-Fermi é admitido como constante ao longo de todo o material.

Na figura 2-7 (b) temos a variação do diagrama de faixas de energia devido à indução por campo num capacitor MOS. Essa é uma situação de não-equilíbrio já que temos o nível de quase-Fermi deslocado em relação ao nível de Fermi do material. A distância, em tensão, entre o nível de quase-Fermi e o nível de Fermi é igual à variação súbita de tensão aplicada na porta do capacitor ou à tensão reversa aplicada na junção PN.

Segundo Pierret, a hipótese assumida por Grove e Fitzgerald de que o nível de quase-Fermi não varia na direção y não está correta, sendo que o mesmo pode apresentar-se segundo as duas configurações mostradas nas figuras 2-8 (a) e (b), ou seja, o quase-nível para minoritários pode sempre permanecer abaixo do nível intrínseco, como mostrado na figura 2-8 (a), ou pode, em algum ponto, cruzar o nível intrínseco.

\footnotetext{
${ }^{1}$ Falamos aqui em nível de quase-Fermi para minoritários. O nível de quase-Fermi para os majoritários é admitido como sendo igual ao nível de Fermi do material.
} 
Na primeira situação, o erro cometido em relação ao modelo de nível constante não é muito grande, podendo até ser ignorado, mas no segundo caso o mesmo torna-se considerável e deve ser corrigido.

A figura 2-9 ilustra a convenção de símbolos para o DCP e que será importante na discussão a seguir.

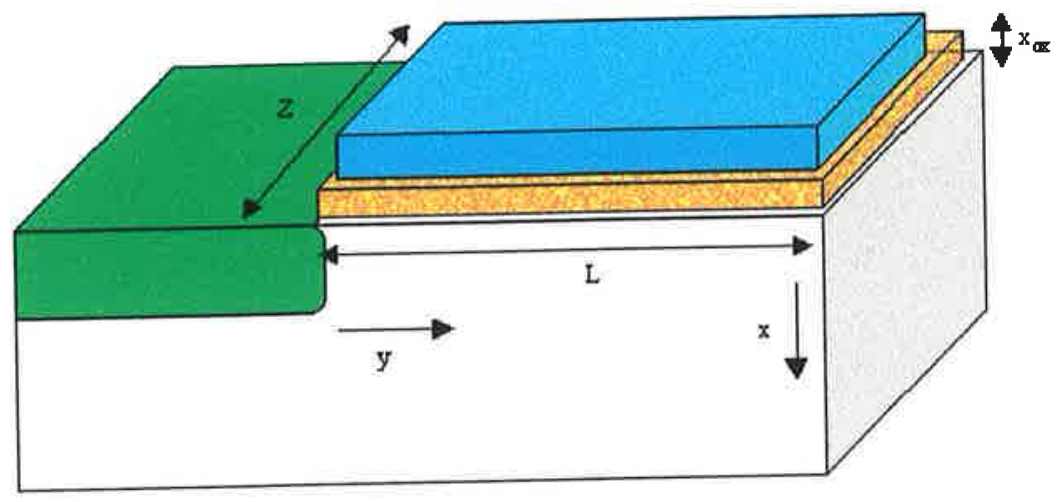

Fig. 2-9: Simbologia adotada

A variação no nível de quase-Fermi, segundo Pierret se dá porque para tensões menores do que a tensão de limiar de condução, a superficie do semicondutor pode apresentar-se fracamente invertida, permitindo a passagem de uma pequena corrente.

Primeiramente, vamos assumir como condições de contorno, que em $y=0$, a separação entre o quase-nível de Fermi e o nível de Fermi seja dada pela tensão aplicada à junção do dispositivo, e que em $y=L$ a corrente seja nula.

Isso pode ser expresso matematicamente por:

$$
\begin{gathered}
F_{P}(0)-F_{N}(0)=E_{F}-F_{N}(0)=q \cdot V_{J} \\
I_{y}(L)=0
\end{gathered}
$$

onde $V_{J}$ é a tensão aplicada à junção do DCP. 
Os cálculos realizados por Grove com relação à corrente reversa, foram baseados nas estatísticas de Shockley, Read e Hall relativas aos centros geradores dentro das regiões de depleção (metalúrgica e induzida) e na superfície.

Mas em inversão fraca, o número de portadores, quer na superfície, quer no final da região de depleção, não são desprezíveis e acabam criando "zonas mortas" (veja figura 2-10), que são regiões onde a taxa de geração de portadores é menor do que no corpo da região de depleção. O efeito disso é modelado através de uma extensão menor da região de depleção, ou seja, um $W$ útil menor do que o $W$ real.

A taxa de geração para o substrato do semicondutor, logo abaixo da porta é dada pela equação 2.3.1-1 a seguir.

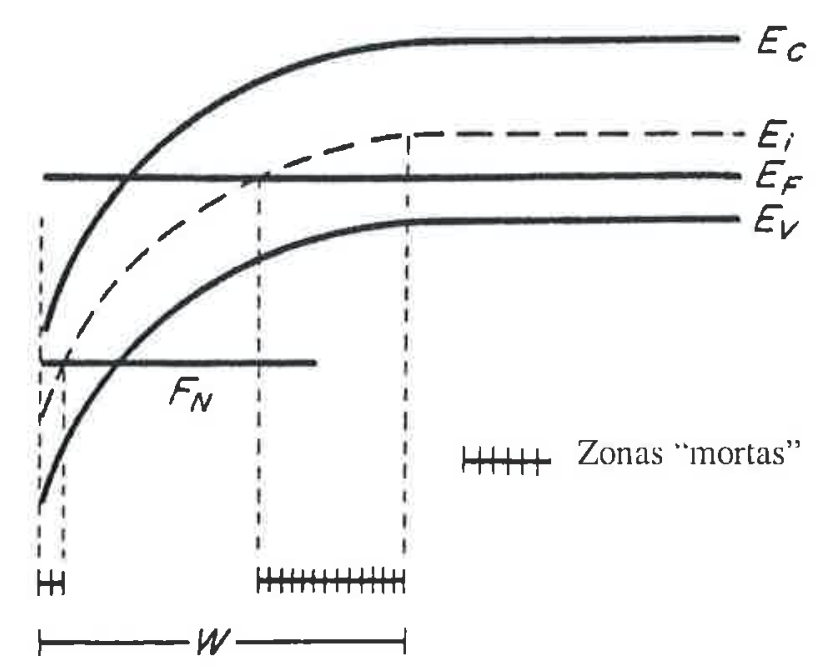

Fig. 2-10: "Regiões mortas" dentro da região de depleção de um DCP

$$
G_{B}=\int_{0}^{w} \frac{n_{i}^{2}-n \cdot p}{\tau_{p 0} \cdot\left(n+n_{1}\right)+\tau_{n 0} \cdot\left(p+p_{1}\right)} d x
$$

onde, segundo SRH, $n_{l}=n_{i}^{2} / p_{I}=n_{i} \cdot \exp \left[\left(E_{T}-E_{i}\right) / k \cdot T\right]$ e $E_{T}$ é o nível de energia médio de armadilhas.

Supondo $\mathrm{E}_{\mathrm{T}} \cong \mathrm{E}_{\mathrm{i}}$, podemos definir agora a largura da depleção útil dada por: 


$$
W_{u}=\int_{0}^{W} \frac{d x}{1+\frac{\left(\tau_{p 0} \cdot n+\tau_{n 0} \cdot p\right)}{2 \cdot n_{i} \cdot \tau_{0}}}
$$

onde:

$$
\tau_{0}=\frac{1}{2} \cdot\left(\tau_{n 0}+\tau_{p 0}\right)
$$

A partir das equações 2.3.1-3 a 2.3.1-5 anteriores, chegamos à taxa de geração no corpo do dispositivo.

$$
G_{B}=\frac{n_{i} \cdot W_{u}}{2 \cdot \tau_{0}} \cdot\left[1-e^{\frac{F_{N}-E_{F}}{k \cdot T}}\right]
$$

Para a superfície, a taxa de geração, segundo SRH, é dada pela equação:

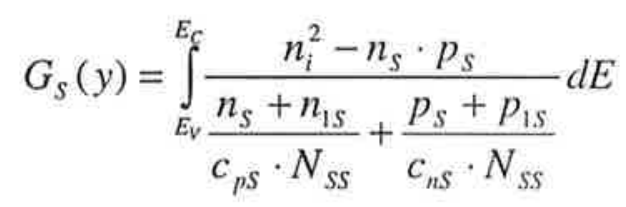

onde o subscrito " $s$ " indica na "superfície", $N_{S S}$ é a densidade de estados superficiais e os termos $c$ são coeficientes de captura para elétrons e lacunas.

Desenvolvendo a equação 2.3.1-7 chegamos na equação 2.3.1-8 a seguir:

$$
G_{S}=\frac{\pi}{2} \cdot c_{S} \cdot\left(k \cdot T \cdot N_{T S}\right) \cdot n_{i} \cdot \gamma \cdot\left[1-e^{\frac{F_{N}-E_{F}}{k \cdot T}}\right]
$$

onde $c_{p S}=c_{n S}=c_{S}$ e $N_{T S}=N_{S S}$ tomado numa faixa central da faixa proibida. 
O coeficiente $\gamma$ varia de 0 a 1 de acordo com a posição do nível de quase-Fermi entre o nível de valência e o nível de condução, conforme pode ser visto na figura 2-11.

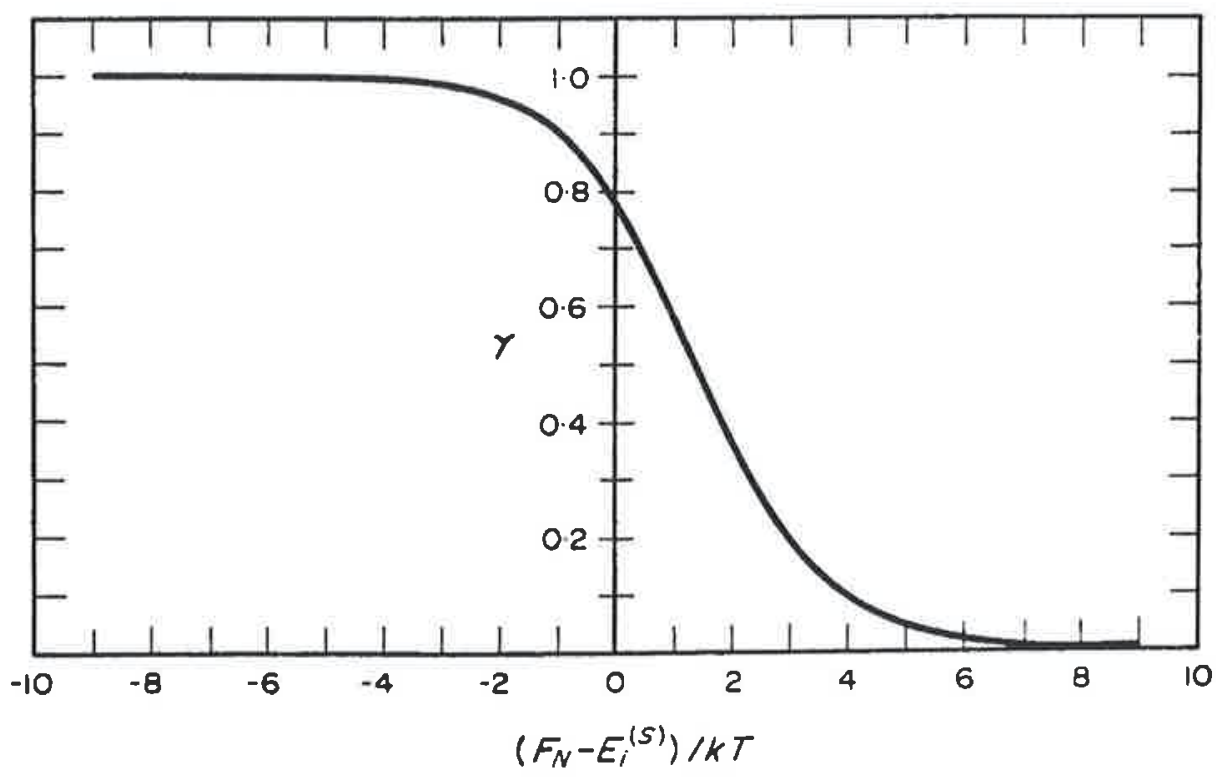

Fig. 2-11: Variação de $\gamma$ em função da posição de $F_{N}$ dentro da faixa proibida

O formato da função $\gamma$ explica porque o erro é desprezível, em relação ao modelo de Grove, quando o nível de quase-Fermi permanece sempre abaixo do nível intrínseco.

O valor de $\gamma$ pode ser obtido através das equações:

$$
\gamma= \begin{cases}\frac{2 / \pi}{\sqrt{1-(\eta+\varphi)^{2}}} \cdot \cos ^{-1}(\eta+\varphi), & \mathrm{p} / 0 \leq \eta+\varphi<1 \\ 2 / \pi, & \mathrm{p} / \eta+\varphi=1 \\ \frac{2 / \pi}{\sqrt{(\eta+\varphi)^{2}-1}} \cdot \ln \left[\eta+\varphi+\sqrt{(\eta+\varphi)^{2}-1}\right], & \mathrm{p} / \eta+\varphi>1\end{cases}
$$

onde: 


$$
\begin{gathered}
\eta=\frac{n_{S}}{2 \cdot n_{i}} \\
\varphi=\frac{p_{S}}{2 \cdot n_{i}}
\end{gathered}
$$

Com a superfície completamente depletada, podemos escrever:

$$
G_{S}=s_{0}^{\prime} \cdot n_{i} \cdot \gamma \cdot\left[1-e^{\frac{F_{N}-E_{F}}{k \cdot T}}\right]
$$

Observando a figura 2-11, fica clara a dependência da taxa de geração superficial com a posição de $F_{N}$ dentro da faixa proibida do material.

Se definirmos agora:

$$
\xi=\frac{y}{L}
$$

temos [PIER'74] que

$$
\frac{d^{2} \eta}{d \xi^{2}}=\frac{1}{2} \cdot\left(\frac{L}{L_{W}}\right)^{2} \cdot\left(1+\frac{2 \cdot \dot{s_{0}} \tau_{0}}{W_{u}} \cdot \gamma\right) \cdot\left(1-e^{\frac{F_{N}-E_{F}}{k \cdot T}}\right)
$$

onde:

$$
L_{W}=\left[\frac{\bar{\mu}_{n} \cdot\left(\frac{k \cdot T}{q}\right)^{2} \cdot \frac{\varepsilon_{S i} \cdot \varepsilon_{0}}{W}}{q \cdot \frac{N_{A}}{2 \cdot \tau_{0}} \cdot W_{u}}\right]^{1 / 2}
$$


A equação 2.3.1-13 admite solução simples para dois casos limites definidos como "limite controlado por substrato" e "limite controlado pela superfície".

O primeiro caso se dá quando:

$$
\frac{2 \cdot s_{0}^{\prime} \cdot \tau_{0}}{W_{u}}<<1
$$

ou seja, os portadores gerados na superfície contribuem muito menos com a corrente reversa do que os gerados no corpo do material. Essa situação ocorre quando a largura da região de depleção torna-se muito extensa o que, como vimos, acontece quando a tensão de junção é grande.

Quando a tensão na junção for suficientemente pequena, a região de depleção também será pouco extensa e a superfície domina o processo de geração de portadores. Isso ocorre para:

$$
\frac{2 \cdot s_{0} \cdot \tau_{0} \cdot \gamma}{W_{u}} \gg 1
$$

Quando estamos numa situação como a especificada por 2.3.1-16, que é o caso quando queremos determinar a velocidade de recombinação superficial, a equação 2.3.1-13 reduz-se a:

$$
\frac{d^{2} \eta}{d \xi^{2}}=-\frac{1}{2} \cdot\left(\frac{L}{L_{S}}\right)^{2} \cdot \gamma
$$

onde: 


$$
L_{S}=\left[\frac{\bar{\mu}_{n} \cdot\left(\frac{k \cdot T}{q}\right)^{2} \cdot \frac{\varepsilon_{S} \cdot \varepsilon_{0}}{W}}{q \cdot s_{0} \cdot N_{A}}\right]^{1 / 2}
$$

Finalmente, através da próxima equação, podemos calcular a velocidade de recombinação superficial verdadeira $\left(s_{0}^{\prime}\right)$ conhecendo-se o seu valor aparente $s_{0}$, que é determinado pelo método desenvolvido por Grove e já detalhado anteriormente.

$$
\frac{s_{0}}{s_{0}}=\left.2 \cdot\left(\frac{L_{S}}{L}\right)^{2} \cdot \frac{d \eta}{d \xi}\right|_{0}
$$

o que resulta em:

$$
\begin{gathered}
\frac{s_{0}}{s_{0}^{\prime}}=\frac{2}{\sqrt{\pi}} \cdot \frac{L_{s}}{L} \cdot\left[\frac{\pi^{2}}{4}-\left(\cos ^{-1} \eta_{1}\right)^{2}\right]^{1 / 2}, \mathrm{p} / 0 \leq \eta_{1} \leq 1 \\
\frac{s_{0}}{s_{0}}=\frac{2}{\sqrt{\pi}} \cdot \frac{L_{S}}{L} \cdot\left\{\frac{\pi^{2}}{4}+\left[\ln \left(\eta_{1}+\sqrt{\eta_{1}^{2}-1}\right)\right]^{1 / 2}, \mathrm{p} / \eta_{1} \geq 1\right.
\end{gathered}
$$

A figura 2-12 mostra a relação de $s_{0}$ com o comprimento efetivo do canal, que é como pode ser interpretado $L_{S}$. 


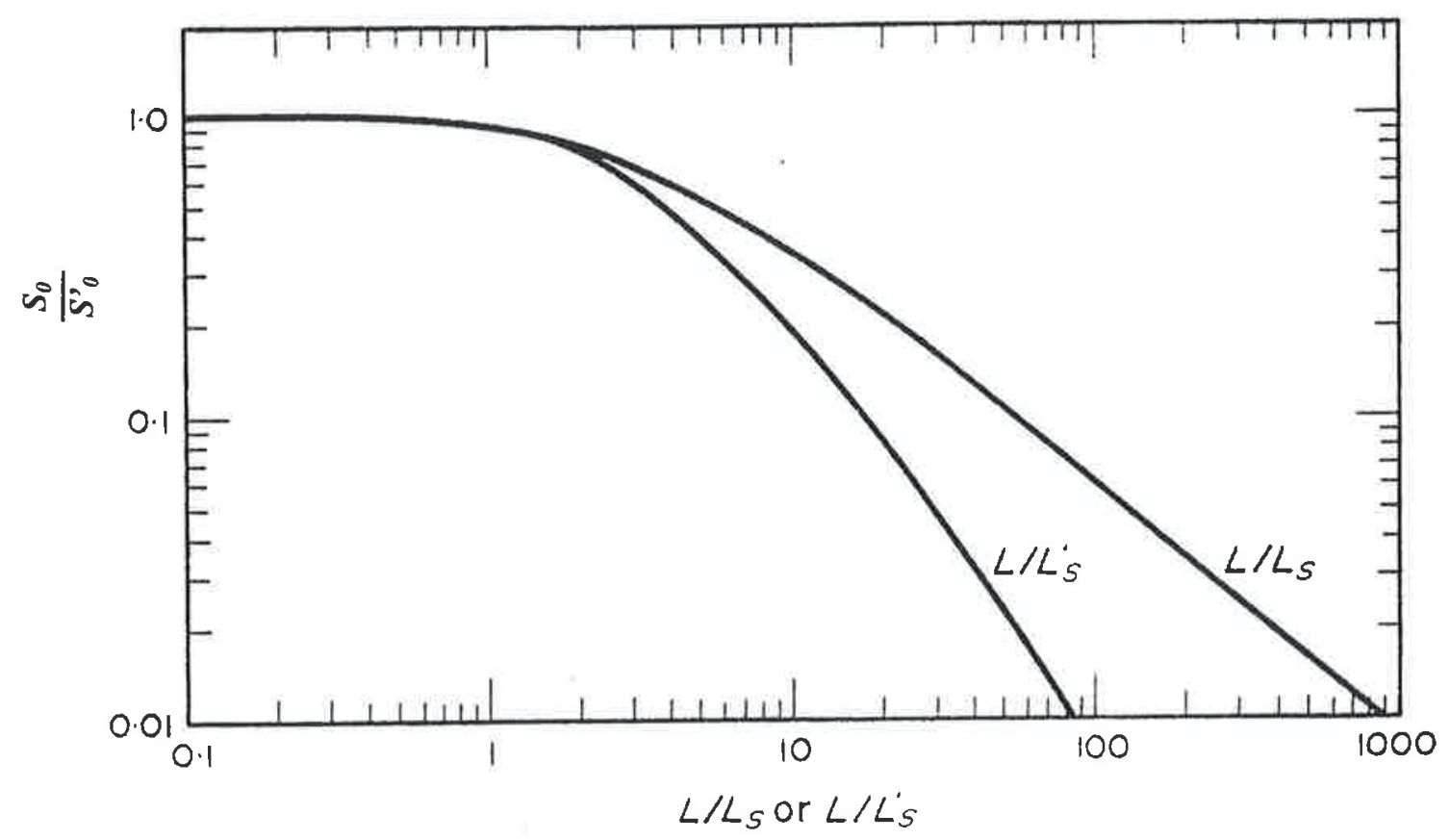

Fig. 2-12: Velocidade de recombinação superficial como função do comprimento efetivo do canal

Como podemos ver, dependendo das condições de operação, a velocidade de recombinação superficial ([CHEN'96], [DUGA'91]), pode ser muito maior do que o valor medido pelo método de Grove.

\section{4 - Aplicações para DCP's}

A estrutura DCP em silício foi inicialmente idealizada visando a caracterização da superfície de substratos de semicondutores no que diz respeito a determinação da velocidade de recombinação superficial, tensão de ruptura de junções, comportamento da corrente reversa em presença de defeitos induzidos na interface $\mathrm{Si}_{-} \mathrm{SiO}_{2}$, sob diversas condições de concentração superficial de portadores, etc. 


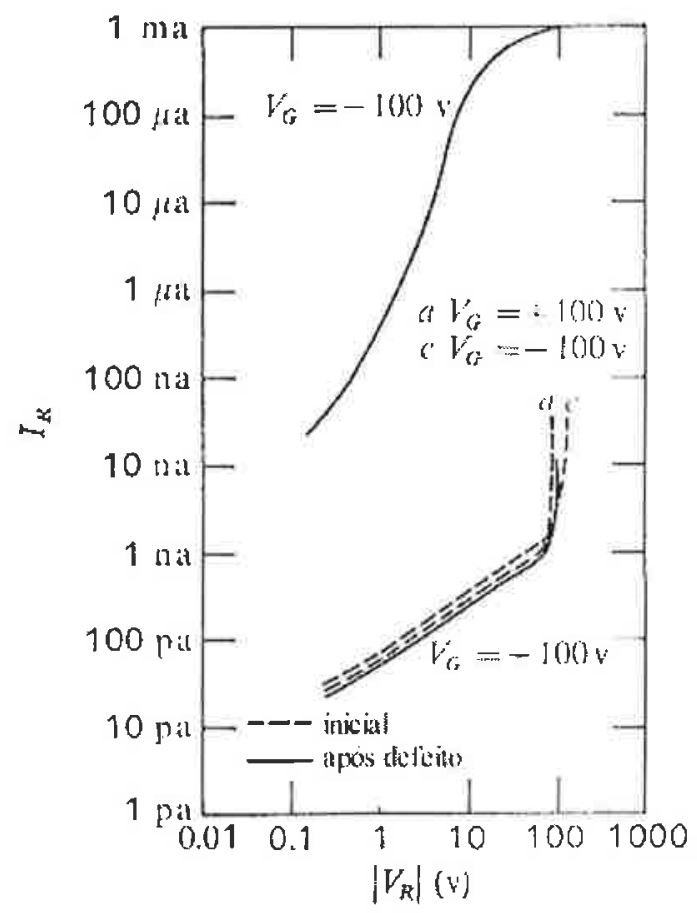

Fig. 2-13: Corrente reversa versus tensão reversa para um DCP $\mathrm{P}^{+} \mathrm{N}$ [GROV'67]

Na figura 2-13, vemos o comportamento da corrente reversa num DCP para duas condições de concentração de portadores na superfície. Note que em acumulação $\left(V_{G}=\right.$ $+100 \mathrm{~V}$ ) os portadores da superfície blindam-na mascarando os efeitos provocados por um defeito induzido na interface, porém em inversão $\left(V_{G}=-100 \mathrm{~V}\right)$ há uma mudança mensurável no comportamento da corrente.
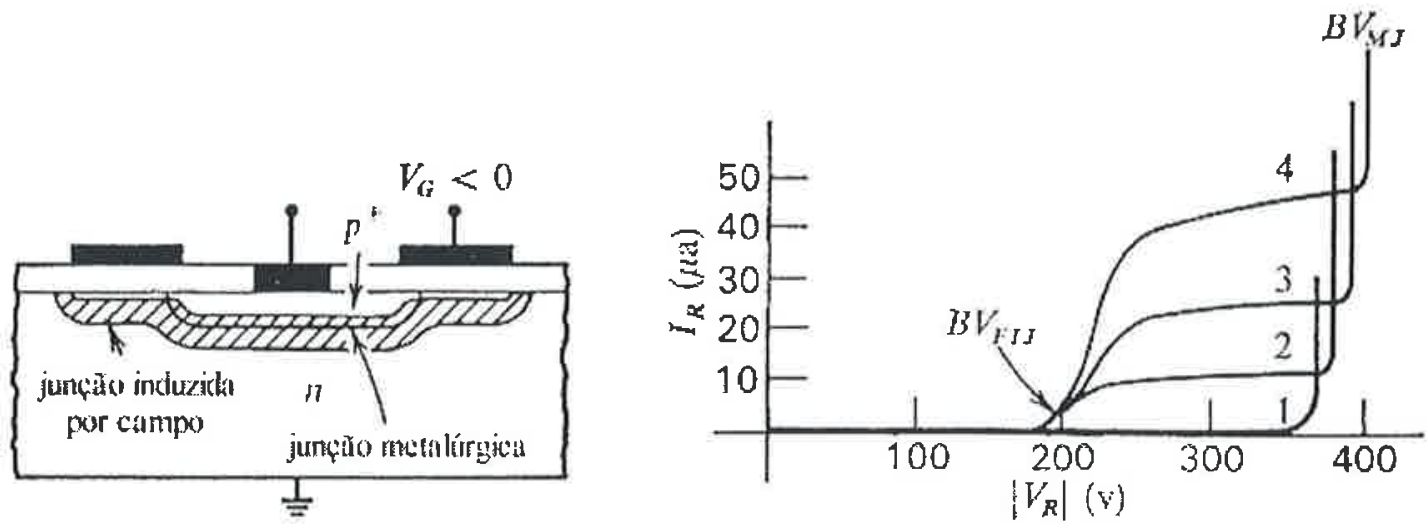

Fig. 2-14: Estudo da tensão de ruptura em junções metalúrgicas e induzjdas [GROV'66] 
Além disso, têm sido feitas experiências para o estudo do comportamento da superfície de semicondutores frente a defeitos induzidos por radiações, e ainda nessa linha, os DCP's também podem servir como sensores para radiação (luminosa ou ionizante) onde atuariam de forma semelhante aos diodos PIN, já que podemos induzir uma extensa região depletada nos DCP's o que eqüivaleria à região intrínseca do PIN com a vantagem de que não seria necessário um controle rigoroso no processo de crescimento de cristais intrínsecos de silício (atualmente não se conseguem concentrações mais baixas do que $10^{13}$ ou $10^{12} \mathrm{~cm}^{-3}$ ) [SZE'81].

A figura 2-14, ilustra a utilização de DCP's no estudo da tensão de ruptura de junções. Note que a junção induzida por tensão de porta rompe-se a tensões menores do que a junção metalúrgica. Isso se deve a um maior encurvamento das linhas de campo nas bordas dessas junções.

Numa nova linha de aplicações para esse dispositivo, Çilingiroglu [ÇחLI'91] propôs o uso de DCP's como elementos de estabilização de células de memória estática a partir de células dinâmicas.

A montagem por ele empregada pode ser vista na figura 2-15 a seguir:

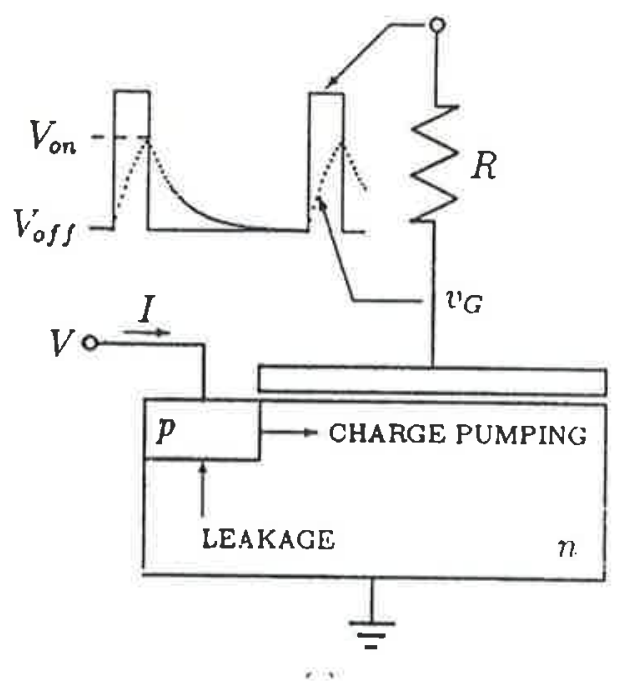

Fig. 2-15: Montagem utilizada para estabilização de nós capacitivos de células de memória 
O princípio de funcionamento está baseado no fato de que a corrente de charge pumping opõe-se à corrente de fuga da junção, de forma que podemos manter a carga no capacitor de junção por um tempo indefinido, bastando para isso mantermos pulsos regulares via resistor de porta [Ç山I'91]. A curva $I x V$ do dispositivo, mostrada na figura 2-16 a seguir, torna mais clara a esta última afirmação:

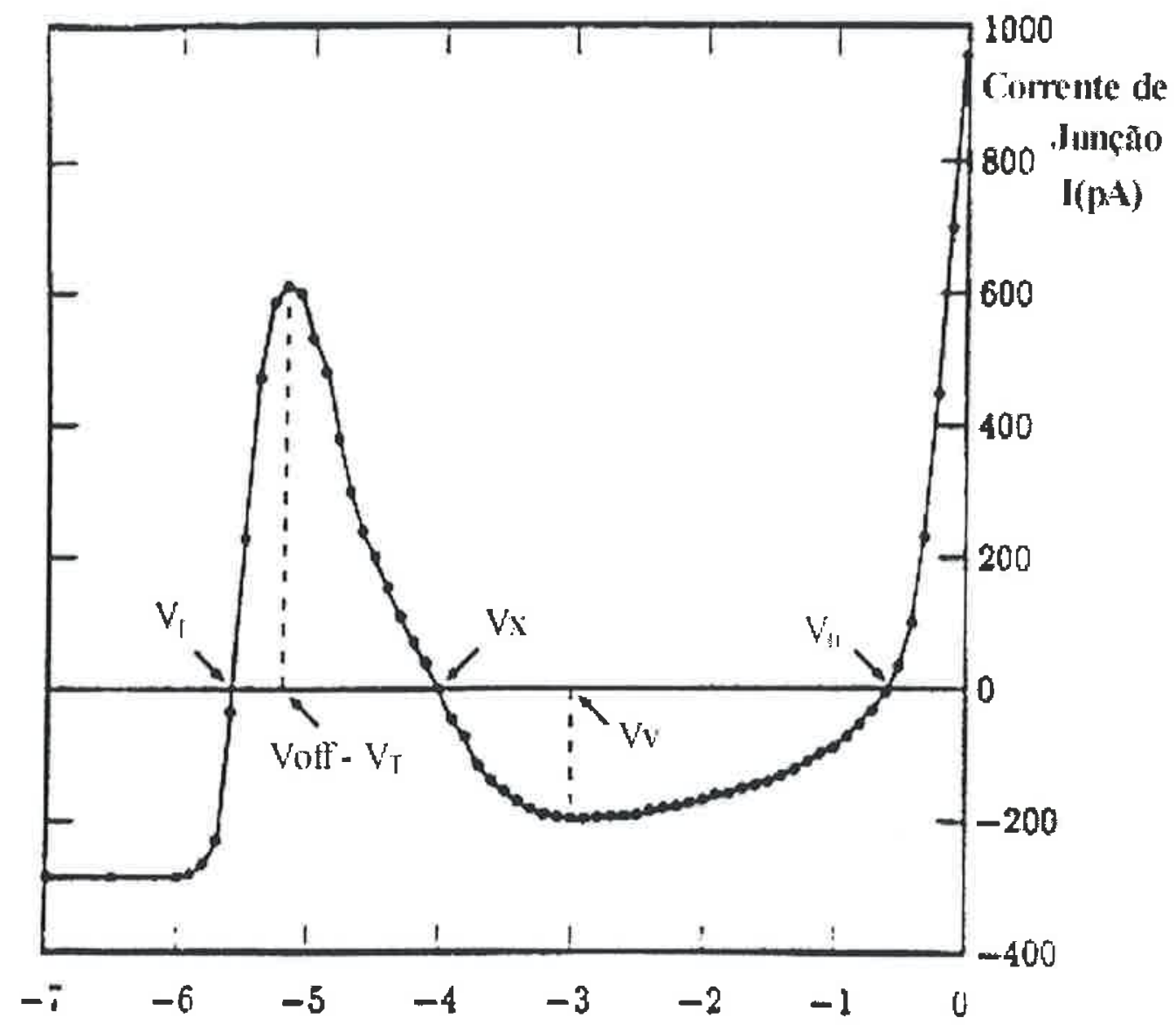

Fig. 2-16: Curva $I x V$ de um DCP pulsado via resistor

A figura 2-16 anterior mostra a curva de corrente versus tensão de porta para a montagem da figura 2-15. Note que a presença da corrente de charge pumping faz com que a corrente reversa da junção mude de sinal para tensões adequadas aplicadas ao terminal de porta. Isso faz surgir um comportamento de resistência negativa, o que acaba por suprir as perdas de carga do capacitor de porta. 
Agora, se o mesmo for utilizado como elemento de memória, poderemos aliar a estabilidade de carga obtida à densidade de integração superior alcançada pelas memórias dinâmicas.

Além dessas, como já foi mencionado, o DCP também encontra aplicações como sensor de luz, aplicação essa que é um dos temas proposto para o presente trabalho. 


\section{3 - Projeto de uma pastilha-teste (Chip-test) para DCP's}

Neste capítulo apresentaremos o projeto de um conjunto de máscaras de uma pastilha-teste para fabricar diodos controlados por porta com dimensão mínima de 1,5 $\mu \mathrm{m}(\lambda=1,5 \mu \mathrm{m})$. Por outro lado, a fim de se ter um bom aproveitamento da área da pastilha, optamos também por inserir uma série de dispositivos básicos incluindo estruturas gerais, capacitores, diodos e transistores, além dos diodos controlados por porta, de modo a se ter um conjunto de máscaras de uso geral para caracterização de processos e dispositivos.

A pastilha teste foi projetada para conter dispositivos de uso genérico além de DCP's de diferentes geometrias. Isso permitirá que as mesmas máscaras, agora projetadas, possam ser mais tarde reutilizadas em outros trabalhos.

O software utilizado para descrever todos os padrões das máscaras foi o Microeletrônica, de Etienne Sicard da Universidade de Toulouse, França. Trata-se de um software educacional que se encontra em sua versão 5.1e. Possui um editor de polígonos com interface gráfica que gera arquivos de saída num padrão próprio com extensão .msk, que pode, por sua vez, ser convertido para o padrão cif (Caltech Interchange Format) através do programa msk2cif, do mesmo autor.

O projeto foi baseado numa tecnologia de $1,5 \mu \mathrm{m}$ num substrato tipo $\mathrm{P}$, e as máscaras foram confeccionadas pelo Centro Tecnológico de Informática (CTI) de Campinas.

\subsection{Etapas de processo e conjunto de máscaras}

A sequiência de etapas de processos a ser empregada na fabricação dos diodos controlados por porta (DCP's) foi escolhida baseado nas facilidades oferecidas pelo 
LSI-EPUSP que possui uma sala limpa e etapas de deposição CVD, metalização, fotogravação e limpeza química. A única etapa que precisou ser realizada fora da USP foi a implantação iônica (CCS-UNICAMP). A seguir, apenas citamos cada etapa da sequiência completa sendo que o seu detalhamento será apresentado no capítulo 4 (Procedimentos experimentais).

1. Limpeza química das lâminas de silício;

2. Oxidação térmica $(23 \mathrm{~nm})$;

3. Deposição de óxido de silício $(600 \mathrm{~nm})$;

4. Densificação do óxido depositado $\left(1000^{\circ} \mathrm{C}, 60 \mathrm{~s}\right)$;

5. Definição da Região Ativa (máscara 1);

6. Limpeza química completa;

7. Oxidação térmica de porta $(20 \mathrm{~nm})$;

8. Deposição de silício policristalino $(500 \mathrm{~nm})$;

9. Dopagem do silício policristalino com fósforo;

10. Definição do silício policristalino (máscara 2);

11. Implantação iônica das junções;

12. Deposição de nitreto de silício (300 nm);

13. Deposição de óxido de silício (200 nm);

14. Densificação e ativação de dopantes $\left(x_{j}=0,2 \mu \mathrm{m}\right.$ ou $\left.x_{j}=0,6 \mu \mathrm{m}\right)$;

15. Abertura de contatos na estrutura óxido/nitreto/óxido (máscara 3);

16. Deposição seletiva de níquel nos contatos como material de barreira (300 nm); 


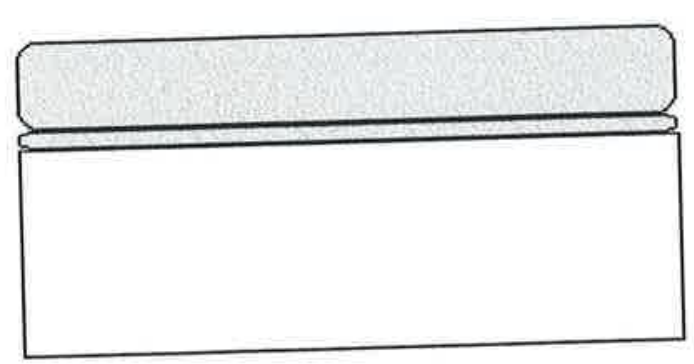

Aspecto da lâmina após o processo 4

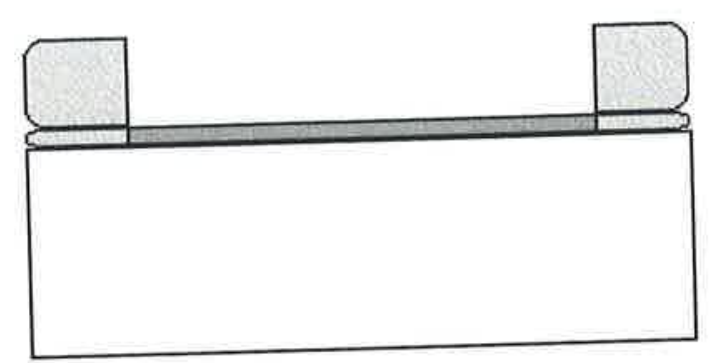

Após o processo 7

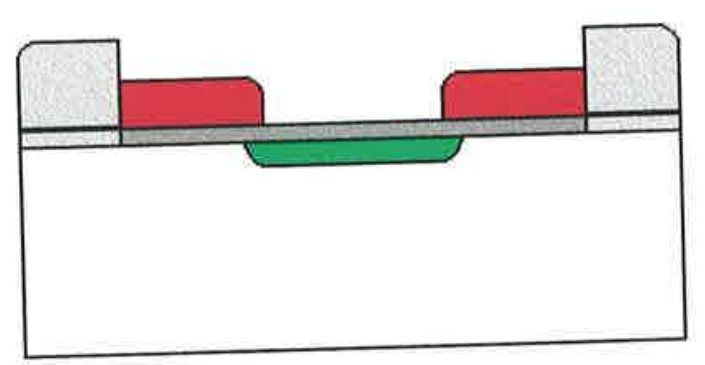

Após o processo 11

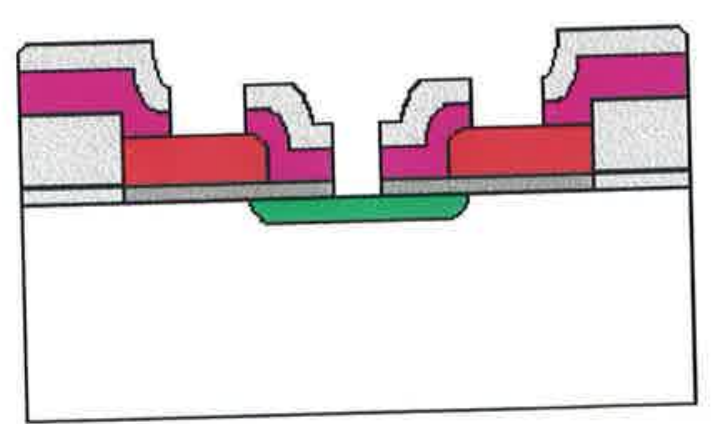

Após o processo 15

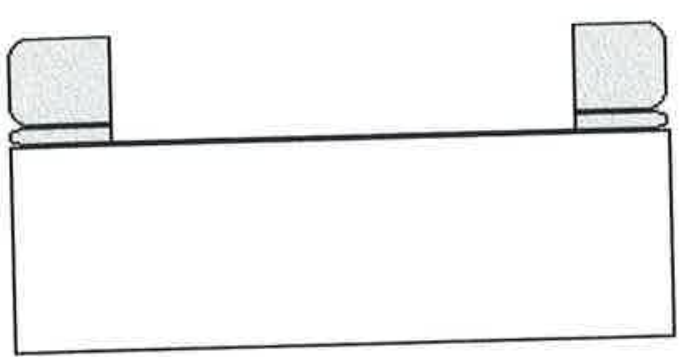

Após o processo 6

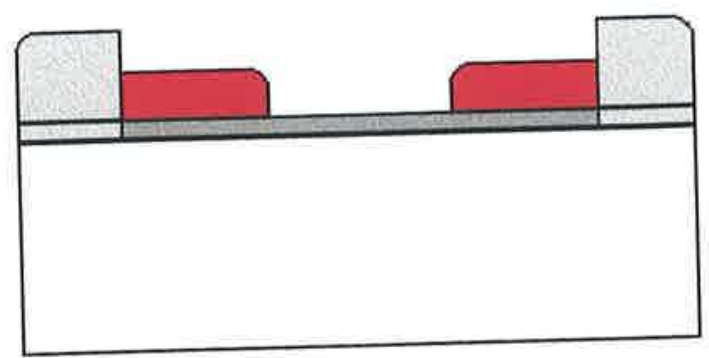

Após o processo 10

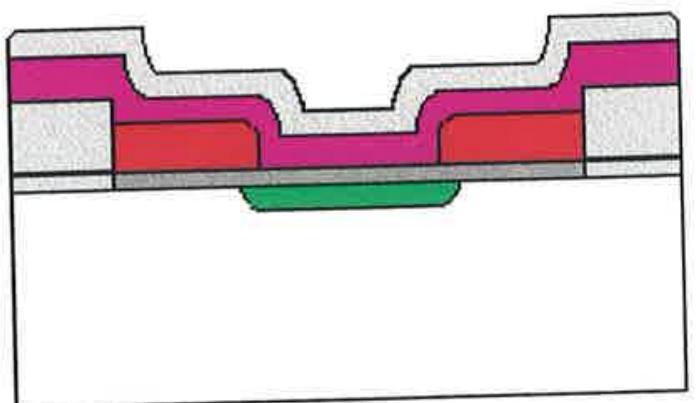

Após o processo 14

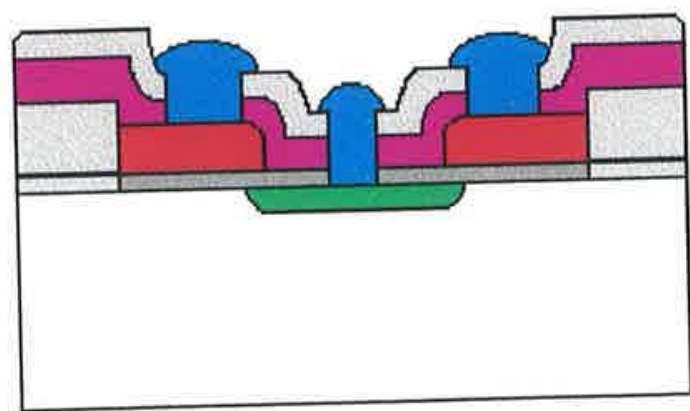

Após o processo 16

Fig. 3-1: Representação esquemática dos processos implementados na fabricação de DCP's. Em cinza temos $\mathrm{SiO}_{2}$ (o cinza escuro é o óxido de porta), em lilás $\mathrm{Si}_{3} \mathrm{~N}_{4}$, em vermelho $\mathrm{Si}$-poli, em verde junções, e em azul o $\mathrm{Ni}$ 
A figura 3-1 ilustra de forma esquemática os processos implementados na construção dos diodos controlados por porta.

Da seqüência de etapas de processos apresentada anteriormente, destacamos que serão empregadas 4 máscaras a saber:

- Região Ativa (máscara 1) - serve para definir uma janela no óxido de campo onde serão implementados os dispositivos;

- Si-poli (máscara 2) - usada na etapa de definição do Si-poli. Esse é um processo auto-alinhado, não sendo necessária uma máscara para a etapa de implantação iônica;

- Contatos (máscara 3) - usada para abrir janelas sobre o óxido de campo nos pontos onde é necessário o preenchimento com metal para contato com estruturas condutoras (Si-poli e difusões);

- Metalização (máscara 4) - para a definição do metal de contato e das linhas metálicas (não empregada pois não depositamos alumínio).

\subsection{Descrição dos dispositivos escolhidos para a pastilha-teste}

Como já mencionado anteriormente, além dos diodos controlados por porta, a pastilha-teste (chip-test) conterá também uma série de dispositivos básicos. O conjunto de dispositivos escolhidos foi o seguinte:

- 1 capacitor de região ativa quadrada de $1000 \mu \mathrm{m} \times 1000 \mu \mathrm{m}$;

- 1 capacitor de região ativa quadrada de $300 \mu \mathrm{m} \times 300 \mu \mathrm{m}$;

- 1 diodo de região ativa quadrada de $1000 \mu \mathrm{m} \times 1000 \mu \mathrm{m}$;

- 1 diodo de região ativa quadrada de $300 \mu \mathrm{m}$ x $300 \mu \mathrm{m}$;

- 1 diodo serpentina de área $300 \mu \mathrm{m}$ x $300 \mu \mathrm{m}$;

- 1 diodo Schottky quadrado de $300 \mu \mathrm{m}$ x $300 \mu \mathrm{m}$; 
- 1 cascata de transistores de $Z=30 \mu \mathrm{m}$ e $L=1,2,5,10,15$ e $20 \mu \mathrm{m}$;

- 1 cascata de transistores de $L=30 \mu \mathrm{m}$ e $Z=1,2,5,10,15$ e $20 \mu \mathrm{m}$;

- 1 inversor nMOS carga enriquecida com transistores de $L=20 \mu \mathrm{m}$ e $Z=30 \mu \mathrm{m}$ (load) e $L=20 \mu \mathrm{m} \mathrm{e} Z=8 \mu \mathrm{m}$ (driver);

- estruturas van der Pauw + Kelvin com linha de Si-poli, difusão N e difusão N exposta;

- estruturas Kelvin para medida da resistência de contato metal/poli de dimensões de $12 \mu \mathrm{m} \times 12 \mu \mathrm{m}, 6 \mu \mathrm{m} \times 6 \mu \mathrm{m} \mathrm{e} 2 \mu \mathrm{m} \times 2 \mu \mathrm{m}$;

- estruturas Kelvin para medida de resistência de contato metal/difusão $\mathrm{N}$ de $12 \mu \mathrm{m} x$ $12 \mu \mathrm{m}, 6 \mu \mathrm{m} \times 6 \mu \mathrm{m} \mathrm{e} 2 \mu \mathrm{m} \times 2 \mu \mathrm{m}$;

- 1 DCP quadrado de $(300 \times 300) \mu \mathrm{m}^{2}$ de área de dreno, com porta de $300 \mu \mathrm{m}$ recoberta por metal;

- 1 DCP quadrado de $(300 \times 300) \mu \mathrm{m}^{2}$ de área de dreno, com porta de $300 \mu \mathrm{m}$ semidescoberta;

- 1 DCP longo e estreito;

- 1 DCP curto e largo;

- 1 DCP quadrado de $(30 \times 30) \mu \mathrm{m}^{2}$ de área de dreno, com porta de $30 \mu \mathrm{m}$;

- 1 DCP Schottky quadrado de $(30 \times 30) \mu \mathrm{m}^{2}$ de área de dreno, com porta de $30 \mu \mathrm{m}$;

- 1 DCP quadrado de $(30 \times 30) \mu \mathrm{m}^{2}$ de área de dreno, com porta de $30 \mu \mathrm{m}$ e resistor de poli de 35,9 quadrados;

- 1 DCP Schottky quadrado de $(30 \times 30) \mu \mathrm{m}^{2}$ de área de dreno, com porta de $30 \mu \mathrm{m}$ e resistor de poli de 35,9 quadrados;

- 1 DCP de porta envolvente;

- 1 DCP quadrado de área exposta e área de porta iguais ao DCP de porta envolvente; 
- 1 transistor de $50 \mu \mathrm{m} \times 50 \mu \mathrm{m}$;

- 1 transistor de $50 \mu \mathrm{m} \times 50 \mu \mathrm{m}$ com a fonte ligada a um capacitor de $50 \mu \mathrm{m} \times 50 \mu \mathrm{m}$;

- 1 transistor de $2 \mu \mathrm{m} \times 2 \mu \mathrm{m}$;

- 1 transistor de $2 \mu \mathrm{m} \times 2 \mu \mathrm{m}$ com a fonte ligada a um capacitor de $50 \mu \mathrm{m} \times 50 \mu \mathrm{m}$;

A figura 3-2 abaixo ilustra a disposição de todos os dispositivos na pastilhateste, que tem aproximadamente $5415 \mu \mathrm{m} \times 5415 \mu \mathrm{m}(\sim 5,4 \mathrm{~mm})$ :

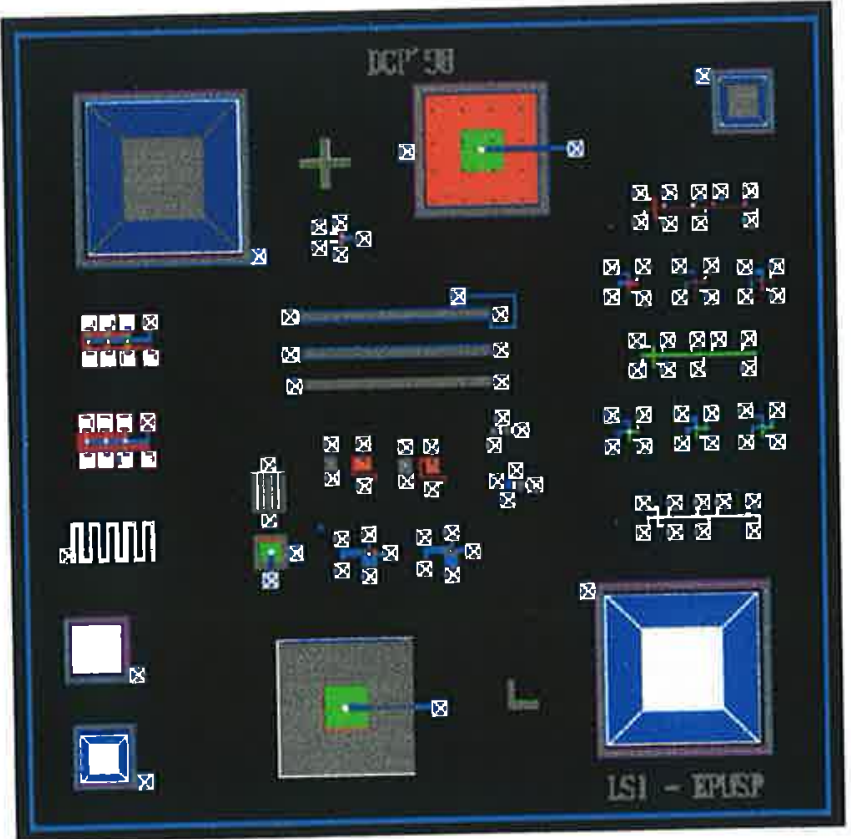

Fig. 3-2: Disposição dos dispositivos na pastilha-teste

A seguir são detalhados os dispositivos enumerados anteriormente e são destacados os parâmetros de maior relevância a eles associados. O valor das capacitâncias foi calculado admitindo-se uma espessura de óxido de $20 \mathrm{~nm}$.

\section{a) Capacitor MOS:}

Foram projetados capacitores MOS de dois tamanhos: de $1000 \mu \mathrm{m} \times 1000 \mu \mathrm{m}$ e de $300 \mu \mathrm{m} \times 300 \mu \mathrm{m}$, onde um dos terminais é o substrato de silício e o outro é composto por metal depositado sobre Si-poli. 
Ambos possuem um anel de guarda que nada mais é do que outro capacitor, polarizado de tal forma a manter o substrato em acumulação, prevenindo-se assim que a região de depleção associada ao capacitor alcance grandes dimensões horizontais.

A figura 3-3 mostra o capacitor em planta e em perfil vertical.

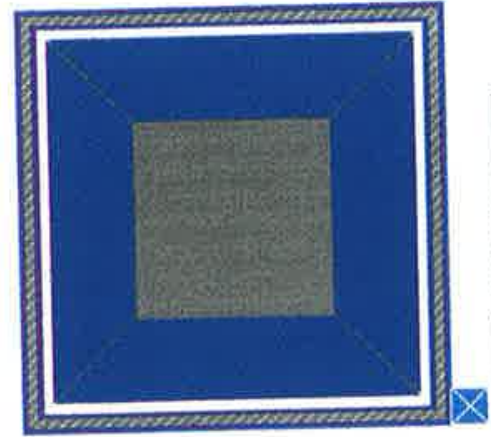

a)

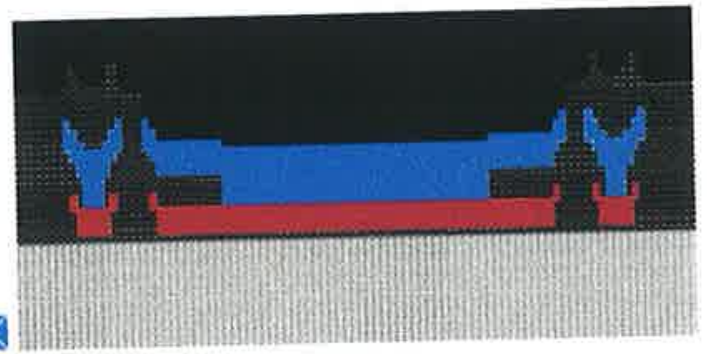

b)

Fig. 3-3: Capacitor MOS em planta a) e em perfil vertical b)

Os dados de máscara projetados para esses capacitores estão apresentados na tabela 3-1:

Tab. 3-1: Dados de máscara dos capacitores MOS projetados

\begin{tabular}{c|cc}
\hline Capacitor & Área de porta $\left[\boldsymbol{\mu m}^{2}\right]$ & Capacitância em acumulação [F] \\
\hline $1000 \times 1000$ & 1.000 .000 & $1,7266 \cdot 10^{-9}$ \\
$300 \times 300$ & 90.000 & $155,3910 \cdot 10^{-12}$ \\
\hline
\end{tabular}

Como já foi citado, capacitores são importantes dispositivos de caracterização e por isso foram aqui incluídos. 
b) Diodo de junção e Schottky:

Também foram projetados diodos de tamanhos e geometrias diferentes para possibilitar a obtenção da corrente reversa e fator de idealidade.

Foram especificados diodos de junção quadrados de (1000 x 1000) $\mu \mathrm{m}^{2} \mathrm{e}(300 \mathrm{x}$ 300) $\mu \mathrm{m}^{2}$, conforme pode-se ver na figura $3-4$.

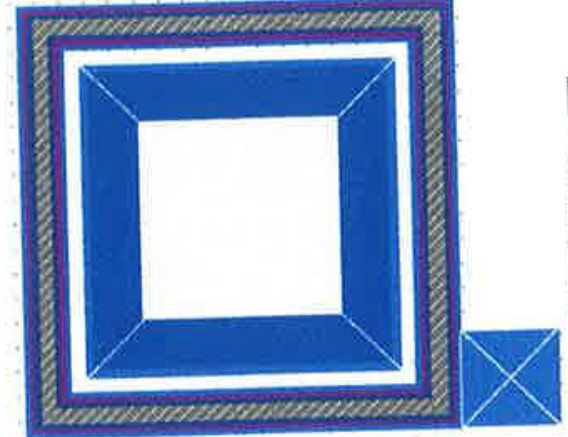

a)

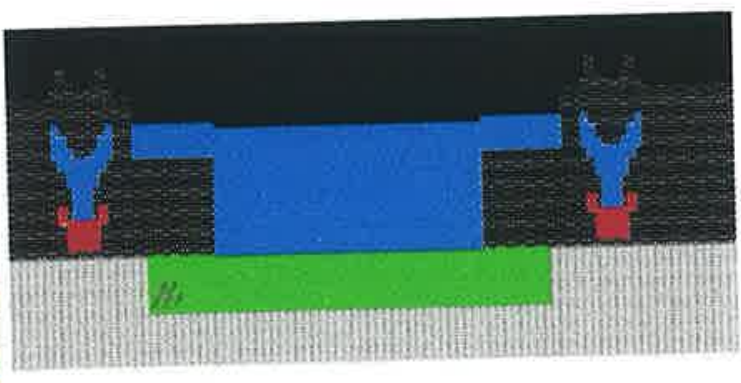

b)

Fig. 3-4: Diodo de junção em planta a) e em perfil vertical b)

Também foram projetados diodos Schottky quadrado e em "serpentina" com as mesmas áreas de $(300 \times 300) \mu \mathrm{m}^{2}$ mas perímetros diferentes conforme mostrado na figura 3-5.

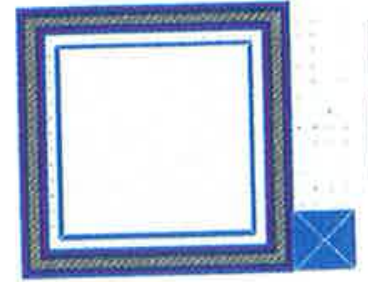

a)

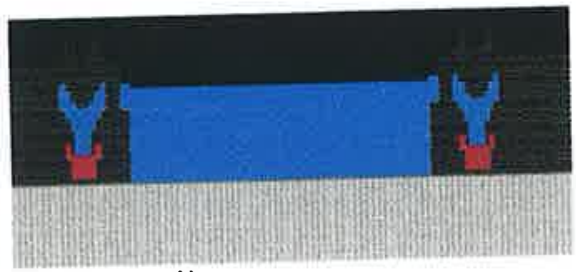

b)

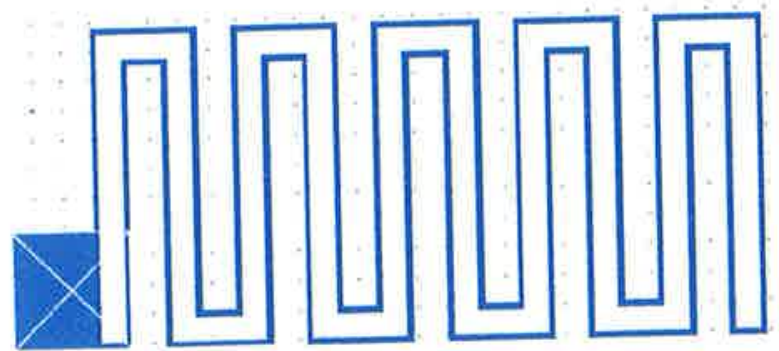

c)

Fig. 3-5: Diodo Schottky em planta (a) e em perfil vertical (b) e diodo de junção "serpentina" (c) 
c) Transistor e cascatas de transistores:

Foram projetadas duas cascatas de transistores, a primeira com $Z=30 \mu \mathrm{m}$ e $L$ variando de 1 a $20 \mu \mathrm{m}$ e outra onde $L=30 \mu \mathrm{m}$ e $Z$ varia de também de 1 a $20 \mu \mathrm{m}$. Além disso, também foram implementados transistores independentes um com $L$ e $Z$ iguais a $50 \mu \mathrm{m}$ e outro de $L$ e $Z$ de $2 \mu \mathrm{m}$, e finalmente outro par de mesmas dimensões mas com o terminal de fonte conectado a um capacitor MOS de $(50 \times 50) \mu \mathrm{m}^{2}$.

Essa última configuração foi sugerida por Viswanathan [VISW'93] de modo a se ter a possibilidade de amplificar a corrente reversa de um DCP formado a partir da junção de dreno e porta de um transistor convencional.

Podemos ver na figura $3-6$ a seguir as duas cascatas de transistores supramencionadas.

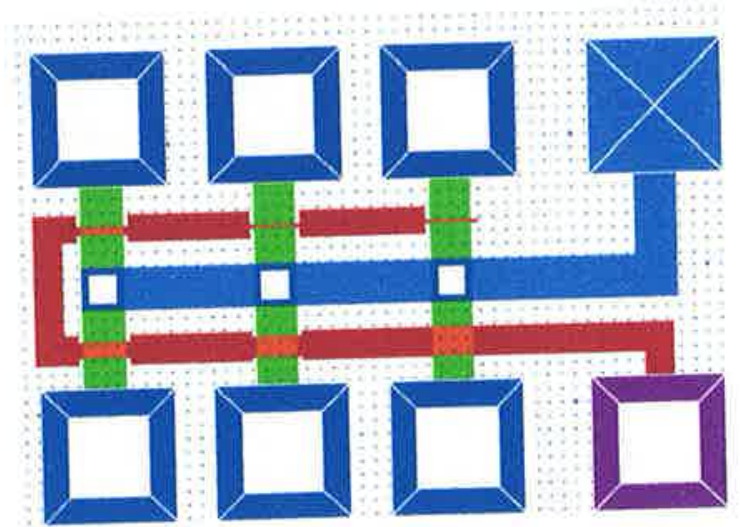

a)

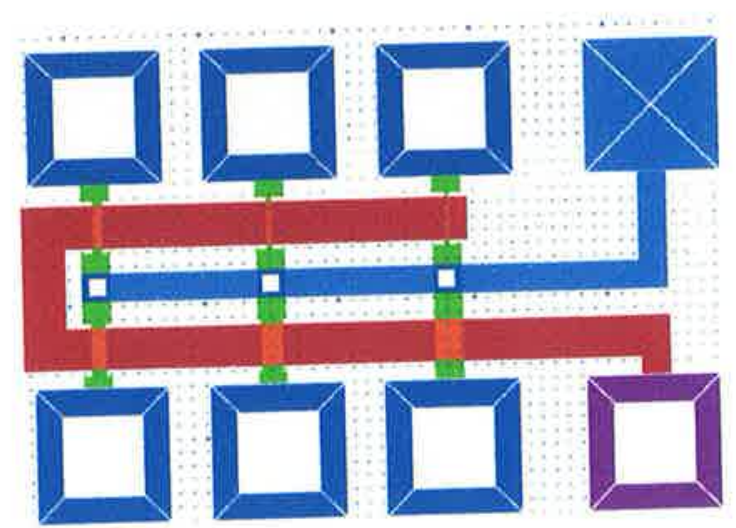

b)

Fig. 3-6: Cascatas de transistores. (a) $L$ variável, (b) $W$ variável 
Na cascata com $L$ variável (figura 3-6 (a)), devido diferentes distâncias entre os contatos de fonte/dreno e os inícios dos canais (regiões abaixo das portas), existem resistências em série distintas para cada transistor. No entanto, estas resistências são notadamente desprezíveis face às resistências de canal. O objetivo das cascatas foi possibilitar a obtenção das larguras efetivas de canal ( $L$ variável) e dos comprimentos efetivos de canal ( $Z$ variável).

d) Inversor:

O inversor nMOS aqui projetado (fig. 3-7) é constituído por dois transistores nMOS (carga enriquecida), um de $L=20 \mu \mathrm{m}$ e $Z=30 \mu \mathrm{m}$ (transistor de carga ou load) e o outro $\operatorname{com} L=20 \mu \mathrm{m}$ e $Z=8 \mu \mathrm{m}$ (transistor de comando ou driver).

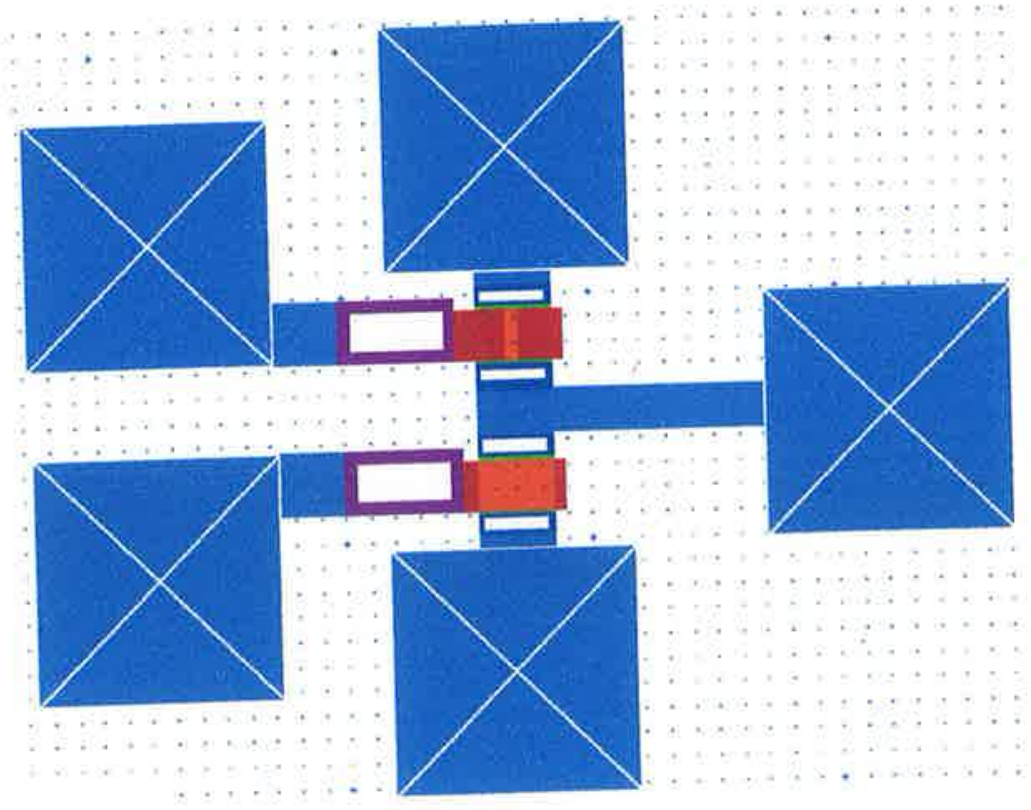

Fig. 3-7: Inversor nMOS 
e) Estruturas van der Pauw + Kelvin:

As estruturas van der Pauw associadas às estruturas Kelvin são importantes elementos de caracterização de parâmetros como resistência de folha e largura elétrica efetiva de filmes de $\mathrm{Al}$, Si-poli ou regiões difundidas.

A figura 3-8 a seguir ilustra as geometrias escolhidas.

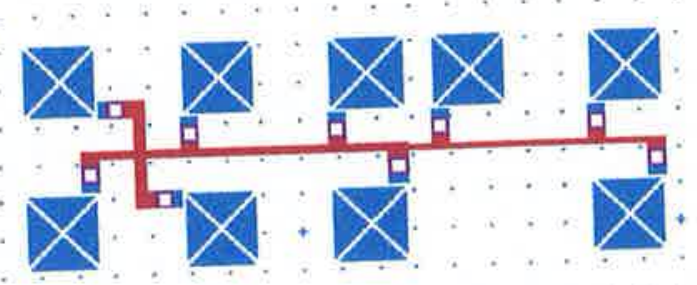

a)

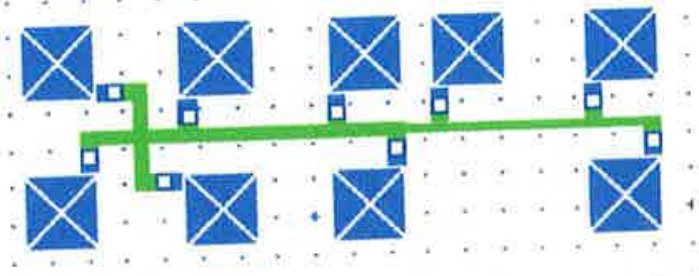

b)

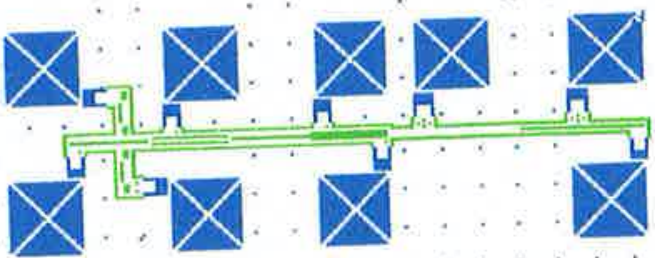

c)

Fig. 3-8: Estruturas Kelvin e van der Pauw. (a) Si-poli, (b) Difusão e (c) Alumínio.

f) Diodo Controlado por Porta:

Apesar de as demais estruturas poderem ser utilizadas como elementos de caracterização do processo construtivo e do substrato empregado, os DCP's são realmente os dispositivos mais importantes nesse trabalho e foram projetados procurando-se variar ao máximo as geometrias dos mesmos a fim de ressaltarmos propriedades e características que não podem ser apreciadas nos modelos convencionais. Muitos dos formatos aqui empregados foram sugeridos pela literatura, outros porém são próprios desse trabalho. A tabela 3-2, resume os principais parâmetros de máscara dos DCP's escolhidos: 
Tab. 3-2: Classificação e parâmetros de máscaras dos DCP's escolhidos

\begin{tabular}{|c|c|c|c|c|c|}
\hline Tipo $^{2}$ & Descrição & 莺 & 吾 & 茪 & Cap. $^{3}[F]$ \\
\hline DCPQC & $\begin{array}{c}\mathrm{DCP}(300 \times 300) \text { com } \\
\text { porta recoberta por } \\
\text { metal }\end{array}$ & 90.000 & 85.050 & 720.000 & $1,243 \cdot 10^{-9}$ \\
\hline DCPQD & $\begin{array}{c}\text { DCP }(300 \times 300) \text { com } \\
\text { porta semi- } \\
\text { descoberta }\end{array}$ & 90.000 & 85.050 & 720.000 & $1,243 \cdot 10^{-9}$ \\
\hline $\mathrm{DCPq}$ & $\mathrm{DCP}(30 \times 30)$ & 900 & 792 & 7.200 & $12,431 \cdot 10^{-12}$ \\
\hline DCPqR & $\begin{array}{l}\mathrm{DCP}(30 \times 30) \mathrm{c} / \\
\text { resistor de porta }\end{array}$ & 900 & 792 & 7.200 & $12,431 \cdot 10^{-12}$ \\
\hline DCPSq & $\begin{array}{c}\text { DCP }(30 \times 30) \\
\text { Schottky }\end{array}$ & 144 & 588 & 7.200 & $12,431 \cdot 10^{-12}$ \\
\hline DCPSqR & $\begin{array}{c}\text { DCP }(30 \times 30) \\
\text { Schottky c/ resistor } \\
\text { de porta }\end{array}$ & 144 & 588 & 7.200 & $12,431 \cdot 10^{-12}$ \\
\hline DCPLe & DCP longo e estreito & 2.500 & 2.000 & 63.500 & $109,64 \cdot 10^{-12}$ \\
\hline DCPLc & DCP largo e curto & 10.202 & 3.816 & 63.500 & $109,64 \cdot 10^{-12}$ \\
\hline DCPE & $\begin{array}{l}\text { DCP de porta } \\
\text { envolvente }\end{array}$ & 32.444 & 22.892 & 27.400 & $47,308 \cdot 10^{-12}$ \\
\hline $\mathrm{DCPqE}$ & $\begin{array}{c}\text { DCP de área } \\
\text { equivalente ao DCPE }\end{array}$ & 22.952 & 20.222 & 27.448 & $47,391 \cdot 10^{-12}$ \\
\hline DCP4P & $\begin{array}{c}\text { DCP c/ } 4 \text { portas } \\
\text { acessíveis }\end{array}$ & 900 & 792 & $4 \times 840$ & $1,450 \cdot 10^{-12}$ \\
\hline DCPS4P & $\begin{array}{l}\text { DCP Schottky c/ } 4 \\
\text { portas acessíveis }\end{array}$ & 144 & 588 & $4 \times 840$ & $1,450 \cdot 10^{-12}$ \\
\hline
\end{tabular}

${ }^{2}$ Código para identificação mnemônica do diodo controlado por porta.

${ }^{3}$ Capacitância máxima calculada para a porta do DCP. 


\begin{tabular}{|c|c|c|c|c|c|}
\hline Tipo $^{2}$ & Descrição & 莺 & 焉 & 芯 & Cap. $^{3}[\mathrm{~F}]$ \\
\hline $\mathrm{DCPCF}^{4}$ & $\begin{array}{l}\mathrm{DCP}(50 \times 50) \mathrm{c} / \\
\text { capacitor }^{5} \text { de fonte }\end{array}$ & $2 \times 1.250$ & $2 \times 500$ & 2.500 & $4,316 \cdot 10^{-12}$ \\
\hline DCPcf & $\begin{array}{c}\mathrm{DCP}(2 \times 2) \mathrm{c} / \\
\text { capacitor de fonte }\end{array}$ & $2 \times 40$ & $2 \times 4$ & 4 & $6,906 \cdot 10^{-15}$ \\
\hline DCPFF & $\begin{array}{c}\text { DCP }(50 \times 50) \mathrm{c} / \text { fonte } \\
\text { flutuante }\end{array}$ & $2 \times 1.250$ & $2 \times 500$ & 2.500 & $4,316 \cdot 10^{-12}$ \\
\hline DCPff & $\begin{array}{c}\mathrm{DCP}(2 \times 2) \mathrm{c} / \text { fonte } \\
\text { flutuante }\end{array}$ & $2 \times 40$ & $2 \times 4$ & 4 & $6,906 \cdot 10^{-15}$ \\
\hline
\end{tabular}

A seguir detalharemos as razões que nos motivaram à inclusão de cada geometria apresentada na tabela 3-2 anterior.

a) DCPQC:

Trata-se de uma estrutura DCP convencional de dimensões grandes (fig. 3-9).

\footnotetext{
${ }^{4}$ A partir daqui até o final da lista os dispositivos são na verdade transistores porém operados como DCP's.

${ }^{5} \mathrm{O}$ valor do capacitor de fonte é de $4,3 \mathrm{pF}$.
} 


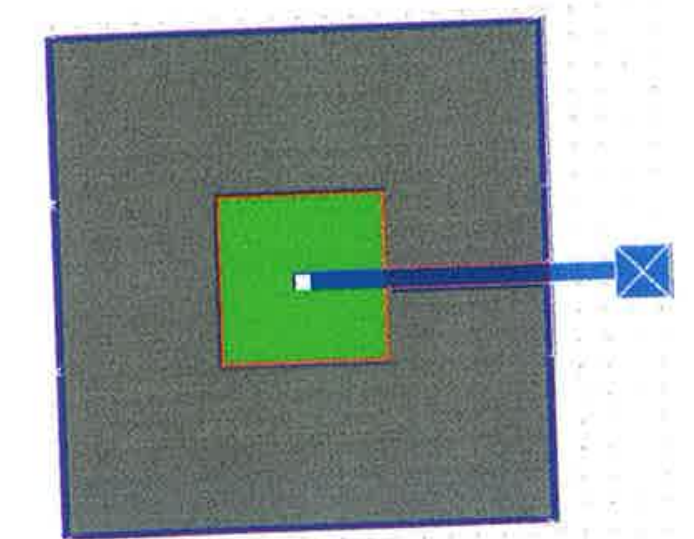

a)

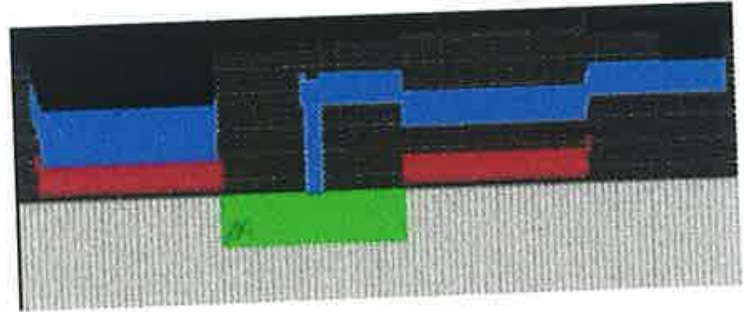

b)

Fig. 3-9: DCPQC em planta (a) e em perfil (b)

b) DCPQD:

Semelhante ao anterior mas nessa estrutura o metal de porta não recobre inteiramente o Si-poli. Essa escolha foi feita a fim de permitir uma maior área disponivel para a incidência direta de luz no Si-poli.

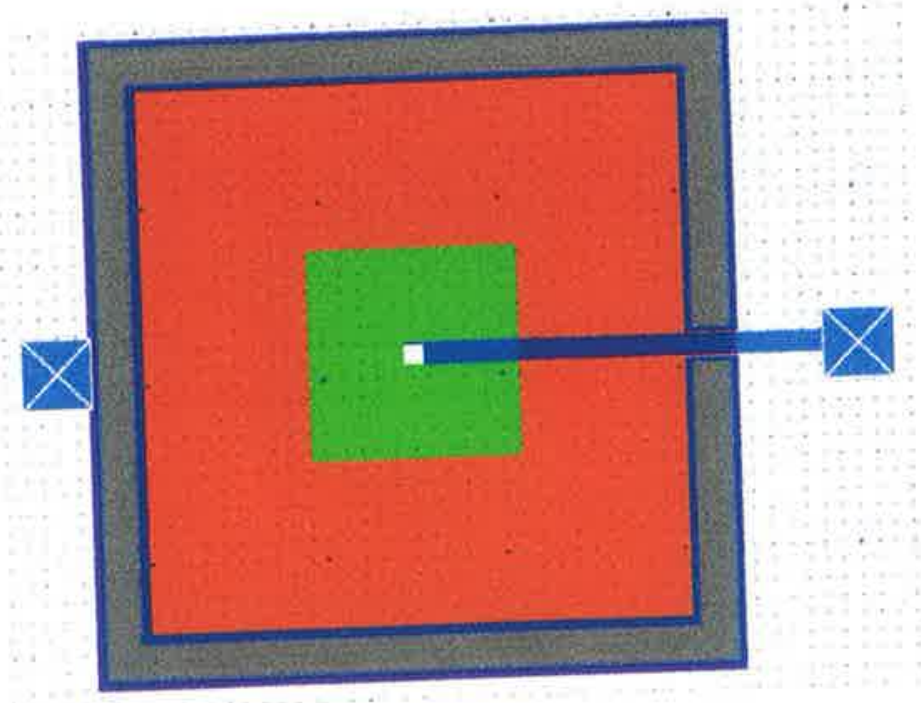

Fig. 3-10: DCPQD 
c) DCPq:

Este DCP é equivalente ao DCPQC, mas com área 100 vezes menor (veja figura 3-9 novamente).

d) DCPqR:

Conforme sugerido por Çilingiroglu [ÇILI'91], o resistor de Si-poli associado à porta pode ser utilizado num arranjo biestável conforme descrito no capítulo 2 , item 2.4 (fig. 3-11). Com esta estrutura pode-se verificar o efeito do resistor na corrente de

\section{Charging pumping.}

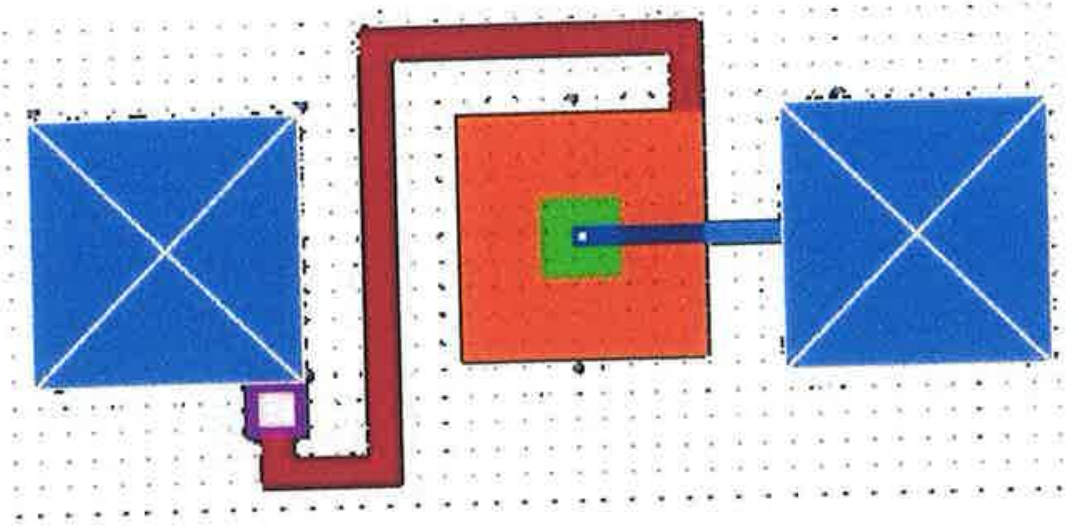

Fig. 3-11: DCPqR

e) DCPSq:

Trata-se de um DCP com junção Schottky. Foi implementado para a análise do efeito de uma junção Schottky no desempenho do DCP como sensor de radiação luminosa (fig. 3-12).

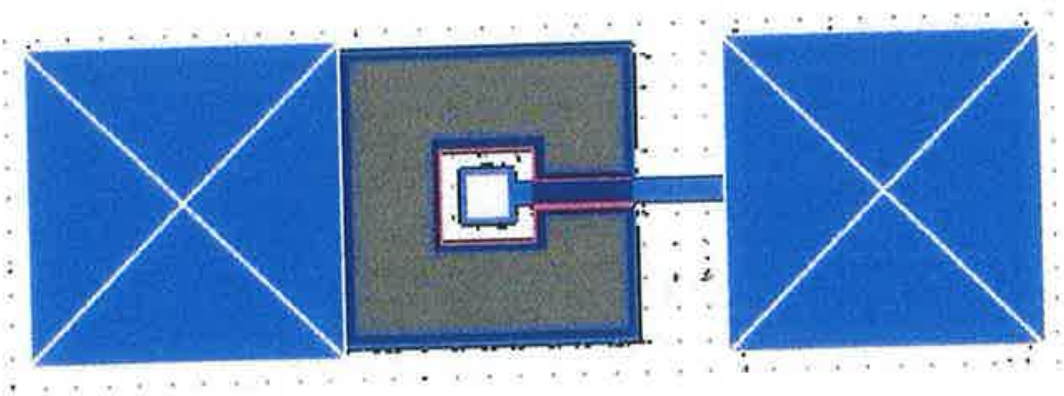

Fig, 3-12: DCPSq 
f) DCPSqR:

Esse DCP é uma combinação dos dois tipos anteriores, isto é, um DCP com junção Schottky mais um resistor ligado na porta (fig. 3-13).
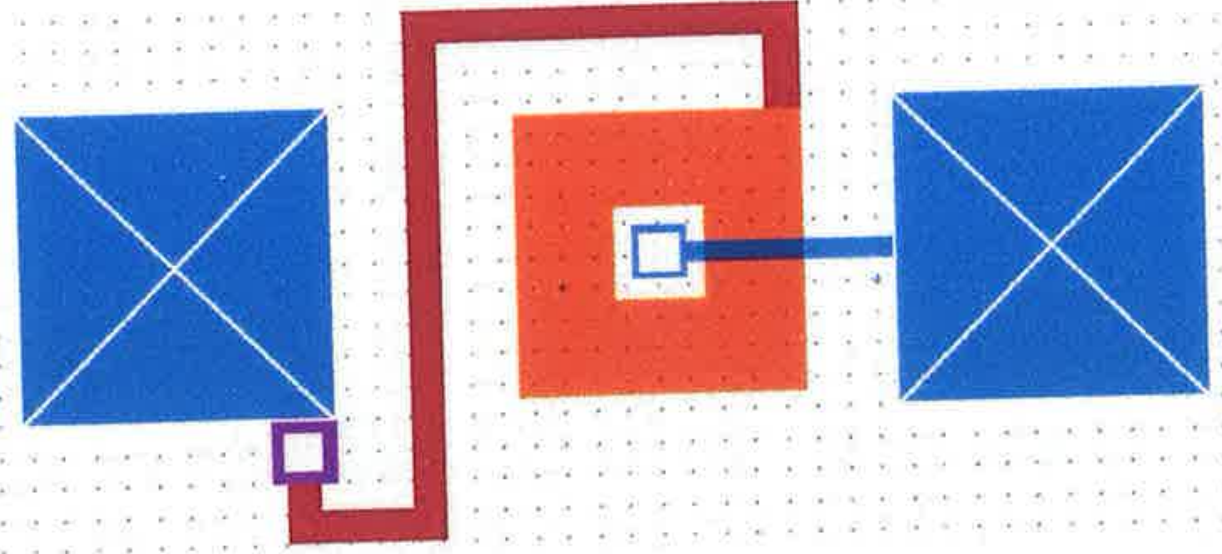

Fig. 3-13: DCPSqR

g) DCPLe:

Esse tipo de DCP foi sugerido por DeMassa [DEMA'85] (figura 3-14) para se verificar o comportamento da capacitância diferencial associada à porta do dispositivo frente a grande variação no comprimento de canal do DCP $(L)$.

Fig. 3-14: DCPLe

h) DCPLc:

Esse tipo de DCP também foi sugerido por DeMassa [DEMA'85] para verificar o comportamento da capacitância diferencial frente a grande variação da largura de canal do DCP (Z) (fig. 3-15). 
Fig. 3-15: DCPLc

i) DCPE:

Neste tipo de DCP temos junção tipo "serpentina" onde pretende-se estudar, o efeito da variação da geometria de porta (3-16).

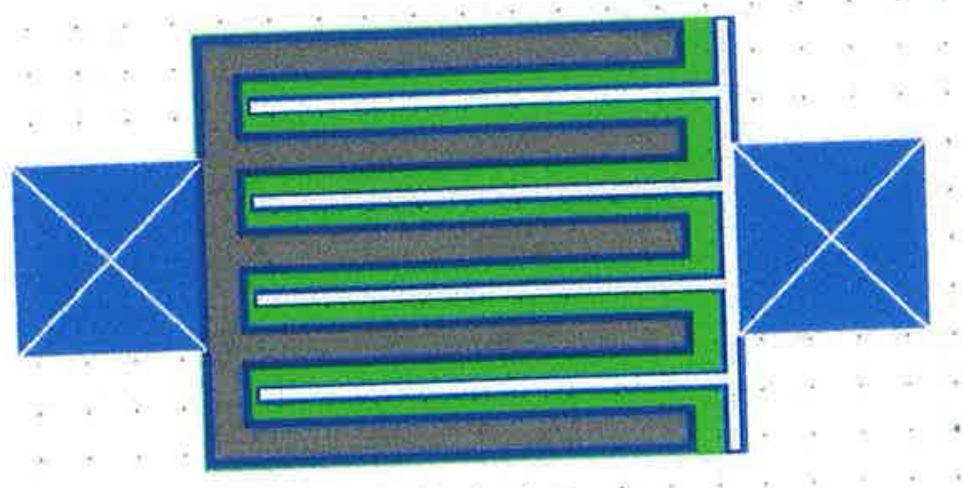

Fig. 3-16: DCPE

j) $\mathrm{DCPqE}$ :

Esse tipo de DCP apresenta a mesma área de junção e porta que o tipo anterior, servindo-se pois para fazer as comparações necessárias (figura 3-17).

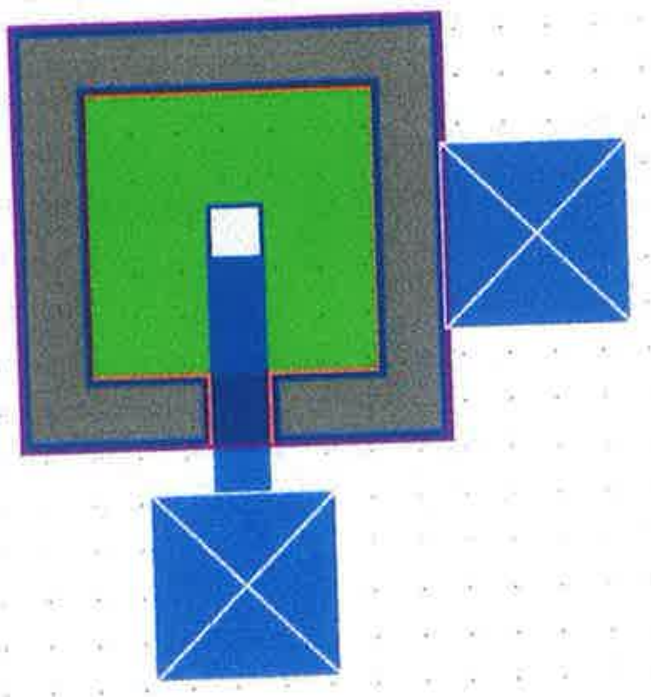

Fig. 3-17: DCPqE 


\section{k) DCP4P:}

Esse tipo de DCP apresenta quatro terminais de porta independentes possibilitando maior liberdade na aplicação de potenciais (figura 3-18).
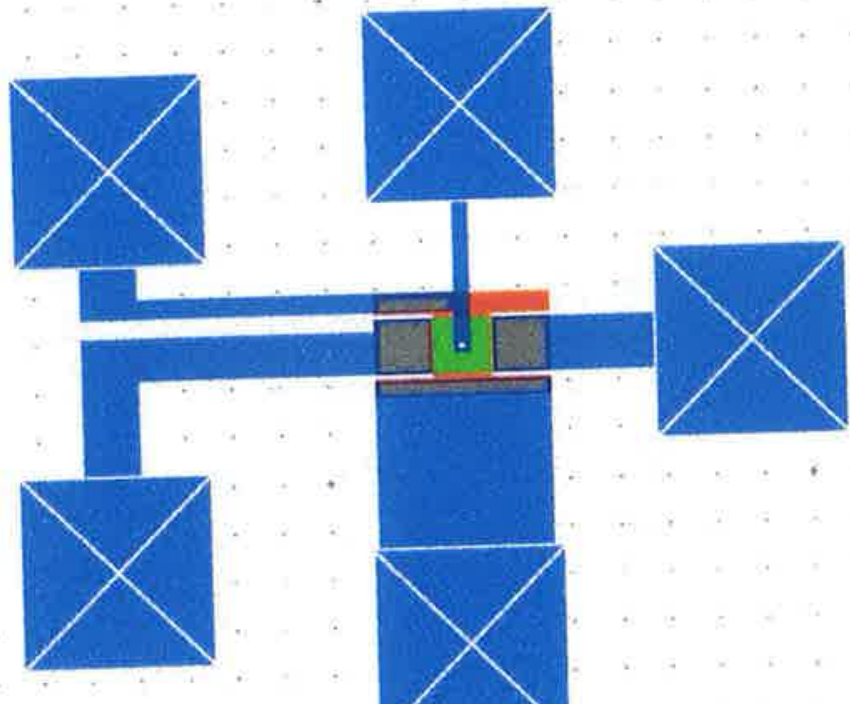

Fig. 3-18: DCP4P

\section{1) DCPS4P:}

Trata-se de um equivalente com junção Schottky do DCP anterior (figura 3-19).
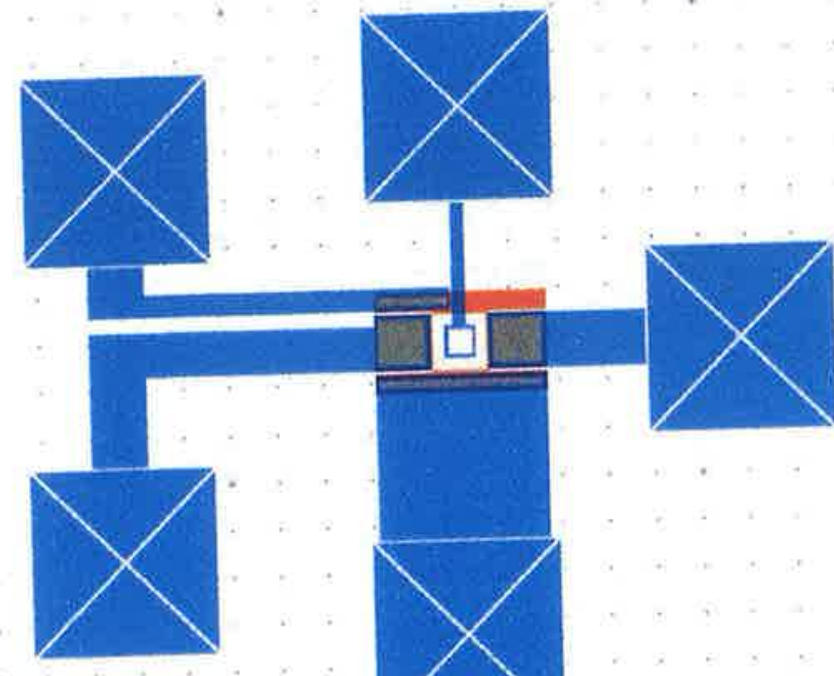

Fig. 3-19: DCPS4P 
m) DCPCF:

Esse tipo de DCP na verdade é um transistor onde o terminal de fonte está conectado a um capacitor de $(50 \times 50) \mu \mathrm{m}^{2}$ de área (veja figura 3-20 (a))

Essa estrutura foi sugerida por Viswanathan et al. [VISW'93] para permitir amplificar o valor da corrente reversa de um DCP e portanto facilitando a sua extração pelos equipamentos de medida.

n) DCPcf:

Esse é um equivalente de dimensões menores do tipo anterior (veja figura 3-20 (b)).

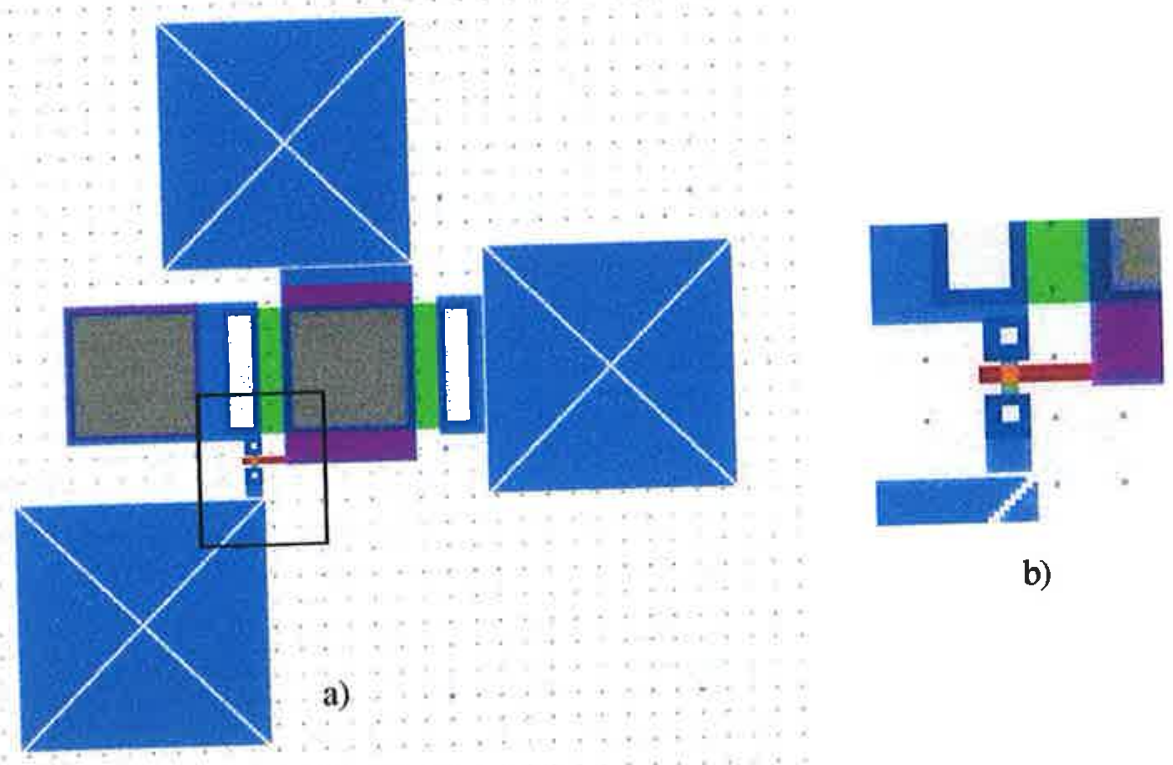

Fig. 3-20: DCPCF (a) e DCPcf em detalhe (b)

o) DCPFF:

Esse tipo é uma versão do DCPCF mas sem capacitor de fonte. É, pois, um transistor, onde o comportamento DCP pode ser obtido curto-circuitando dreno e fonte, ou ligando-se um capacitor a um dos dois terminais (veja figura 3-21 (a)). 
p) DCPff:

Trata-se de um equivalente de menores dimensões do tipo anterior (veja figura

3-21(b))

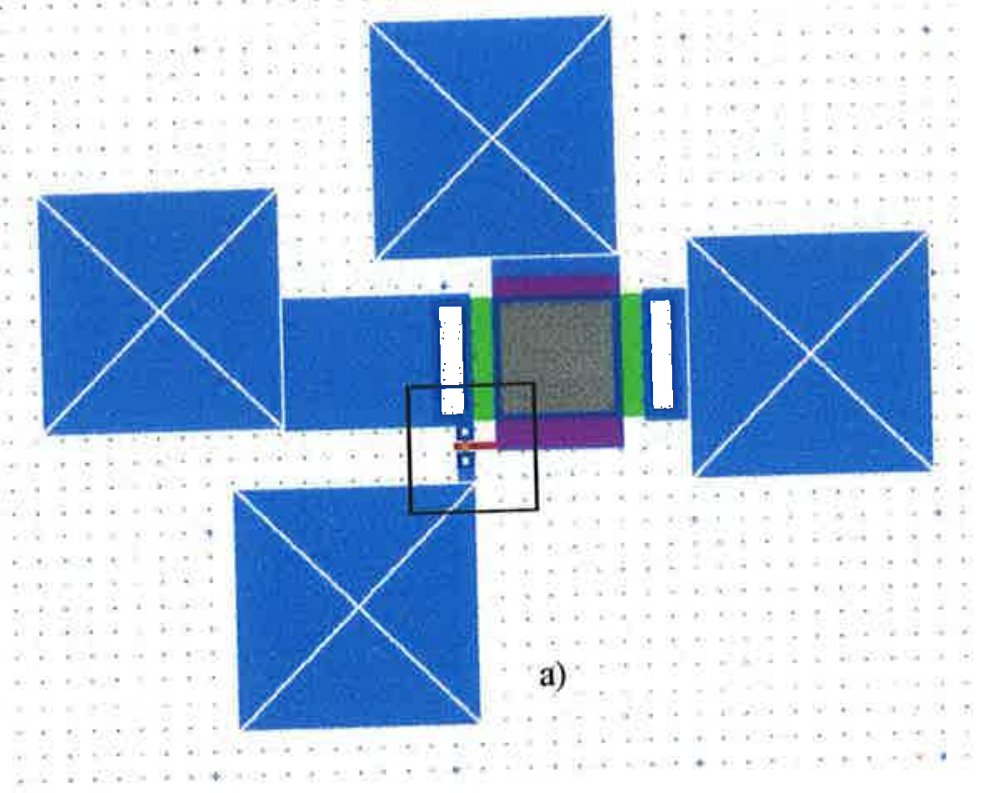

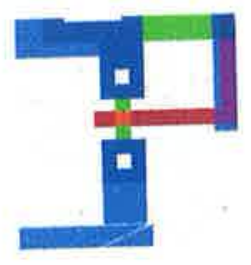

b)

Fig. 3-21: DCPFF (a) e DCPff em detalhe (b)

Nesse ponto, voltamos a destacar que o presente trabalho não abrange a caracterização elétrica de todas as estruturas apresentadas. Conforme já especificado no capítulo 1, vamos nos limitar a fazer todo o processamento da pastilha-teste e utilizar a estrutura básica do DCP para realizar medidas elétricas. Em continuação a este trabalho de mestrado, pretendemos em uma segunda etapa (parte do doutorado) caracterizar todos os DCP's propostos após fazer mais duas corridas independentes. 


\section{4 - Procedimentos experimentais}

Neste capítulo apresentaremos os procedimentos experimentais referentes à seqüência de fabricação dos diodos controlados por porta onde são feitos detalhamentos de cada etapa de processo. Em seguida, são descritos os procedimentos empregados para a caracterização elétrica preliminar dos diodos controlados por porta (DCP's).

\section{1 - Processo de fabricação}

A sequiência de processos construtivos constituiu-se de 16 etapas. Foram processadas 7 lâminas $\mathrm{CZ}$ de orientação $<100>$, sendo 2 do tipo $\mathrm{P}, 2$ tipo $\mathrm{N}$ e 3 do tipo epitaxial N/N ${ }^{+}$. Destas, apenas $4(1 \mathrm{~N}, 1 \mathrm{P}$ e 2 epitaxiais) completaram as 16 etapas de processamento. Cada lote de lâminas possuía uma faixa de resistividades especificada cuja variação resultava da variação na concentração de dopantes obtida durante o processo de crescimento do cristal.

As lâminas foram escolhidas em cada lote o mais resistivas possível de modo que a largura da região de depleção na estrutura MOS pudesse se estender até profundidades maiores do que $\sim 2,1 \mu \mathrm{m}$, o que equivale a aproximadamente 3 vezes o valor de $W_{\text {máx }}$ teório para a lâmina de mais alta concentração, N1, de acordo com as simulações com o DCPSim.

Esse foi então o critério de escolha para as lâminas de processo, ou seja, a sua resistividade, obtida indiretamente através da medida de sua resistência de folha (método de 4 pontas efetuado num FPP5000 four point probe da Veeco Instruments inc). Os valores obtidos durante essa etapa prévia de caracterização, bem como os demais dados sobre as lâminas encontram-se na tabela 4-1.

Os dados apresentados na coluna resistividade foram obtidos por cálculo através da seguinte equação: 


$$
\rho=R_{Q} \cdot t
$$

onde $\rho$ é a resistividade, $R_{Q}$ é a resistência de folha em $\Omega /$ e $t$ é a espessura da lâmina.

A resistência de folha de $R_{Q}$ é dada por:

$$
R_{Q}=\frac{1}{t \cdot q \cdot N \cdot \mu}
$$

onde $q$ é a carga elementar, $N$ é a concentração do substrato e $\mu$ é a mobilidade para elétrons ou lacunas dependendo do tipo da lâmina. E finalmente:

$$
N=\frac{1}{q \cdot \rho \cdot \mu}
$$

Foram assumidos os valores de $1350 \mathrm{~cm}^{2} / \mathrm{V} \cdot \mathrm{s}$ para a mobilidade de elétrons e

\begin{tabular}{|c|c|c|c|c|c|c|}
\hline है & $\stackrel{8}{8}$ & $\begin{array}{l}\text { Res. } \\
\text { folha } \\
{[\Omega /]}\end{array}$ & $\begin{array}{c}\text { Resistividade } \\
{[\Omega \cdot \mathrm{cm}]}\end{array}$ & $\begin{array}{c}\text { Concentração } \\
{\left[\mathrm{cm}^{-3}\right]}\end{array}$ & $\begin{array}{c}\text { Espessura } \\
{[\mu \mathrm{m}]}\end{array}$ & $\begin{array}{c}\text { Epitaxia } \\
{[\mu \mathrm{m}]}\end{array}$ \\
\hline P1 & $\mathrm{P}$ & 287,0 & 14,35 & $9,06 \cdot 10^{14}$ & $475-575$ & - \\
\hline N1 & $\mathrm{N}$ & 78,4 & 2,979 & $1,55 \cdot 10^{15}$ & $380 \pm 50$ & - \\
\hline EN1 & $\mathrm{N} / \mathrm{N}+$ & - & $10-15$ & $3,70 \cdot 10^{14}$ & $500-550$ & $10 \pm 2$ \\
\hline EN3 & $\mathrm{N} / \mathrm{N}+$ & - & $10-15$ & $3,70 \cdot 10^{14}$ & $500-550$ & $10 \pm 2$ \\
\hline
\end{tabular}
$480 \mathrm{~cm}^{2} / \mathrm{V} \cdot \mathrm{s}$ para lacunas.

Tab. 4-1: Dados das lâminas de processo

Não foi possível medir a resistência de folha das lâminas epitaxiais pois a sua resistividade $(0,02 \Omega \cdot \mathrm{cm})$ é determinada pelo seu corpo (bulk) pouco resistivo. 
Todos os cálculos foram feitos para valores médios de espessura e para as lâminas epitaxiais tomou-se $12,5 \Omega \cdot \mathrm{cm}$ como valor da resistividade (média entre $10 \mathrm{e} 15$ $\Omega \cdot \mathrm{cm}$ do lote especificado).

As lâminas $\mathrm{P}$ e epitaxiais, por serem lâminas de $100 \mathrm{~mm}$, tiveram que ser clivadas, já que os equipamentos disponíveis no laboratório comportavam apenas lâminas de 75 mm de diâmetro (fig. 4-1).

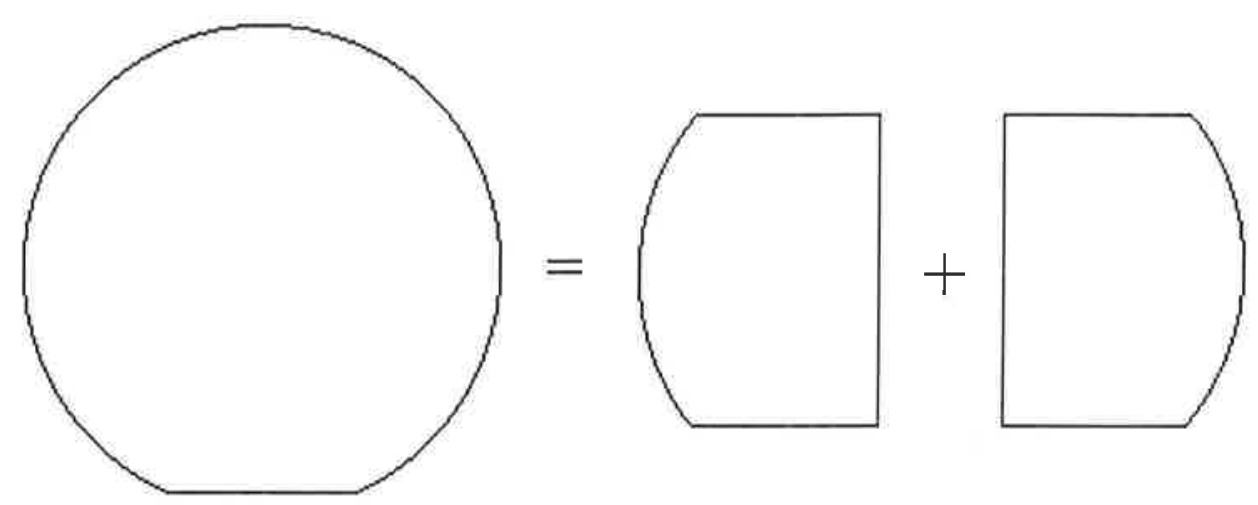

Fig. 4-1: Obtenção, por clivagem, de 2 lâminas de processo a partir de uma lâmina de $100 \mathrm{~mm}$ de diâmetro

A seguir, detalharemos a seqüência de processos para a fabricação da pastilhateste, que consistiu dos seguintes passos:

\section{1) limpeza das lâminas de silício (piranha + RCA + HF)}

- Enxágüe em água DI por $5 \mathrm{~min}$;

- Fervura em $4 \mathrm{H}_{2} \mathrm{SO}_{4}+1 \mathrm{H}_{2} \mathrm{O}_{2}$ por $15 \mathrm{~min}$, para a remoção de compostos orgânicos;

- Enxágüe em água DI por 5 min;

- Imersão durante $100 \mathrm{~s}$ em solução $20 \mathrm{H}_{2} \mathrm{O}+1 \mathrm{HF}$ para a remoção do óxido formado pelo $\mathrm{H}_{2} \mathrm{SO}_{4}$ no processo anterior;

- Enxágüie em água DI por $3 \mathrm{~min}$; 
- Fervura em solução $4 \mathrm{H}_{2} \mathrm{O}+1 \mathrm{H}_{2} \mathrm{O}_{2}+1 \mathrm{NH}_{4} \mathrm{OH}$ por 15 min, para a remoção de material particulado e metais;

- Enxágüe em água DI por $5 \mathrm{~min}$;

- Fervura em solução $4 \mathrm{H}_{2} \mathrm{O}+1 \mathrm{H}_{2} \mathrm{O}_{2}+1 \mathrm{HCl}$ durante $15 \mathrm{~min}$, para a remoção de metais;

- Enxágüe em água DI por 5 min;

- Imersão em solução $20 \mathrm{H}_{2} \mathrm{O}+1 \mathrm{HF}+1 \mathrm{HCl}$ durante $100 \mathrm{~s}$, para a remoção do óxido nativo;

- Enxáguie em água DI por 5 min;

- Secagem em fluxo de $\mathrm{N}_{2}$.

Após a limpeza das lâminas, também foi feita a limpeza das suas respectivas Placas de Petri para serem guardadas.

A etapa de limpeza é muito importante pois dela depende o conteúdo e quantidade de metais e partículas na superfície da lâmina bem como a sua rugosidade, ou seja, parâmetros que afetam grandemente o comportamento elétrico dos dispositivos que venham a ser implementados na lâmina.

\section{2) oxidação térmica}

tem por objetivo obter-se um óxido com boas qualidades interfaciais que fará o casamento entre a superfície do semicondutor e a camada de $\mathrm{SiO}_{2}$ mais espessa depositada como óxido de campo. O motivo de introduzirmos essa etapa extra é que óxidos térmicos apresentam melhores propriedades mais demandam mais tempo para a sua obtenção, e óxidos depositados podem ser conseguidos em grandes espessuras e em tempos pequenos mas apresentam pior qualidade. 
Esse processo foi feito em forno convencional, Thermco MB-80, a $900{ }^{\circ} \mathrm{C}$ durante $120 \mathrm{~min}$ em atmosfera de $\mathrm{O}_{2}$ ultra puro $(3,5 \mathrm{sccm})$, resultando numa espessura de óxido aproximada de $23 \mathrm{~nm}$.

\section{3) deposição de óxido de silício}

Foi depositada, por LPCVD, uma espessura de $624 \mathrm{~nm}$ sob as seguintes condições:

- $450 \mathrm{sccm}$ de $\mathrm{O}_{2}$;

- $100 \mathrm{sccm}$ de $\mathrm{Ar}$;

- $7,5 \mathrm{sccm}$ de TEOS;

- Pressão: 1 Torr;

- Temperatura: $360^{\circ} \mathrm{C}$;

- Potência: $400 \mathrm{~W}$;

- Tempo: $6 \mathrm{~min}$.

A taxa de deposição foi de $104 \mathrm{~nm} / \mathrm{min}$.

\section{4) densificação do óxido depositado}

Após a densificação, óxido de campo adquire melhores propriedades estruturais. Essa etapa foi feita num forno RTP Heatpulse 410 da AG Associates, a $1100{ }^{\circ} \mathrm{C}$ por $120 \mathrm{~s}$. O gráfico da figura 4-2 ilustra o perfil temporal de temperatura realizado em ambiente de nitrogênio ultra puro: 


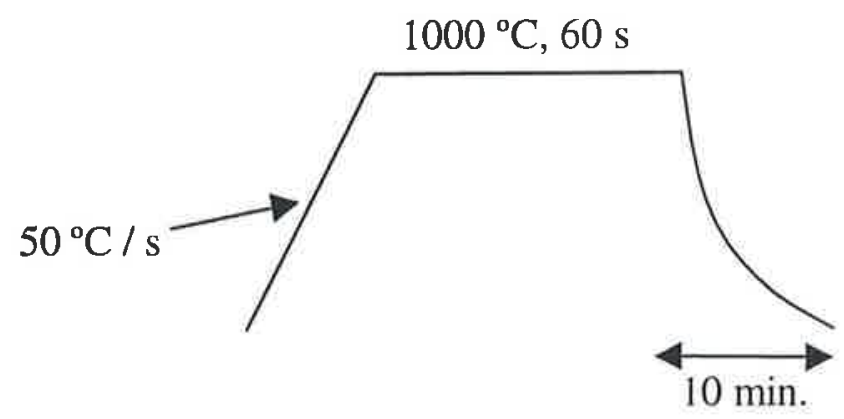

Fig. 4-2: Perfil térmico do processo de RTP

\section{5) definição da região ativa 1. (máscara 1, veja item 3.1)}

Trata-se de uma abertura de janela no óxido de campo para a região ativa, ou seja, o local onde serão implementados os dispositivos de teste.

Consiste em duas etapas, uma de fotogravação da máscara 1, utilizando-se fotoresiste positivo OFPR800. E uma etapa de corrosão do óxido não protegido pelo resiste, obtida por imersão das lâminas em DLV, conforme segue:

- enxágüe em água DI por $3 \mathrm{~min}$;

- imersão em $6 \mathrm{NH}_{4} \mathrm{~F}+1 \mathrm{HF}$ (DLV), de 6 a 7 min;

- enxágüe em água DI por $3 \mathrm{~min}$.

Por fim, é necessário retirar-se o fotoresiste remanescente das lâminas antes de guardá-las.

A seqüência empregada é a que se segue:

- fervura em acetona durante $10 \mathrm{~min}$.;

- fervura em IPA (álcool isopropílico) durante 10 min.;

- enxágüe em água DI por 5 min.;

6) limpeza química completa das lâminas

- fervura em solução $4 \mathrm{H}_{2} \mathrm{SO}_{4}+1 \mathrm{H}_{2} \mathrm{O}_{2}$ durante 15 min.;

- enxáguie em água DI durante 5 min.; 
- fervura em solução $4 \mathrm{H}_{2} \mathrm{O}+1 \mathrm{H}_{2} \mathrm{O}_{2}+1 \mathrm{NH}_{4} \mathrm{OH}$ durante 15 min.;

- enxágüe em água DI durante 5 min.;

- imersão em solução $20 \mathrm{H}_{2} \mathrm{O}+1 \mathrm{HF}+1 \mathrm{HCl}$ por 100 s;

- enxágüe final em água DI durante 5 min.

\section{7) oxidação térmica de porta;}

O óxido de porta foi obtido por oxidação térmica em forno convencional resultando numa espessura de $23 \mathrm{~nm}$ segundo a receita:

- entrada no forno em $10 \mathrm{~min}$. em fluxo de $\mathrm{N}_{2}$;

- oxidação por $2 \mathrm{~h}$ em ambiente de $\mathrm{O}_{2}$ ultra puro;

- passivação em $\mathrm{N}_{2}$ durante o resfriamento natural com o forno desligado.

\section{8) deposição de silício policristalino;}

A receita empregada na deposição de silício-policristalino foi a seguinte:

- Temperatura: $630^{\circ} \mathrm{C}$;

- Pressão: 630 mTorr;

- Vazão de $\mathrm{SiH}_{4}: 49,5 \mathrm{sccm}$;

- Vazão de $\mathrm{N}_{2}: 280 \mathrm{sccm}$;

- Tempo: $50 \mathrm{~min}$;

A taxa de deposição foi de $10 \mathrm{~nm} / \mathrm{min}$.

9) dopagem do silício policristalino e remoção do SOG;

A dopagem do Si-poli foi obtida por spin-on glass, ou SOG, que é um óxido dopado com fósforo que servirá como fonte sólida de dopantes na etapa de penetração (drive-in) no forno convencional.

O SOG foi depositado por processo de spiner a $3000 \mathrm{rpm}$ durante $10 \mathrm{~min}$. e a cura que se seguiu foi de $30 \mathrm{~min}$. a $200^{\circ} \mathrm{C}$. 
A difusão propriamente dita ocorreu em forno convencional a $1100^{\circ} \mathrm{C}, 3 \mathrm{sccm}$ de $\mathrm{N}_{2}$, por 10 min., demandando-se ainda outros 10 min. para a lâmina chegar até a posição central do forno e mais 10 para ser retirada.

Após a difusão, o SOG foi retirado por meio da seguinte sequiência:

- enxágüe em água DI durante 5 min.;

- imersão em solução $1 \mathrm{HF}+6 \mathrm{NH}_{4} \mathrm{~F}$ (DLV), durante 2 min.;

- enxágüe em água DI durante 5 min.;

- imersão em solução $300 \mathrm{H}_{2} \mathrm{O}+15 \mathrm{HF}+10 \mathrm{HNO}_{3}$ (p-etch) durante min.;

- fervura em solução $4 \mathrm{H}_{2} \mathrm{O}+1 \mathrm{H}_{2} \mathrm{O}_{2}+1 \mathrm{NH}_{4} \mathrm{OH}$ durante 15 min.;

- enxágüe em água DI durante 5 min.;

- fervura em solução $4 \mathrm{H}_{2} \mathrm{O}+1 \mathrm{H}_{2} \mathrm{O}_{2}+1 \mathrm{HCl}$ durante 15 min.

\section{0) definição do silício policristalino (máscara 2, veja item 3.1);}

Esta definição é composta de duas etapas: uma de fotogravação, dessa vez consistindo em alinhamento da máscara 2 com a anterior, sensibilização e remoção do resiste. A segunda etapa é a remoção do Si-poli não protegido.

A remoção do Si-poli foi obtida por corrosão em plasma de $\mathrm{SF}_{6}, 25 \mathrm{sccm}$, à pressão de 100 mTorr. A potência empregada foi de 100 W e as lâminas demandaram em torno de 2 min para que a corrosão completa ocorresse.

A limpeza do fotoresiste remanescente seguiu a mesma seqüência já delineada no item 5.

\section{1) implantação iônica;}

As junções $\mathrm{N}^{+} \mathrm{P}$ e $\mathrm{P}^{+} \mathrm{N}$ foram obtidas por implantação iônica. Nas lâminas $\mathrm{N}$ e $\mathrm{N} / \mathrm{N}+$ foi implantado Boro e nas lâminas $\mathrm{P}$ foi implantado Fósforo. Os parâmetros de implantação, obtidos por simulação SUPREM 3, estão mostrados na tabela 4-2. 
Os dados mostrados na tabela 4-2 foram obtidos para uma espessura de óxido de $10 \mathrm{~nm}$ na superfície da lâmina funcionando como barreira de implantação. Este óxido ficou remanescente da etapa de corrosão de Si-poli (o óxido tinha $23 \mathrm{~nm}$ de espessura antes da corrosão).

Tab. 4-2: Condições de implantação e recozimento de dopantes simulados no SUPREM 3

\begin{tabular}{|c|c|c|c|c|c|c|c|c|}
\hline $\begin{array}{l}\text { Lâmi } \\
\text { na }\end{array}$ & $\begin{array}{ll}\dot{\mathscr{S}} \\
\stackrel{\Xi}{\Xi}\end{array}$ & 惡 & $\begin{array}{l}\text { Tempo } \\
\text { [min] }\end{array}$ & $\begin{array}{l}\text { Temp. } \\
{\left[{ }^{\circ} \mathrm{C}\right]}\end{array}$ & $\begin{array}{c}\text { Dose } \\
{\left[\mathrm{cm}^{-2}\right]}\end{array}$ & $\begin{array}{c}\text { Energia } \\
\text { [keV] }\end{array}$ & $\begin{array}{c}\text { Conc. Sup. } \\
\qquad\left[\mathrm{cm}^{-2}\right]\end{array}$ & 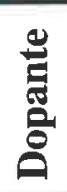 \\
\hline P1 & 0,6 & 0,56 & 20 & 900 & $7,5 \cdot 10^{15}$ & 30 & $1,73 \cdot 10^{20}$ & $\mathrm{P}$ \\
\hline N1 & 0,2 & 0,34 & 20 & 900 & $7,5 \cdot 10^{15}$ & 20 & $6,76 \cdot 10^{19}$ & B \\
\hline EN1 & 0,2 & 0,37 & 10 & 900 & $7,5 \cdot 10^{15}$ & 20 & $6,76 \cdot 10^{19}$ & B \\
\hline EN3 & 0,6 & 0,64 & 25 & 900 & $7,5 \cdot 10^{15}$ & 20 & $9,08 \cdot 10^{19}$ & B \\
\hline
\end{tabular}

O alto valor de concentração superficial, como pode ser visto na tabela 4-2, garantirá um bom contato ôhmico com o metal.

\section{2) deposição de nitreto de silício $(30 \mathrm{~nm})$}

Foi depositada uma camada de $\mathrm{Si}_{3} \mathrm{~N}_{4}$ de aproximadamente $30 \mathrm{~nm}$, a ser utilizada como material de proteção de superfície. A escolha recaiu sobre o nitreto ao invés do óxido de silício, como normalmente ocorre, devida à etapa de deposição química de Ni (electroless), cuja solução ataca o óxido.

As condições de deposição do nitreto foram as seguintes:

- Vazão de $\mathrm{NH}_{3} 322 \mathrm{sccm}$;

- Vazão de $\mathrm{SiHCl}_{2}$ (diclorosilana): 20,5 sccm;

- Pressão: 500 mTorr; 
- Temperatura: $720^{\circ} \mathrm{C}$;

- Tempo: $354 \mathrm{~min}$.

\section{3) deposição de óxido de silício $(20 \mathrm{~nm})$}

Foi depositada uma camada de $20 \mathrm{~nm}$ de $\mathrm{SiO}_{2}$ sobre a camada de $\mathrm{Si}_{3} \mathrm{~N}_{4}$ e que servirá de máscara para o mesmo, já que a solução de ácido fosfórico ataca o fotorresiste.

As condições de deposição do óxido foram as seguintes:

- Vazão de $\mathrm{O}_{2}: 450 \mathrm{sccm}$;

- Vazão de Ar: 100 sccm;

- Vazão de TEOS: 7,5 sccm;

- Pressão: 1 Torr;

- Temperatura: $360^{\circ} \mathrm{C}$;

- Potência: $400 \mathrm{~W}$;

- Tempo: $2 \mathrm{~min}$.

A taxa de deposição é de $104 \mathrm{~nm} / \mathrm{min}$.

14) densificação do material de campo e ativação de portadores

Consistiu numa etapa para a ativação elétrica dos dopantes previamente implantados, amenização dos defeitos cristalinos introduzidos no processo de implantação e densificação da estrutura óxido de silício/nitreto. Os parâmetros para o recozimento podem ser encontrados na tabela 4-2.

15) abertura de contatos (máscara 3 , veja item 3.1)

abertura de janelas no óxido de campo expondo-se as regiões dos terminais dos dispositivos para o contato elétrico. 
16) deposição química espontânea de níquel nos contatos de porta e junção

Nesta etapa, utilizou-se uma solução de deposição espontânea de níquel com a seguinte composição [SULL'57]:

- Cloreto de níquel $\left(\mathrm{NiCl}_{2} \cdot 6 \mathrm{H}_{2} \mathrm{O}\right): 30 \mathrm{~g} / \mathrm{l}$;

- Hipofosfito de sódio $\left(\mathrm{NaH}_{2} \mathrm{PO}_{2} \cdot \mathrm{H}_{2} \mathrm{O}\right): 10 \mathrm{~g} / \mathrm{l}$;

- Citrato do amônio $\left[\left(\mathrm{NH}_{4}\right)_{2} \mathrm{HC}_{6} \mathrm{H}_{5} \mathrm{O}_{7}\right]: 65 \mathrm{~g} / 1$;

- Cloreto de amônio $\left(\mathrm{NH}_{4} \mathrm{Cl}\right): 50 \mathrm{~g} / \mathrm{l}$;

- Hidróxido de amônio $\left(\mathrm{NH}_{4} \mathrm{OH}\right)$ : foi adicionado na solução até que a mesma mudasse do verde para o azul escuro ( $\mathrm{pH}$ na faixa de 8 a 10 ).

A temperatura foi ajustada até ficar estável em cerca de $90^{\circ} \mathrm{C}$.

A figura 4-3 ilustra a fabricação do DCP após as etapas 4, 6, 7, 10, 12, 14, 15 e 16 respectivamente.

A sinterização do níquel não foi realizada e uma caracterização elétrica posterior à etapa de deposição do mesmo mostrou que os contatos obtidos na lâmina EN3 apresentavam-se bons não demandando nenhuma etapa extra de processamento. 


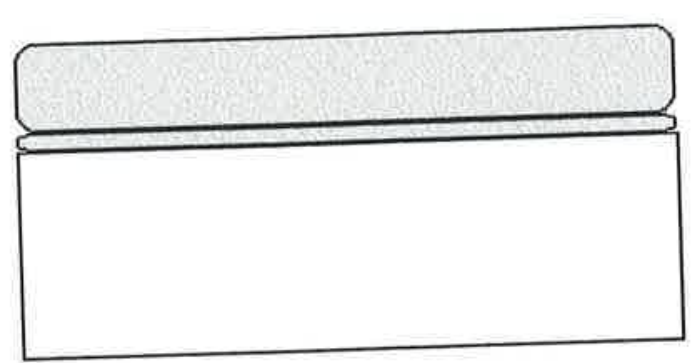

Aspecto da lâmina após o processo 4

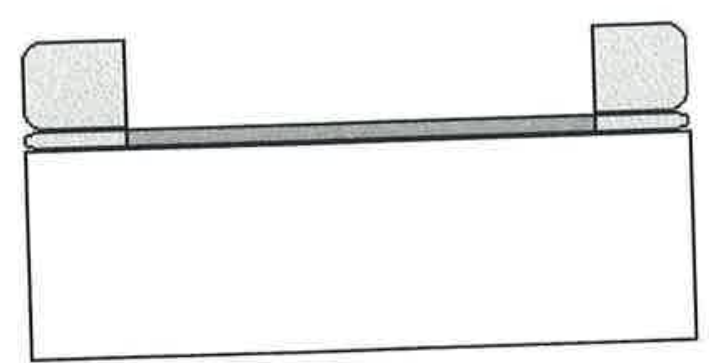

Após o processo 7

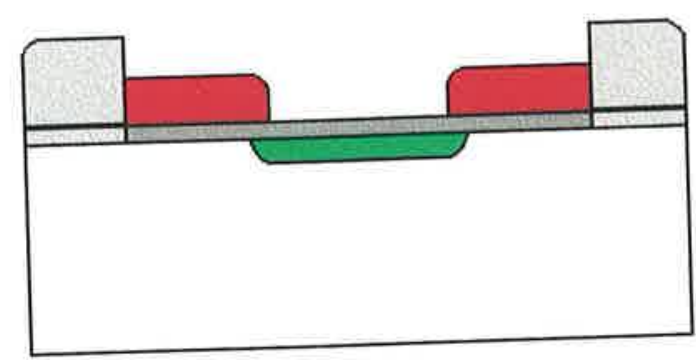

Após o processo 11

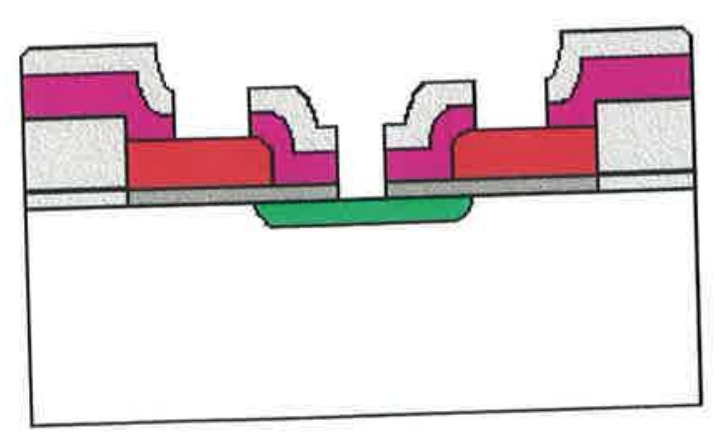

Após o processo 15

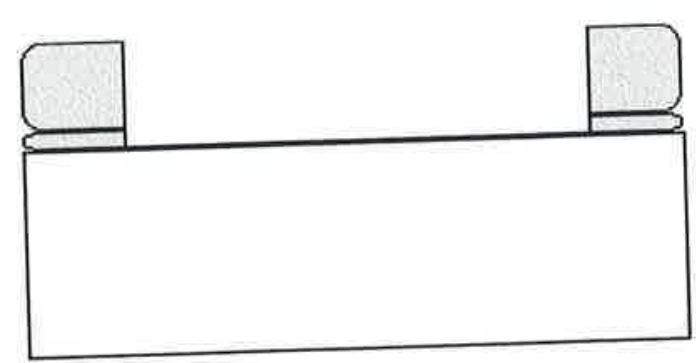

Após o processo 6

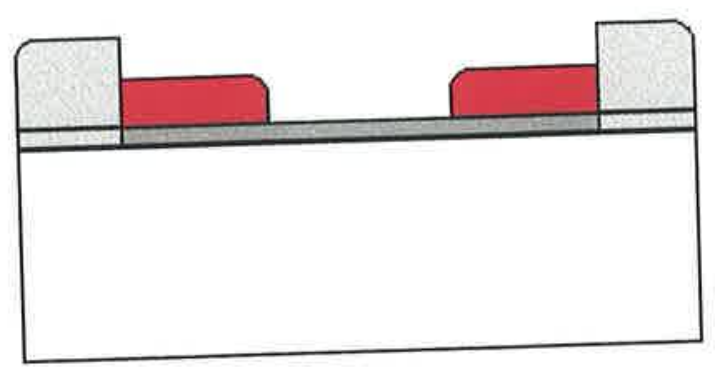

Após o processo 10

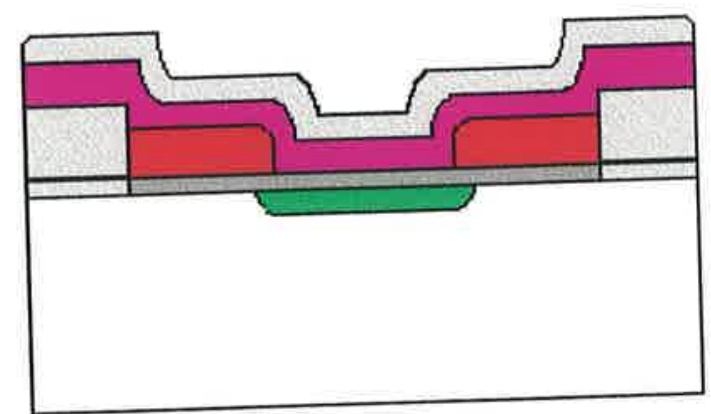

Após o processo 14

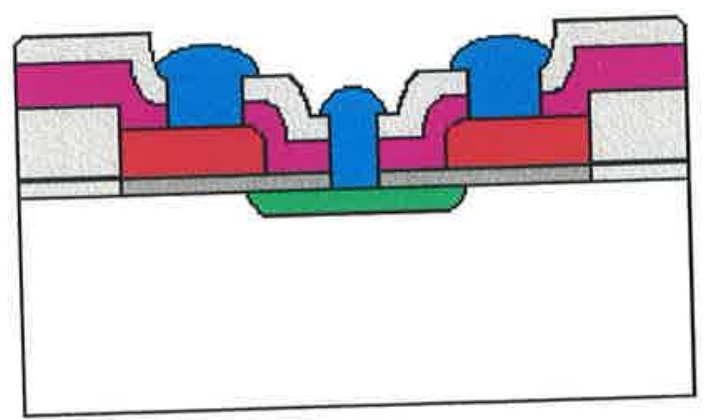

Após o processo 16

Fig. 4-3: Representação esquemática dos processos implementados na fabricação de DCP's. Em cinza temos $\mathrm{SiO}_{2}$ (o cinza escuro é o óxido de porta), em lilás $\mathrm{Si}_{3} \mathrm{~N}_{4}$, em vermelho Si-poli, em verde junções, e em azul o $\mathrm{Ni}$ 


\section{2 - Medidas elétricas}

As medidas elétricas levadas a efeito nesse trabalho podem dividir-se basicamente em dois tipos: caracterização do processo construtivo e caracterização do dispositivo implementado.

No primeiro grupo ressaltamos a determinação da concentração de substrato e velocidade de recombinação superficial.

Quanto à caracterização dos dispositivos propriamente, temos o levantamento de suas características $I x V$ e $C x V$.

\subsection{1 - Determinação da concentração de substrato}

O método que seria utilizado para a determinação da dopagem do substrato seria a análise da curva $C x V$ de um capacitor MOS implementado na pastilha-teste.

\subsection{2 - Determinação da velocidade de recombinação superficial}

O método para a determinação da velocidade de recombinação superficial, foi inicialmente proposto por Grove e consiste em analisar o comportamento da curva $I_{r e v} \mathrm{x} V_{\text {porta }}$ para uma baixa polarização aplicada à junção (veja capítulo 2), conforme pode ser visto na figura 4-4 a seguir. 


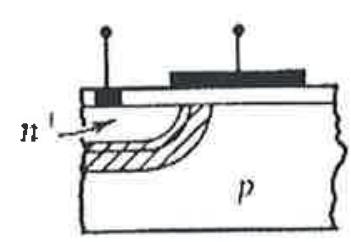

(a)

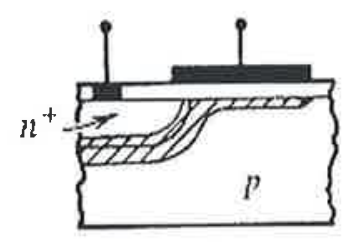

(b)

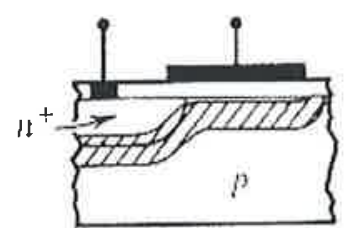

(c)

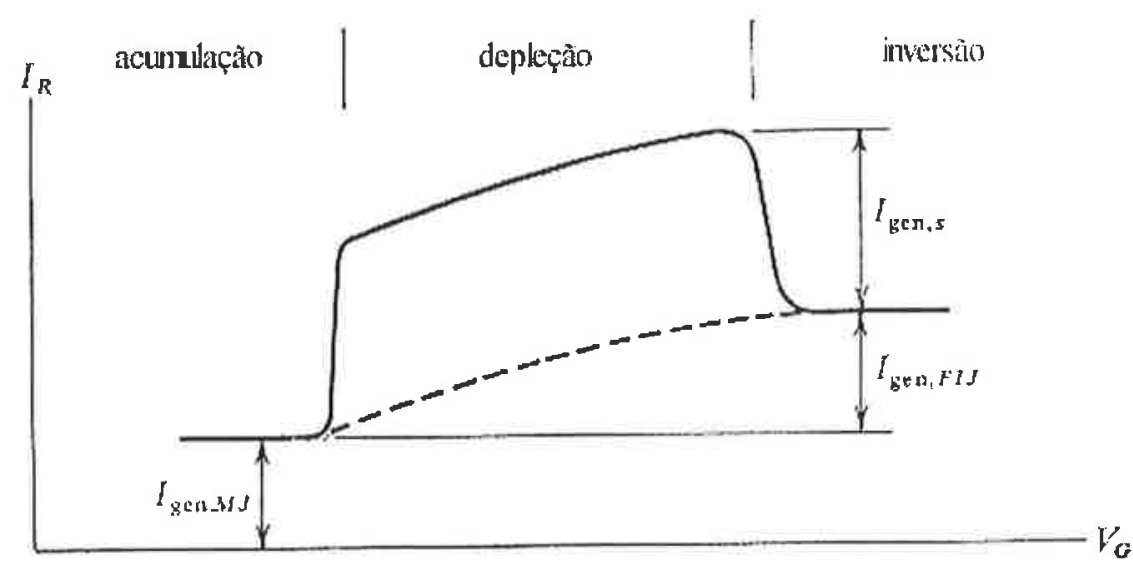

Fig. 4-4: Característica $I_{r e v} x V_{\text {purta }}$ evidenciando os três regimes de operação: acumulação, depleção e inversão

A velocidade de recombinação superficial, $s_{0}$, é proporcional à diferença nos níveis de corrente na transição do regime de depleção para o de inversão, ou seja, $s_{0}$ é proporcional à $I_{g e n, s}$ mostrada na figura 4-4 segundo a equação a seguir:

$$
I_{g e n, s}=q \cdot n_{i} \cdot s_{0} \cdot A_{s}
$$

onde $q$ é a carga eletrônica, $n_{i}$ é a concentração intrínseca no equilíbrio térmico, $s_{0}$ é a velocidade de recombinação superficial e $A_{s}$ é a área sob a porta do dispositivo.

Esse método para a determinação de $s_{0}$ baseia-se no seguinte raciocínio (já visto no capítulo 2): em acumulação, a corrente reversa total medida na junção é função apenas dos portadores gerados dentro dos limites da região de depleção metalúrgica.

Essa componente é constante e está representada na figura 4-4 por $I_{g e n, M J}$.

A partir do momento em que começa a haver depleção abaixo da porta do dispositivo, teremos também as contribuições de mais duas componentes, quais sejam 
as devidas respectivamente aos portadores gerados na região de depleção induzida por campo sob a porta do DCP (componente essa que aumenta com o aumento da tensão de porta e portanto da largura da região depletada até que esta chegue ao seu valor máximo) e aos portadores gerados na superfície do dispositivo logo na interface Si$\mathrm{SiO}_{2}$, (que são devidos aos estados de energia disponíveis gerados por defeitos interfaciais). O valor final da velocidade de recombinação superficial $\left(s_{0}\right)$ foi corrigido de acordo com o método proposto por Pierret [PIER74'] e que também está descrito no capítulo 2 . 


\section{5 - Apresentação e discussão dos resultados}

\section{1 - Simulações}

A fim de verificar a aplicabilidade de DCP's como sensores de radiação luminosa, foram levadas a efeito dois tipos de simulações. A primeira, feita em MATLAB ${ }^{\circledR}$, tem por objetivo avaliar a influência da variação de parâmetros como largura da região de depleção e velocidade de recombinação superficial sobre as equações de corrente de uma junção PN sob iluminação.

A segunda, para a qual foi elaborado um programa em linguagem $\mathrm{C}$, estuda o comportamento de um capacitor MOS em regime de depleção profunda. Os ítens seguintes apresentam e discutem os resultados obtidos a partir destas simulações.

\subsection{1 - Simulações MATLAB ${ }^{\circledR}$}

O uso de junções PN como sensores e células solares já está bastante difundido e aperfeiçoado. Para cada faixa de comprimentos de onda é utilizado um material particular com características adequadas [SZE'81].

$\mathrm{O}$ que nos propomos a justificar aqui é que para um dado material, o silício por exemplo, o rendimento de absorção para cada comprimento de onda é função, entre outras coisas, da largura da região de depleção do dispositivo. Para isso, levemos em consideração uma junção $\mathrm{N}^{+} \mathrm{P}$ como a da figura 5.1 a seguir. 


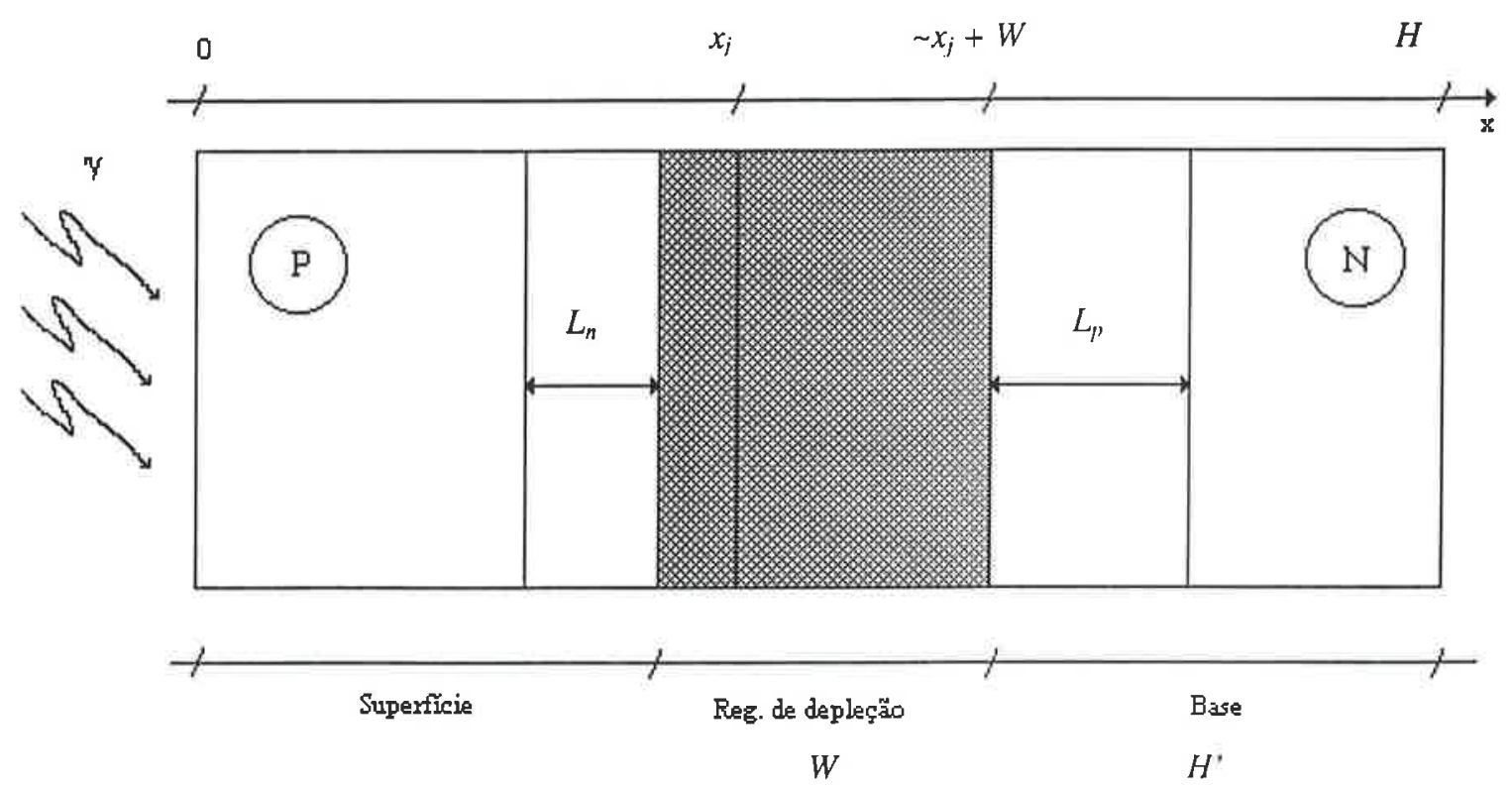

Fig. 5.1: Junção $\mathrm{N}^{+} \mathrm{P}$ sob iluminação.

A corrente total através dessa junção é composta por, basicamente, três partes: uma gerada na região quase-neutra perto da superfície, outra na região quase-neutra de base e a última gerada dentro da região de depleção.

As regiões quase-neutras estendem-se por alguns comprimentos médios de difusão $(L=\sqrt{D \cdot \tau})$ a partir da borda da região de depleção e são definidas pelo volume onde, uma vez gerado um par elétron-lacuna, o portador tem tempo suficiente para difundir-se até a borda da região de depleção, onde o forte campo elétrico local o acelera para o outro lado da junção onde é majoritário e portanto não se recombinará.

Nem todo portador minoritário gerado dentro das regiões quase-neutras comporá efetivamente a corrente total do dispositivo já que o mesmo pode difundir-se na direção oposta à da região de depleção e será então perdido por recombinação.

Por outro lado, todo portador gerado dentro da camada de depleção será efetivamente utilizado na corrente total pois a separação entre os pares gerados é 
praticamente instantânea graças ao campo elétrico e também à ausência (aproximação de depleção) de portadores móveis nessa região.

É devido a essas características que deseja-se uma região de depleção o mais larga possível, o que pode ser conseguido utilizando-se dopagens fracas em ambos ao lados da junção.

Tal abordagem tem o inconveniente de produzir elevadas resistências de contato o que deteriora grandemente o rendimento do dispositivo. O que se tem feito é utilizar uma camada quase-intrínseca (baixíssima dopagem) entre duas regiões (uma $\mathrm{N}$ e outra P) altamente dopadas. Com isso teremos baixa resistência de contato e uma região de depleção tão larga quanto a camada intrínseca. Tal dispositivo é conhecido como diodo PIN (de estrutura P-Intrínseca-N) [SZE'81].

O diodo PIN é um dispositivo já bastante estudado na literatura para aplicações associadas ao sensoriamento de radiação luminosa. Uma outra possibilidade é o diodo controlado por porta (DCP), o qual ainda não foi empregado como sensor de radiação luminosa, mas tem grande potencial nesse sentido.

No presente capítulo vamos demonstrar que o diodo controlado por porta pode ser utilizado como sensor seletivo de luminosidade a partir de um projeto adequado da sua estrutura.

Para uma junção convencional, em função do comprimento de onda, teremos uma taxa de geração óptica em função do comprimento de onda $(\lambda), G$, dada pela equação [SZE'81]:

$$
G(\lambda, x)=\alpha(\lambda) \cdot F(\lambda) \cdot[1-R(\lambda)] \cdot e^{-\alpha(\lambda) \cdot x}
$$


onde, $\alpha$ é o coeficiente de absorção, $F$ é o fluxo de fótons incidentes, $R$ é a Reflectância (parcela refletida) e $x$ é a profundidade dentro do semicondutor.

Como podemos ver pela equação 5.1.1-1 e pela tabela 5-1, comprimentos de onda mais energéticos e que portanto têm um $\alpha$ maior, são absorvidos mais na superfície enquanto que os comprimentos menos energéticos podem chegar a atingir a região de base.

Tab. 5.1: Valor do coeficiente de absorção para vários comprimentos de onda [JELL'82]

\begin{tabular}{c|ccc}
\hline$\lambda[\mathrm{nm}]$ & $\alpha\left[\mathrm{cm}^{-1}\right]$ & $E[\mathrm{eV}]$ & Cor \\
\hline 694 & $2,705 \cdot 10^{3}$ & 1,7865 & vermelho \\
533 & $4,070 \cdot 10^{3}$ & 1,9587 & vermelho \\
532 & $1,0086 \cdot 10^{4}$ & 2,3305 & verde \\
514 & $1,2556 \cdot 10^{4}$ & 2,4121 & verde \\
488 & $1,7992 \cdot 10^{4}$ & 2,5407 & azul \\
485 & $1,8585 \cdot 10^{4}$ & 2,5564 & azul \\
458 & $2,9179 \cdot 10^{4}$ & 2,7071 & azul \\
405 & $1,1255 \cdot 10^{5}$ & 3,0613 & violeta \\
355 & $1,0531 \cdot 10^{6}$ & 3,4925 & U.V.próx. \\
337 & $1,1435 \cdot 10^{6}$ & 3,6791 & U.V.próx. \\
308 & $1,5247 \cdot 10^{6}$ & 4,0255 & U.V.próx. \\
\hline
\end{tabular}

Isso significa que para comprimentos de onda menos energéticos, quanto maior o volume disponibilizado para a absorção na região de depleção da junção PN, maior o seu rendimento. Já para os comprimentos mais energéticos, como os mesmos são absorvidos praticamente à superfície do material, a largura da região de depleção de 
uma dada junção PN pode não afetar em nada o processo de absorção. Os comprimentos de onda intermediários apresentam um comportamento tal que o rendimento de absorção aumenta com o aumento de $W$ até atingir um valor máximo, quando então se estabiliza.

A seguir, apresentamos o equacionamento utilizado nas simulações. Para uma taxa de geração como a da equação 5.1.1-1, as equações de continuidade de estado estacionário para elétrons e lacunas, em uma dimensão, seriam dadas por [SZE'81]:

$$
\begin{aligned}
& G_{n}-\frac{n_{p}-n_{p 0}}{\tau_{n}}+\frac{1}{q} \cdot \frac{\partial J_{n}}{\partial x}=0 \\
& G_{p}-\frac{p_{n}-p_{n 0}}{\tau_{p}}-\frac{1}{q} \cdot \frac{\partial J_{p}}{\partial x}=0
\end{aligned}
$$

sendo as equações de corrente para elétrons e lacunas respectivamente:

$$
\begin{gathered}
J_{n}=q \cdot \mu_{n} \cdot n_{p} \cdot E+q \cdot D_{n} \cdot \frac{\partial n_{p}}{\partial x} \\
J_{p}=q \cdot \mu_{p} \cdot p_{n} \cdot E-q \cdot D_{p} \cdot \frac{\partial p_{n}}{\partial x}
\end{gathered}
$$

Para lacunas na região quase-neutra do lado N, substituindo 5.1.1-3b e 5.1.1-1 em 5.1.1-2b e desprezando a componente de corrente devida ao campo, temos:

$$
D_{p} \cdot \frac{\partial^{2} p_{n}}{\partial x^{2}}+\alpha \cdot F \cdot(1-R) \cdot e^{-\alpha \cdot x}-\frac{p_{n}-p_{n 0}}{\tau_{p}}=0
$$

a solução geral para a equação diferencial 5.1.1-4 acima tem o seguinte formato [SZE'81]: 


$$
p_{n}-p_{n 0}=A \cdot \cosh \left(x / L_{p}\right)+B \cdot \sinh \left(x / L_{p}\right)-\frac{\alpha \cdot F \cdot(1-R) \cdot \tau_{p}}{\alpha^{2} \cdot L_{p}^{2}-1} \cdot e^{-\alpha \cdot x}
$$

onde $A$ e $B$ são constantes a serem determinadas pelas condições de contorno e $L_{p}=$ $\left(D_{p} \cdot \tau_{p}\right)^{1 / 2}$

As condições de contorno (para a equação 5.1.1-5) são as seguintes:

a) na superfície do material temos recombinação de portadores a uma velocidade $S_{p}$ :

$$
D_{p} \cdot \frac{\partial\left(p_{n}-p_{n 0}\right)}{\partial x}=S_{p} \cdot\left(p_{n}-p_{n 0}\right)
$$

b) na extremidade da região quase-neutra, devemos ter um excesso de portadores aproximadamente nulo:

$$
p_{n}-p_{n 0} \cong 0
$$

Usando essas condições de contorno, chegamos finalmente à equação de corrente devida a lacunas na região próxima da superfície (tipo P na figura 5.1):

$$
J_{\text {sp }}=J_{p}=\left[\frac{q \cdot F \cdot(1-R) \cdot \alpha \cdot L_{p}}{\alpha^{2} \cdot L_{p}^{2}-1}\right] \cdot\left[\frac{\left(\frac{S_{p} \cdot L_{p}}{D_{p}}+\alpha \cdot L_{p}\right)-e^{-\alpha \cdot x_{p}} \cdot\left(\frac{S_{p} \cdot L_{p}}{D_{p}} \cdot \cosh \frac{x_{j}}{L_{p}}+\sinh \frac{x_{j}}{L_{p}}\right)}{\frac{S_{p} \cdot L_{p}}{D_{p}} \cdot \sinh \frac{x_{j}}{L_{p}}+\cosh \frac{x_{p}}{L_{p}}}-\alpha \cdot L_{p} \cdot e^{-\alpha \cdot x_{p}}\right]
$$

analogamente, para os elétrons na base (tipo $\mathrm{N}$ na figura 5.1) temos:

$$
J_{\text {buse }}=J_{n}=\left[\frac{q \cdot F \cdot(1-R) \cdot \alpha \cdot L_{n}}{\alpha^{2} \cdot L_{n}^{2}-1}\right] \cdot e^{-\alpha \cdot\left(x_{1}+W\right)} \cdot\left[\alpha \cdot L_{n} \frac{\left(\frac{S_{n} \cdot L_{n}}{D_{n}}\right) \cdot\left[\cosh \frac{H}{L_{n}}-e^{-x t H \cdot}\right]+\sinh \frac{H^{\prime}}{L_{n}}+\alpha \cdot L_{n} \cdot e^{-\alpha \cdot H}}{\frac{S_{n} \cdot L_{n}}{D_{n}} \cdot \sinh \frac{H^{\prime}}{L_{n}}+\cosh \frac{H^{\prime}}{L_{n}}}\right]
$$


onde os parâmetros $x_{j}, L_{p}, H^{\prime}, W$ e $L_{n}$ estão indicados na figura 5.1.

Já para a região de depleção, a equação de corrente fica:

$$
J_{d p}=q \cdot F \cdot(1-R) \cdot e^{-\alpha \cdot x_{j}} \cdot\left[1-e^{-\alpha \cdot W}\right]
$$

A corrente total na junção será a soma de três parcelas, ou seja:

$$
J_{T}=J_{\text {sup }}+J_{\text {hase }}+J_{d p}
$$

O rendimento, ou resposta espectral, $R E$, desse dispositivo é, por definição, a corrente total gerada opticamente dividida pelo fluxo transmitido de fótons e pela carga do elétron, ou seja:

$$
R E=\frac{J_{T}}{q \cdot F \cdot(1-R)}
$$

A partir das equações 5.1.1-8, 5.1.1-9, 5.1.1-10, 5.1.1-11 e 5.1.1-12 acima, simulamos no MATLAB ${ }^{\circledR}$ v. 5.0.0.4069, a resposta espectral $(R E)$ para uma junção em função do valor de $W$, ou seja, da largura da camada de depleção.

Alguns resultados obtidos estão apresentados nas figuras 5.2, a 5.5 a seguir: 


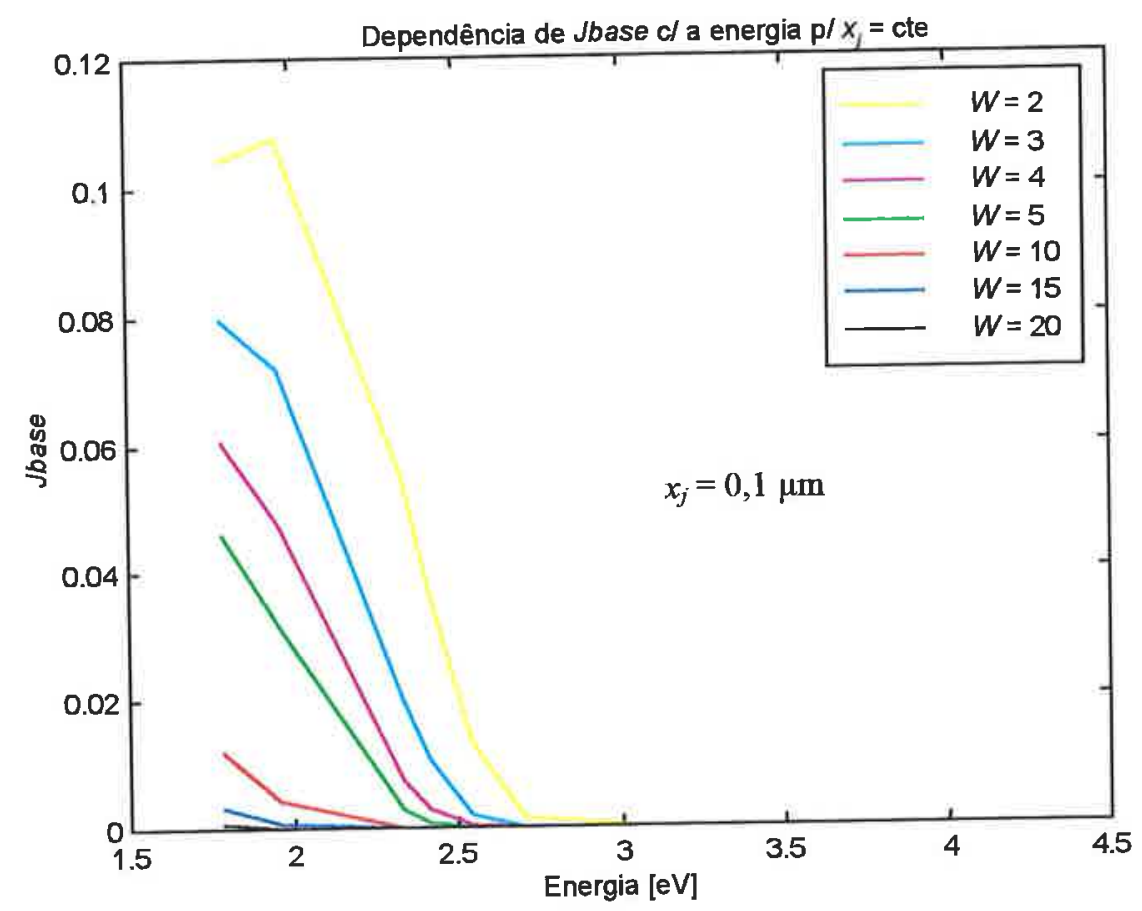

Fig. 5.2: Componente de base, $J_{\text {base }} \times$ Energia, parametrizada em $W$ para $x_{j}=0,1 \mu \mathrm{m}\left(S_{p}=5 \cdot 10^{6} \mathrm{~cm} / \mathrm{s}\right)$

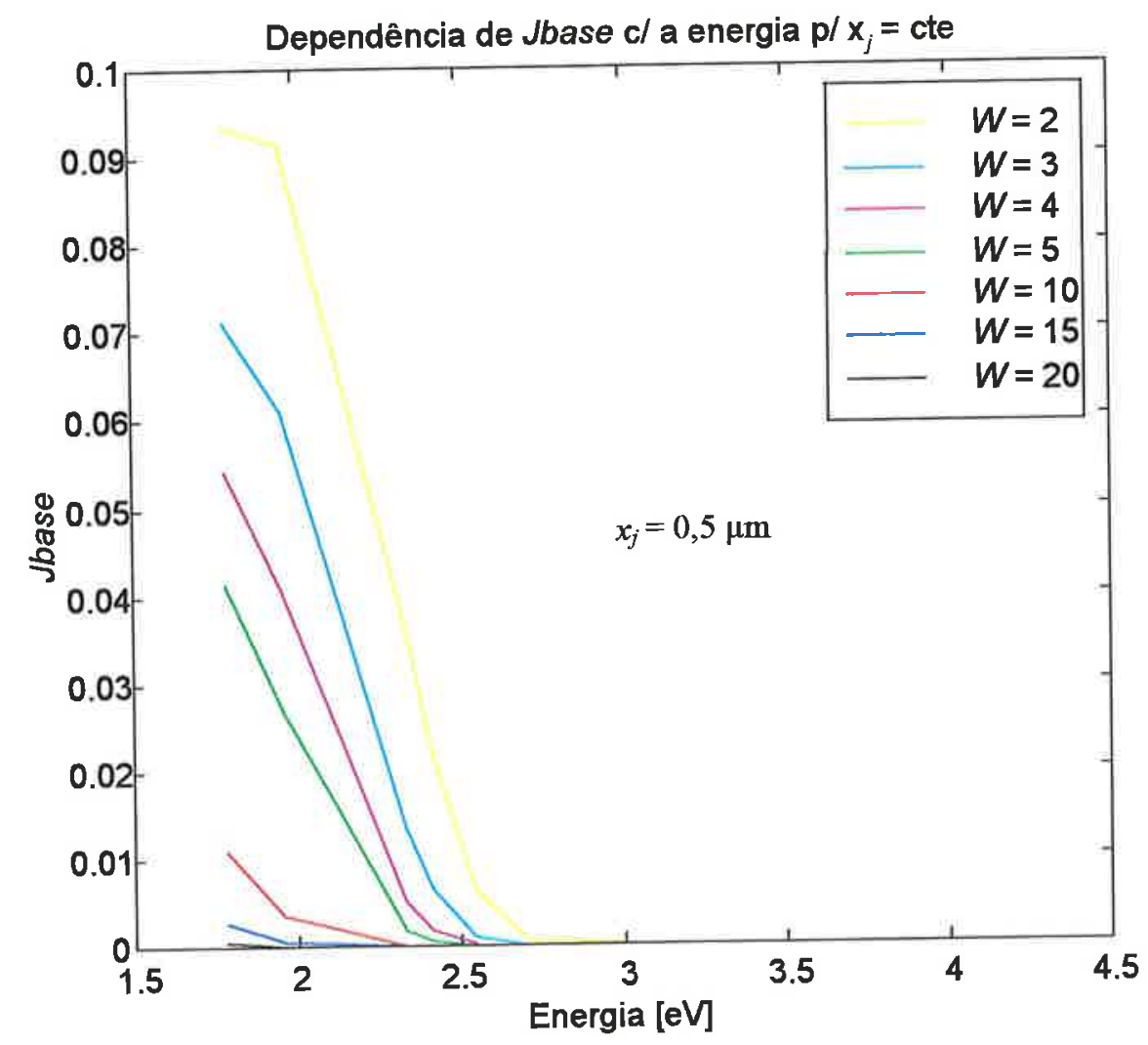

Fig. 5.3: Componente de base, $J_{\text {base }} \times$ Energia, parametrizada em $W$ para $x_{j}=0,5 \mu \mathrm{m}\left(S_{p}=5 \cdot 10^{6} \mathrm{~cm} / \mathrm{s}\right)$ 


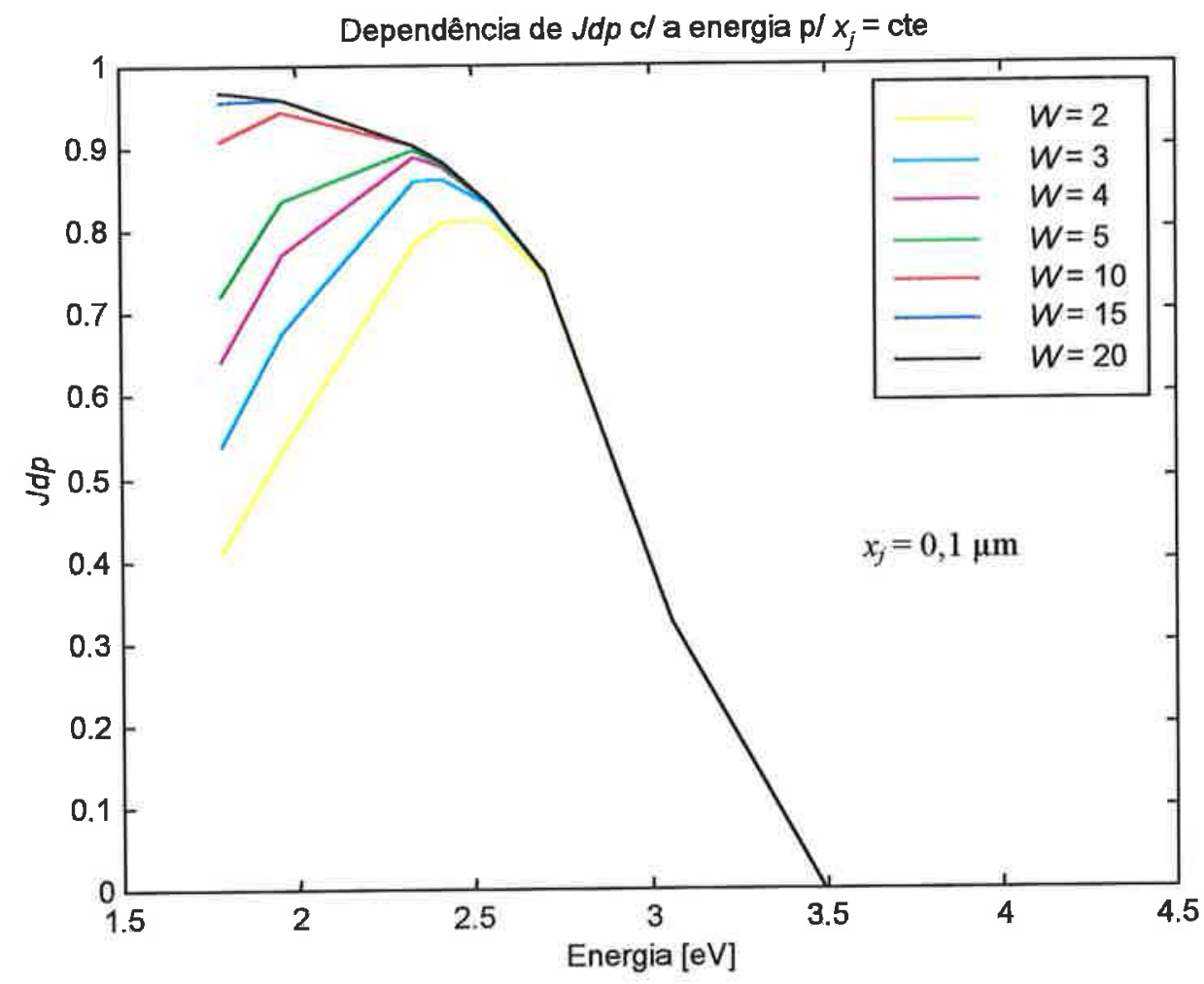

Fig. 5.4: Componente da corrente de depleção, $J_{d p} \times$ Energia parametrizada em $W \mathrm{p} / x_{j}=0,1 \mu \mathrm{m}\left(S_{p}=\right.$ $5 \cdot 10^{6} \mathrm{~cm} / \mathrm{s}$ )

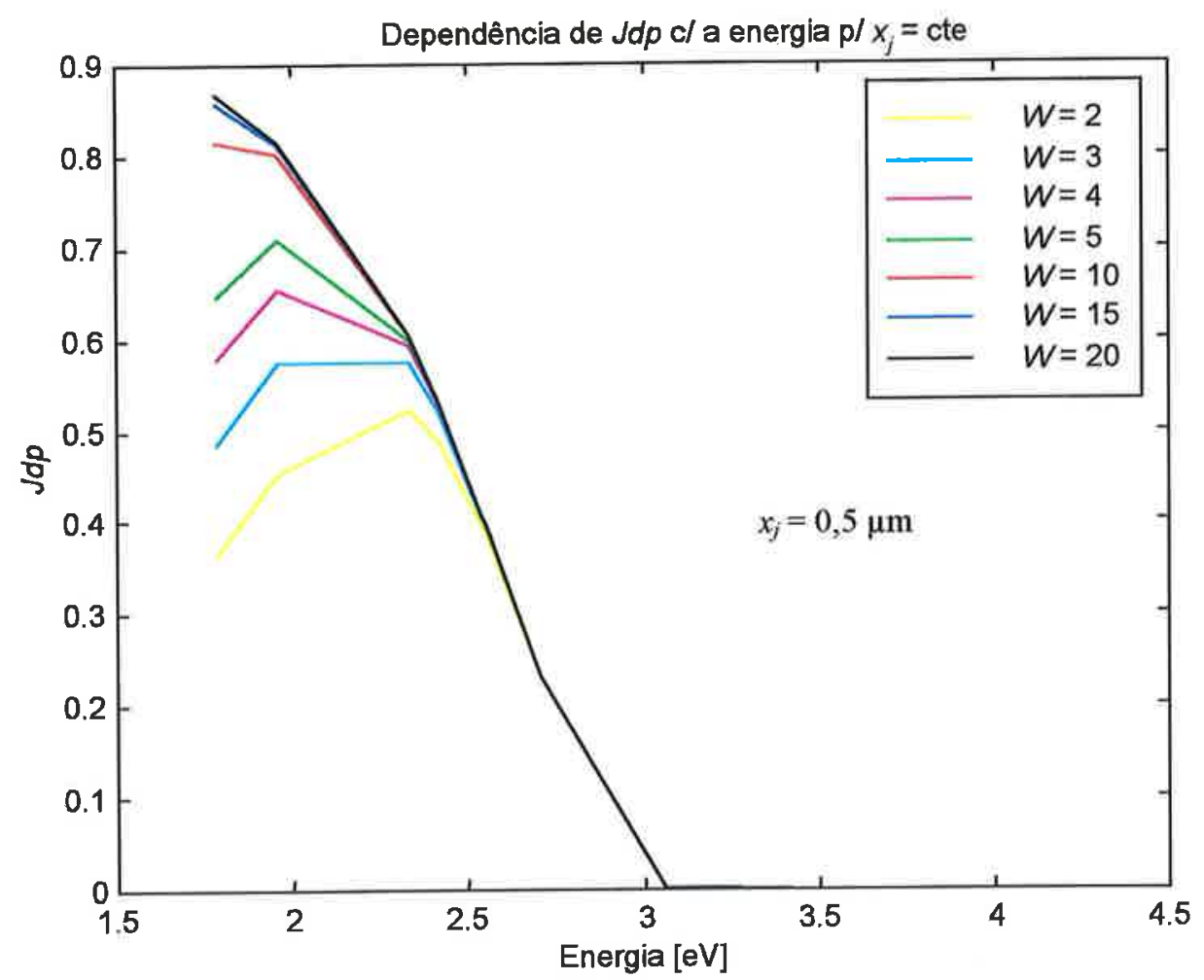

Fig. 5.5: Componente da corrente de depleção, $J_{d p} \times$ Energia parametrizada em $W \mathrm{p} / x_{j}=0,5 \mu \mathrm{m}\left(S_{p}=\right.$ $5 \cdot 10^{5} \mathrm{~cm} / \mathrm{s}$ ) 


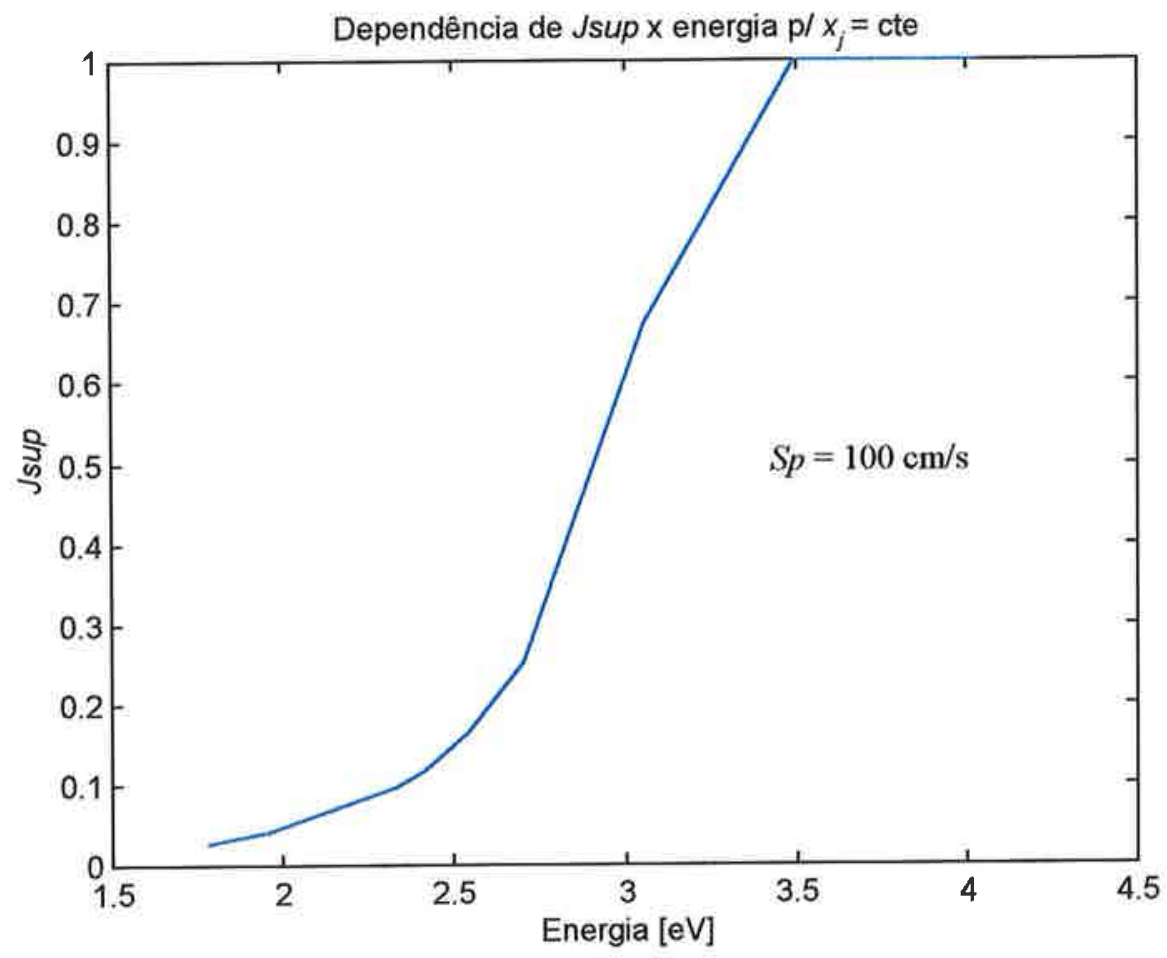

Fig. 5.6: $J_{\text {sup }} \times$ Energia para $S_{p}=100 \mathrm{~cm} / \mathrm{s}\left(x_{j}=0,1 \mu \mathrm{m}\right)$

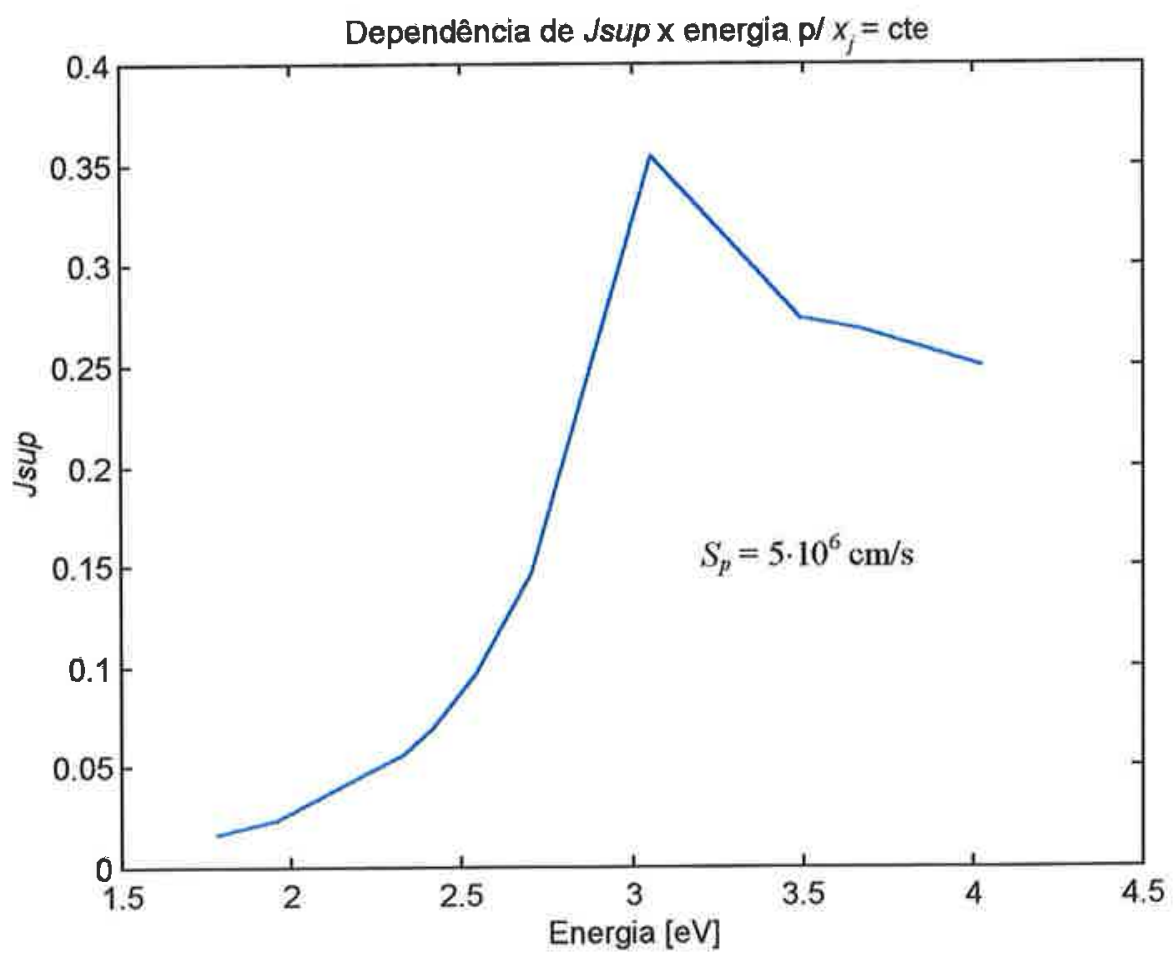

Fig. 5.7: $J_{\text {sup }} \times$ Energia para $S_{p}=5 \cdot 10^{6} \mathrm{~cm} / \mathrm{s}\left(x_{j}=0,1 \mu \mathrm{m}\right)$ 


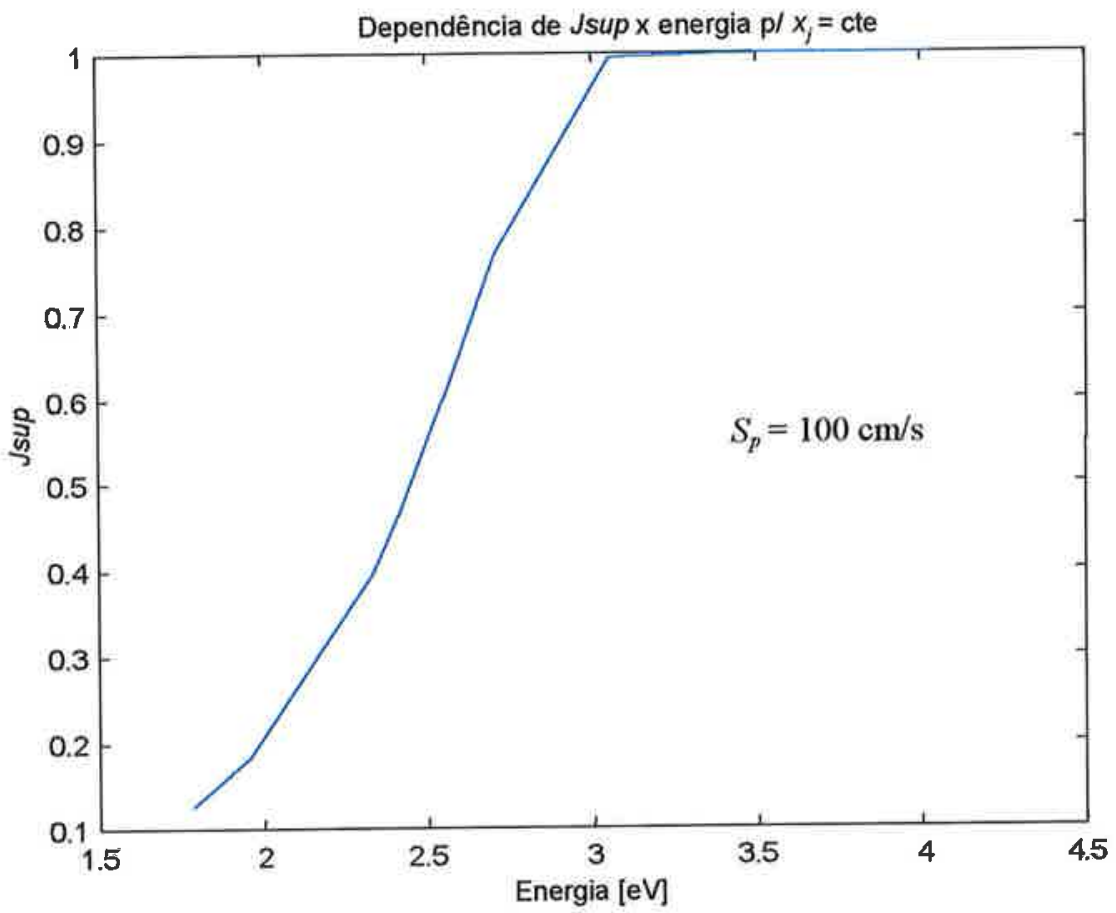

Fig. 5.8: $J_{\text {sup }} \times$ Energia para $S_{p}=100 \mathrm{~cm} / \mathrm{s}\left(x_{j}=0,5 \mu \mathrm{m}\right)$

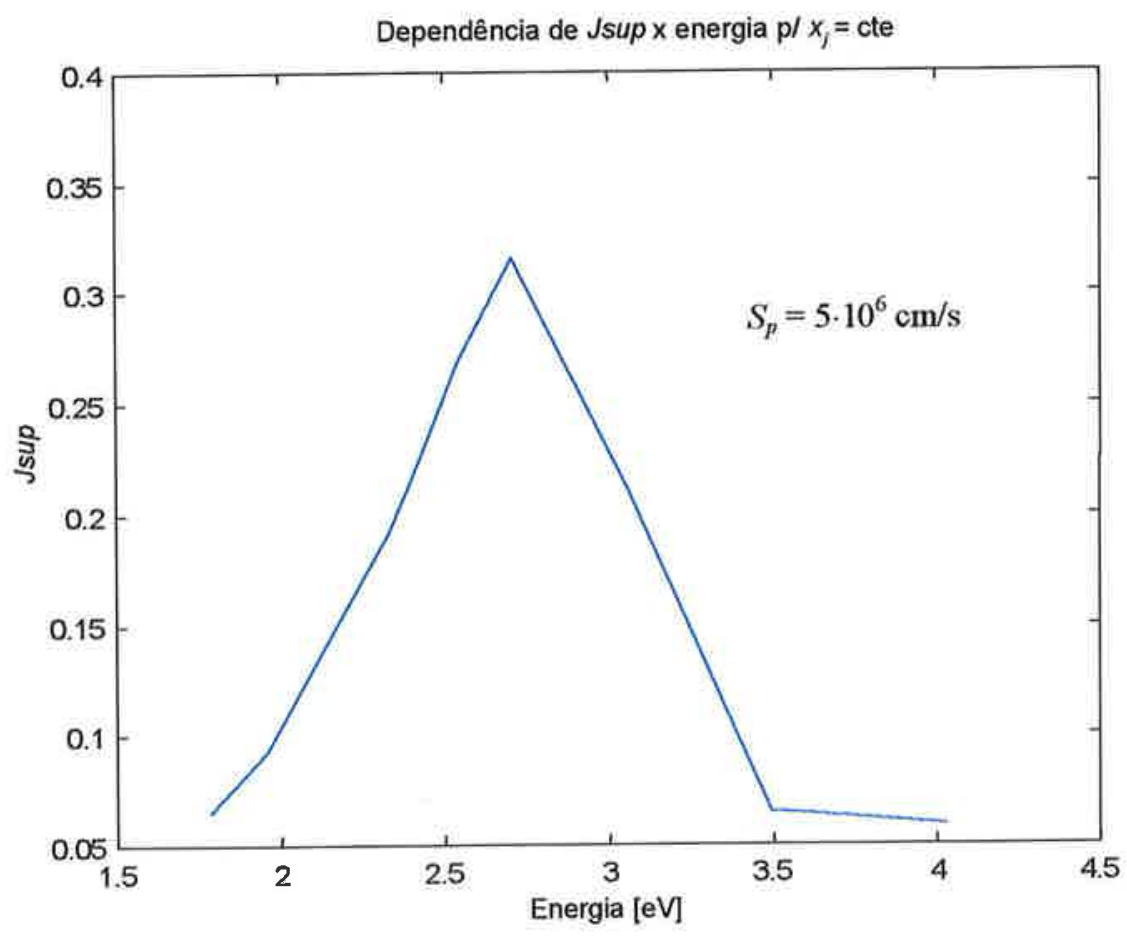

Fig. 5.9: $J_{\text {sup }} \times$ Energia para $S_{p}=5 \cdot 10^{6} \mathrm{~cm} / \mathrm{s}\left(x_{j}=0,5 \mu \mathrm{m}\right)$ 
Pudemos verificar que, quanto maior o valor de $x_{j}$, ou seja, quanto mais profunda a junção, menor o rendimento das três componentes, por isso, uma junção mais rasa é mais conveniente.

Isso ocorre porque em junções profundas, ambas as regiões quase-neutras e a própria região de depleção encontram-se mais distantes da superfície do semicondutor, o que implica numa maior perda de intensidade luminosa à medida que a luz penetra no material.

Também, pudemos observar que a componente de superfície não depende do valor de $W$ mas tão somente da velocidade de recombinação superficial e da profundidade da junção pois, uma junção mais profunda implica numa maior profundidade para a região quase-neutra de superfície. Por outro lado, a variação em $W$ não mais afeta essa componente já que a região de depleção inicia-se quando termina a região quase-neutra de superfície.

As simulações mostradas nas figuras 5.2, 5.3, 5.4 e 5.5, indicaram uma dependência, com relação a $W$, das correntes de base e de depleção, sendo que a primeira diminui com o aumento do mesmo ao passo que a segunda aumenta. $O$ aumento da componente de depleção se deve ao aumento do volume de absorção obtido dentro daquela região. Já a diminuição observada na componente de base é explicada pelo fato de que quanto maior o valor de $W$, mais profundamente fica situada a região quase-neutra de base, o que implica numa menor intensidade luminosa no local e conseqüiente perda de rendimento.

Nos gráficos mostrados nas figuras 5.10 e 5.11, podemos ver a resposta espectral completa $(R E)$, ou seja, o rendimento de conversão para todos os comprimentos de onda (proporcionais à energia dos fótons), e levando-se em consideração todas as três 
componentes de corrente, para valores de $W=2$ e $10 \mu \mathrm{m}$, para uma profundidade de junção, $x_{j}=0,1 \mu \mathrm{m}$. Nos dois casos tomou-se $S_{p}=5 \cdot 10^{6} \mathrm{~cm} / \mathrm{s}$ e $S_{n}=5 \cdot 10^{8} \mathrm{~cm} / \mathrm{s}$.

Em seguida, temos os mesmos gráficos para $S_{p}=100 \mathrm{~cm} / \mathrm{s}$ (figuras 5.12 e 5.13 ), mantendo-se o valor de $S_{n}=5 \cdot 10^{8} \mathrm{~cm} / \mathrm{s}$ e finalmente temos os resultados das figuras 5.14 e 5.15 admitindo-se velocidades baixas $\left(100 \mathrm{~cm} / \mathrm{s}\right.$ tanto para $S_{p}$ quanto para $\left.S_{n}\right)$. 


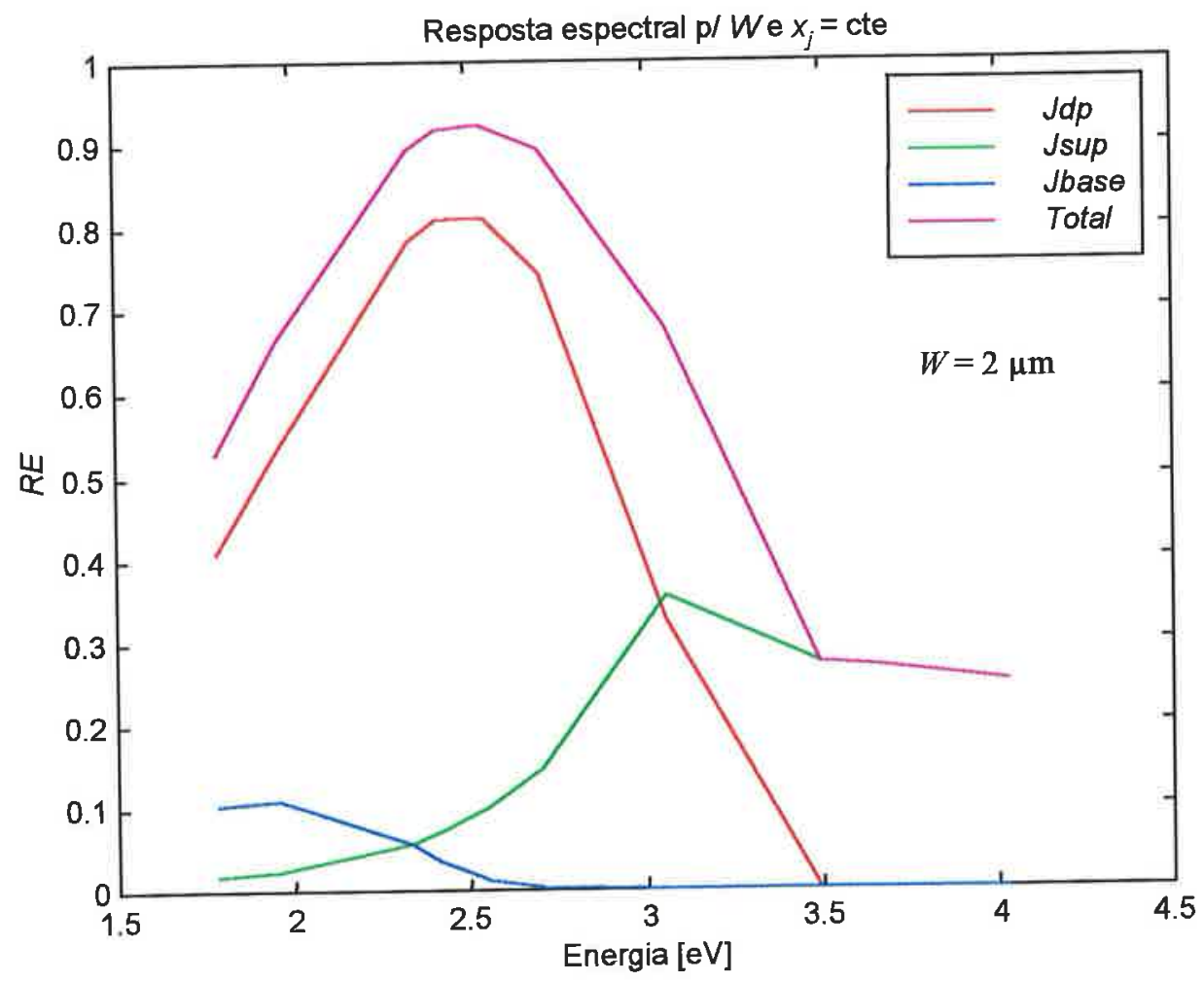

Fig. 5.10: $R E$ x Energia para $W=2 \mu \mathrm{m} . S_{p}=5 \cdot 10^{6} \mathrm{~cm} / \mathrm{s}$ e $S_{n}=5 \cdot 10^{8} \mathrm{~cm} / \mathrm{s}, x_{j}=0,1 \mu \mathrm{m}$

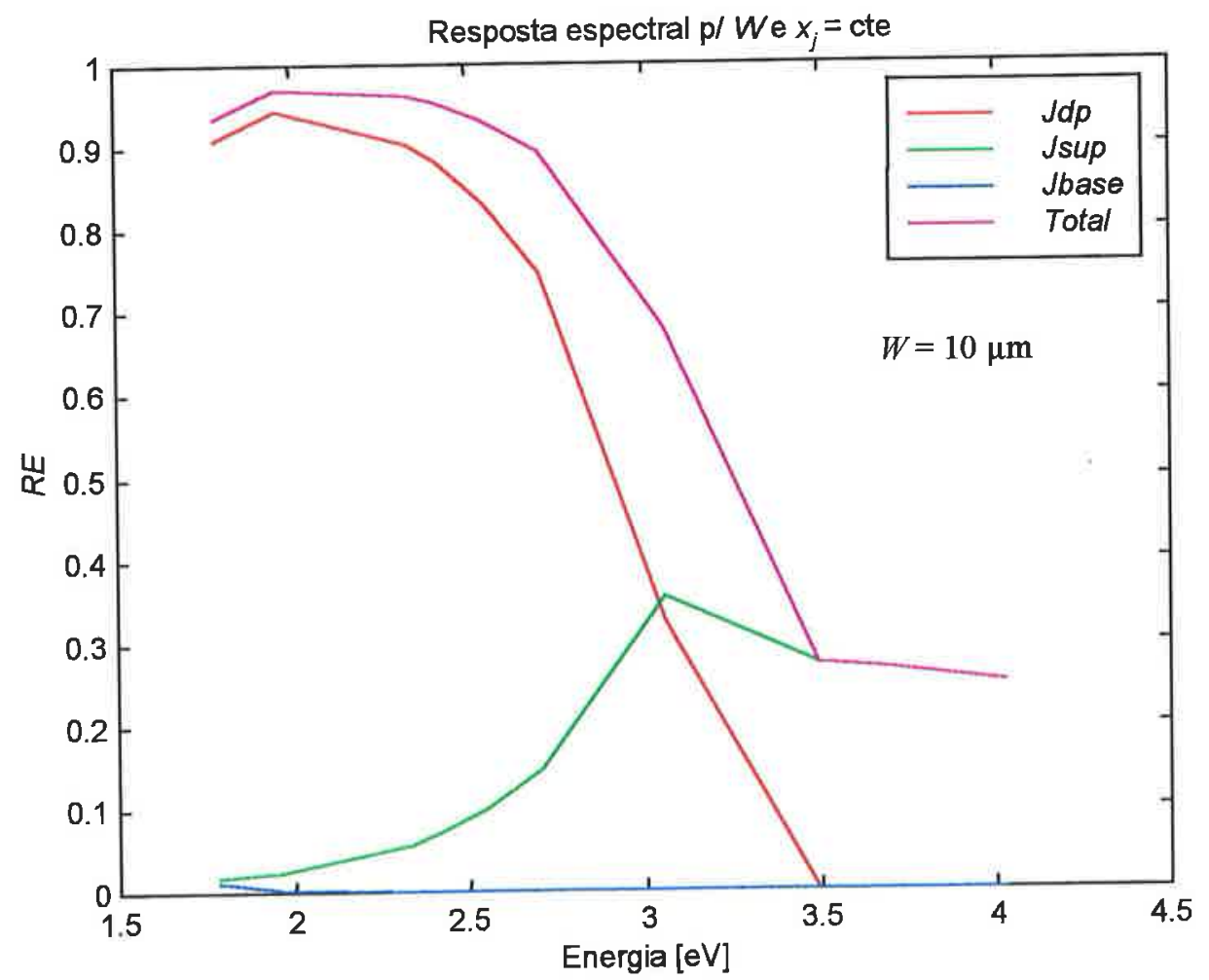

Fig. 5.11: $R E$ x Energia para $W=10 \mu \mathrm{m} . S_{p}=5 \cdot 10^{6} \mathrm{~cm} / \mathrm{s}$ e $S_{n}=5 \cdot 10^{8} \mathrm{~cm} / \mathrm{s}, x_{j}=0,1 \mu \mathrm{m}$ 


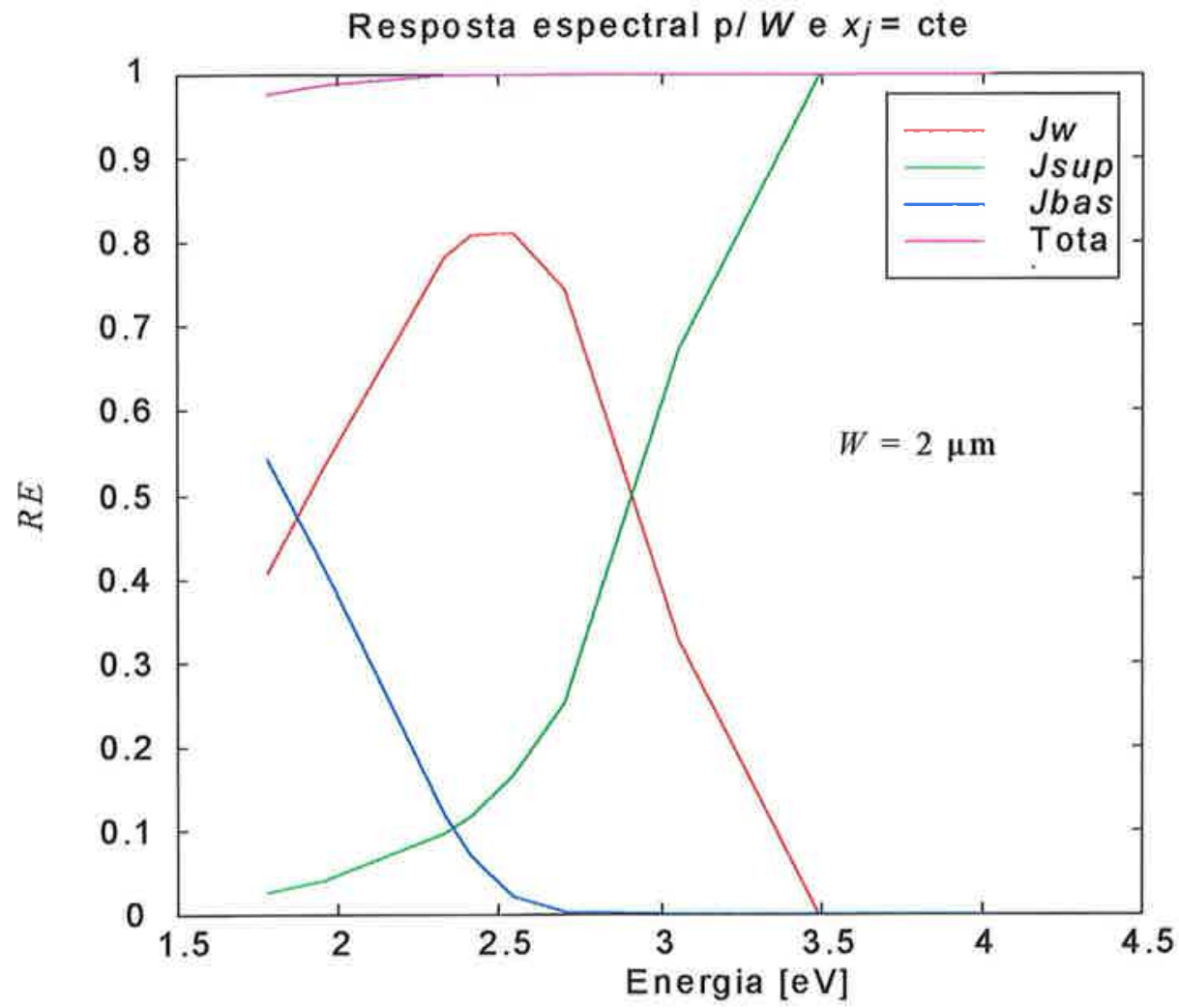

Fig. 5.12: $R E \times$ Energia para $W=2 \mu \mathrm{m} . S_{p}=100 \mathrm{~cm} / \mathrm{s}$ e $S_{n}=5 \cdot 10^{8} \mathrm{~cm} / \mathrm{s}, x_{j}=0,1 \mu \mathrm{m}$

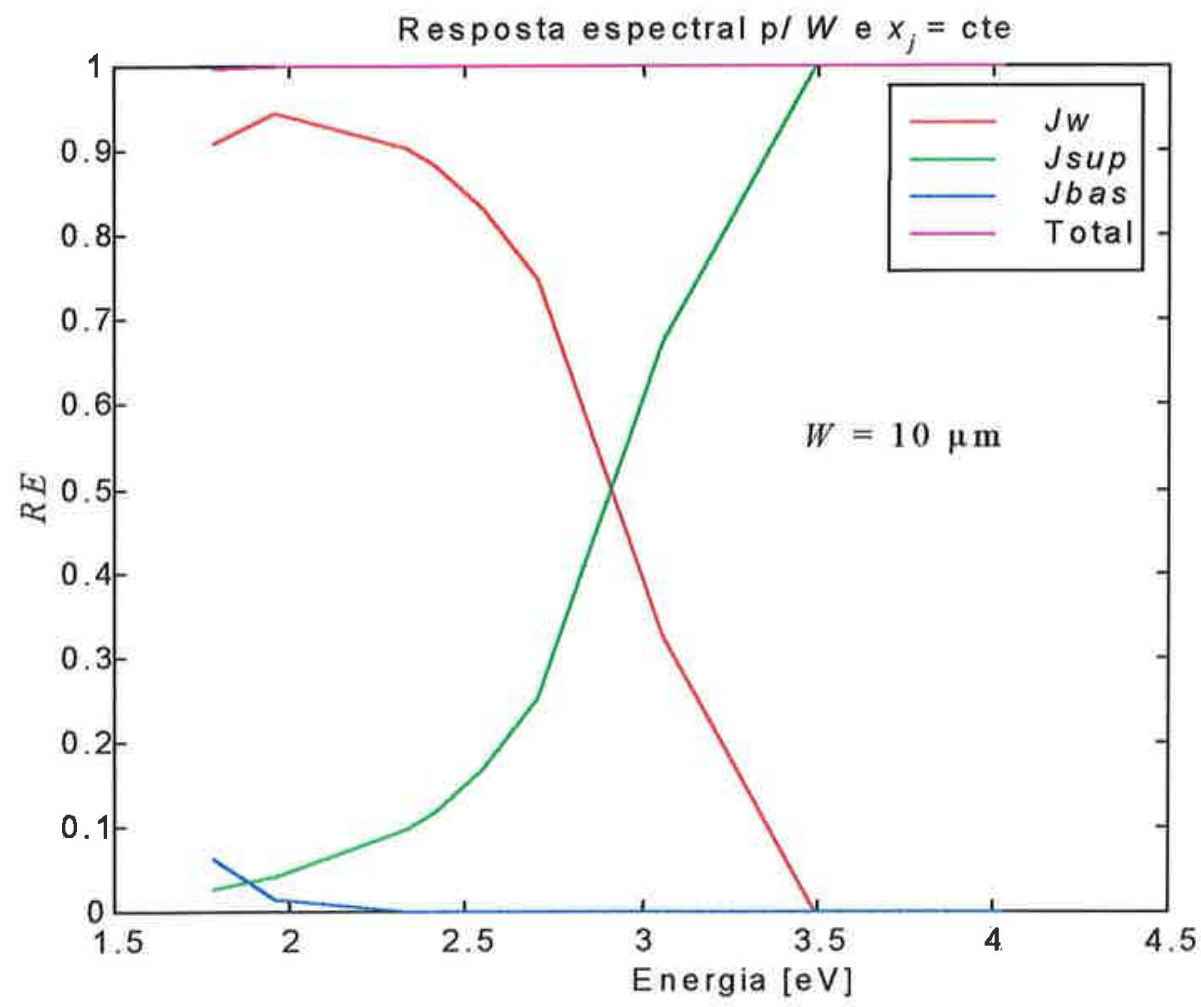

Fig. 5.13: RE x Energia para $W=10 \mu \mathrm{m} . S_{p}=100 \mathrm{~cm} / \mathrm{s}$ e $S_{n}=5 \cdot 10^{8} \mathrm{~cm} / \mathrm{s}, x_{j}=0,1 \mu \mathrm{m}$ 


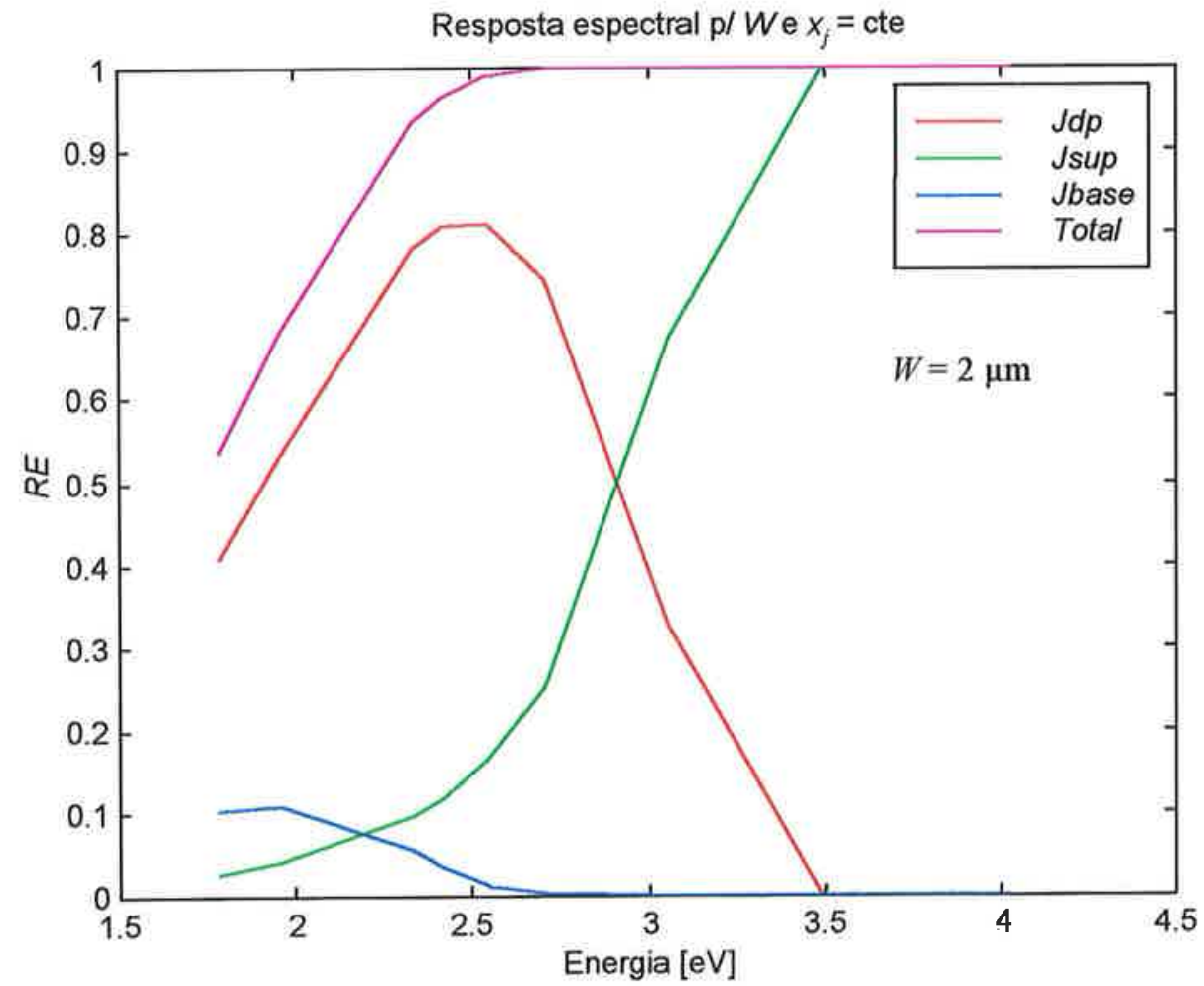

Fig. 5.14: $R E \times$ Energia para $W=2 \mu \mathrm{m} . S_{p}=100 \mathrm{~cm} / \mathrm{s} \mathrm{e} S_{n}=100 \mathrm{~cm} / \mathrm{s}, x_{j}=0,1 \mu \mathrm{m}$

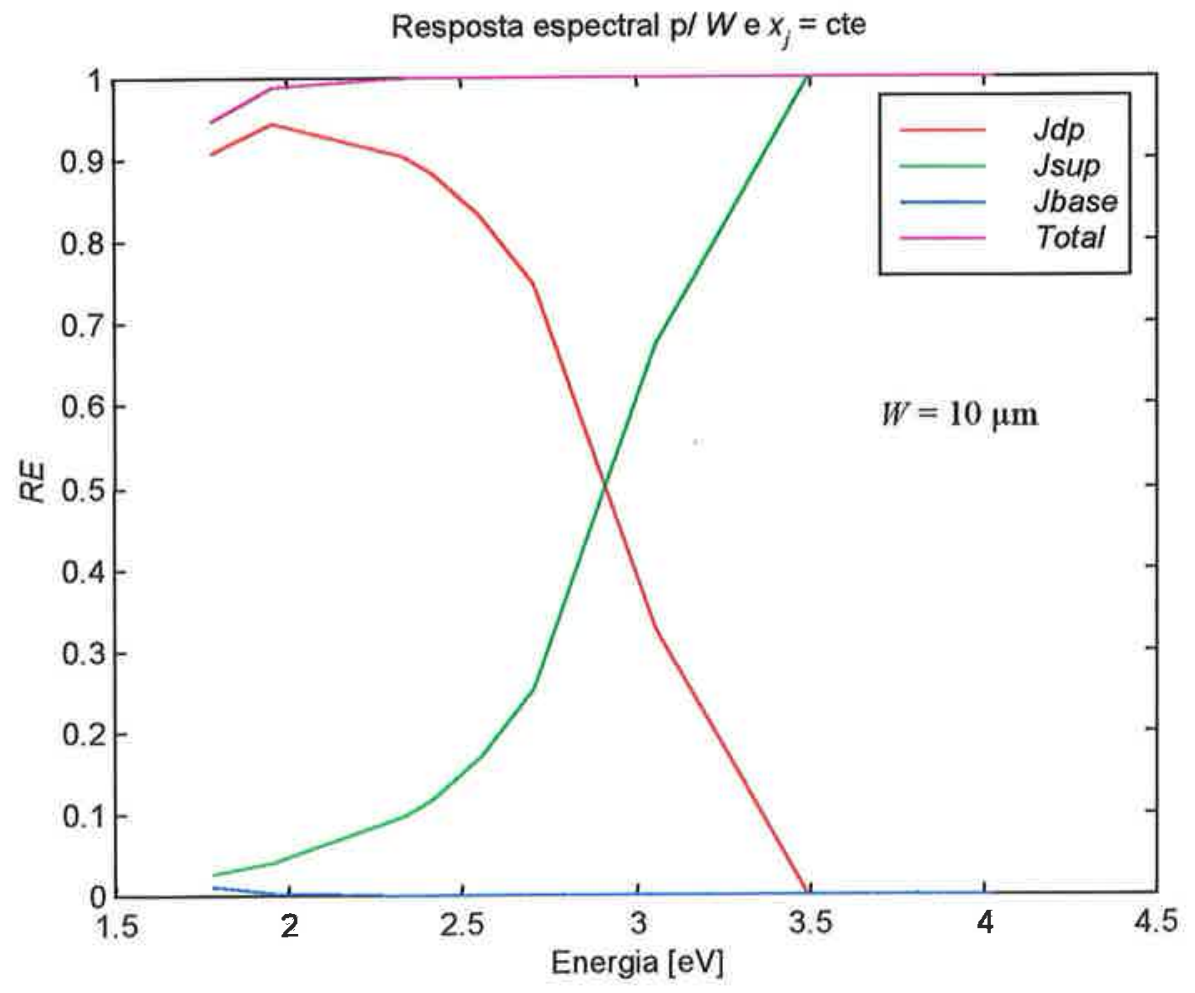

Fig. 5.15: $R E \times$ Energia para $W=10 \mu \mathrm{m} . S_{p}=100 \mathrm{~cm} / \mathrm{s}$ e $S_{n}=100 \mathrm{~cm} / \mathrm{s}, x_{j}=0,1 \mu \mathrm{m}$ 
Dos gráficos das figuras 5.10 e 5.11 anteriores, podemos ver que quando as velocidades de recombinação de base $\left(S_{n}\right)$ e superfície $\left(S_{p}\right)$ são muito altas, a resposta espectral $(R E)$ assume um aspecto de filtro passa-faixa. Por outro lado, nos gráficos das figuras 5.14 e 5.15, podemos observar que $R E$ assume um aspecto de filtro passa-altas já que as velocidades de recombinação de base e superfície são muito pequenas.

Por outro lado, dos gráficos das figuras 5.10, 5.11, 5.12 e 5.13, podemos observar que basta a velocidade de recombinação de superfície $\left(S_{p}\right)$ ser alta para termos um filtro seletivo (passa-faixa), não importando o valor da velocidade de recombinação de base $\left(S_{n}\right)$.

Portanto, para se obter um sensor seletivo para determinados comprimentos de onda dentro da faixa do visível, devemos eliminar as componentes que não nos interessam, o que nesse caso, é devido a corrente gerada na região quase-neutra de superfície.

Para conseguirmos isso devemos fazer $S_{p}$ elevado (figuras 5.10 e 5.11 ), o que pode ser obtido para um tempo de vida médio de portadores da ordem de $1 \cdot 10^{-10} \mathrm{~s}$ [SZE'81]. Um valor assim tão baixo é possível de se obter se fizermos, por exemplo, uma implantação iônica de ouro em altas concentrações, que introduzirão vários níveis de armadilha reduzindo-se o tempo de vida dos portadores minoritários especificamente na região quase-neutra de superfície.

Resta-nos agora, verificar o comportamento do dispositivo para diferentes comprimentos de onda. Assim, nas simulações das figuras 5.16 e 5.17 seguintes, temos o rendimento em função de $W$ para $x_{j}=0,1$ e $0,5 \mu \mathrm{m}$. Em ambos os casos temos $S_{p}=$ $5 \cdot 10^{6} \mathrm{~cm} / \mathrm{s}$ e $S_{n}=5 \cdot 10^{8} \mathrm{~cm} / \mathrm{s}$. 


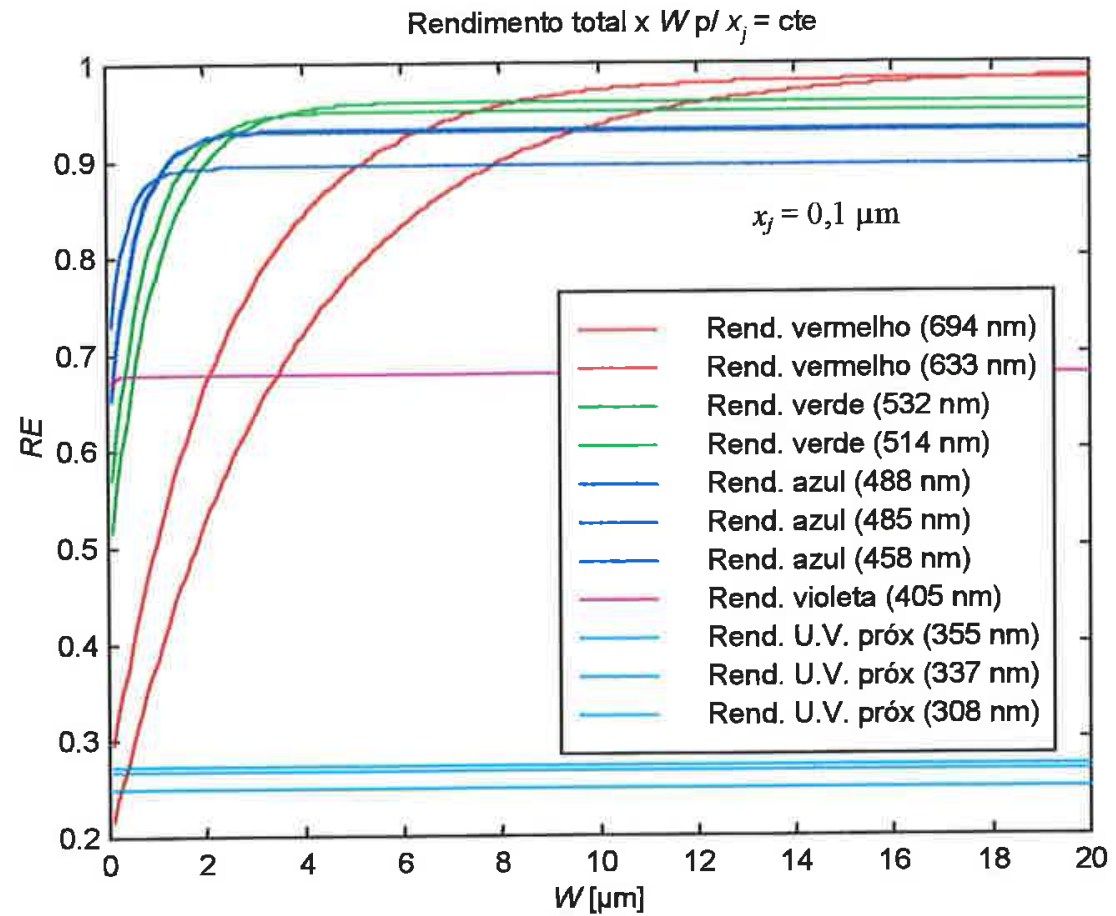

Fig. 5.16: $R E \times \mathrm{x} W$ para $x_{j}=0,1 \mu \mathrm{m} .\left(S_{p}=5 \cdot 10^{6}\right.$ e $\left.S_{n}=5 \cdot 10^{8} \mathrm{~cm} / \mathrm{s}\right)$

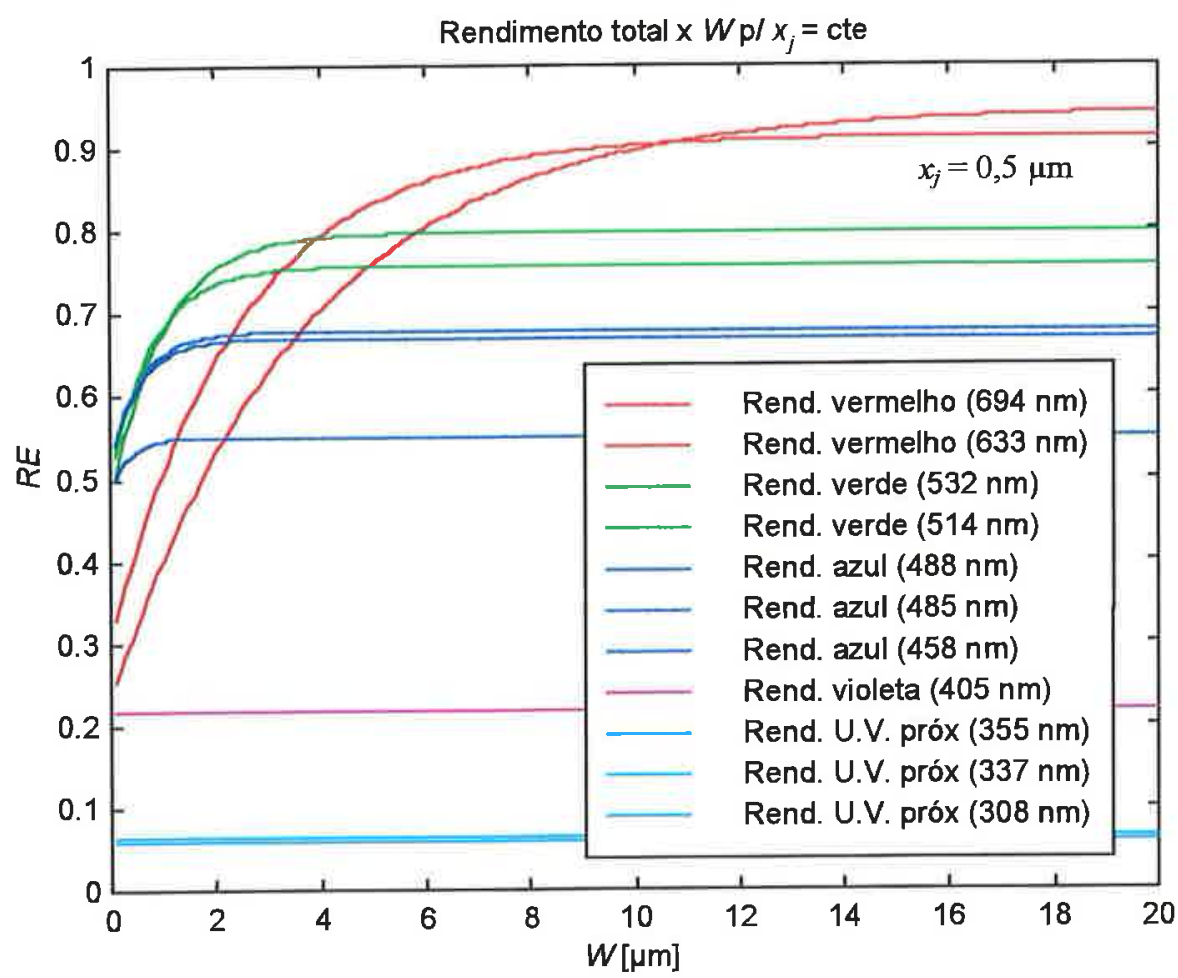

Fig. 5.17: $R E \mathrm{x} W$ para $x_{j}=0,5 \mu \mathrm{m} .\left(S_{p}=5 \cdot 10^{6}\right.$ e $\left.S_{n}=5 \cdot 10^{8} \mathrm{~cm} / \mathrm{s}\right)$ 
Podemos inferir dos gráficos já vistos de resposta espectral (figuras 5.10 a 5.15), que para cada valor de $W$ devemos ter um comprimento de onda de rendimento máximo. As figuras 5.16 e 5.17 são o resultado simulado desta inferência onde claramente, as maiores larguras da região de depleção $W$ das junções apresentam maiores rendimentos para os maiores comprimentos de onda. A tabela 5.2 mostra o rendimento máximo $\left(\eta_{\text {maxx }}\right)$ para cada valor de $W$ e o correspondente comprimento de onda $\left(\lambda_{d o m}\right)$.

Tab. 5.2: Rendimento máximo em cada $W$

\begin{tabular}{c|cccc}
\hline$W[\mu m]$ & $\lambda_{\text {dom }}[\mathrm{nm}]$ & $E[\mathrm{eV}]$ & $\eta_{\text {máx }}$ & cor \\
\hline 1,0 & 458 & 2,7071 & 0,7066 & azul \\
2,0 & 488 & 2,5407 & 0,8125 & azul \\
3,0 & 514 & 2,4121 & 0,8616 & verde \\
5,0 & 532 & 2,3305 & 0,8982 & verde \\
10,0 & 633 & 1,9587 & 0,9437 & Vermelho \\
15,0 & 633 & 1,9587 & 0,9580 & Vermelho \\
20,0 & 694 & 1,7865 & 0,9690 & Vermelho \\
\hline
\end{tabular}

A tabela 5.2 nos permite escolher comprimentos de onda que desejemos monitorar e qual o valor de $W$ ideal para cada caso.

No gráfico da fig. 5.18, selecionamos três comprimentos de onda: vermelho 694 $\mathrm{nm}$, verde $532 \mathrm{~nm}$ e azul $458 \mathrm{~nm}$, para $x_{j}=0,1 \mu \mathrm{m}$ e $S_{p}=5 \cdot 10^{6} \mathrm{~cm} / \mathrm{s}$. Nota-se que devemos escolher $W \geq 15 \mu \mathrm{m}$ para $\lambda=694 \mathrm{~nm}, W \geq 4 \mu \mathrm{m}$ para $\lambda=532 \mathrm{~nm}$ e $W \geq 2 \mu \mathrm{m}$ para $\lambda=458 \mathrm{~nm}$. 


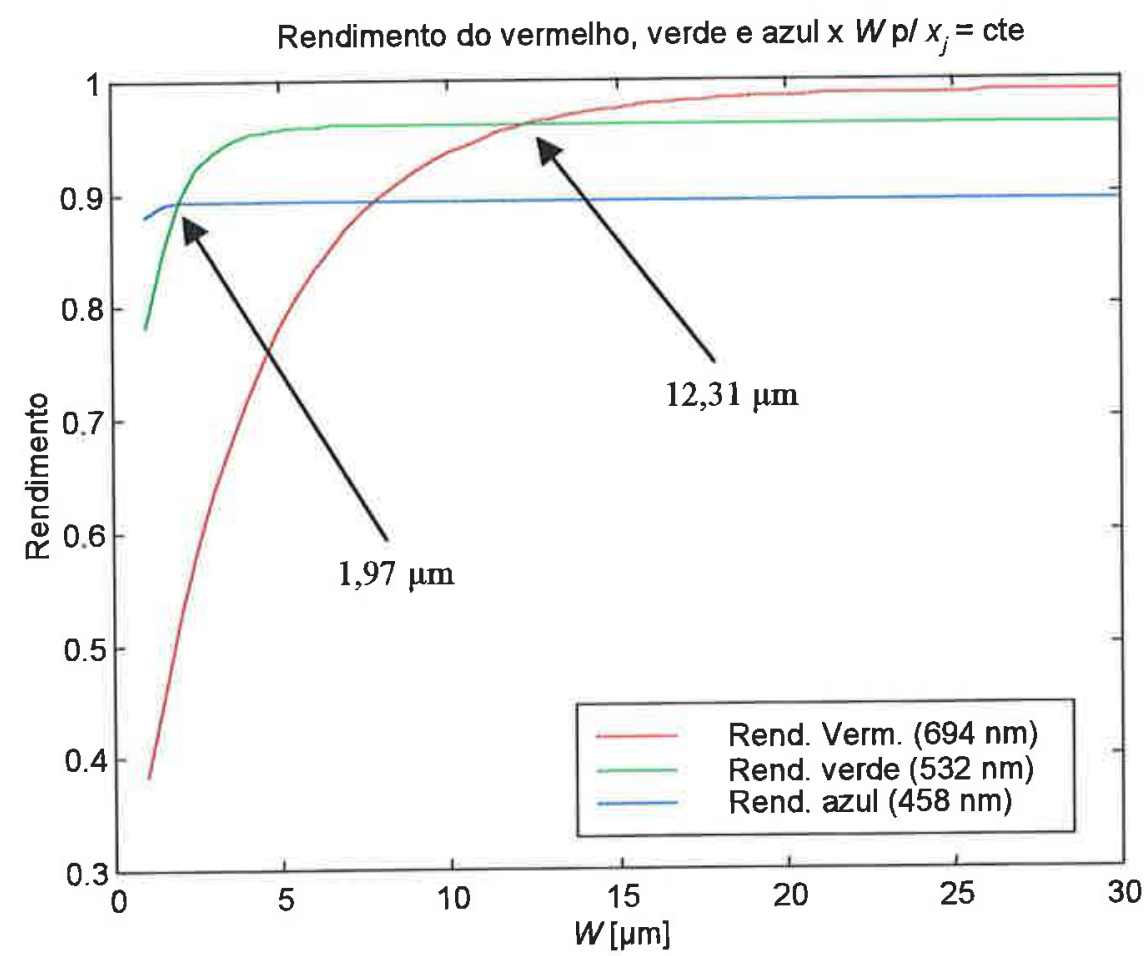

Fig. 5.18: Rendimento para 694, 532 e $458 \mathrm{~nm}\left(x_{j}=0,1 \mu \mathrm{m}\right.$ e $\left.S_{p}=5 \cdot 10^{6} \mathrm{~cm} / \mathrm{s}\right)$

Podemos também concluir da figura 5.18 que para altos valores de $W$, o comprimento de onda do azul é o que tem o pior rendimento $(\sim 0,90)$, o comprimento de onda do verde apresenta rendimento máximo de 0,95 e o comprimento de onda do vermelho apresenta o maior rendimento $(\sim 0,99)$.

Para valores pequenos de $W$ é o azul que apresenta rendimento superior e para $W$ intermediários é o comprimento de onda do verde que apresenta rendimento maior do que os outros dois

As características estudadas até aqui nos permitem propor um método de filtragem seletiva para esses três comprimentos de onda em função da largura da região de depleção, que num DCP pode ser variada em função da tensão reversa aplicada na junção ou através de um trem de pulsos de características adequadas aplicado em sua porta (veja o capítulo 2). As regiões úteis, em termos do valor de $W$, para cada comprimento de onda estão mostradas na tabela 5.3 a seguir. 
Tab. 5.3: Faixa utilizável para os três comprimentos de onda selecionados $\left(x_{j}=0,1 \mu \mathrm{m}\right)$

\begin{tabular}{c|ccc}
\hline & Azul (458 $\mathbf{n m})$ & Verde $(532 \mathrm{~nm})$ & Vermelho $(694 \mathrm{~nm})$ \\
\hline$W_{i}[\mu \mathrm{m}]$ & 1,0 & 1,97 & 12,31 \\
$W_{f}[\mu \mathrm{m}]$ & 1,97 & 12,31 & 20,0 \\
$\eta_{i}$ & 0,88 & 0,89 & 0,96 \\
$\eta_{f}$ & 0,89 & 0,96 & 0,99 \\
\hline
\end{tabular}

Na tabela 5.3, temos que $W_{i}$ é o valor de $W$ a partir do qual o rendimento para aquele comprimento de onda é superior aos demais e $W_{f}$ é o valor final, correspondente ao rendimento máximo $\left(\eta_{f}=\eta_{\max }\right)$, ou seja, o rendimento de um dado comprimento de onda é superior aos outros comprimentos dentro da faixa vai de $W_{i}$ até $W_{f}$.

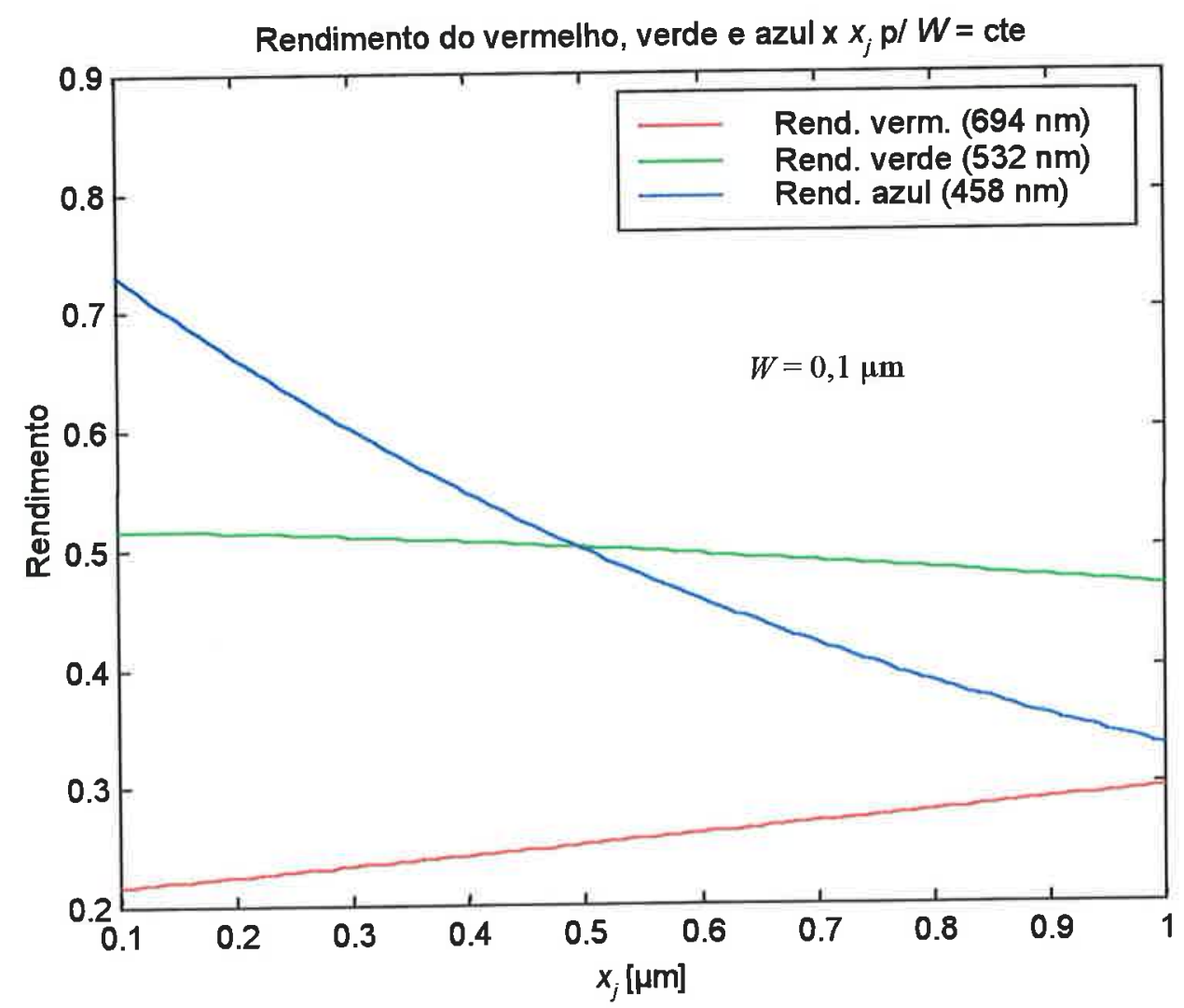

Fig. 5.19: Rendimento por comprimento de onda para $W=0,1 \mu \mathrm{m}$ 


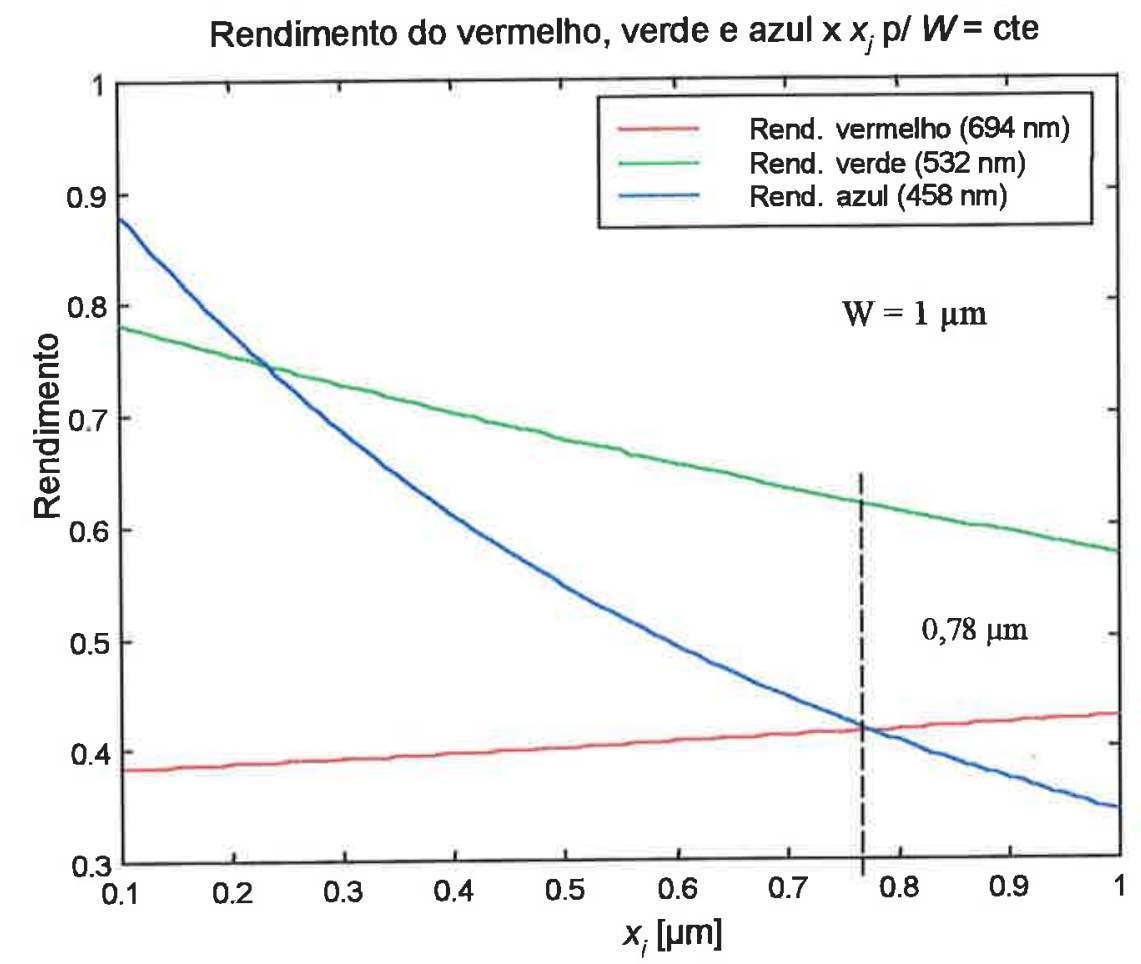

Fig. 5.20: Rendimento por comprimento de onda para $W=1,0 \mu \mathrm{m}$

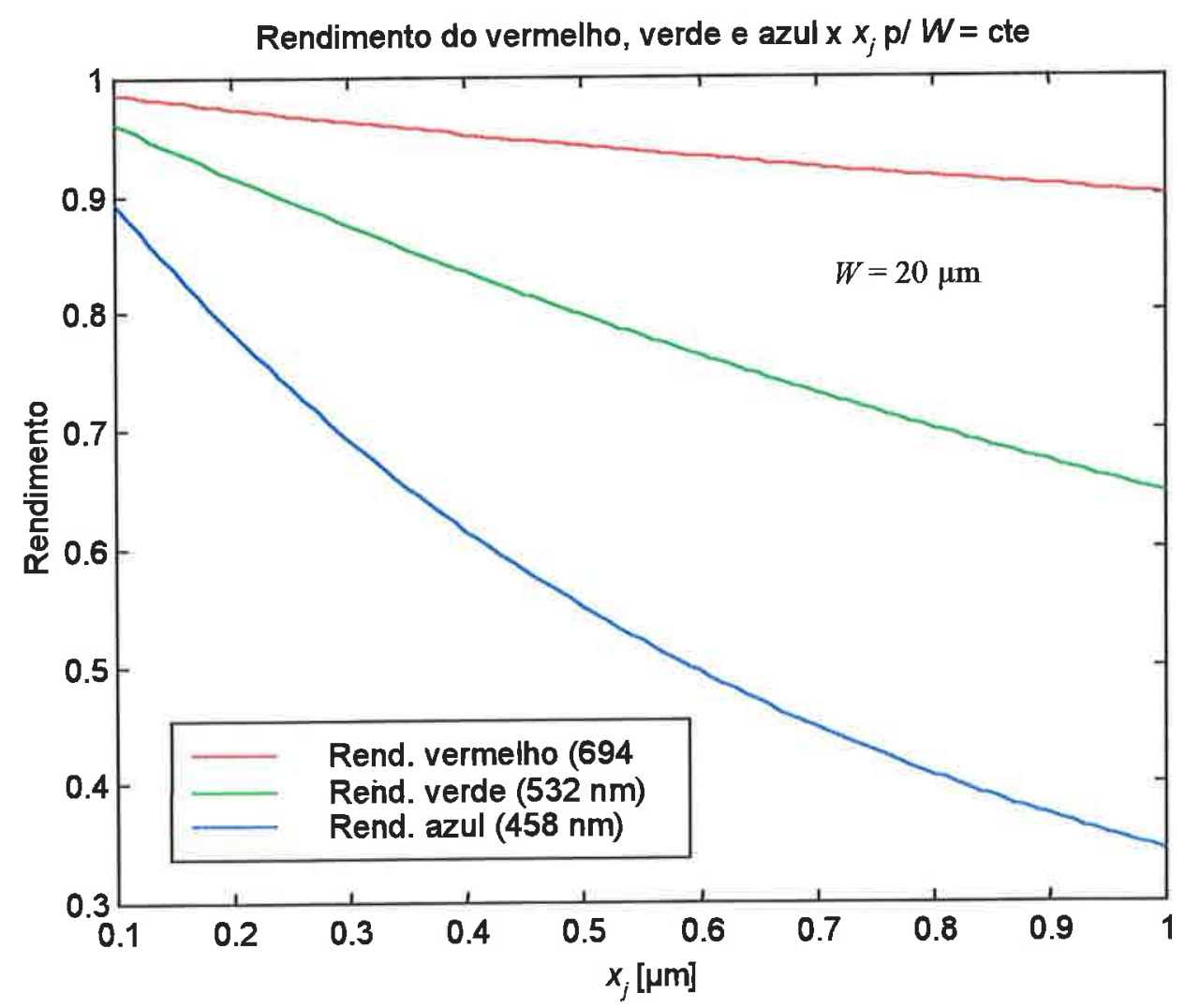

Fig. 5.21: Rendimento por comprimento de onda para $W=20,0 \mu \mathrm{m}$ 
Os valores de $W$ apresentados na tabela 5.3, trazem-nos, no entanto, algumas restrições de projeto já que para alcançarmos grandes profundidades de depleção, tais como 10,0 $\mu \mathrm{m}$, precisaremos de substratos pouquíssimo dopados $\left(<1 \cdot 10^{14} \mathrm{~cm}^{-3}\right)$.

As figuras 5.19 a 5.21 mostram o rendimento como função agora da profundidade de junção parametrizada nos comprimentos de onda de $694 \mathrm{~nm}$ (vermelho), $532 \mathrm{~nm}$ (verde) e $458 \mathrm{~nm}$ (azul), considerando $W=1 \mu \mathrm{m}$ (figura 5.19), $W=$ $5 \mu \mathrm{m}$ (figura 5.20) e $W=20 \mu \mathrm{m}$ (figura 5.21). Observa-se, de forma geral, a diminuição do rendimento a medida que $x_{j}$ aumenta.

Da figura 5.21, é fácil concluir que um filtro capaz de selecionar apenas o "vermelho" pode ser obtido fazendo-se a profundidade de junção grande (por exemplo, $x_{j} \geq 1 \mu \mathrm{m}$ ) para $W=20 \mu \mathrm{m}$. Na situação em que $x_{j} \geq 1 \mu \mathrm{m}$, para $W=20 \mu \mathrm{m}$, temos $\eta_{\text {verde }}$ $<0,72 \cdot \eta_{\text {vermelho }}$ e $\eta_{a z u l}<0,38 \cdot \eta_{\text {vermelho. }}$

Da figura 5.20, verifica-se que para se ter um filtro capaz de selecionar apenas o "verde", basta fazer $x_{j}=0,78 \mu \mathrm{m}$ para $W=1 \mu \mathrm{m}$. Neste caso temos $\eta_{\text {iermellho }}=\eta_{\text {azul }}<$ $0,68 \cdot \eta_{\text {verde }}$

Finalmente, para selecionar apenas o "azul", deveríamos ter $x_{j}=0,1 \mu \mathrm{m}$ e $W=$ $0,1 \mu \mathrm{m}$ de acordo com as simulações (figura 5.19). Neste caso temos $\eta_{\text {verde }}<0,71 \cdot \eta_{\text {azul }}$ e $\eta_{\text {vermelho }}<0,30 \cdot \eta_{\text {azul }}$.

Observe que o critério empregado anteriormente refere-se apenas aos comprimentos de onda fixos de $458 \mathrm{~nm}, 532 \mathrm{~nm}$ e $694 \mathrm{~nm}$. Para estabelecer a extinção de dois comprimentos de onda em relação a um dominante, admitimos que isso ocorria quando o rendimento fosse inferior, ou no mínimo igual, a $72 \%$ do rendimento associado ao comprimento de onda dominante.

As informações acima estão sintetizadas na tabela 5.4 a seguir. 
Tab. 5.4: Dados dos filtros para 694, 532 e $458 \mathrm{~nm}$

\begin{tabular}{|c|c|c|c|c|c|c|c|c|}
\hline \multicolumn{3}{|c|}{ Filtro "Vermelho": 694 nm } & \multicolumn{3}{|c|}{ Filtro "Verde": $532 \mathrm{~nm}$} & \multicolumn{3}{|c|}{ Filtro "Azul": $458 \mathrm{~nm}$} \\
\hline \multicolumn{2}{|c|}{$\eta$} & \multirow{2}{*}{$\begin{array}{c}\eta / \eta_{\text {máx }} \\
1,00\end{array}$} & \multicolumn{2}{|c|}{$\eta$} & \multirow{2}{*}{$\begin{array}{c}\eta / \eta_{\max x} \\
0,68\end{array}$} & \multicolumn{2}{|c|}{$\eta$} & \multirow{2}{*}{$\begin{array}{c}\eta / \eta_{\text {max }} \\
0,30\end{array}$} \\
\hline$\eta_{\text {vermelho }}$ & 0,90 & & $\eta_{\text {vermelho }}$ & 0,42 & & $\eta_{\text {vermelho }}$ & 0,22 & \\
\hline$\eta_{\text {verde }}$ & 0,65 & 0,72 & $\eta_{\text {verde }}$ & 0,62 & 1,00 & $\eta_{i e r d e}$ & 0,52 & 0,71 \\
\hline$\eta_{a z u l}$ & 0,34 & 0,38 & $\eta_{a z u l}$ & 0,42 & 0,68 & $\eta_{\text {czul }}$ & 0,73 & 1,00 \\
\hline \multicolumn{3}{|c|}{$x_{j}=1,0 \mu \mathrm{m}$ e $W=20 \mu \mathrm{m}$} & \multicolumn{3}{|c|}{$x_{j}=0,78 \mu \mathrm{m} \mathrm{e} W=1 \mu \mathrm{m}$} & \multicolumn{3}{|c|}{$x_{j}=0,1 \mu \mathrm{m}$ e $W=0,1 \mu \mathrm{m}$} \\
\hline
\end{tabular}

A equação 5.1.1-13 [GROV'67] nos dá uma aproximação do quanto podemos estender a região de depleção além da largura máxima, onde $\Delta V$ é a altura do pulso aplicado à porta do DCP, sendo ela limitada pelo rompimento da rigidez dielétrica do óxido de porta.

$$
W_{\max }=\sqrt{\frac{2 \cdot \varepsilon_{S i}}{q} \cdot\left(\frac{1}{N_{B}}\right) \cdot\left(2 \cdot \Phi_{F}+\Delta V\right)}
$$

onde $\Phi_{F}$ é o potencial de Fermi, $N_{B}$ é a dopagem do substrato, $q$ a carga do elétron e $\varepsilon_{S i}$ é a permissividade do silício.

Através das simulações com MATLAB ${ }^{\circledR}$, ficou demonstrado que o DCP pode ser empregado como um elemento de rendimento diferenciado para comprimentos de onda na região do visível, sendo para isso necessário, deteriorarmos o tempo de vida médio dos portadores minoritários, reduzindo-se assim, o tamanho da região quaseneutra de superfície. Em assim procedendo, teremos um comportamento do tipo filtro seletivo, mais adequado para selecionar comprimentos de onda específicos. 


\subsection{2 - Simulações elétricas}

Antes da construção física de qualquer protótipo faz-se necessária uma etapa prévia de simulação onde procura-se prever o comportamento do dispositivo final quer do ponto de vista de processos, tais como profundidades de junção, espessura de óxidos, etc., como também do ponto de vista do seu comportamento elétrico.

Infelizmente nunca é possível predizermos o comportamento real que o dispositivo apresentará ficando-se assim restritos à fidelidade do modelo frente ao objeto modelado.

Quando as simulações a serem realizadas envolvem a simulação de comportamentos transitórios tal qual a depleção profunda, torna-se difícil o uso dos simuladores comerciais onde o custo dos módulos específicos podem ser proibitivamente altos e o tempo de aprendizado na utilização pode ser grande. Nesse caso justifica-se a elaboração de um software dedicado ao problema em particular.

Para a presente etapa desse trabalho, foi desenvolvido o software DCPSim em linguagem $\mathrm{C}$, que resolve a equação de Poisson unidimensionalmente para estruturas MOS, substrato $\mathrm{N}$, onde a porta é polarizada com uma certa tensão $V_{\text {inicickl }}$ e sobre a qual é aplicado um pulso de amplitude $\Delta V$, chegando-se a $V_{\text {finul }}$, como indicado na figura 5.22 . 


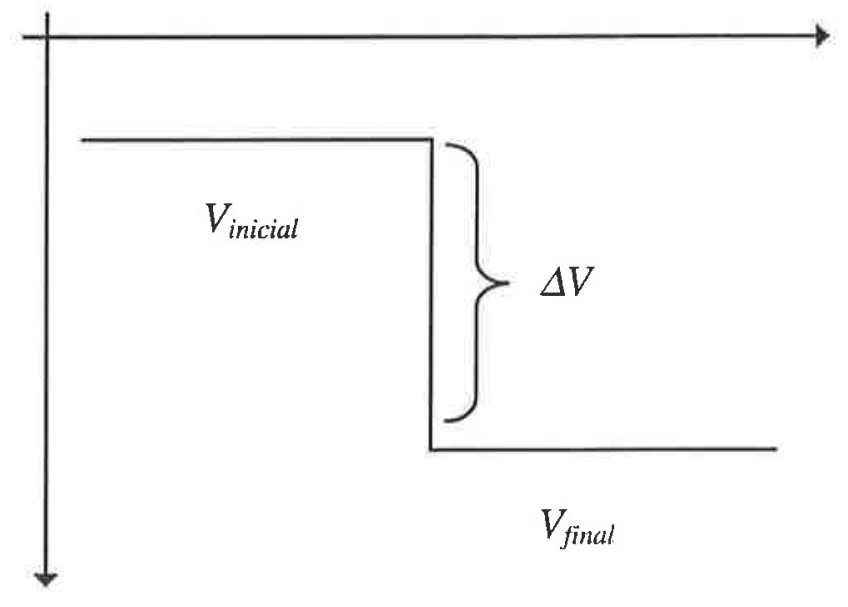

Fig. 5.22: Convenção adotada no software DCPSim

O efeito do pulso de tensão é modelado, definindo-se um nível de quase-Fermi ([STRE'95], [PIER'74]) que, por simplicidade, é mantido constante ao longo de todo o corpo do semicondutor e que tem por efeito depletar lacunas (portadores minoritários de carga).

O objetivo inicial das simulações feitas pelo DCPSim foi o de observar o comportamento de estruturas MOS no regime de depleção profunda, determinando-se a máxima largura da região de depleção que pode ser atingida.

A seguir veremos em maiores detalhes o funcionamento desse software.

A simulação para semicondutores envolve a resolução, pelo menos, da equação de Poisson (5.1.2-1) discretizada sobre o domínio do problema.

$$
\operatorname{div} \cdot \operatorname{grad} \psi=-\frac{q \cdot\left(N_{D}-N_{A}+p-n\right)}{\varepsilon_{S}}
$$

onde $n$ é a concentração de elétrons, $p$ a de lacunas, $N_{D}$ é a concentração de doadores, $N_{A}$ é a concentração de aceitadores, $\psi$ é o potencial elétrico e $\varepsilon_{S}$ é a permissividade do semicondutor. 
Para a resolução numérica da equação 5.1.2-1, algumas manipulações algébricas são necessárias, tais como a substituição do operador derivada por uma aproximação por diferenças, conforme proposto por Selberher [SELB'84]:

$$
\psi_{i}=\frac{\psi_{i+1}+\psi_{i-1}}{2}+\frac{q \cdot h^{2}}{2 \cdot \varepsilon_{S}} \cdot(p-n+C)
$$

que é a equação de Poisson discretizada para uma dimensão, $C$ é a diferença entre as concentrações de doadores e aceitadores e $h$ é o passo de discretização do domínio, no nosso caso o mesmo foi escolhido igual a $1 / 200$ do valor do $W_{\text {mixix }}$ teórico, dado pela equação 5.1.2-3. A escolha deste passo muito pequeno permitiu-nos sempre uma precisão muito boa no cálculo da distribuição de potencial. Também escolhemos $N_{B}=$ $N_{D}-N_{A}=1 \cdot 10^{14} \mathrm{~cm}^{-3}$, o que resultou num $W_{\text {máx }}=2,45 \mu \mathrm{m}$.

$$
W_{\text {max }}=\sqrt{\frac{2 \cdot \varepsilon_{S i} \cdot 2 \cdot \Phi_{F}}{q \cdot N_{B}}}
$$

O software DCPSim foi implementado para resolver a equação de Poisson iterativamente sobre um conjunto de 850 pontos, onde 50 compõem o óxido, de espessura de $30 \mathrm{~nm}$, e os demais 800 estendem-se até a uma profundidade equivalente a 4 vezes o valor de $W_{\text {máx }}$.

Para cada ponto, após o cálculo do potencial, foram obtidos, através das equações (5.1.2-4a) e (5.1.2-4b) os valores das concentrações de portadores. Para lacunas (minoritários) levou-se em conta o nível de quase-Fermi conforme definido no capítulo 2. 


$$
\begin{gathered}
n=n_{i} \cdot e^{\frac{q \cdot\left(\psi-\Phi_{F}\right)}{k \cdot T}} \\
p=n_{i} \cdot e^{\frac{-q \cdot\left(\psi-\Phi_{F}+\Phi_{U F}\right)}{k \cdot T}}
\end{gathered}
$$

onde $\psi$ é considerado nulo no substrato, $\Phi_{F}$ é o potencial de Fermi e $\Phi_{Q F}=\Delta V$ é a distância em tensão entre o nível de quase-Fermi e o nível intrínseco (veja figura 2.7 (b) que ilustra o caso para substrato $\mathrm{P})$.

A resolução, seguidamente, da equação de Poisson e das equações 5.12-4a e 5.12-4b converge para um valor de equilíbrio tanto para o perfil de potencial em profundidade quanto para a concentração de portadores.

A partir dos valores de potencial, foi também calculado o campo elétrico ao longo da profundidade do semicondutor, substituindo-se a derivada (gradiente) pela seguinte equação de diferenças:

$$
E_{i}=-\left(\frac{\psi_{i+1}-\psi_{i}}{h}\right)
$$

O diagrama em blocos da figura 5.23 ilustra o funcionamento do software DCPSim. 


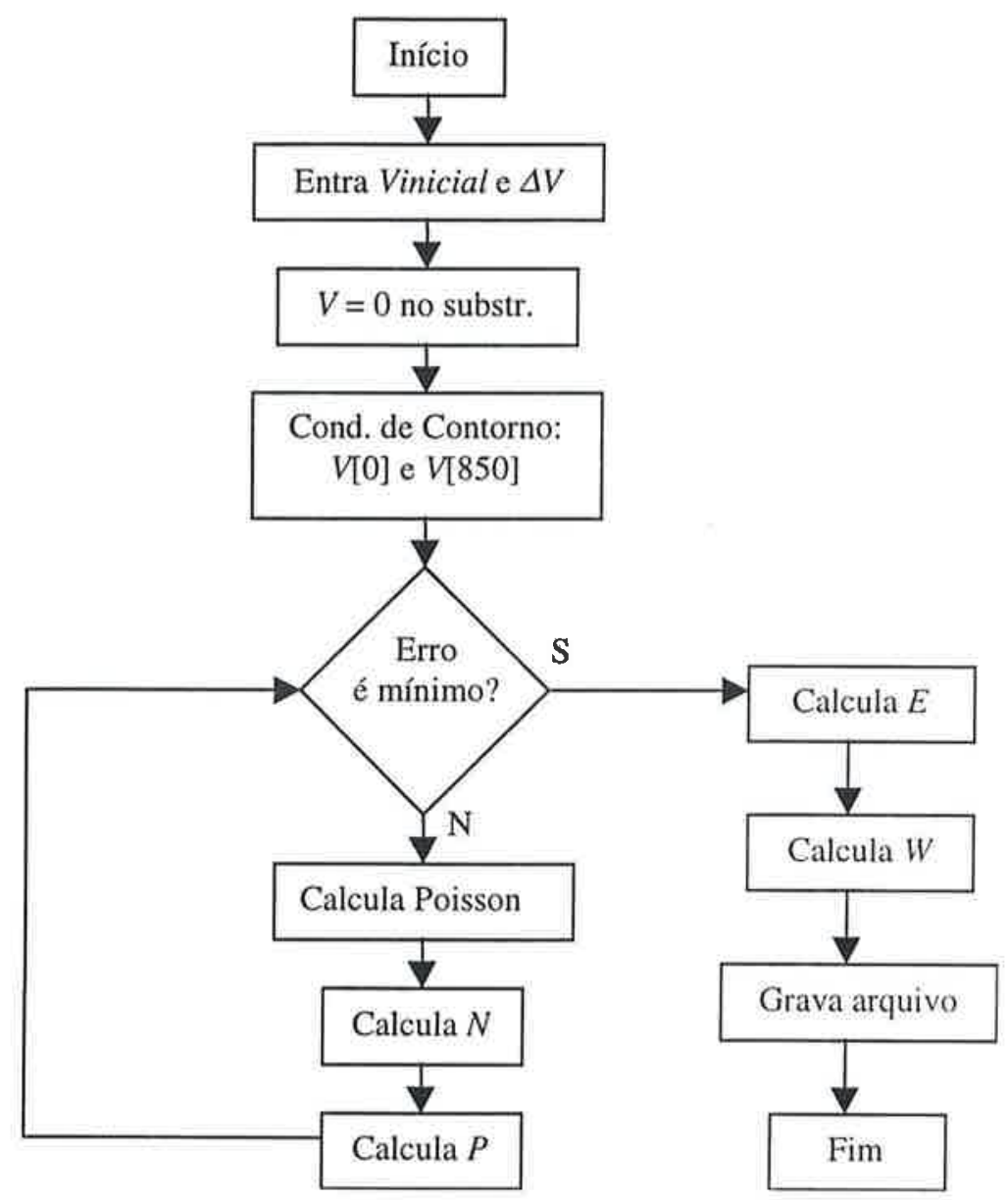

Fig. 5.23: Fluxograma do software DCPSim

A seguir, apresentaremos alguns resultados obtidos a partir das simulações.

Os gráficos das figuras 5.24 a 5.32 a seguir apresentam, para uma lâmina tipo $\mathrm{N}$ com $N_{B}=1 \cdot 10^{14} \mathrm{~cm}^{-3}$, os perfis de campo elétrico, potencial e concentração de portadores para diversas condições de polarização de porta e também para a aplicação de degraus de tensão na mesma da inversão fraca para a inversão forte. 


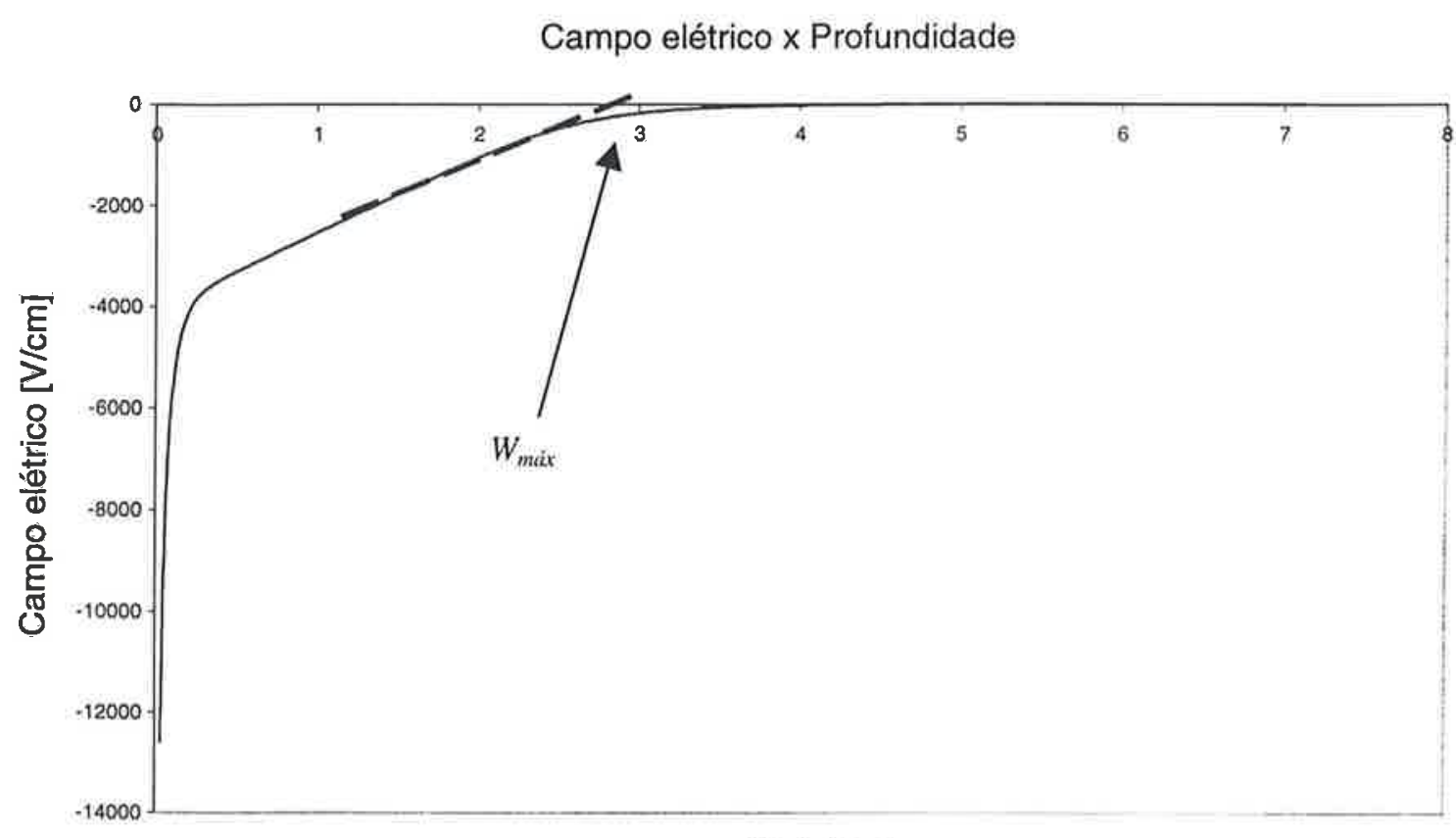

Prof. $[\mu \mathrm{m}]$

Fig. 5.24: Campo elétrico $\times$ Profundidade para $V_{\text {intical }}=-3,0 \mathrm{~V}$ e $\Delta V=0,0 \mathrm{~V}$

\section{Potencial x Profundidade}

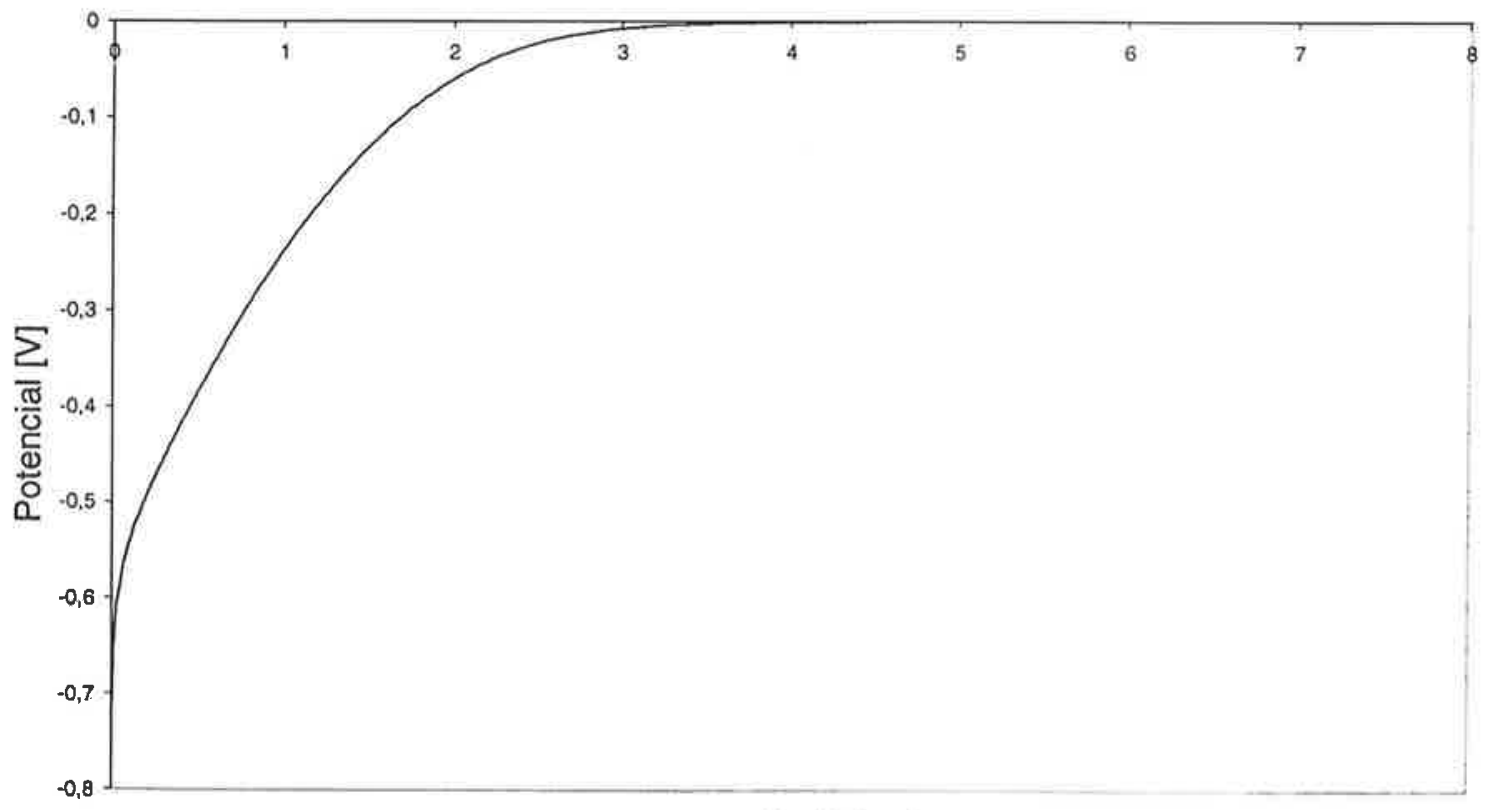

Prof. $[\mu \mathrm{m}]$

Fig. 5.25: Potencial $x$ Profundidade para $V_{\text {iniciul }}=-3,0 \mathrm{~V}$ e $\Delta V=0,0 \mathrm{~V}$ 
Concentração de portadores

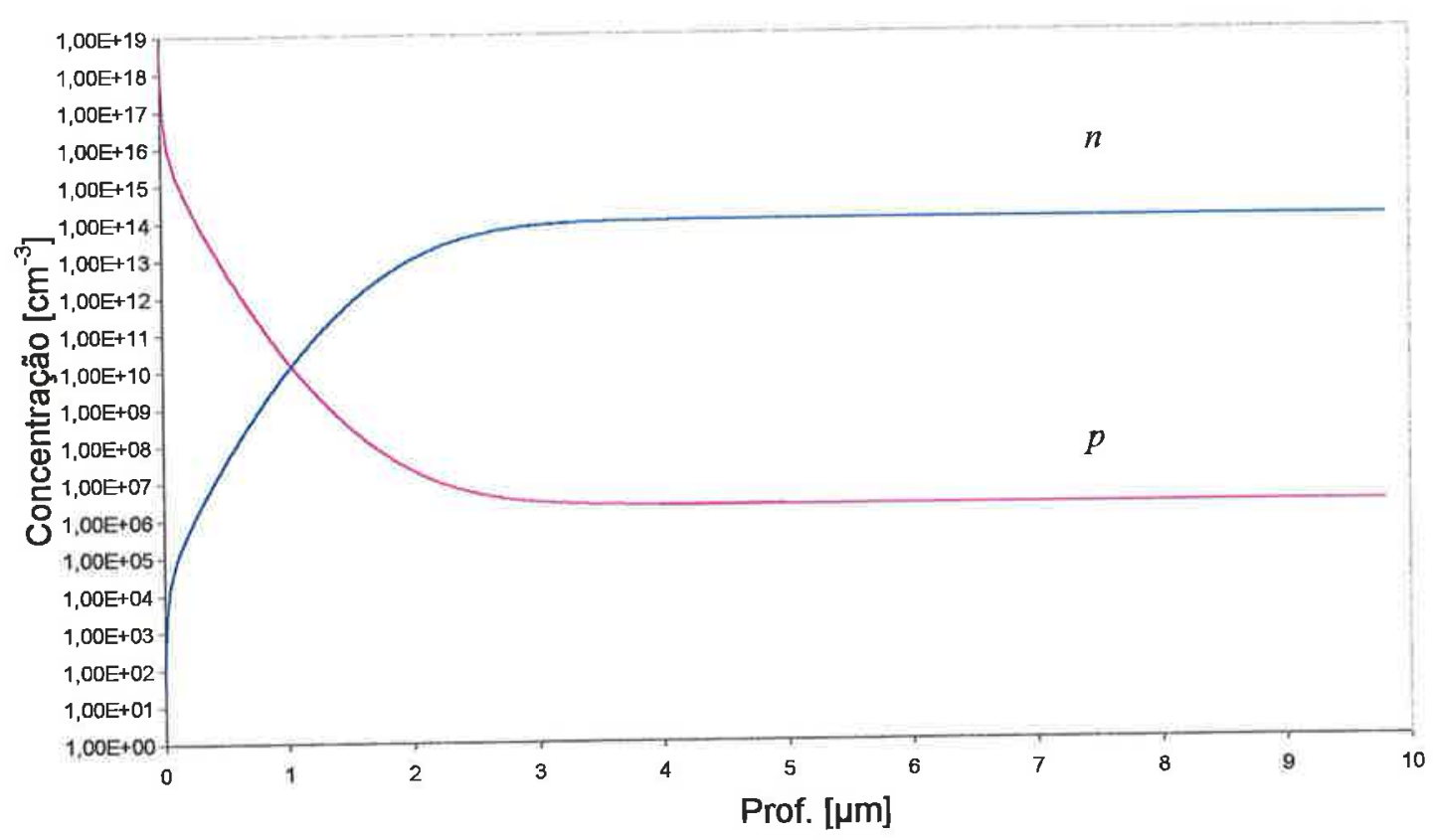

Fig. 5.26: Concentração de portadores x Profundidade para $V_{\text {inicial }}=-3,0 \mathrm{~V}$ e $\Delta V=0,0 \mathrm{~V}$

Nos gráficos das figuras 5.24, 5.25 e 5.26, temos os gráficos de Campo elétrico, Potencial e Concentração de portadores em função da Profundidade para $V_{\text {inicial }}=-3,0 \mathrm{~V}$ e $\Delta V=0,0$ V. Para esses valores de tensão aplicadas, a estrutura MOS encontra-se em inversão, como se pode ver pelo gráfico de portadores (figura 5.26). Neste caso, a região de depleção é aproximadamente igual ao valor máximo teórico de $2,45 \mu \mathrm{m}$ (veja figura 5.24).

Agora, se para o mesmo valor de $V_{\text {inicial }}=-3,0 \mathrm{~V}$, aplicarmos um degrau de amplitude $\Delta V=-10,0 \mathrm{~V}$, poderemos levar a largura da região de depleção a um valor maior que o previsto para o caso não pulsado.

Isso é o que vemos nos gráficos das figuras $5.27,5.28$ e 5.29 a seguir, onde a única diferença para o caso anterior é a presença de um degrau de tensão de -10,0 V. 


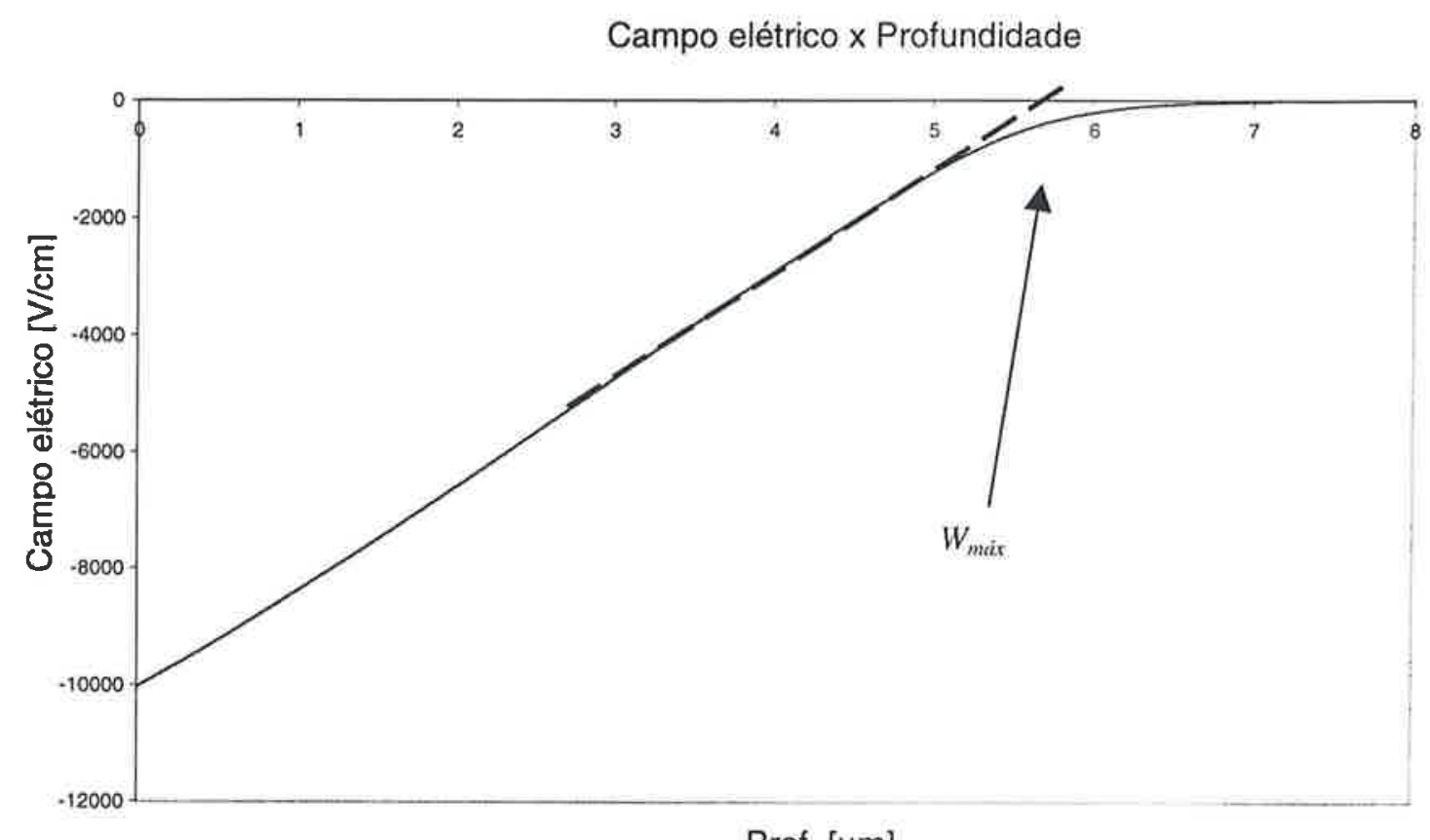

Prof. $[\mu \mathrm{m}]$

Fig. 5.27: Campo elétrico $x$ Profundidade para $V_{\text {iniciat }}=-3,0 \mathrm{~V}$ e $\Delta V=-10.0 \mathrm{~V}$

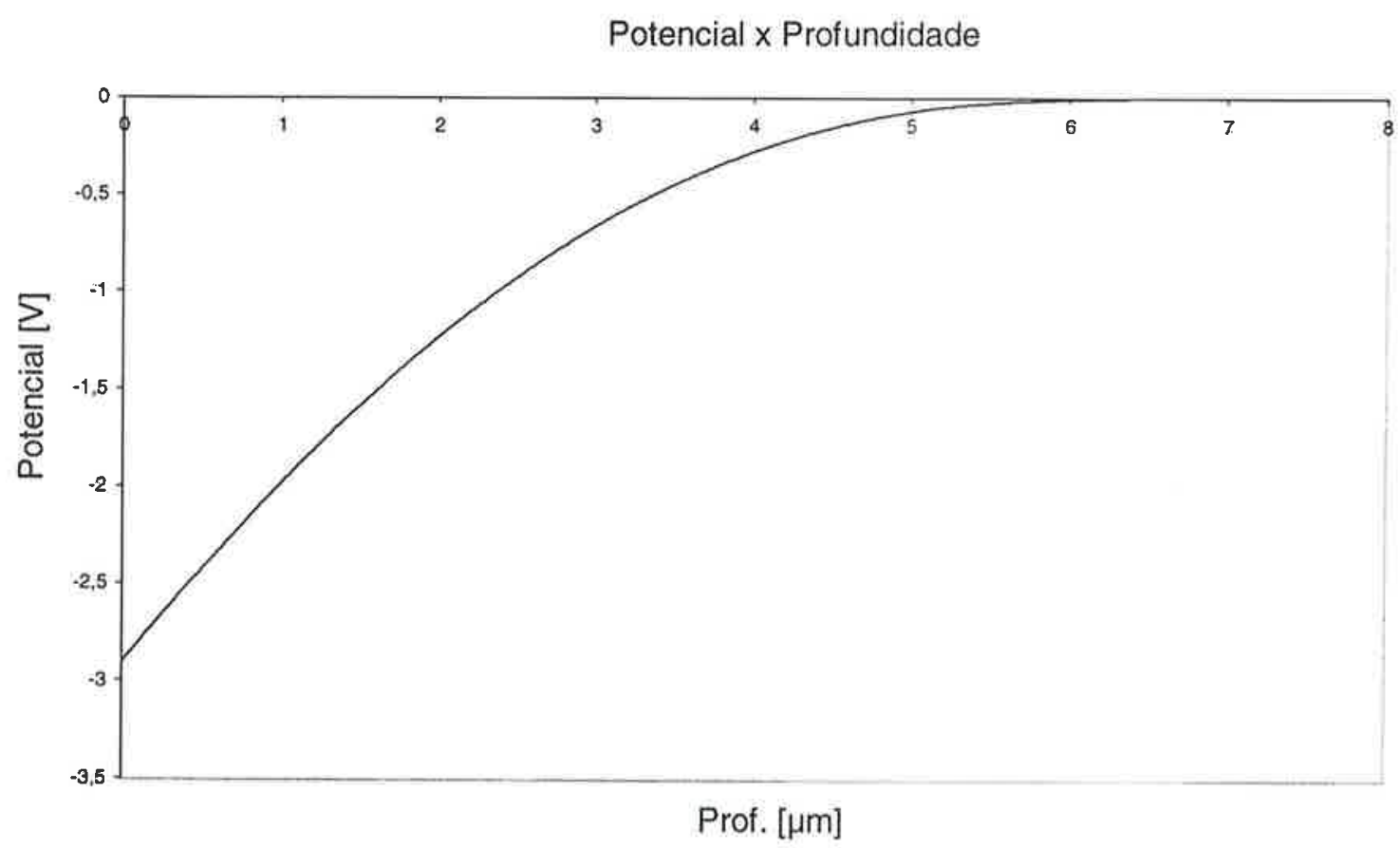

Fig. 5.28: Potencial $x$ Profundidade para $V_{\text {iniciat }}=-3,0 \mathrm{~V}$ e $\Delta V=-10,0 \mathrm{~V}$ 
Concentração de portadores

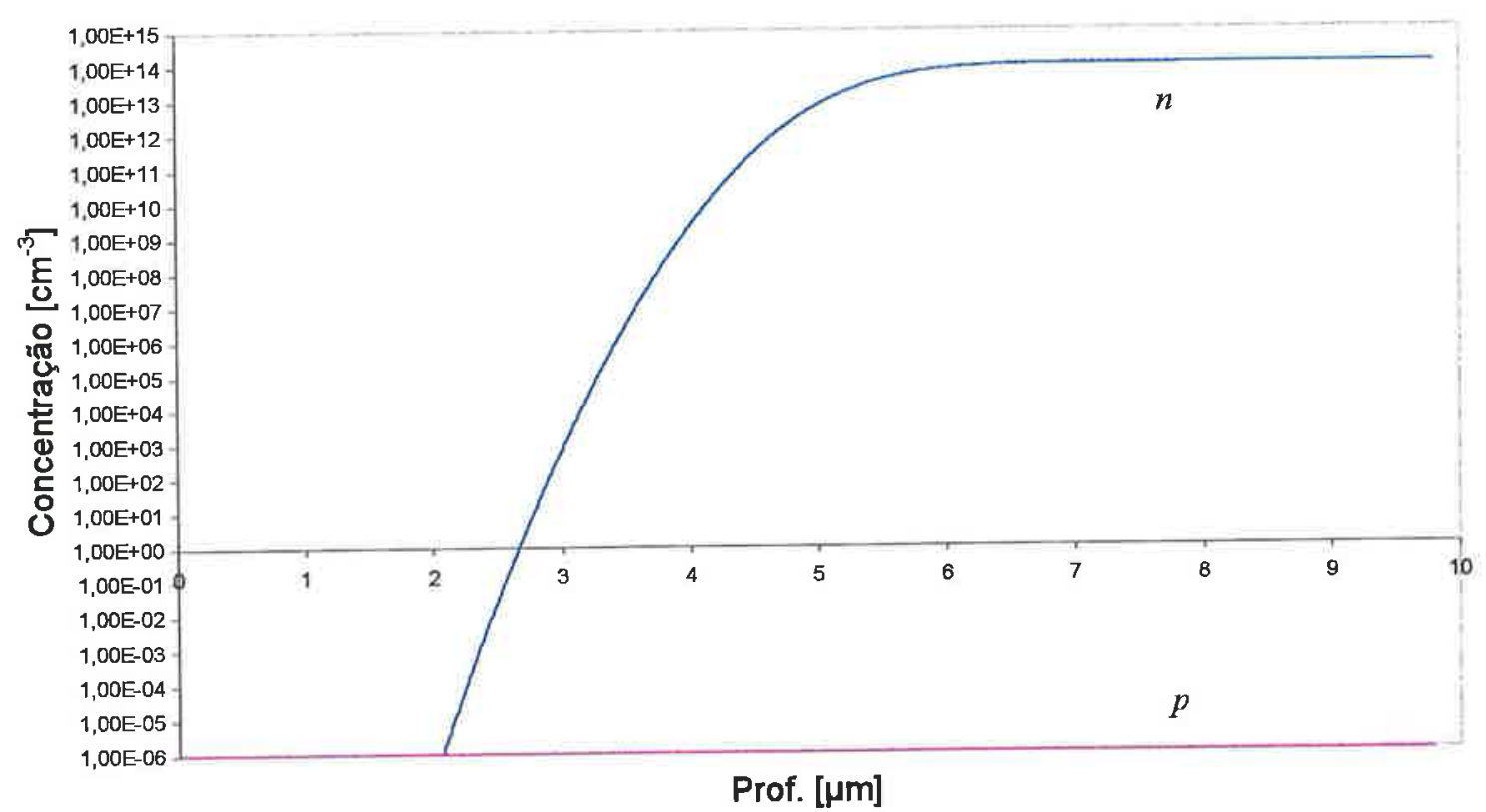

Fig. 5.29: Concentração de portadores x Profundidade para $V_{\text {inicial }}=-3,0 \mathrm{~V}$ e $\Delta V=-10,0 \mathrm{~V}$

No gráfico da figura 5.29, ou seja, Concentração de portadores x Profundidade, observamos que os portadores majoritários, elétrons, também foram depletados, não restando assim nem elétrons nem lacunas por uma profundidade considerável $(\sim 5,0 \mu \mathrm{m})$ a partir da superficie do substrato.

O que acontece é que, na primeira situação (figuras 5.24, 5.25 e 5.26) o acúmulo de lacunas e a depleção de elétrons foi suficiente para contrabalançar a carga negativa presente na placa superior do capacitor MOS. Já no segundo caso, como o pulso de tensão aplicado é rápido demais para que os portadores minoritários possam responder. Nesse caso é necessário que os majoritários sejam eles também, depletados para manterse o equilíbrio de cargas elétricas no capacitor MOS. Tal é o fenômeno da depleção profunda. 
Os dois casos acima ilustram bem a diferença entre o comportamento da estrutura MOS, polarizada na inversão e quando é aplicado um pulso de tensão em sua porta.

Há, no entanto, mais um fenômeno interessante associado à estrutura MOS pulsada. Trata-se da inversão de sua superfície, mesmo em depleção profunda.

Isso ocorre quando o potencial inicial de porta começa a tornar-se muito negativo, e aí a depleção pura e simples dos majoritários também não é mais suficiente para manter-se o equilíbrio de cargas no capacitor MOS.

As figuras $5.30,5.31$ e 5.32 a seguir, onde $V_{\text {inicial }}=-20,0 \mathrm{~V}$ e $\Delta V=-15,0 \mathrm{~V}$, ilustram o que acabamos de dizer.

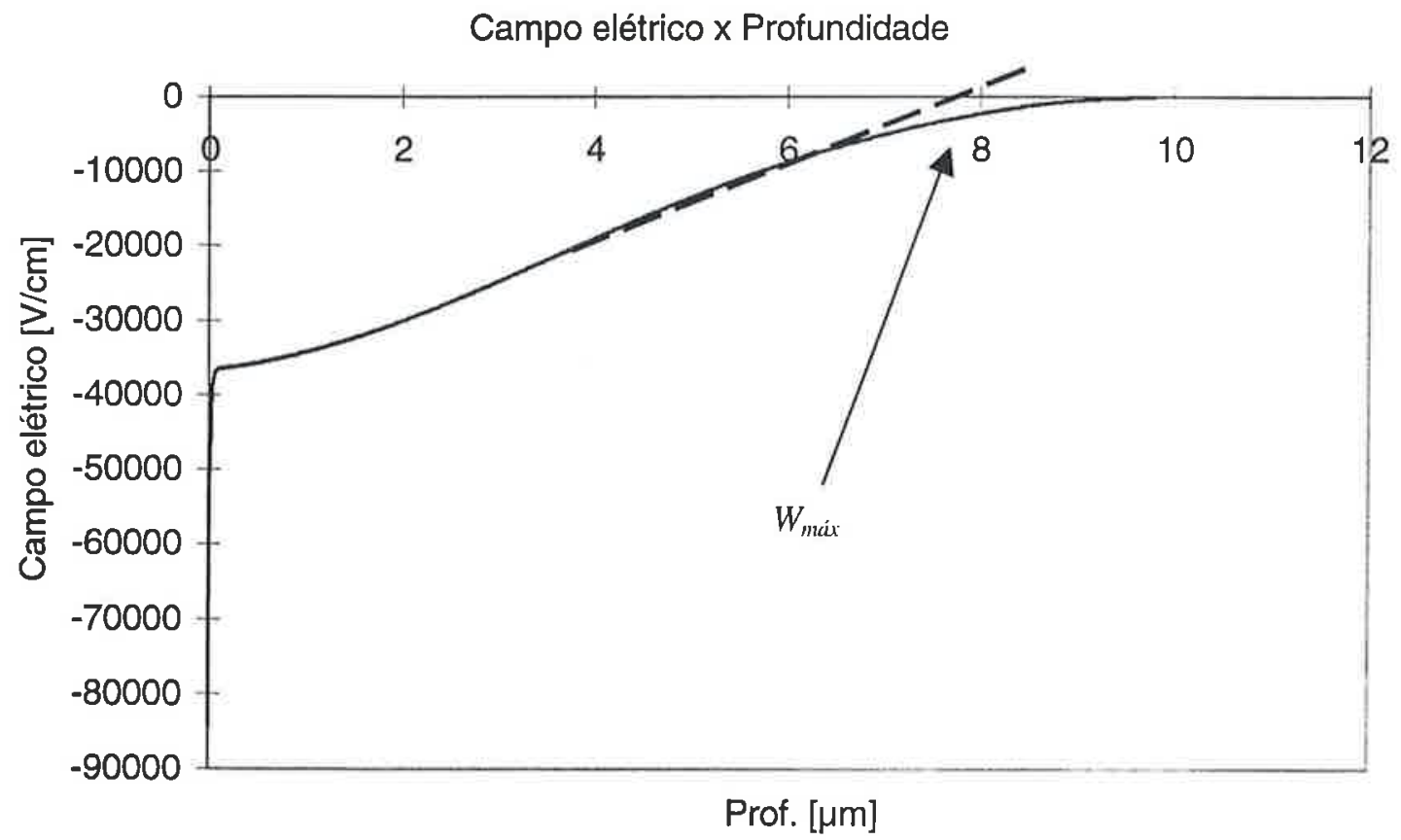

Fig. 5.30: Campo elétrico x Profundidade para $V_{\text {inicicill }}=-20,0 \mathrm{~V}$ e $\Delta V=-15,0 \mathrm{~V}$ 
Potencial x Profundidade

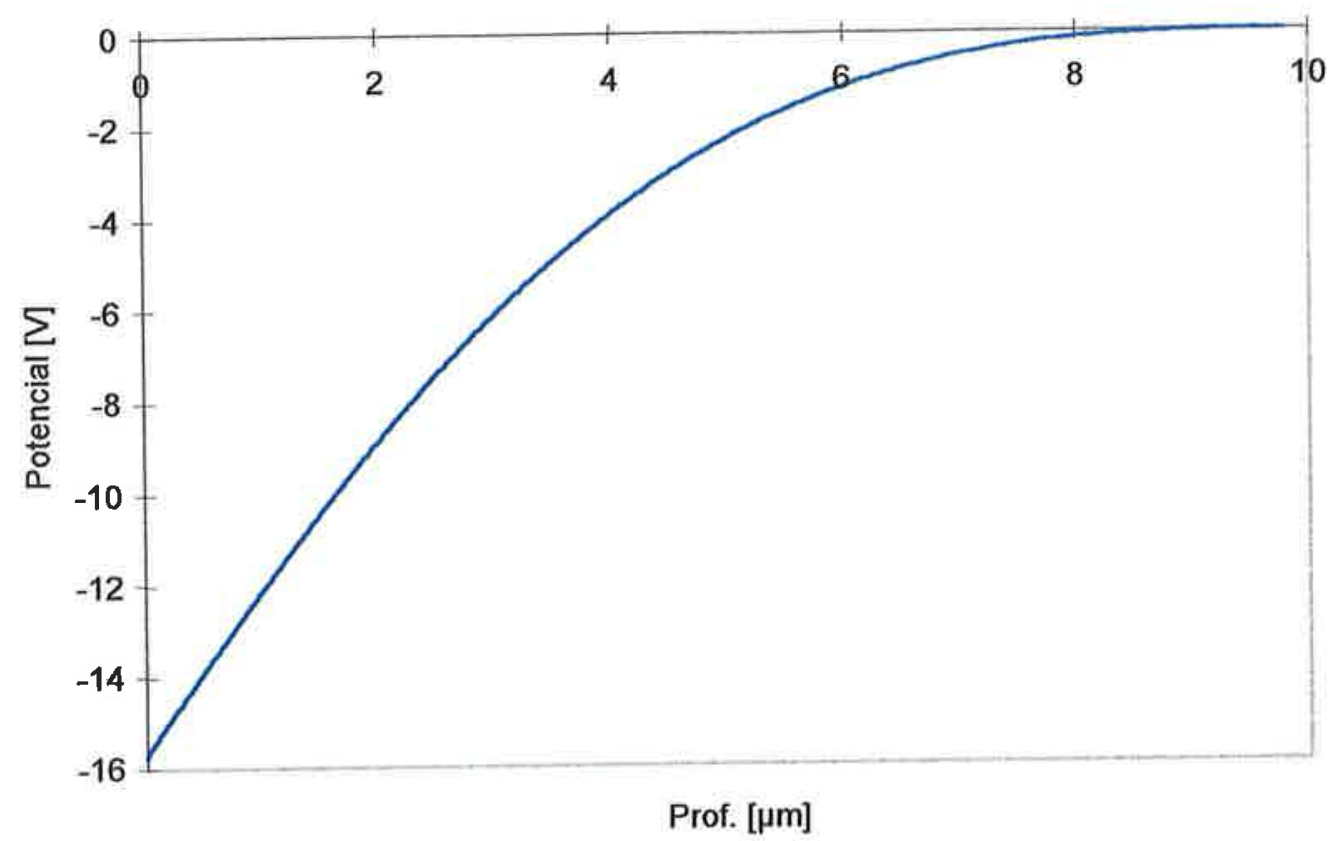

Fig. 5.31: Potencial x Profundidade para $V_{\text {inicial }}=-20,0 \mathrm{~V} \mathrm{e} \Delta V=-15,0 \mathrm{~V}$

\section{Concentração de portadores}

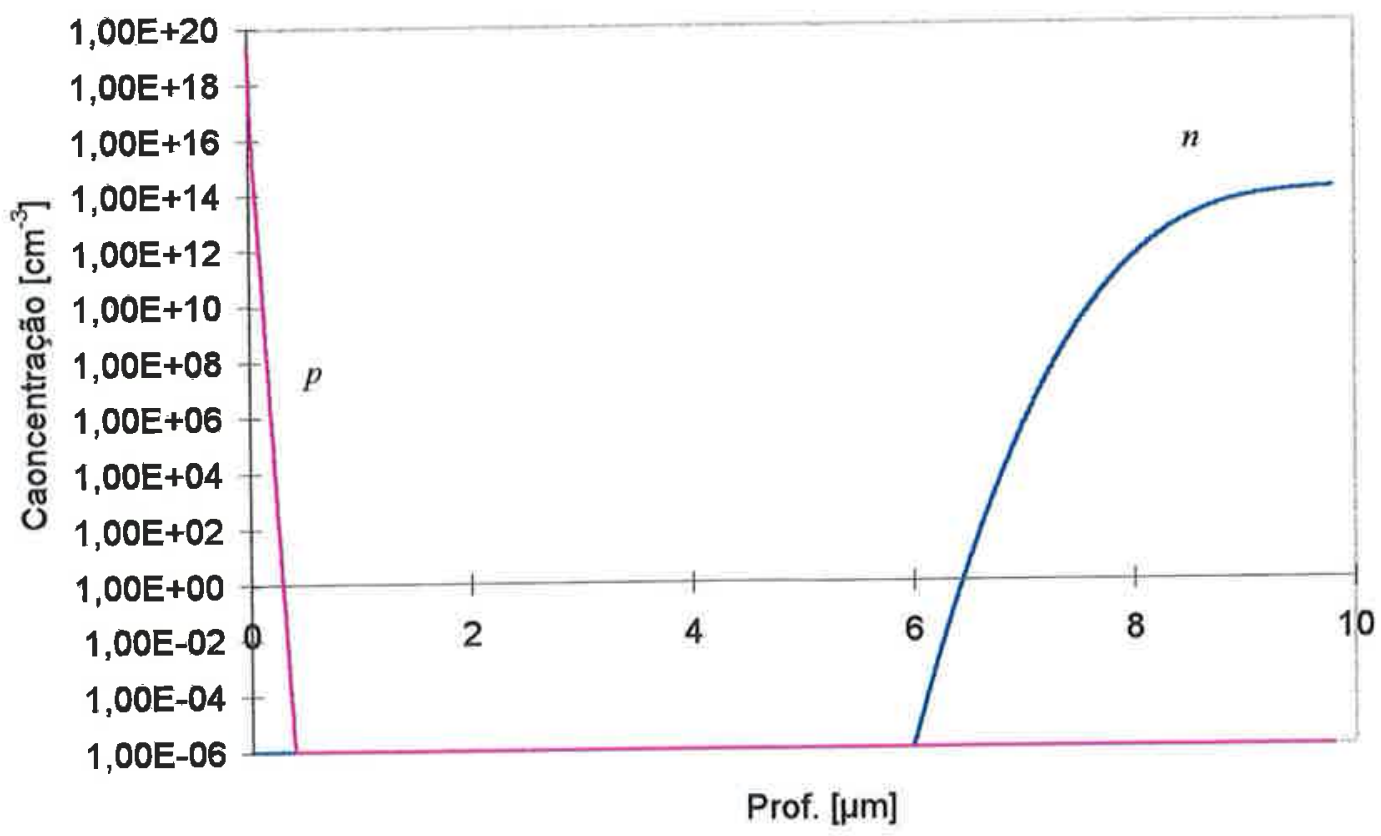

Fig. 5.32: Concentração de portadores $x$ Profundidade para $V_{\text {inicial }}=-20,0 \mathrm{~V}$ e $\Delta V=-15,0 \mathrm{~V}$ 
Do gráfico da figura 5.32 podemos ver que, mesmo estando a população de elétrons depletada em uma grande profundidade $(\sim 8,0 \mu \mathrm{m})$, ainda assim a concentração superficial de lacunas ultrapassa o valor de $1 \cdot 10^{18} \mathrm{~cm}^{-3}$, ou seja, a superfície está em forte inversão.

A largura da região de depleção foi também obtida como função dos potenciais de porta e $\Delta V$ aplicados à estrutura MOS, resultando na tabela 5.5. O método de obtenção da mesma foi o seguinte: a partir do gráfico de campo elétrico x profundidade, extrapola-se a região linear do mesmo anotando-se o valor da intersecção da reta com o eixo da profundidade $(x)$ (veja figura 5.24). O valor aí lido corresponde à largura da região de depleção.

A tabela 5.5 a seguir apresenta o valor da profundidade da região de depleção para vários pares tensão de porta / tensão de degrau.

Tab. 5.5: Valor de $W$, em $\mu \mathrm{m}$, como função do potencial de polarização, $V_{\text {iniciul, }}$ e da amplitude do degrau $\Delta V$. Estruturas em inversão ou depleção profunda

\begin{tabular}{c|ccccc}
\hline & \multicolumn{5}{|c}{$V_{\text {inicial }}[\mathrm{V}]$} \\
\hline$\Delta V[\mathrm{~V}]$ & $-1,0$ & $-2,0$ & $-3,0$ & $-5,0$ & $-10,0$ \\
\hline 0,0 & 2,69 & 2,70 & 2,70 & 2,70 & 2,57 \\
$-1,0$ & 3,49 & 4,48 & 4,49 & 4,49 & 4,45 \\
$-2,0$ & 3,49 & 4,85 & 5,48 & 5,50 & 5,57 \\
$-3,0$ & 3,49 & 4,85 & 5,66 & 6,12 & 6,29 \\
$-5,0$ & 3,49 & 4,85 & 5,66 & 6,57 & 6,88 \\
$-10,0$ & 3,49 & 4,85 & 5,66 & 6,57 & 7,54 \\
$-15,0$ & 3,49 & 4,85 & 5,66 & 6,57 & 7,54 \\
$-20,0$ & 3,49 & 4,85 & 5,66 & 6,57 & 7,54 \\
\hline
\end{tabular}


Observando o valor de $W$ para $\Delta V=0 \mathrm{~V}$ na tabela 5.5 , podemos reparar que o mesmo cresce com o aumento da tensão de polarização mas que para $V_{\text {inicial }}=-10,0 \mathrm{~V}$ o mesmo cai ligeiramente. Esse fenômeno parece estar associado à inversão da superfície, ou seja, ao invertermos a mesma, precisaremos de uma região de depleção menor para ajustarmos o balanço de cargas no capacitor. Isso, no entanto, deixa de ocorrer para $\Delta V$ $\neq 0$, nesse caso, mesmo com inversão de superficie, a região de depleção aumenta cada vez mais com o aumento de $\Delta V$.

Também devemos notar que, para $\Delta V \geq V_{\text {inicial, }}$ o valor de $W$ satura em seu valor máximo, não aumentando para posteriores aumentos da amplitude do pulso.

Os gráficos das figuras $5.33,5.34,5.35$ e 5.36 a seguir, ilustram o que foi dito anteriormente:

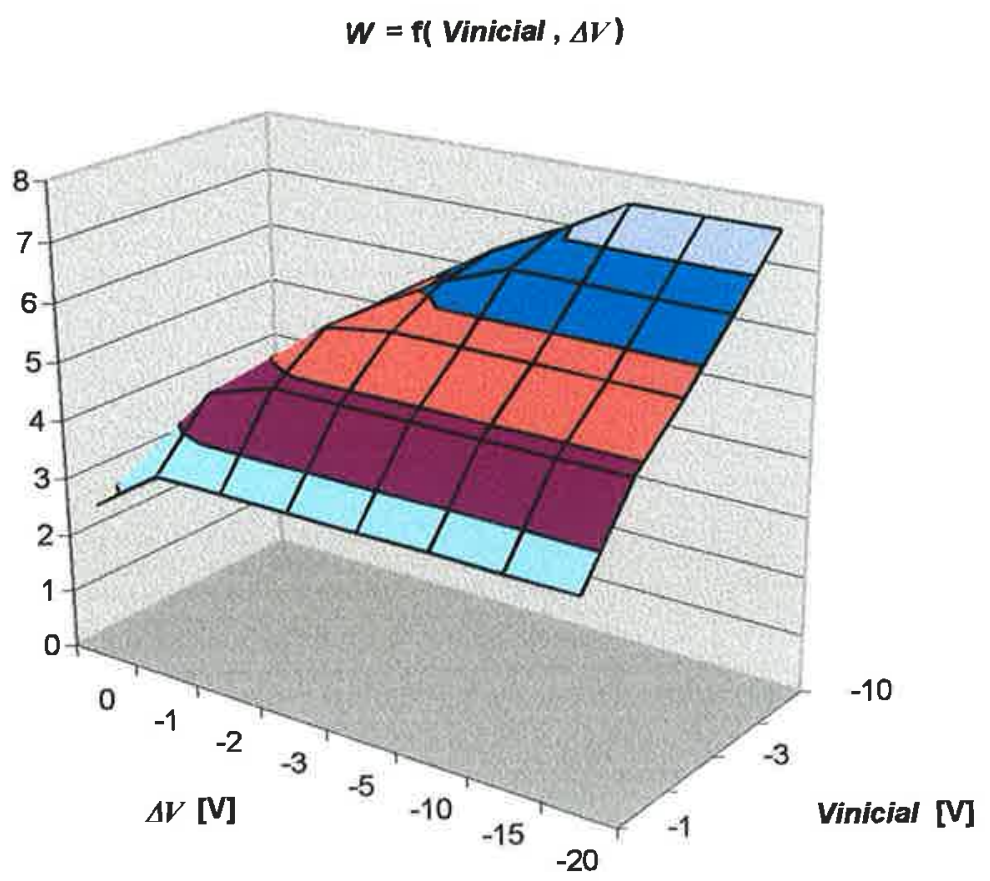

Fig. 5.33: Largura da região de depleção para vários valores de $V_{\text {inicial }} \times \Delta V$ 


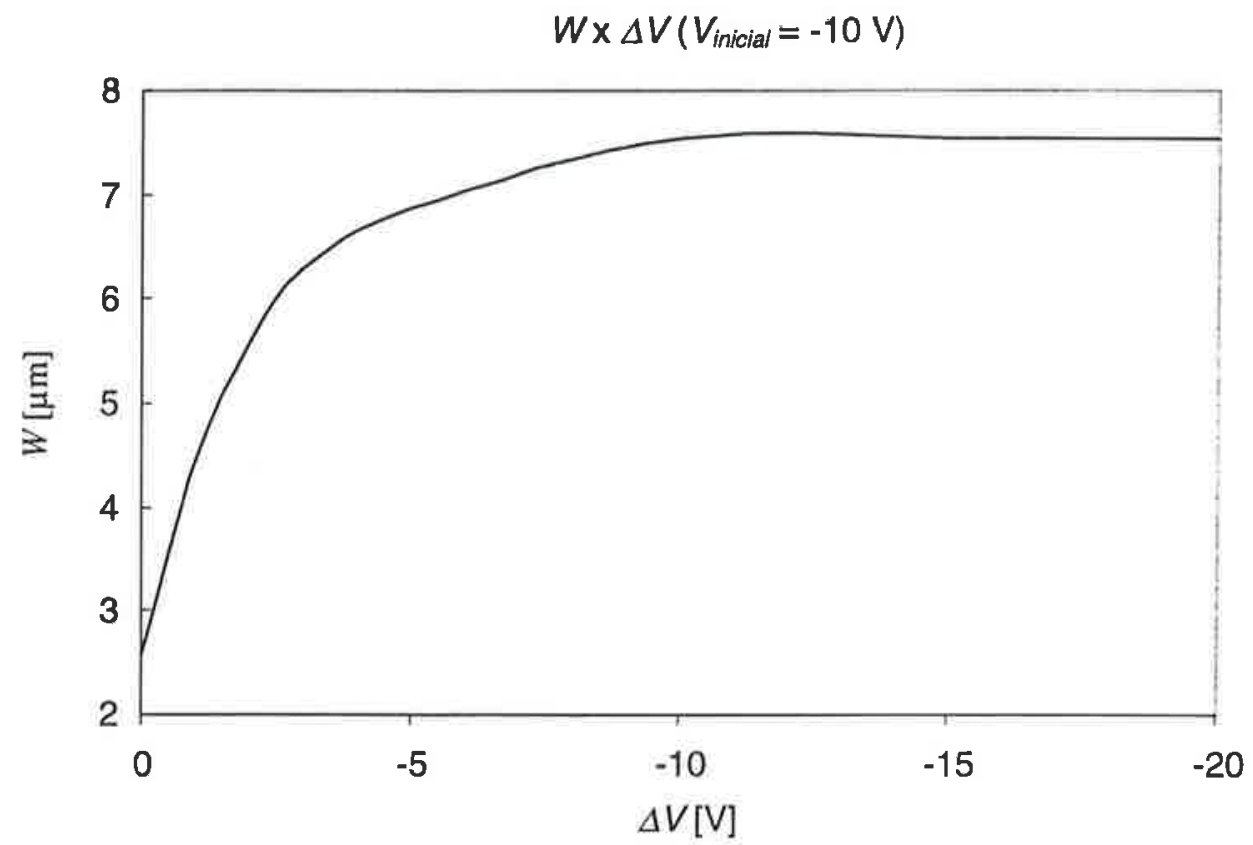

Fig. 5.34: Largura da região de depleção $x$ amplitude de pulso. Note que $W$ satura para $\Delta V \geq V_{\text {inicial }}$

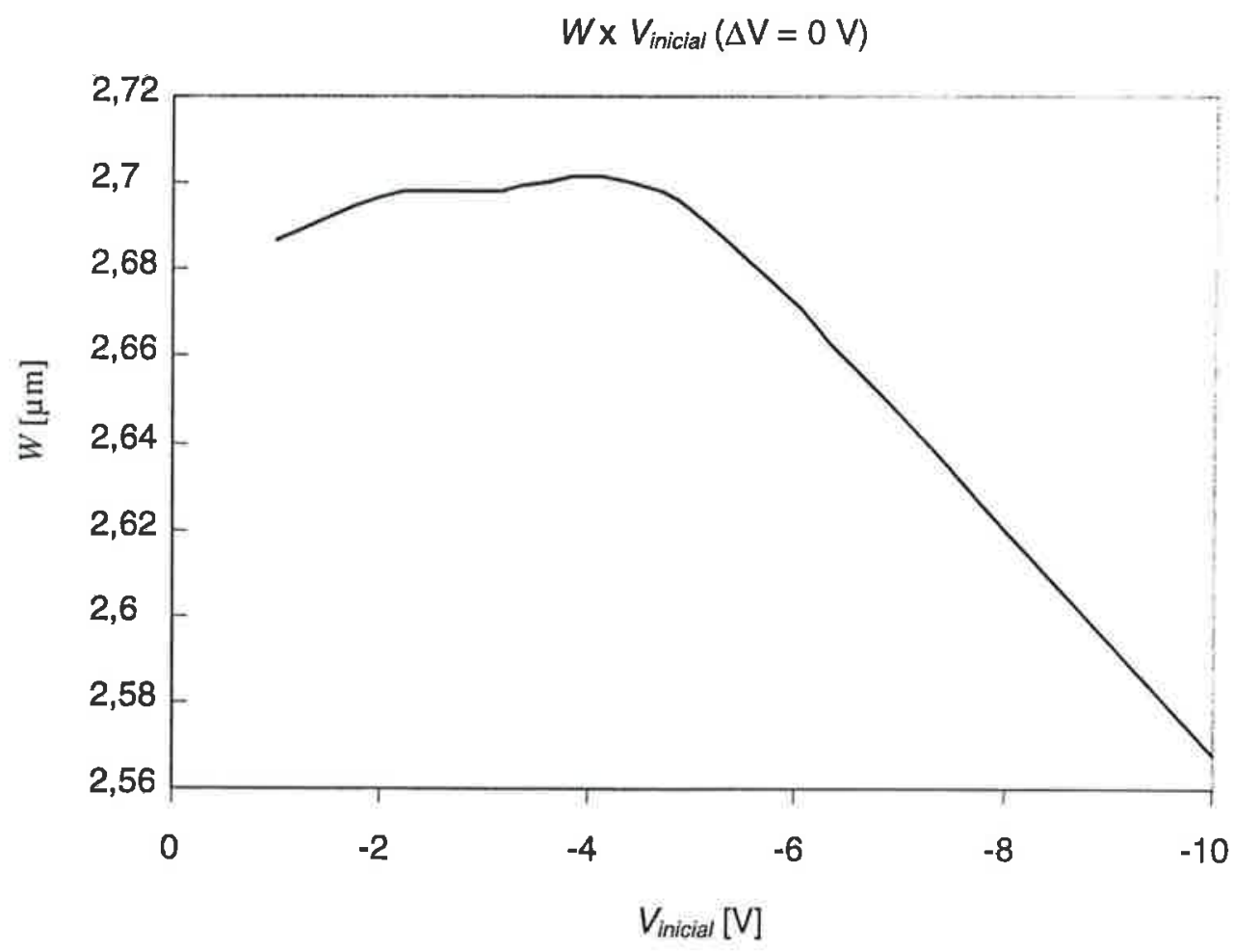

Fig. 5.35: Queda da largura da região de depleção devido à inversão de superfície, sem degrau aplicado 
$W \times V_{\text {inicial }}(\Delta V=-15 V)$

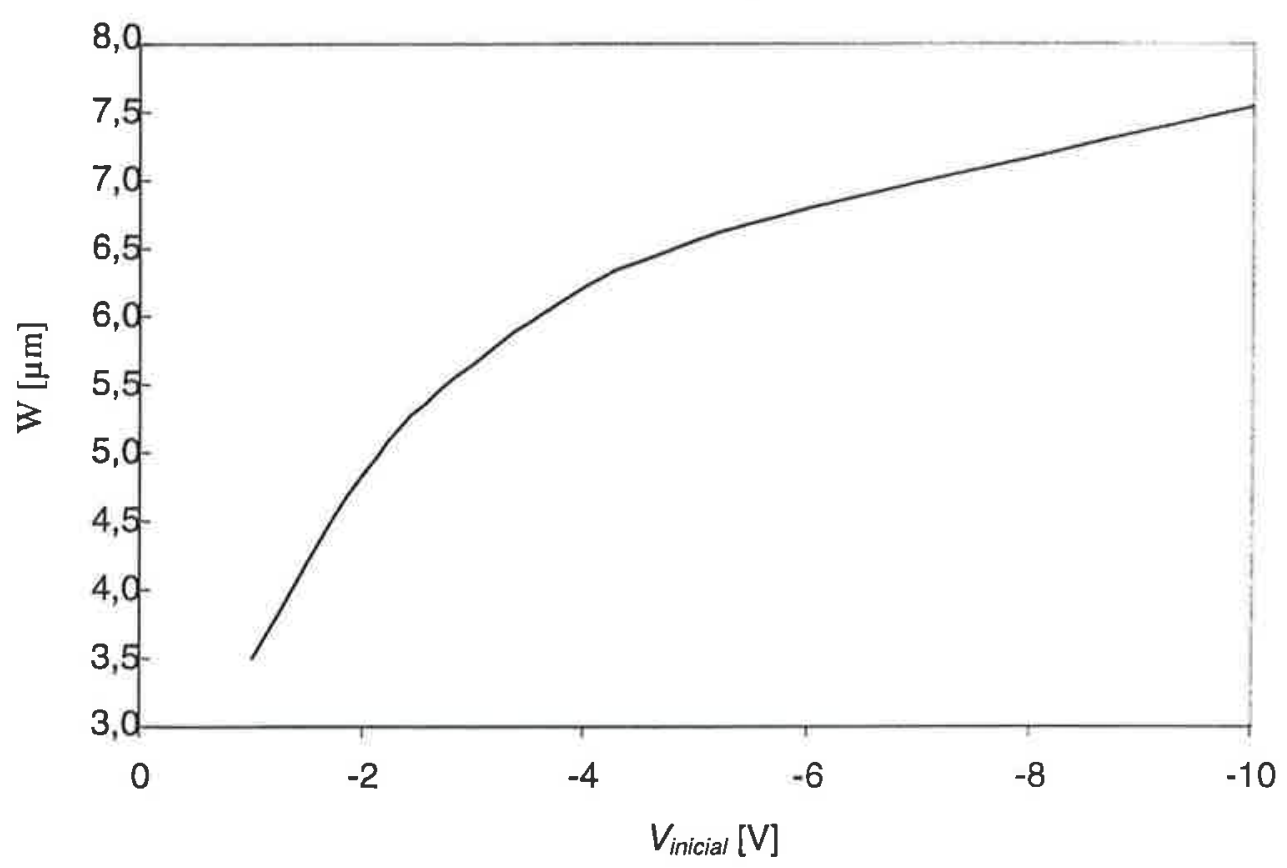

Fig. 5.36: Aumento da largura da região de depleção em função de $V_{\text {inicial }}$ pară $\Delta V=-15,0 \mathrm{~V}$

A figura 5.33 corresponde a um gráfico em três dimensões da tabela 5.5 já apresentada. A figura 5.34 é um corte do gráfico da figura 5.33 para $V_{\text {inicial }}=-10 \mathrm{~V}$. A figura 5.35 é um corte do gráfico da figura 5.33 para $\Delta V=0 \mathrm{~V}$ e finalmente, a figura 5.36 é um corte para $\Delta V=-15 \mathrm{~V}$.

Cabe aqui destacar que após a aplicação do degrau de amplitude $\Delta \mathrm{V}$, segue-se o acomodamento de cargas desde a situação de depleção profunda até a inversão forte. $O$ tempo que isto leva para acontecer é o tempo de retenção e pode ir desde tipicamente alguns segundos a algumas centenas de segundos e está diretamente relacionado ao tempo de vida dos portadores no substrato [SZE'81]. Tal situação não foi levada em consideração nas simulações anteriores. A manutenção da condição de depleção profunda é obtida, na prática, através de um trem de pulsos entre $V_{\text {inicial }}$ e $V_{\text {final }}$, sendo que a distância entre os pulsos deve ser pelos menos a décima parte do tempo de retenção. 
Finalmente, o conjunto de simulações com o programa DCPSim permite-nos agora, prever os valores de $V_{\text {inicial }}$ e $\Delta V$ do trem de pulsos a ser aplicado na porta dos DCP's de forma a se obter profundidades de $W$ junto às junções PN compatíveis com os sensores de radiação luminosa seletivos propostos no ítem 5.1.1 anterior.

\section{2 - Medidas experimentais em alguns dispositivos implementados}

O processo construtivo, levado a efeito até a etapa 16 , como pode ser visto no capítulo 4, resultou em 4 lâminas a serem submetidas aos métodos de caracterização elétrica também descritos no capítulo 4.

Em nenhuma dessas 4 lâminas foi possível encontrar algum capacitor funcional pois, como foi averiguado, o Si-poli, utilizado como material de porta, acabou entrando em curto com o substrato e a junção. Uma possível explicação para esse fato é que o óxido de porta de espessura pequena $(\sim 20 \mathrm{~nm})$ acabou se rompendo em alguma etapa de processo, possivelmente durante a dopagem do Si-poli (etapa 9).

Dessa forma, somente foi possível a caracterização de diodos nas lâminas de processo (P1, N1, EN1 e EN3 no ítem 4.1).

Porém, a título de ilustração do método de determinação da velocidade de recombinação superficial real $\left(s_{0}^{\prime}\right)$, também foi caracterizado um transistor já encapsulado, cedido pelo prof. João Antonio Martino, donde extraímos curvas $I x V$.

\subsection{1 - Caracterização das lâminas de processo (P1, N1, EN1 e EN3)}

Alguns dispositivos das lâminas de processo foram ensaiados em um equipamento HP4140, com o qual foram extraídas curvas $I x V$ conforme descrito no capítulo 4. 
Como não obtivemos DCP's funcionais, limitamo-nos a extrair curvas dos diodos de $(1000 \times 1000) \mu \mathrm{m}^{2}$, conforme segue.

\section{a) Lâmina $\mathrm{N1}$}

A curva da figura 5.37 foi extraída de um diodo de $(1000 \times 1000) \mu m^{2}$ na lâmina N1.

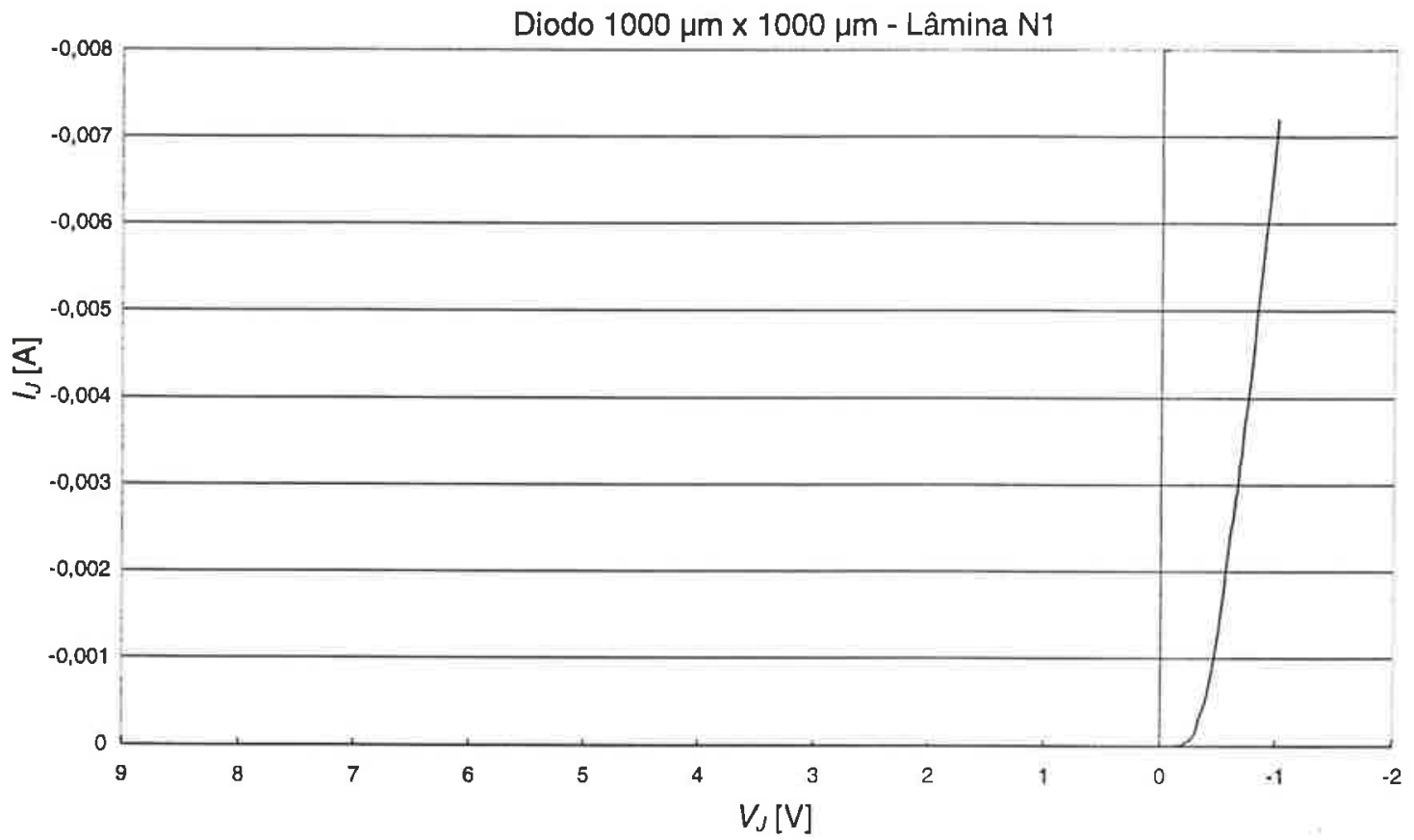

Fig. 5.37: Curva $I x V$ de diodo - lâmina N1

Observamos na curva da figura 5.37 que o diodo implementado não apresenta corrente de fuga observável até tensões tão altas quanto $10 \mathrm{~V}$, ressaltando a alta assimetria de sua junção.

Da região de polarização direta do gráfico da figura 5.37, e a partir das equações 5.2.1-1a e 5.2.1-1b, podemos extrair dois parâmetros importantes na caracterização de um diodo, quais sejam a sua corrente reversa e o fator de idealidade. 


$$
\begin{gathered}
I_{D}=I_{0} \cdot e^{\frac{q \cdot V}{\eta_{i} \cdot k \cdot T}} \\
\ln \left(I_{D}\right)=\ln \left(I_{0}\right)+\frac{q}{\eta_{i} \cdot k \cdot T} \cdot V
\end{gathered}
$$

$\mathrm{O}$ valor de $I_{0}$ foi obtido pelo gráfico no ponto onde a tensão era de $0,1 \mathrm{~V}$ na região reversa, já que é para essa tensão que seriam efetuadas as medidas de velocidade de recombinação superficial. O fator de idealidade $\left(\eta_{i}\right)$ pode ser extraído a partir da inclinação do gráfico do logaritmo natural da corrente $\mathrm{x}$ tensão, como pode ser visto na equação 5.2.1-1 (b).

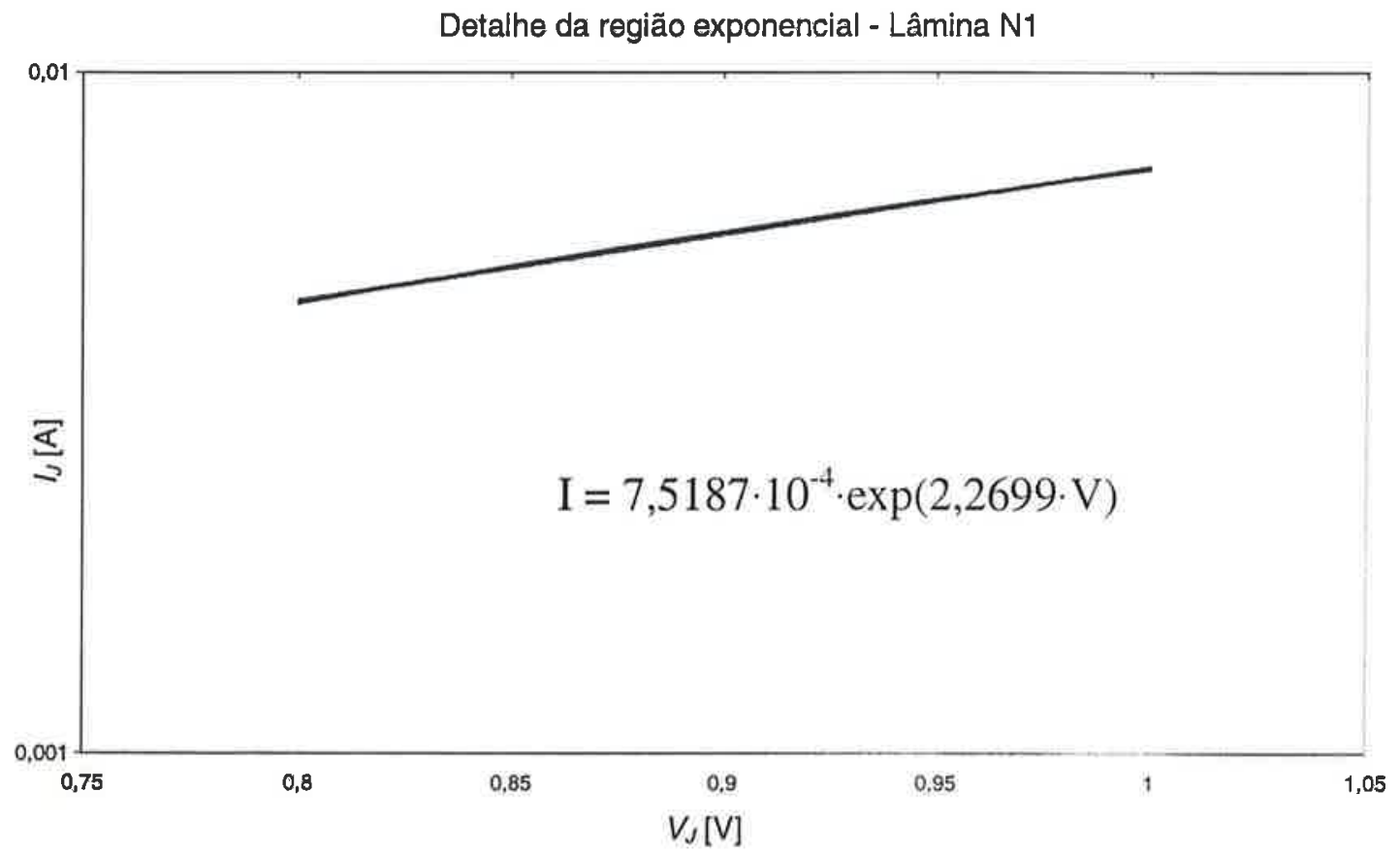

Fig. 5.38: Detalhe da regiăo exponencial - lâmina NI

No gráfico da figura 5.38, temos um detalhe da região exponencial e a equação exponencial que a ajusta. Desta equação tiramos o valor do fator de idealidade como segue:

$$
\eta_{i}=1 / 2,2699 \cdot 0,0259 \cong 17,01
$$


que é um valor anormalmente elevado ${ }^{6}$. Isso se dá provavelmente, devido a uma alta resistência em série com a junção. Tal resistência atribuímos ao contato de níquel já que o mesmo não foi sinterizado. A corrente reversa para tensão de $0,1 \mathrm{~V}$ em módulo é de $1,23 \cdot 10^{-7} \mathrm{~A}$, o que para uma área de $1 \cdot 10^{-2} \mathrm{~cm}^{2}$, nos fornece $J_{0}=$ $1,23 \cdot 10^{4} \mathrm{nA} / \mathrm{cm}^{2}$

\section{b) Lâmina P1}

A figura 5.39 ilustra a curva de diodo para a lâmina P1.

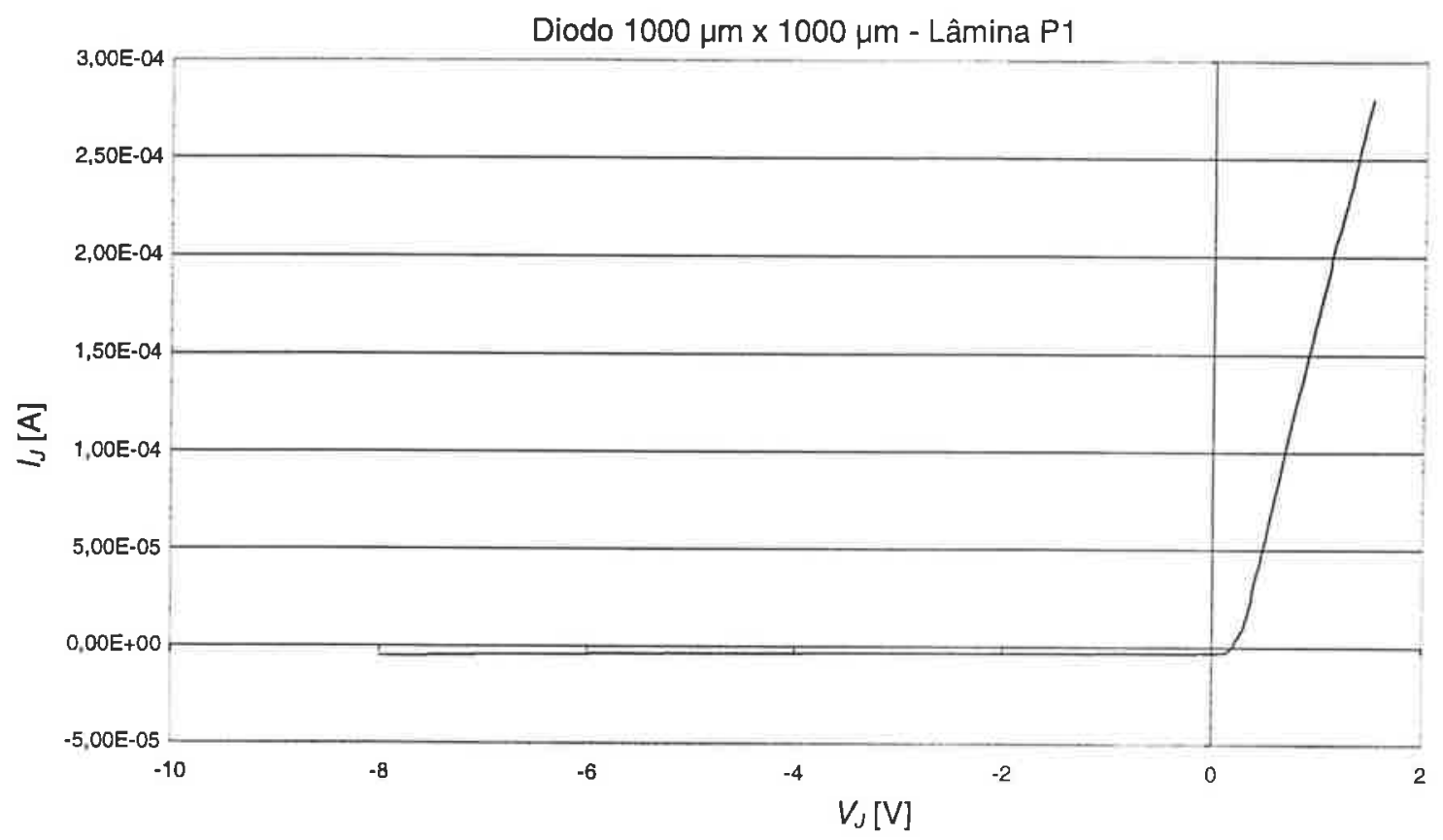

Fig. 5.39: Curva do diodo - lâmina P1

A curva da figura 5.39 nos mostra uma pequena corrente de fuga o que não descaracteriza o efeito retificador dessa junção.

$\mathrm{Na}$ figura 5.40 temos um detalhe da região exponencial para o calculo do fator de idealidade e corrente reversa.

${ }^{6}$ A faixa normal de variação é de 1 a 2. 


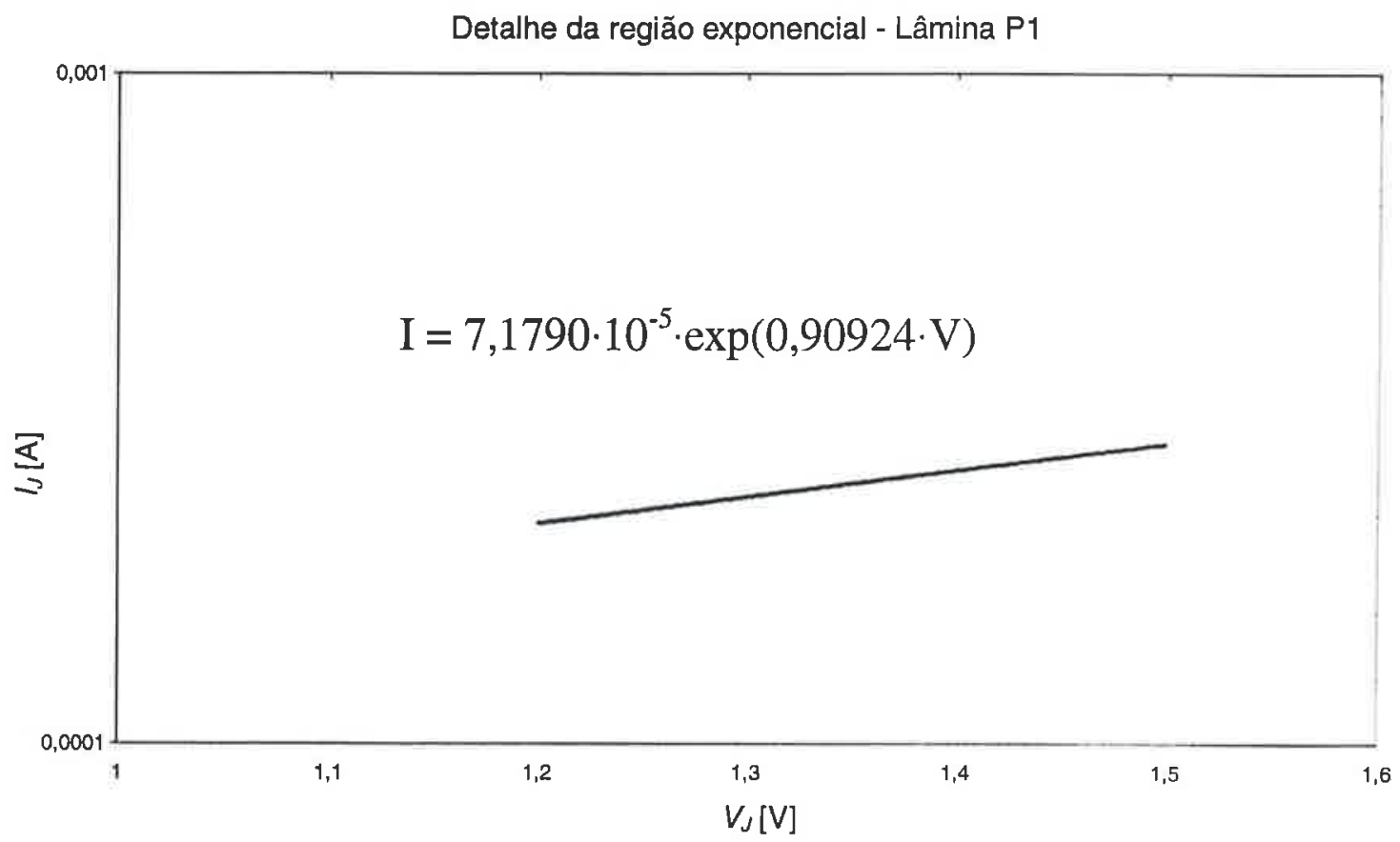

Fig. 5.40: Detaihe da região exponencial - lâmina Pl

Da equação na curva tiramos para o fator de idealidade

$$
\eta_{i}=1 / 0,90924 \cdot 0,0259 \cong 42,46
$$

O valor encontrado é muito grande, implicando possivelmente num resistência em série com a junção bastante elevada. No entanto, tal fato pode ser explicado pelo menor tempo de imersão ( 3 min.) que a lâmina P1 sofreu na solução de deposição eletroquímica devido ao fato da mesma ter-se instabilizado precipitando $\mathrm{Ni}$ nas paredes no béquer. A corrente reversa no ponto $0,1 \mathrm{~V}$ é de $3,19 \mu \mathrm{A}$, logo $J_{0}=$ $3,19 \cdot 10^{5} \mathrm{nA} / \mathrm{cm}^{2}$.

\section{c) Lâmina EN1}

Segue, na figura 5.41, o gráfico de um diodo na lâmina EN1. 


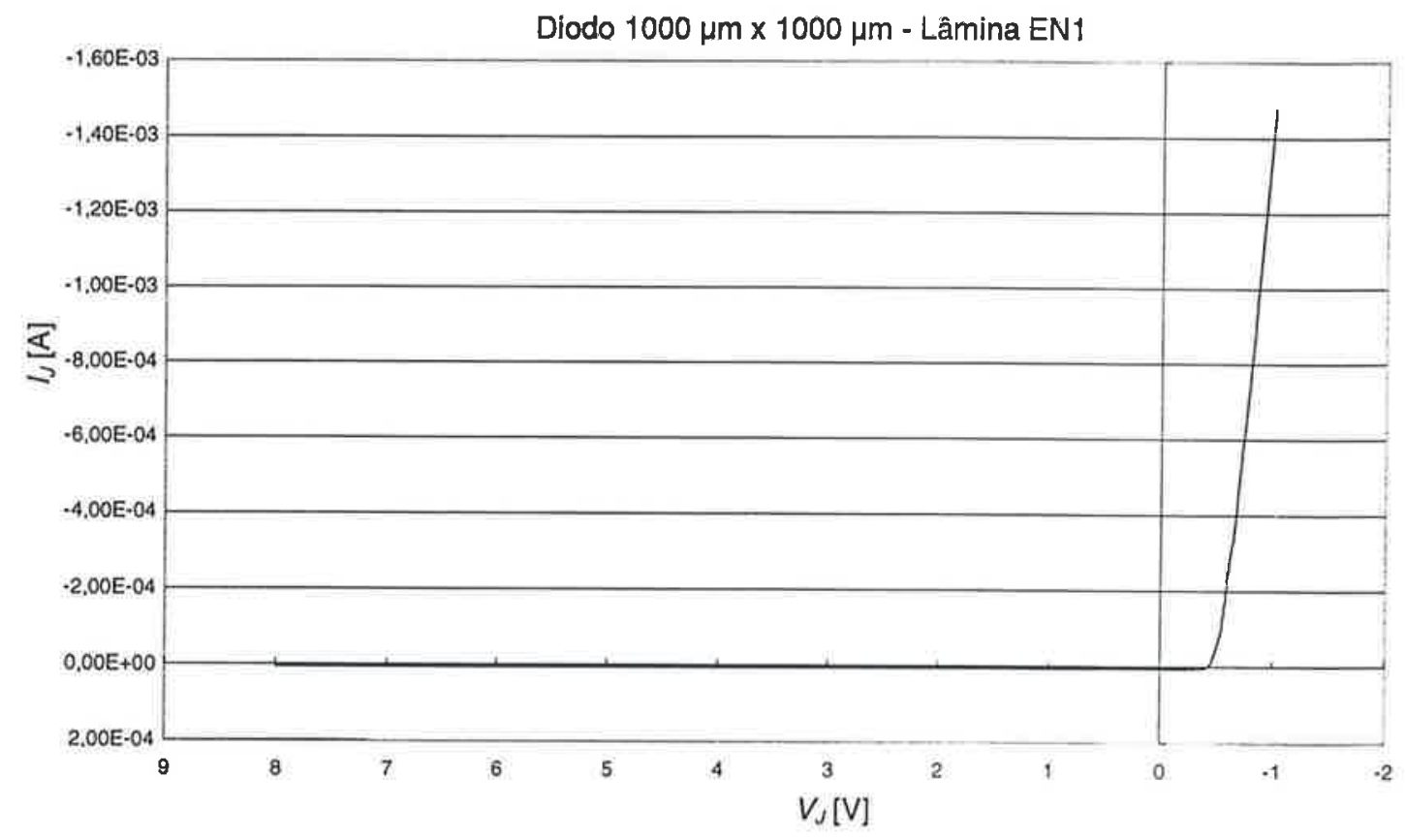

Fig. 5.41: Curva de diodo - Lâmina EN1

Também nesse caso conseguimos uma junção retificadora e com baixa corrente de fuga até tensões da ordem de $8 \mathrm{~V}$.

Detalhe da regiăo exponencial - Lâmina EN1

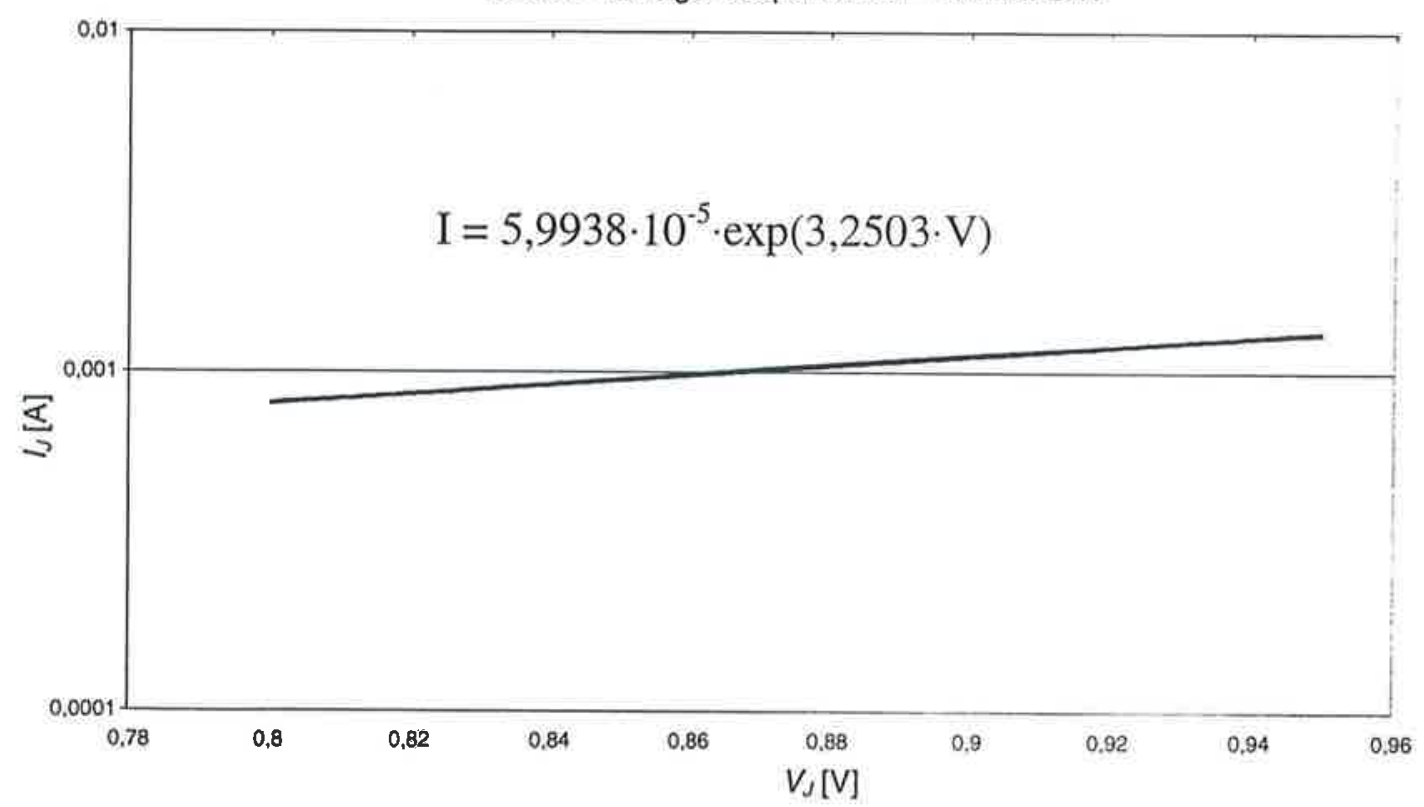

Fig. 5.42: Detalhe da região exponencial - lâmina ENI 
Na figura 5.42, através da equação de ajuste de curva obtemos para o fator de idealidade

$$
\eta_{i}=1 / 3,2503 \cdot 0,0259 \cong 11,88
$$

Novamente obtivemos um valor elevado indicativo de um contato ôhmico de resistência elevada com o níquel não sinterizado. A corrente reversa no ponto $0,1 \mathrm{~V}$ é de $4,39 \mu \mathrm{A}$ o que nos dá $J_{0}=4,39 \cdot 10^{5} \mathrm{nA} / \mathrm{cm}^{2}$.

\section{d) Lâmina EN3}

A curva de diodo para a lâmina EN3 pode ser vista na figura 5.43

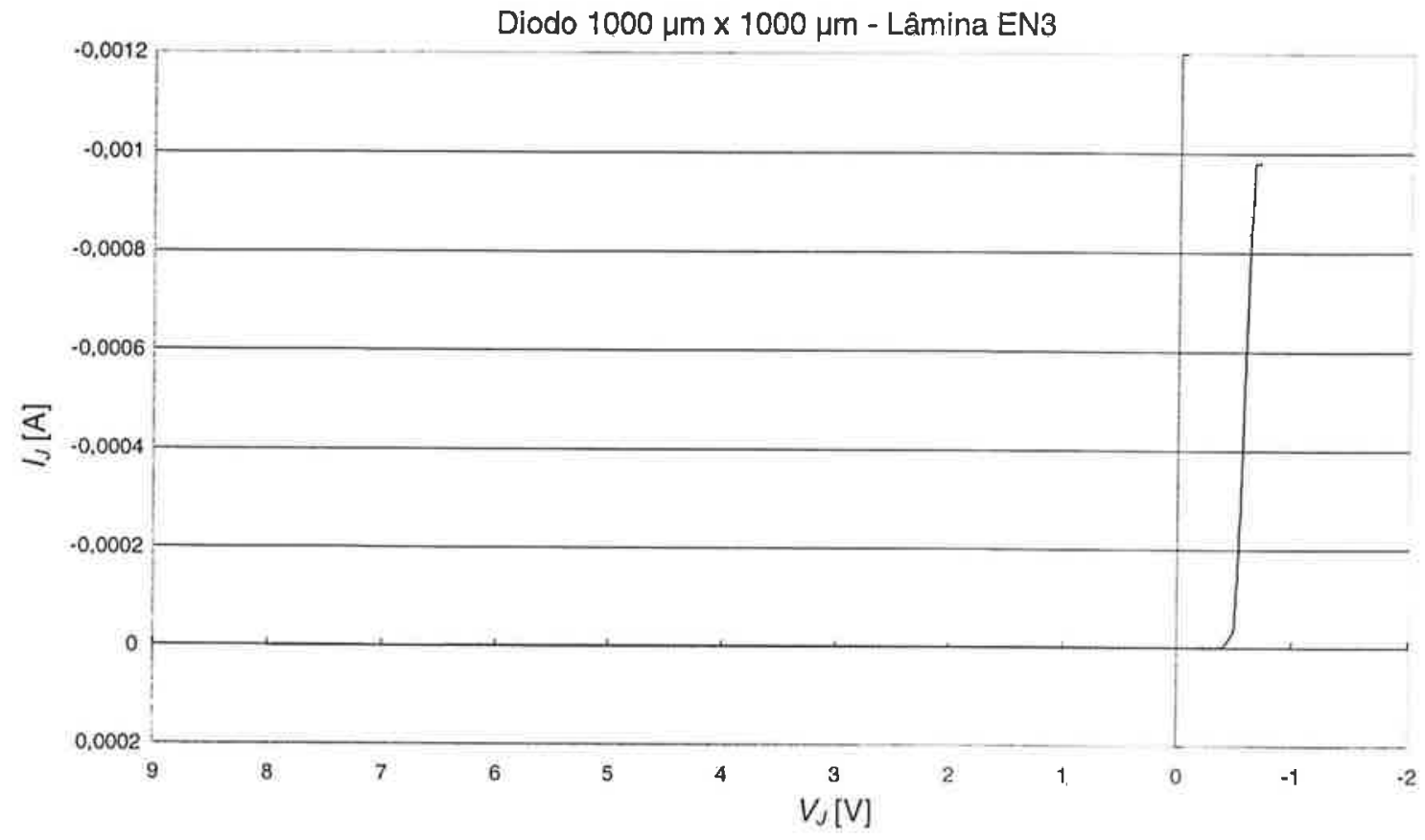

Fig. 5.43: Curva de diodo - lâmina EN3

Na figura 5-43 temos uma junção retificadora e com corrente de fuga não observável até tensão tão altas quanto $10 \mathrm{~V}$. 
Detalhe da região exponencial - Lâmina EN3

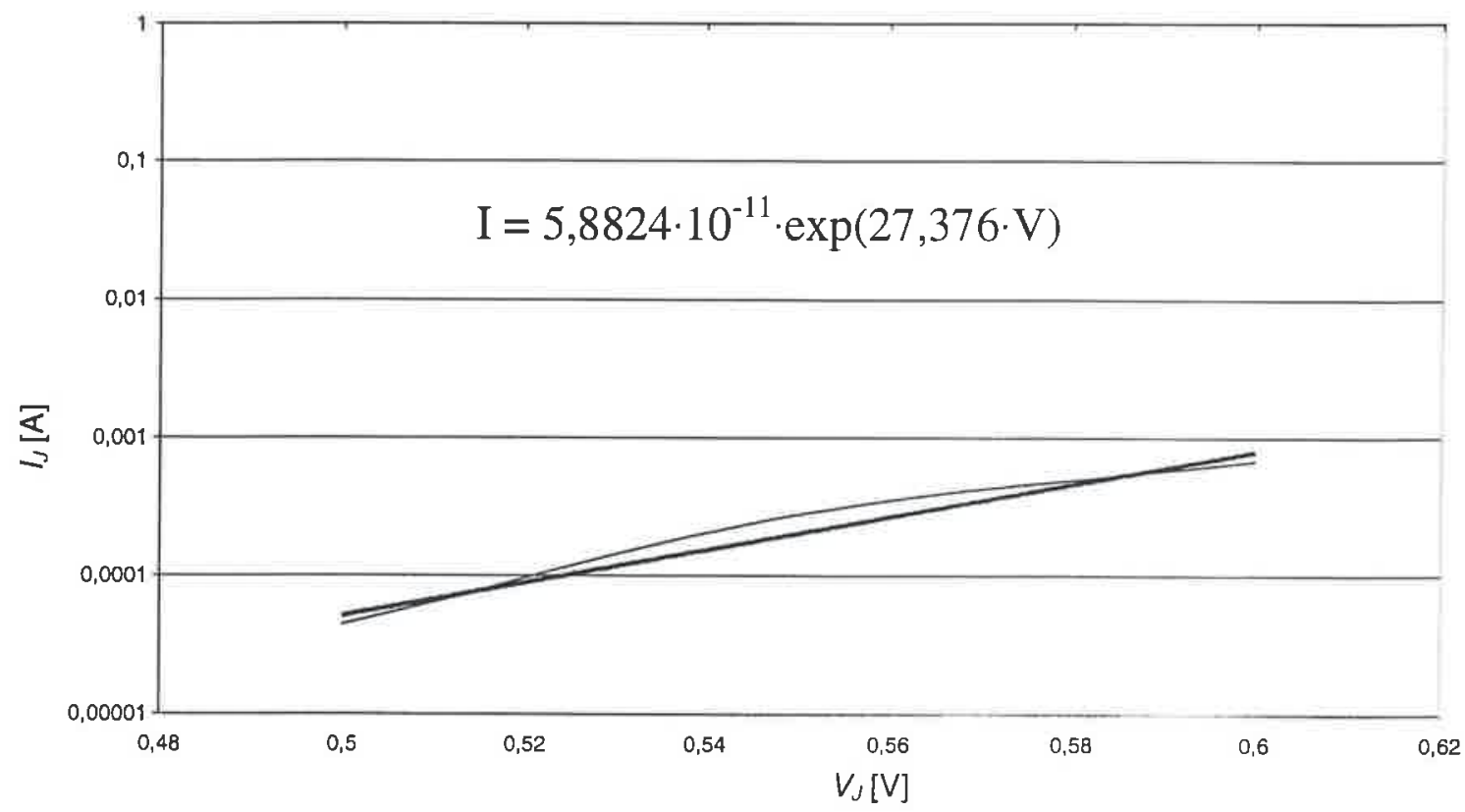

Fig. 5.44: Detalhe da região exponencial - lâmina EN3

Da equação no gráfico da figura 5.44 para o fator de idealidade

$$
\eta_{i}=1 / 27,376 \cdot 0,0259 \cong 1,41
$$

Tal valor de $\eta_{i}$ é normal para uma junção PN, o que indica que o contato com o níquel, apesar de não sinterizado, apresentou baixa resistência ôhmica nesse caso.

De fato, a lâmina EN3 foi a primeira a passar pela etapa de deposição de níquel, mas devido a um acidente perdemos a solução que foi usada na mesma. Nas demais lâminas foram utilizadas outras soluções que, ao contrário da primeira, logo se desestabilizaram formando precipitados de níquel, o qual depositou-se no béquer ou sobre a lâmina em forma de particulado.

A corrente reversa no ponto de $0,1 \mathrm{~V}$ é de $5,93 \mu \mathrm{A}, \log 0 J_{0}=5,93 \cdot 10^{5} \mathrm{nA} / \mathrm{cm}^{2}$. 
Nas figuras 5.45 a 5.48, apresentamos imagens do filme de níque sobre a lâmina no melhor (EN3) e pior caso (N1).

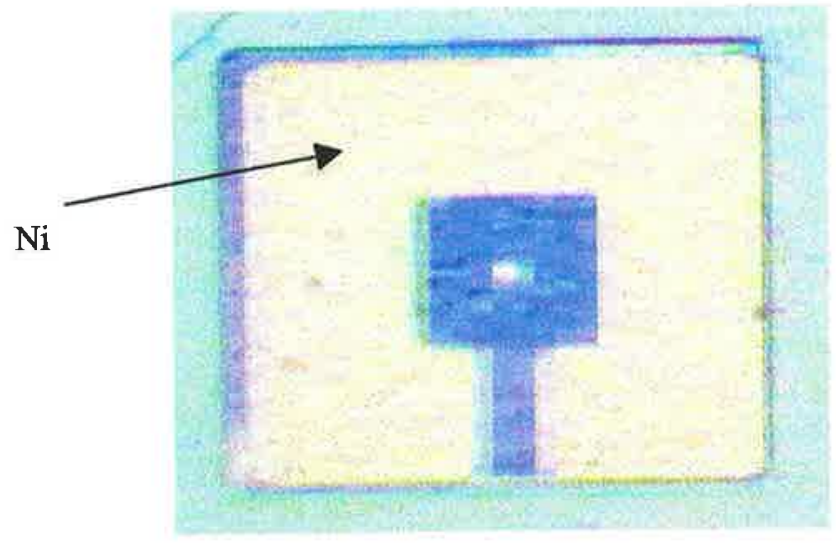

Fig. 5.45: Filme de níquel sobre um dispositivo em EN3 (20X)

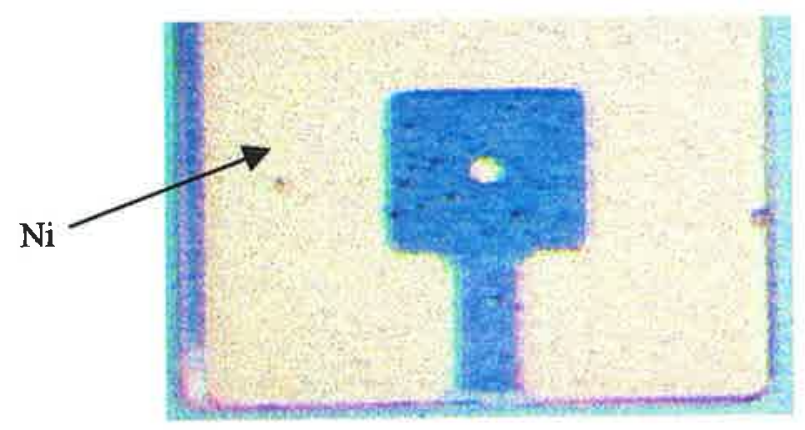

Fig. 5.46: Filme de níquel sobre um dispositivo em EN3 (50X)

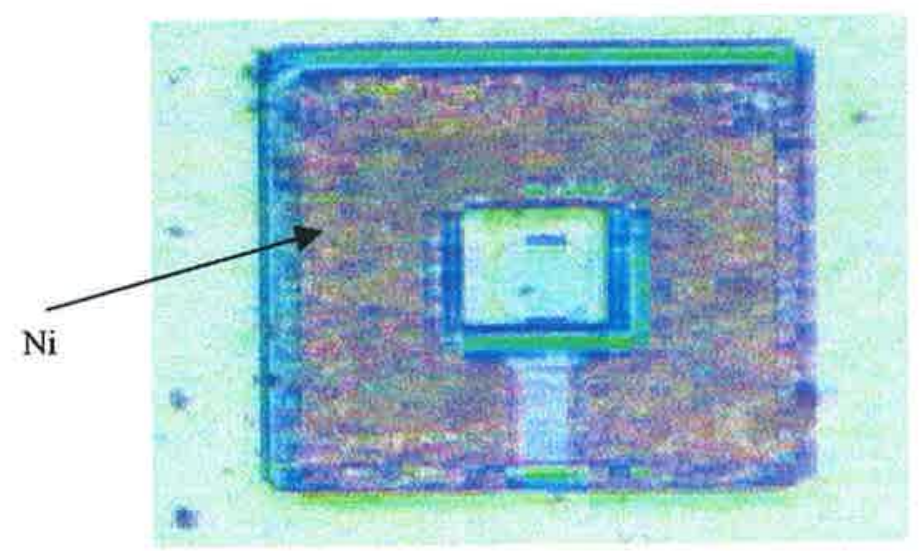

Fig. 5.47: Filme de níquel sobre um dispositivo em N1 (20X) 


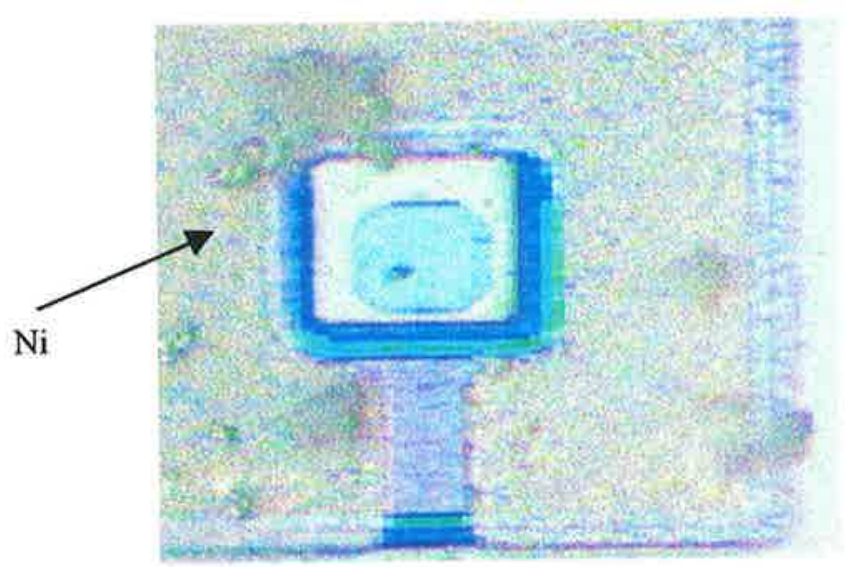

Fig. 5.48: Filme de níquel sobre um dispositivo em N1 (50X)

Como podemos ver, a qualidade do filme de níquel na lâmina EN3 é bem superior ao conseguido na lâmina N1, onde podemos destacar que além de escuro, o mesmo ainda apresenta particulado sobre a superficie.

Quanto às características elétricas, podemos concluir que o fator de idealidade apresentado pelo diodo sobre a lâmina N1 é bastante elevado (17,01), ao passo que o do diodo da lâmina EN3 está dentro dos limites normais esperados para uma junção PN $(1,41)$, provavelmente, por termos um melhor contato ôhmico nesta última.

Tab. 5.6: Características das lâminas de processo

\begin{tabular}{c|cccc}
\hline & $x_{j}[\mu \mathrm{m}]$ & $J_{0}\left[\mathrm{nA} / \mathrm{cm}^{2}\right]$ & $\eta_{i}$ & Filme \\
\hline \hline P1 & 0,56 & $3,19 \cdot 10^{5}$ & 42,46 & Bom \\
N1 & 0,34 & $1,23 \cdot 10^{4}$ & 17,01 & Ruim (escuro + particulado) \\
EN1 & 0,37 & $4,39 \cdot 10^{5}$ & 11,88 & Bom \\
EN3 & 0,64 & $5,93 \cdot 10^{5}$ & 1,41 & Muito Bom (Claro) \\
\hline
\end{tabular}

A tabela 5.6 resume as características obtidas para as lâminas de processo. Como podemos ver, as lâminas que apresentaram filme de Ni ruim também possuem um alto 
fator de idealidade, o que é um indicativo de que o contato ôhmico nessas lâminas não ficou bom. Por outro lado, a lâmina EN3, que apresenta filme com as melhores qualidades, também apresenta um valor de $\eta_{i}$ compatível com junções PN de boa qualidade.

A lâmina P1, apesar de apresentar um filme de bom aspecto. possui o mais alto fator de idealidade de todo o conjunto. Isso pode ser explicado pelo menor tempo (3 minutos contra 5 para as demais) em que a mesma permaneceu na solução de desposição eletroquímica. Foi necessário retirá-la antes pois a solução ficou instável e acabou depositando Ni sobre as paredes do béquer.

Com isso também fica demonstrado que se a etapa de deposição de $\mathrm{Ni}$ for bem sucedida, não é necessária a sinterização do filme obtido.

\subsection{2 - Caracterização do transistor}

Foi utilizado um transistor nMOS de $(20 \times 20) \mu^{2}$, encapsulado, onde $N_{A}=$ $9,7 \cdot 10^{16} \mathrm{~cm}^{-3}$. As curvas $I x V$ foram levantadas por meio de um HP4145 e de um suporte para permitir o acesso aos terminais do CI.

Os seguintes ensaios foram realizados:

\section{a) Levantamento da curva $I_{D S} \times V_{G S}$ na região triodo}

Foi utilizada a montagem indicada na figura 5.49, onde a tensão $V_{D S}$ é pequena $(0,1$ V). 


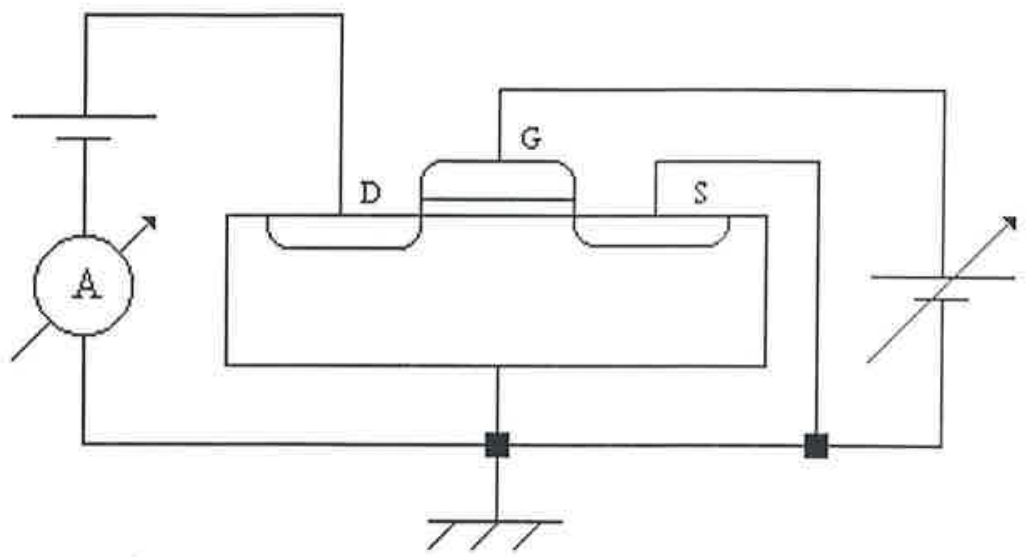

Fig. 5.49: Montagem utilizada para o levantamento da curva $I D_{S} \times V G_{S}$

A curva obtida pode ser vista no gráfico da figura 5.50.

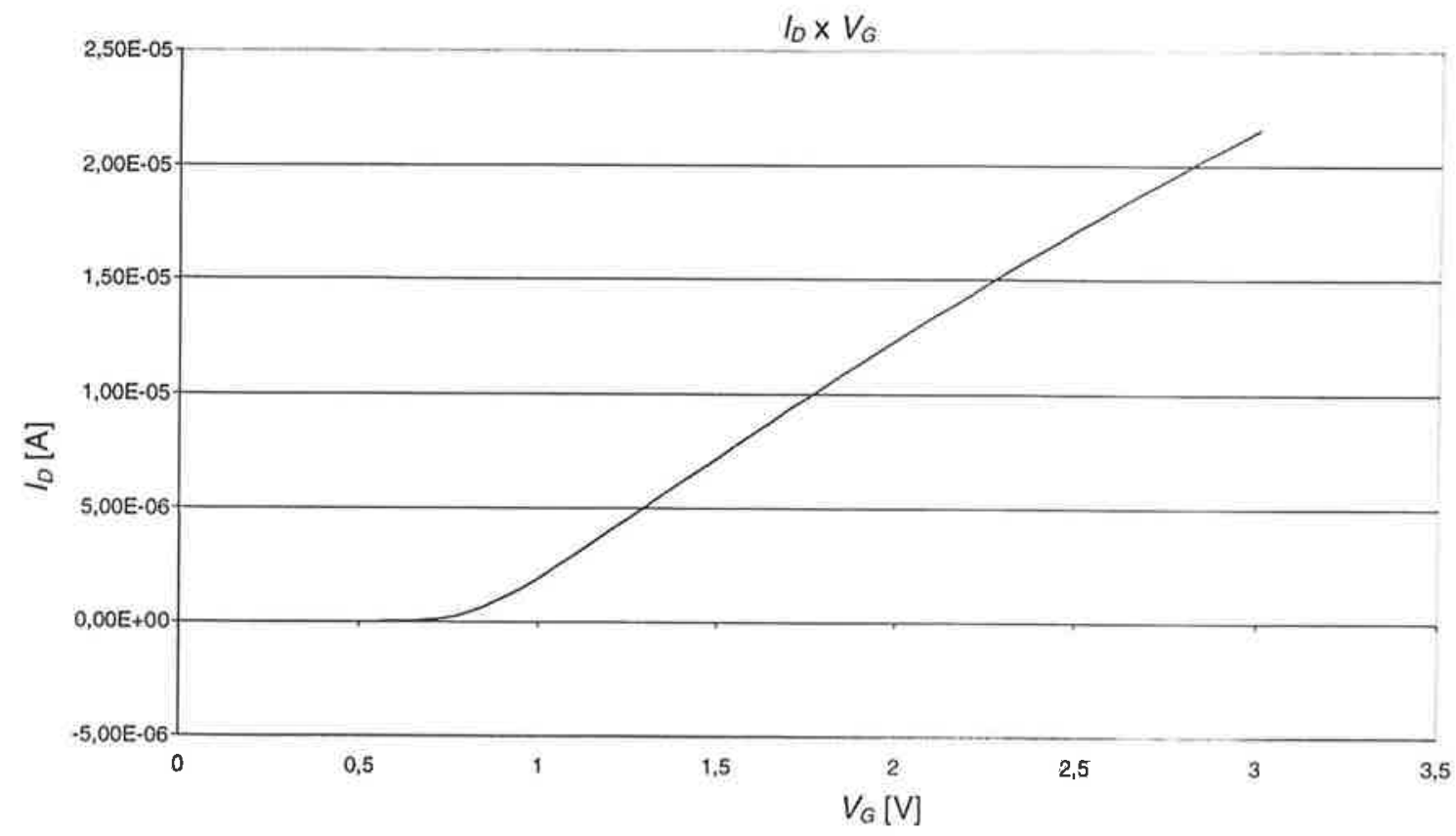

Fig. 5.50: Curva $I_{D S} x V_{G S}$ na região triodo

A partir da figura 5.50 podemos extrair o valor da tensão de limiar do transistor que é dada pela equação (5.2.2-1).

$$
V_{T H}=V_{G S 0}-V_{D S} / 2
$$


onde $V_{G s o}$ é a interseção do prolongamento da parte linear da curva de corrente com o eixo de tensão. Assim, como $V_{D S}=0,1 \mathrm{~V}$, temos que $V_{T H}=0,8 \mathrm{~V}$.

\section{b) Curva de diodo da junção de dreno}

A fim de verificarmos o estado de funcionamento do diodo formado pela junção de dreno, levantamos a sua característica $I x V$ através da montagem da figura 5.51.

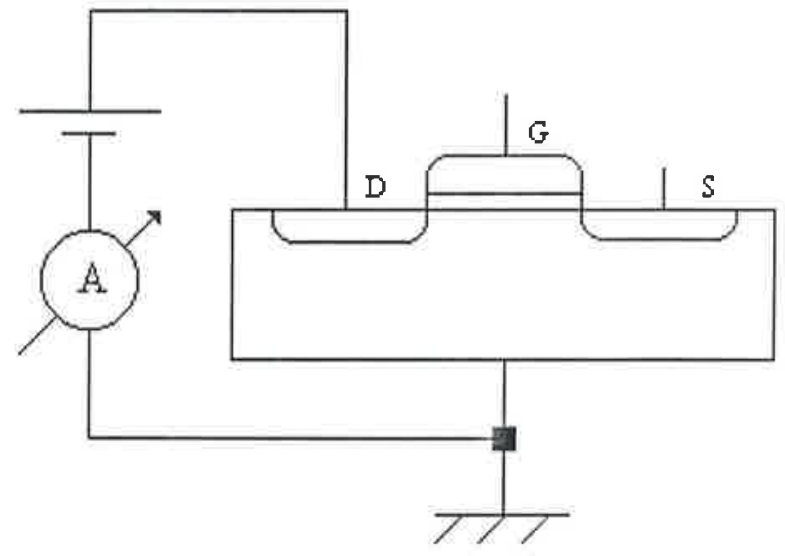

Fig. 5.51: Montagem empregada para o levantamento da curva $I x V$ do diodo

A curva, $I_{D} \times V_{D}$ obtida pode ser vista na figura 5.52 .

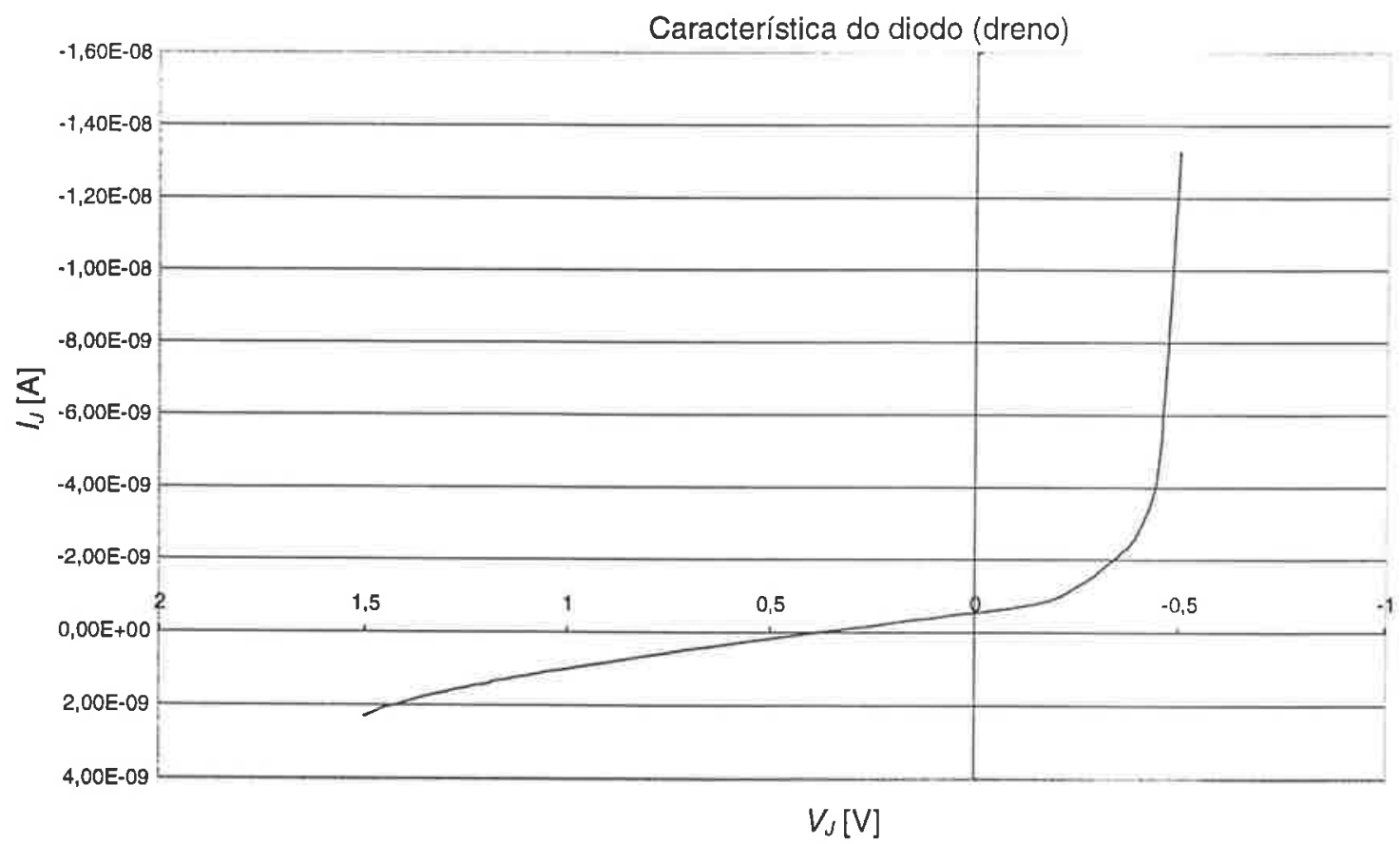

Fig. 5.52: Característica $I x V$ do diodo de dreno 
No gráfico da figura 5.52, há uma pequena corrente através da junção mesmo quando a tensão é nula. Tal corrente pode ser devida à geração térmica no semicondutor.

Do gráfico da figura 5.53, podemos então determinar esses dois parâmetros.

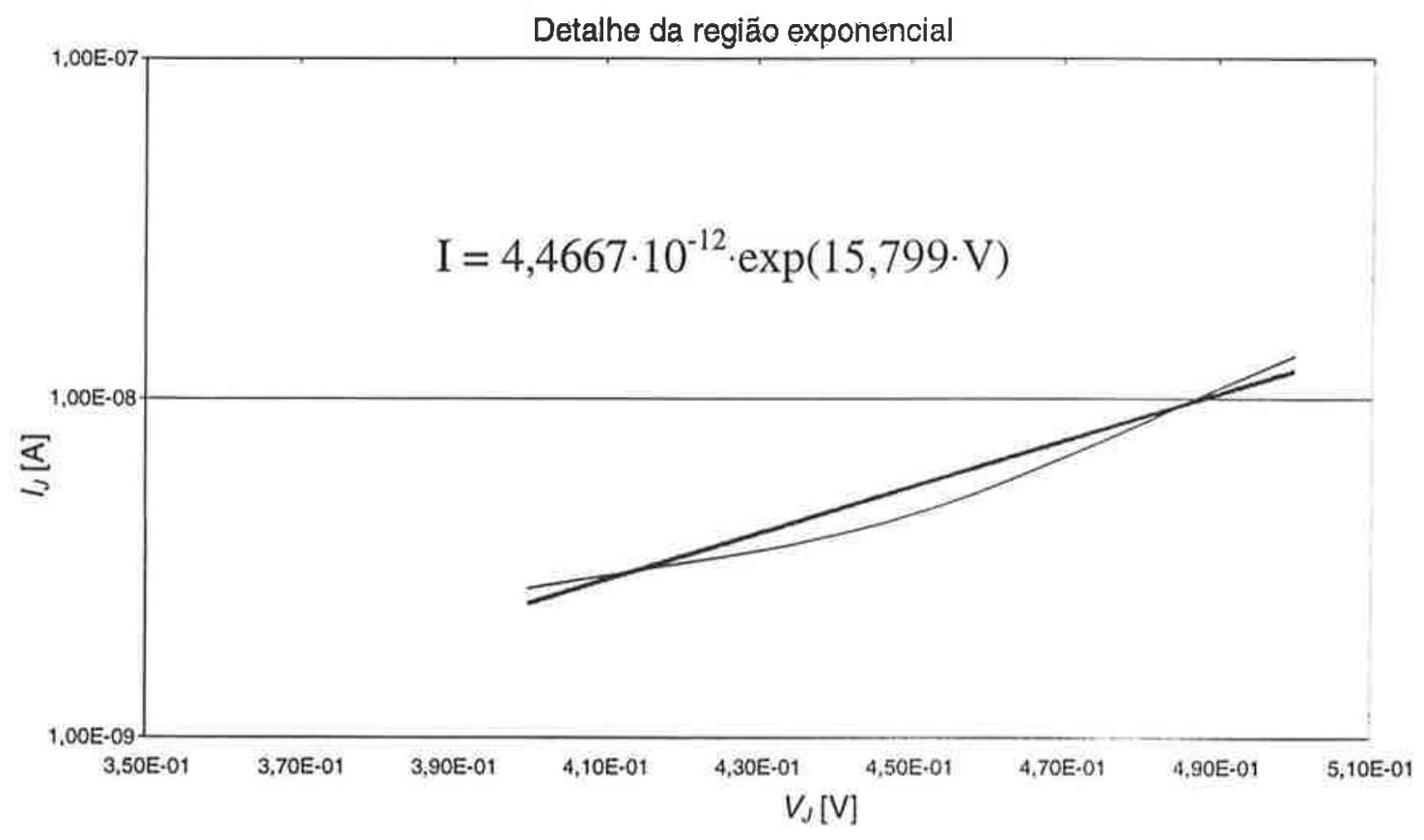

Fig. 5.53: Detalhe da região direta da curva da figura 5.52

$\mathrm{Na}$ figura 5.53, temos já a equação de uma curva exponencial estatisticamente ajustada à curva experimental. Portanto, para o fator de idealidade

$$
\eta_{i}=1 /(15,799 \cdot 0,0259) \cong 2,44
$$

Utilizamos nesse caso o mesmo critério para a determinação da densidade de corrente reversa, ou seja, medimos o valor de $I_{0}$ em $0,1 \mathrm{~V}$ reverso, o que resultou em $7,92 \mathrm{pA}$. Para uma área de $4 \cdot 10^{-6} \mathrm{~cm}^{2}, J_{0}=1,98 \cdot 10^{3} \mathrm{nA} / \mathrm{cm}^{2}$. 
A fim de analisarmos o comportamento do diodo variando-se o volume da região de carga espacial, levantamos também a característica $I x V$ para três tensões de polarização de porta. O resultado pode ser visto na figura 5.54 .

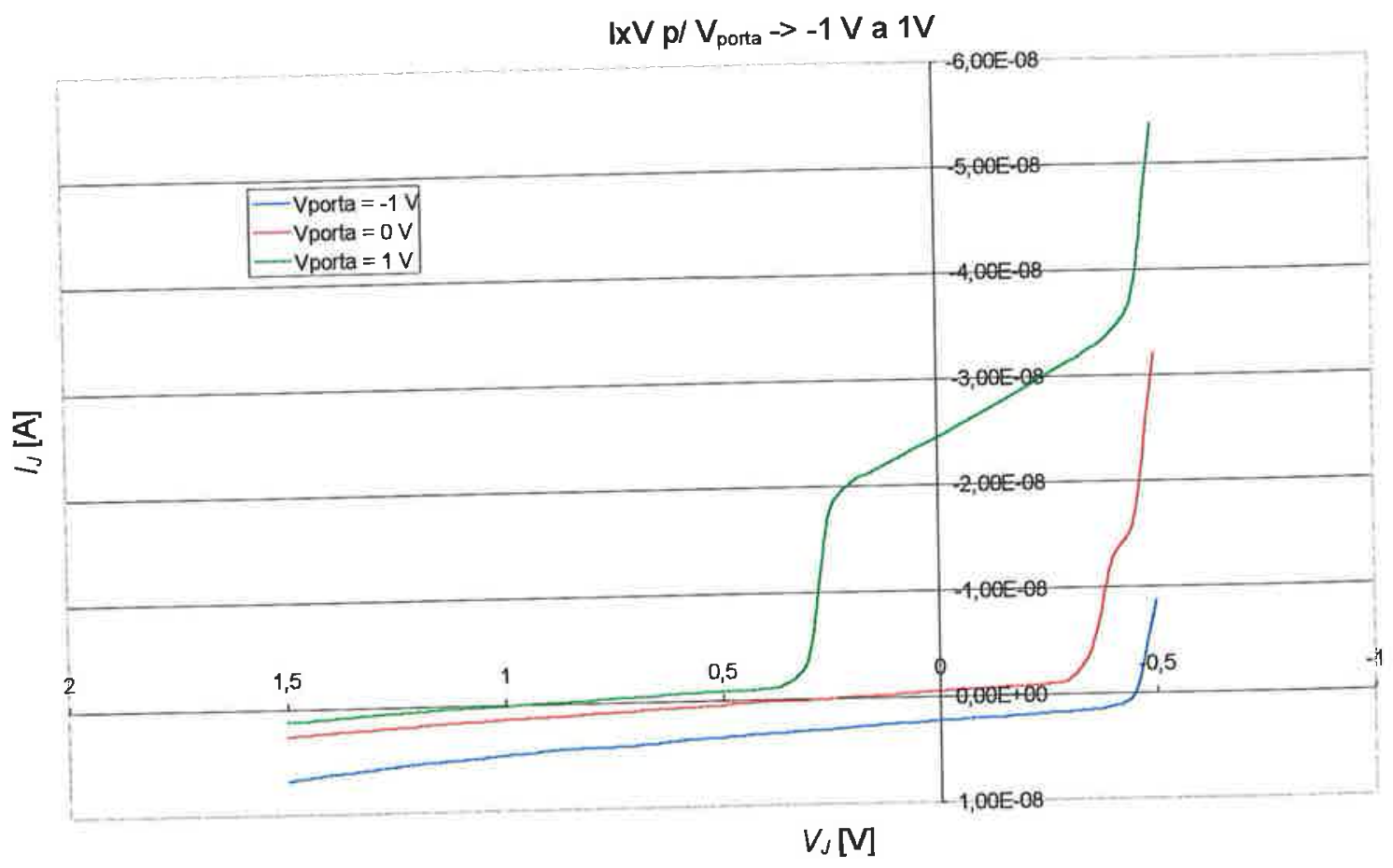

Fig. 5.54: Curva $I x V$ para tensão de porta variando de $-1,0 \mathrm{~V}$ a $1,0 \mathrm{~V}$

Como já visto, o $V_{T H}$ do transistor é de $0,8 \mathrm{~V}$, logo, para $V_{\text {porta }}=1,0 \mathrm{~V}$ temos que a superfície abaixo da porta está em inversão forte aumentando a região de depleção e portanto a corrente na junção como pode ser visto em verde na figura 5.54

Já para $V_{\text {porta }}=-1,0 \mathrm{~V}$, a superficie está em acumulação, blindando os estados interfaciais e reduzindo a corrente reversa na junção. 
O comportamento da curva em verde na figura 5.54 se deve ao fato de que a junção induzida abaixo da porta permite a passagem de corrente para tensões menores do que a junção metalúrgica.

\section{c) Determinação de $s_{0}^{\prime}$}

Como visto no capítulo 2 , a determinação de $s_{0}$ requer o levantamento da curva de corrente reversa na junção em função da tensão de porta, onde a tensão de polarização de junção não pode ser muito grande para que os centros de geração/recombinação presentes na região de carga espacial não acabem mascarando a corrente devida aos estados de superfície, escopo desse tipo de medida.

A partir de um transistor, podemos obter diodos controlados por porta (DCP's) a partir de duas montagens a saber: ou colocamos a fonte em curto com o dreno ou a deixamos em aberto.

A primeira montagem dobra a área da junção aumentando a sua corrente, por outro lado aumenta também a influência dos centros de geração/recombinação no corpo do material o que, como dito acima, queremos evitar. Assim optamos pela segunda montagem que é mostrada na figura 5.55. 


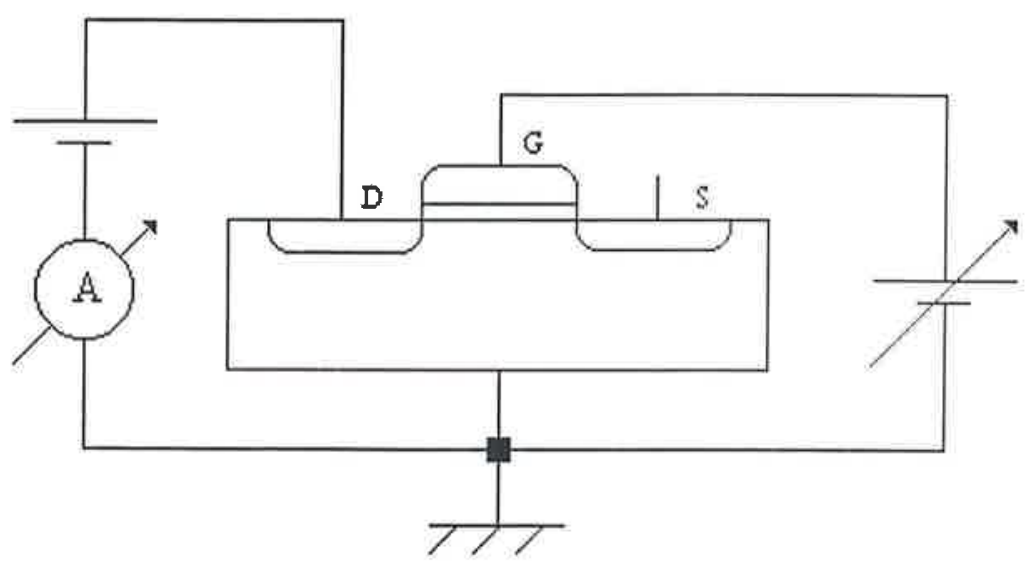

Fig. 5.55: Montagem empregada para a determinação de $s_{0}$

A partir da montagem da figura 5.55 levantamos a curva $I_{D} \times V_{G}$, a qual está mostrada na figura 5.56 .

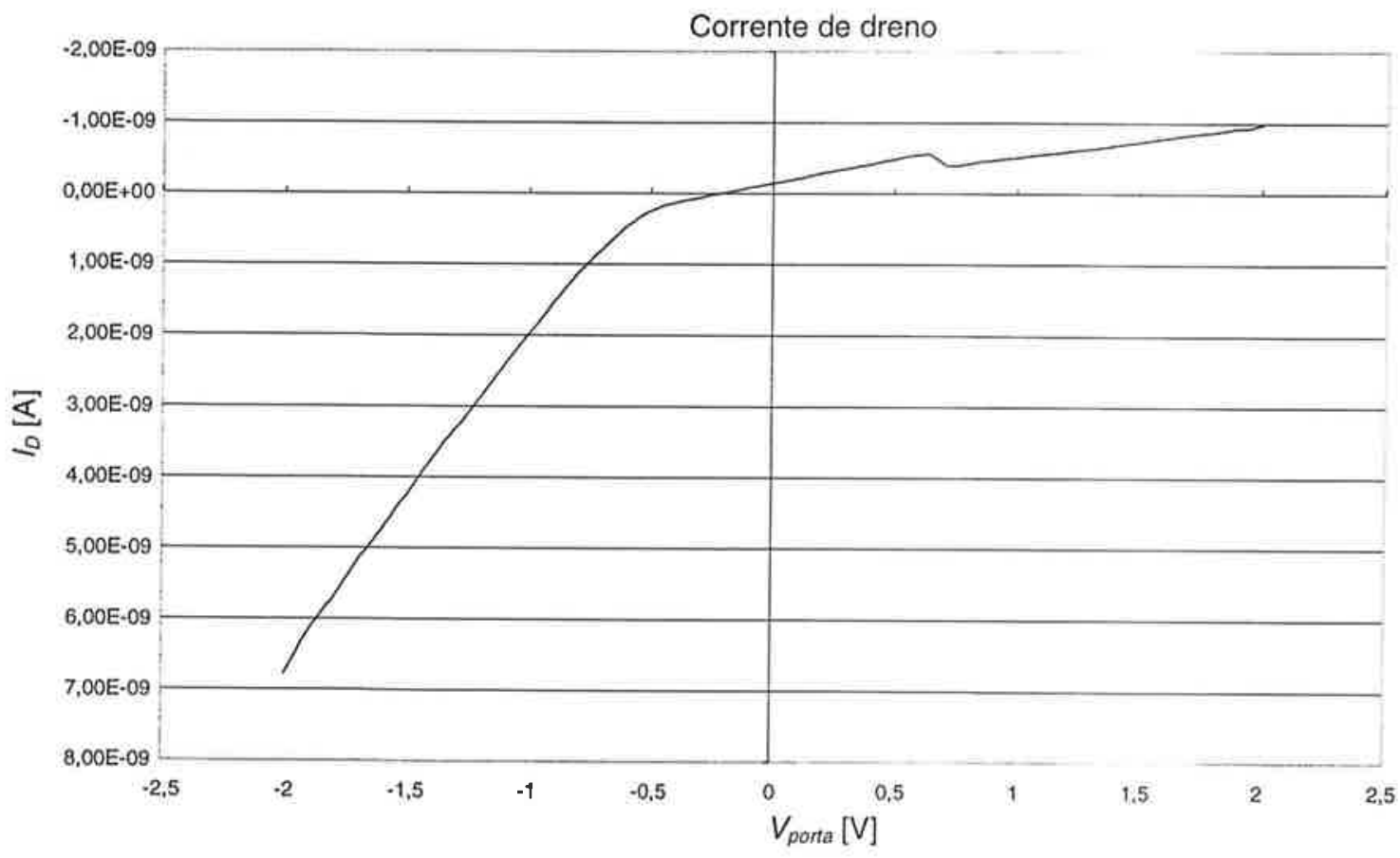

Fig. 5.56: Corrente de dreno versus tensão de porta 
Como podemos notar, ao começarmos a entrar em regime de inversão, a corrente reversa apresenta uma queda devida à subtração da componente de geração na interface.

Assim, a diferença entre os níveis de corrente antes e após a inversão é proporcional à s 0 , conforme capítulo 2. Como resultado, do gráfico da figura 5.56 temos que $I_{\text {gen, }}$ $=154,8$ pA. Na equação $2.3-8$, para $A_{S}=4,0 \cdot 10^{-6} \mathrm{~cm}^{2}, n_{i}=1,45 \cdot 10^{10} \mathrm{~cm}^{-3}$ e $q=$ $1,602 \cdot 10^{-19}$, temos que $s_{0}=16660,21 \mathrm{~cm} / \mathrm{s}$.

Calculamos então a largura da região de depleção no limiar de inversão forte obtendo $W=10,529 \cdot 10^{-6} \mathrm{~cm}$. Com o valor de $W$ e para $\mu_{n}=460 \mathrm{~cm}^{2} / \mathrm{V} \cdot \mathrm{s}$, obtivemos, a partir da equação $2 \cdot 3 \cdot 1-18$ o valor de $L_{S}=10,934 \cdot 10^{-6} \mathrm{~cm}$. Assim, a relação $L / L_{S}=182,92$, o que no gráfico da figura 2.12 , nos mostra que a relação entre as velocidades de recombinação real e aparente é de 0,003 , ou seja, a velocidade real é

$$
s_{0}^{\prime}=\frac{s_{0}}{0,01}=\frac{16660,21}{0,003} \cong 5,5 \cdot 10^{6} \mathrm{~cm} / \mathrm{s}
$$

que é um valor bastante elevado, mas que pode explicar a presença de corrente mesmo para tensão nula sobre a junção. 


\section{6 - Conclusões e perspectivas futuras}

\section{1 - Conclusões}

Os resultados obtidos nas simulações Matlab mostraram uma dependência sistemática entre o rendimento de conversão, da energia luminosa em elétrica, com a largura da região de depleção. Tal relação mostra que larguras maiores de $W$ propiciam um melhor rendimento para comprimentos de onda maiores e vice-versa.

Um problema prático que surge na análise dessas simulações é que, em verdade, não podemos variar $W$ em uma faixa tão ampla quanto a que foi usada, a título de demonstração, nas simulações. O valor mínimo de $W$ está preso ao valor devido à própria junção metalúrgica, enquanto o valor máximo, alcançado operando-se o dispositivo em depleção profunda, está limitado pelo valor máximo de pulso que podemos utilizar sem romper o óxido de porta.

Foi simulada, nesse trabalho, a operação em depleção profunda de capacitores MOS, onde os resultados de saída foram os perfis de campo e potencial elétricos e o de portadores ao longo da profundidade no semicondutor.

Tais simulações foram feitas através do programa DCPSim desenvolvido em linguagem $\mathrm{C}$ e que permite a resolução da equação de Poisson, com condições de contorno adequadas, no sistema MOS.

A partir do perfil de campo elétrico, foi possível a determinação aproximada do valor de $W$, o qual pode ser até três vezes maior, em depleção profunda, do que em regime não-pulsado. A possibilidade de variação de $W$ em uma faixa razoável, aliada à dependência do rendimento de conversão em função do comprimento de onda da luz incidente, nos permitiu propor os DCP's como sensores de cor. 
Também ficou mostrado nesse trabalho que contatos de níquel depositados por electroless podem ser utilizados, mesmo sem sinterização, dependendo apenas das condições da solução utilizada no processo.

Nesse caso, os diodos implementados podem ter excelentes características retificadoras. Por outro lado, também medimos a velocidade de recombinação superficial aparente $\left(s_{0}\right)$ e real $\left(s_{0}^{\prime}\right)$ cujos valores acabaram sendo muito diferentes, demonstrando assim, a necessidade de se fazer a correção proposta por Pierret [PIER'74].

\section{2 - Perspectivas futuras}

Como perspectivas futuras, devemos primeiramente fazer novas simulações elétricas colocando-se agora a junção ao lado da estrutura MOS, em um único programa, para podermos avaliar melhor todos os fenômenos envolvidos.

Também, para uma próxima etapa, é fundamental a caracterização da estrutura DCP sob diversos comprimentos de onda para podermos avaliar a possibilidade de a utilizarmos como sensor de cor.

Uma possibilidade seria a de levarmos o dispositivo para a depleção profunda e amostrarmos o valor da sua corrente reversa conforme $W$ retrocede ao valor normal. Com isso, esperamos poder extrair uma relação entre as correntes e o comprimento de onda incidente e assim podermos determinar a cor da luz utilizada.

Para tanto, é necessário ao menos mais duas corridas de lâminas incluindo concentrações de substrato abaixo de $1 \cdot 10^{14} \mathrm{~cm}^{-3}$ e ensaios de rendimento para os três comprimentos de onda propostos no ítem 5.1.1. 


\section{Anexo A - Conceitos básicos sobre ondas eletromagnéticas, faixas de energia e absorção de radiação}

A grosso modo, podemos dividir todas as partículas existentes no universo em duas grandes categorias a saber: os férmions, de spin fracionário $(1 / 2,3 / 2 \ldots)$ e os bósons, de spin inteiro $(0,1,2 \ldots)$.

As partículas da primeira classe, composta por prótons, elétrons, nêutrons, etc. são o que chamamos propriamente de matéria. Elas compõem o núcleo atômico e sua coroa eletrônica e, dessa forma, todo e qualquer elemento natural ou produzido em reatores e aceleradores de partículas.

Já na segunda categoria temos as radiações, que nada mais são do que partículas mediadoras das quatro interações ou forças conhecidas até o momento: interação nuclear forte, nuclear fraca, eletromagnética e gravitacional, conforme tabela A-1 a seguir.

Tab. A-1: Interações e partículas mediadoras

\begin{tabular}{c|cc}
\hline Interação & Partícula mediadora & Símbolo \\
\hline Nuclear forte & Glúons (8) & - \\
Nuclear fraca & Bósons de Gauge (3) & $W^{+}, W, Z^{0}$ \\
Eletromagnética & Fóton & $\gamma$ \\
Gravitacional & Gráviton $^{7}$ & $g$ \\
\hline
\end{tabular}

As duas categorias apresentam comportamento diferenciado entre silício, seguindo a primeira a distribuição de probabilidade de Fermi-Dirac (Eq. A-1)

\footnotetext{
${ }^{7}$ Ainda não detectado experimentalmente.
} 
enquanto que as partículas da segunda classe obedecem à distribuição de BoseEinstein (Eq. A-2).

$$
\begin{gathered}
F(E)=\frac{1}{1+e^{\left(\frac{E-E_{F}}{k \cdot T}\right)}} \\
F(E)=\frac{1}{e^{\frac{E}{k \cdot T}}-1}
\end{gathered}
$$

onde $k$ é a constante de Boltżmann e $E_{F}$ é a energia de Fermi definida como sendo a energia onde a probabilidade de se encontrar a partícula é igual a 1/2.

Os gráficos das figuras A-1 e A-2 a seguir ilustram melhor a diferença entre as duas funções de distribuição em energia.

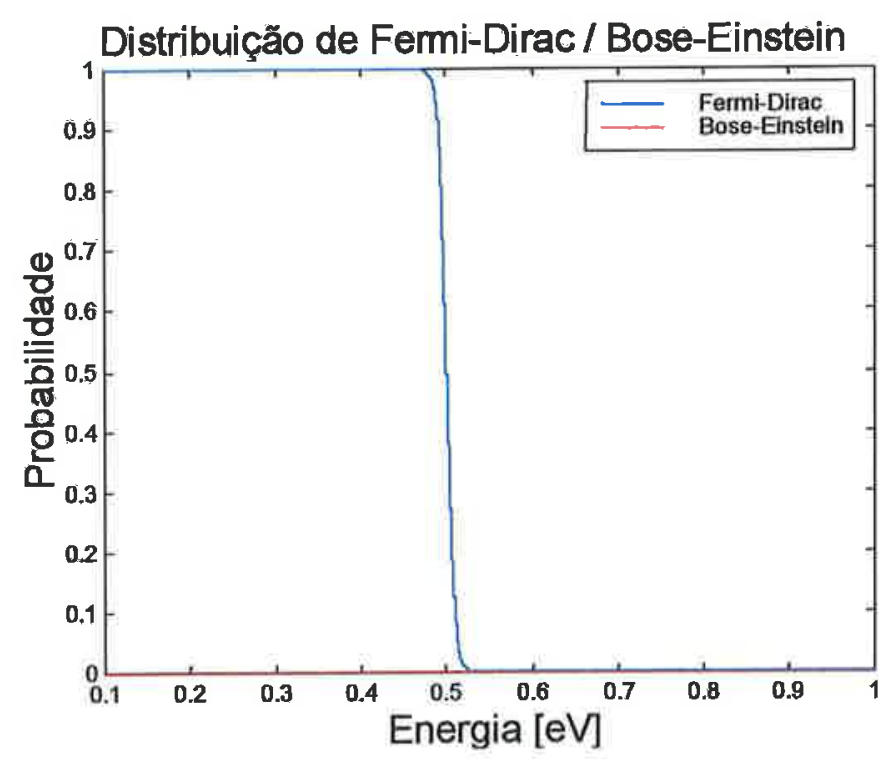

Fig. A-1: Funções de distribuição de probabilidade em energia para: $T=50 \mathrm{~K}, E_{\vec{F}}=0,5 \mathrm{eV}$ 


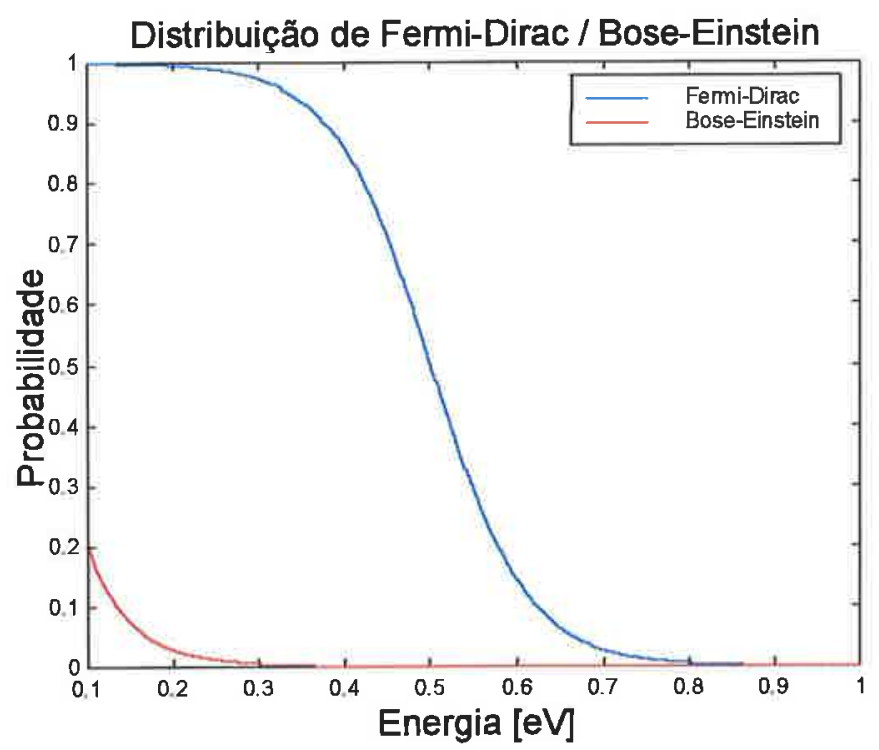

Fig. A-2: Funções de distribuição de probabilidade em energia para $T=650 \mathrm{~K}, E_{F}=0,5 \mathrm{eV}$

Outra diferença entre as partículas das duas classes é que somente as da primeira obedecem ao princípio de exclusão de Pauli, que diz que dois férmions não podem estar no mesmo estado quântico ao mesmo tempo e no mesmo lugar. Isso acaba resultando numa espécie de "comportamento individual" ou de partícula para os férmions, e "coletivo" ou ondulatório para os bósons, macroscopicamente falando é claro, já que o princípio de dualidade onda-partícula garante um mesmo tratamento matemático, no âmbito microscópico, para ambas as classes.

Como o principal escopo do presente trabalho é o estudo da relação entre a matéria sólida, no caso semicondutores, e a radiação eletromagnética, no que diz respeito à sua absorção e modulação, deixaremos de lado as outras três interações da tabela A-1, só nos concentrando na eletromagnética. Assim as próximas secções cobrem com detalhamento o estudo de fenômenos eletromagnéticos em freqüências ópticas (infravermelho a ultravioleta). 


\section{A.1 - Natureza das ondas eletromagnéticas}

Do ponto de vista clássico, ondas eletromagnéticas nada mais são do que perturbações nos campos elétricos associados a partículas carregadas, que se propagam sem a necessidade de um meio material para que isso ocorra.

Toda onda eletromagnética é composta por dois campos perpendiculares entre silício, um elétrico e outro magnético, cujo sentido de variação é perpendicular ao sentido de propagação da onda (fig. A-3).

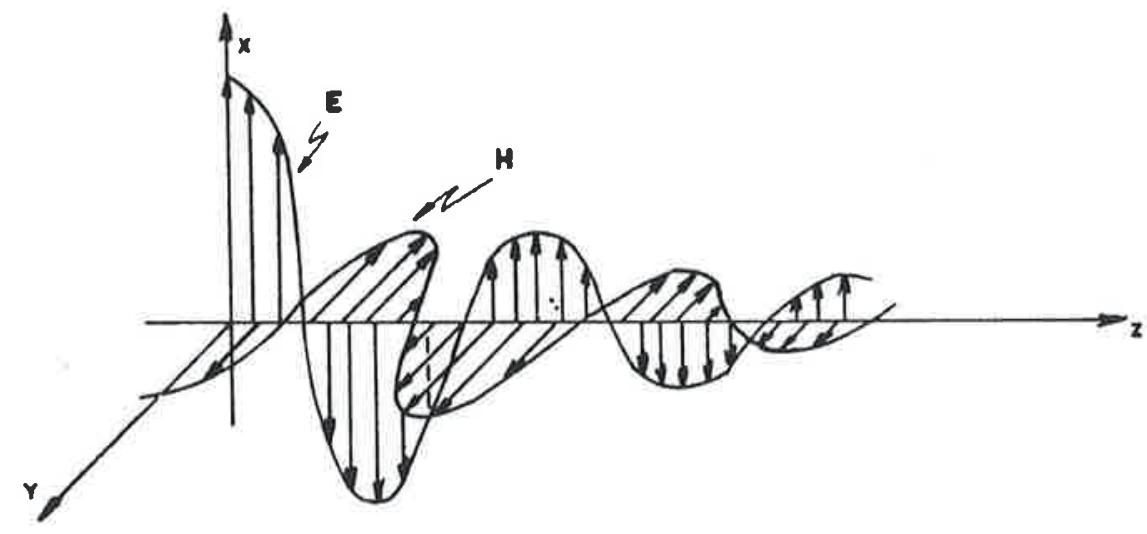

Fig. A-3: Onda eletromagnética se propagando na direção :

A teoria eletromagnética clássica está toda ela embasada nas quatro equações de Maxwell apresentadas a seguir (A.1-1 a A.1-4):

$$
\begin{gathered}
\vec{\nabla} \wedge \vec{E}=-\frac{\partial \vec{B}}{\partial t} \\
\vec{\nabla} \wedge \vec{H}=\vec{J}+\frac{\partial \vec{D}}{\partial t} \\
\vec{\nabla} \times \vec{B}=0 \\
\vec{\nabla} \times \vec{D}=\rho
\end{gathered}
$$


onde $\vec{\nabla} \times$ é o operador divergente e $\vec{\nabla}^{\wedge}$ é o operador rotacional, $\vec{E}$ é o campo elétrico, $\vec{H}$ é o campo magnético, $\vec{D}$ é o vetor deslocamento, $\vec{B}$ é o vetor indução magnética, $\vec{J}$ é o vetor densidade de corrente e $\rho$ é a densidade de carga elétrica.

Além das quatro equações anteriores (A.1-1 a A.1-4), temos ainda relações constitutivas entre os vetores conforme segue:

$$
\begin{gathered}
\vec{J}=\sigma \cdot \vec{E} \\
\vec{B}=\mu \cdot \mu_{0} \cdot \vec{H} \\
\vec{B} \cong \mu_{0} \cdot \vec{H} \\
\vec{D}=\varepsilon \cdot \varepsilon_{0} \cdot \vec{E} \\
\vec{D}=\varepsilon_{0} \cdot \vec{E}+\vec{P}
\end{gathered}
$$

onde $\sigma$ é a condutividade do meio, $\mu$ é a permeabilidade magnética e $\vec{P}$ é o vetor polarização, resultado do deslocamento de cargas elétricas ao longo da direção na qual o campo é aplicado ao material.

Nas relações acima estamos considerando meio homogêneo e isotrópico. Caso contrário teríamos que substituir os escalares $\sigma, \mu, \rho$ e $\varepsilon$ pelos tensores equivalentes.

Através das equações acima, podemos deduzir a equação de onda que relaciona os campos elétrico e magnético variáveis no tempo e espaço.

Assim, eliminando o vetor $\vec{B}$ e tomando-se o rotacional de ambos os lados da equação A.1-1 temos:

$$
\vec{\nabla} \wedge(\vec{\nabla} \wedge \vec{E})=-\mu_{0} \cdot \vec{\nabla} \wedge \frac{\partial \vec{H}}{\partial t}
$$


Usando adequadamente as relações constitutivas e as equações de Maxwell e permutando os operadores rotacional e derivada, temos:

$$
\vec{\nabla} \wedge(\vec{\nabla} \wedge \vec{E})=-\mu_{0} \cdot \frac{\partial}{\partial t}\left(\sigma \cdot \vec{E}+\varepsilon \cdot \varepsilon_{0} \cdot \frac{\partial \vec{E}}{\partial t}\right)
$$

para (vide apêndice C, Eq. C-13)

$$
\overrightarrow{\nabla^{2}} \vec{E}=\nabla(\vec{\nabla} \times \vec{E})-\vec{\nabla} \wedge(\vec{\nabla} \wedge \vec{E})
$$

onde $\nabla^{2}$ é o operador Laplaciano e $\nabla(\cdot)$ é o operador gradiente.

Substituindo a equação A.1-10 em A.1-9, e utilizando a equação A.1-4 temos:

$$
\overrightarrow{\nabla^{2}} \vec{E}-\nabla\left(\frac{\rho}{\varepsilon \cdot \varepsilon_{0}}\right)=\mu_{0} \cdot \frac{\partial}{\partial t}\left(\sigma \cdot \vec{E}+\varepsilon \cdot \varepsilon_{0} \cdot \frac{\partial \vec{E}}{\partial t}\right)
$$

desenvolvendo as derivadas e rearranjando os termos:

$$
\overrightarrow{\nabla^{2}} \vec{E}-\mu_{0} \cdot \varepsilon \cdot \varepsilon_{0} \cdot \frac{\partial^{2} \vec{E}}{\partial t^{2}}-\mu_{0} \cdot \sigma \cdot \frac{\partial \vec{E}}{\partial t}=\nabla\left(\frac{\rho}{\varepsilon \cdot \varepsilon_{0}}\right)
$$

Considerando apenas uma dimensão na equação A. 1-12:

$$
\frac{\partial^{2} E}{\partial x^{2}}-\mu_{0} \cdot \varepsilon \cdot \varepsilon_{0} \cdot \frac{\partial^{2} E}{\partial t^{2}}-\mu_{0} \cdot \sigma \cdot \frac{\partial E}{\partial t}=\frac{1}{\varepsilon \cdot \varepsilon_{0}} \cdot \frac{\partial \rho}{\partial x}
$$

Para o caso particular em que $\rho$ representa uma distribuição constante de cargas, o que é perfeitamente válido quando consideramos uma região de depleção por exemplo, a equação A.1-13 reduz-se à equação A.1-14, cuja solução é apresentada em seguida (A.1-15).

$$
\frac{\partial^{2} E}{\partial x^{2}}-\mu_{0} \cdot \varepsilon \cdot \varepsilon_{0} \cdot \frac{\partial^{2} E}{\partial t^{2}}-\mu_{0} \cdot \sigma \cdot \frac{\partial E}{\partial t}=0
$$




$$
E_{z}=E_{0} \cdot e^{i \omega \cdot\left(1-\frac{\xi \cdot x}{c}\right)}
$$

onde $c$ é a velocidade da luz no vácuo, $t$ é a coordenada temporal, $x$ é a direção de propagação da onda, $i$ é a unidade dos números imaginários e $\xi$ é a constante de propagação dada por:

$$
\xi^{2}=c^{2} \cdot\left(\mu_{0} \cdot \varepsilon \cdot \varepsilon_{0}-\frac{i \cdot \sigma \cdot \mu_{0}}{\omega}\right)
$$

Podemos rescrever A.1-16 como:

$$
\xi^{2}=c^{2} \cdot \mu_{0} \cdot \varepsilon_{0} \cdot\left(\varepsilon-\frac{i \cdot \sigma}{\omega \cdot \varepsilon_{0}}\right)
$$

Como já sabemos, no vácuo

$$
1=c^{2} \cdot \mu_{0} \cdot \varepsilon_{0}
$$

que é relação que define que a velocidade da luz no vácuo é uma constante.

Portanto A.1-17 resulta em:

$$
\xi^{2}=\varepsilon-\frac{i \cdot \sigma}{\omega \cdot \varepsilon_{0}}
$$

Separando A.1-19 em suas partes real e imaginária:

$$
\xi=n-i \cdot k
$$

sendo $n$ o índice de refração do meio e $k$ o seu índice de absorção.

Tendo-se em vista a equação acima, podemos rescrever a equação A.1-15 da seguinte maneira: 


$$
E_{z}=E_{0} \cdot\left(e^{-\frac{\omega \cdot k \cdot x}{c}}\right) \cdot\left(e^{i \cdot \omega\left(t-\frac{n l \cdot x}{c}\right)}\right)
$$

A equação acima representa uma onda de frequiência $v=\omega / 2 \cdot \pi$ que caminha a uma velocidade $c / n$ na direção $x$.

A primeira exponencial de A.1-21 representa a atenuação sofrida pela onda que vemos ser devida à parte imaginária de A.1-20, ou seja, é um termo proporcional à condutividade do meio em que a onda estiver se propagando.

Já a segunda exponencial é uma função oscilatória que tem a primeira como envelope (veja a figura A-4).

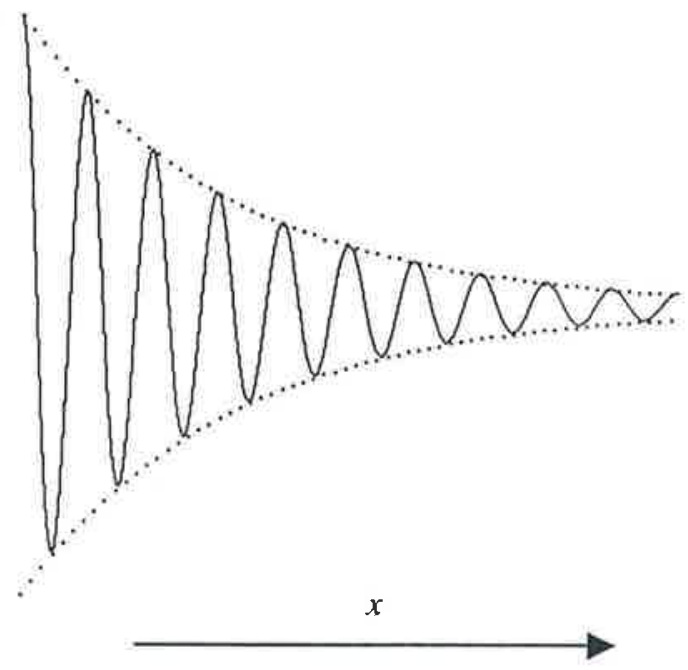

Fig. A-4: Campo elétrico para uma onda eletromagnética em meio de condutividade não nula propagando-se na direção $x$

Seguindo raciocínio análogo podemos calcular também a equação de onda para o vetor campo magnético (A.1-22).

$$
H_{y}=\frac{(n-i \cdot k)}{\mu_{0} \cdot c} \cdot E_{0} \cdot\left(e^{-\frac{\omega \cdot k \cdot x}{c}}\right) \cdot\left(e^{i \cdot \omega \cdot\left(1-\frac{n \cdot x}{c}\right)}\right)
$$

Analisando as equações A.1-19 e A.1-20, podemos chegar às seguintes relações: 


$$
\left\{\begin{array}{l}
n^{2}-k^{2}=\varepsilon \\
2 \cdot n \cdot k=\frac{\sigma}{\omega \cdot \varepsilon_{0}}
\end{array}\right.
$$

o que leva diretamente às equações:

$$
\begin{aligned}
& 2 \cdot n^{2}=\varepsilon \cdot\left(1+\frac{\sigma^{2}}{\omega^{2} \cdot \varepsilon^{2} \cdot \varepsilon_{0}^{2}}\right)^{1 / 2}+\varepsilon \\
& 2 \cdot k^{2}=\varepsilon \cdot\left(1+\frac{\sigma^{2}}{\omega^{2} \cdot \varepsilon^{2} \cdot \varepsilon_{0}^{2}}\right)^{1 / 2}-\varepsilon
\end{aligned}
$$

Por meio das equações A.1-24 (a) e (b) vemos que quando $\sigma \rightarrow 0$, ou seja, em dielétricos perfeitos, $k \rightarrow 0$ e $n \rightarrow \sqrt{\varepsilon}$, conforme se vê na figura A-5 a seguir, para o Si.

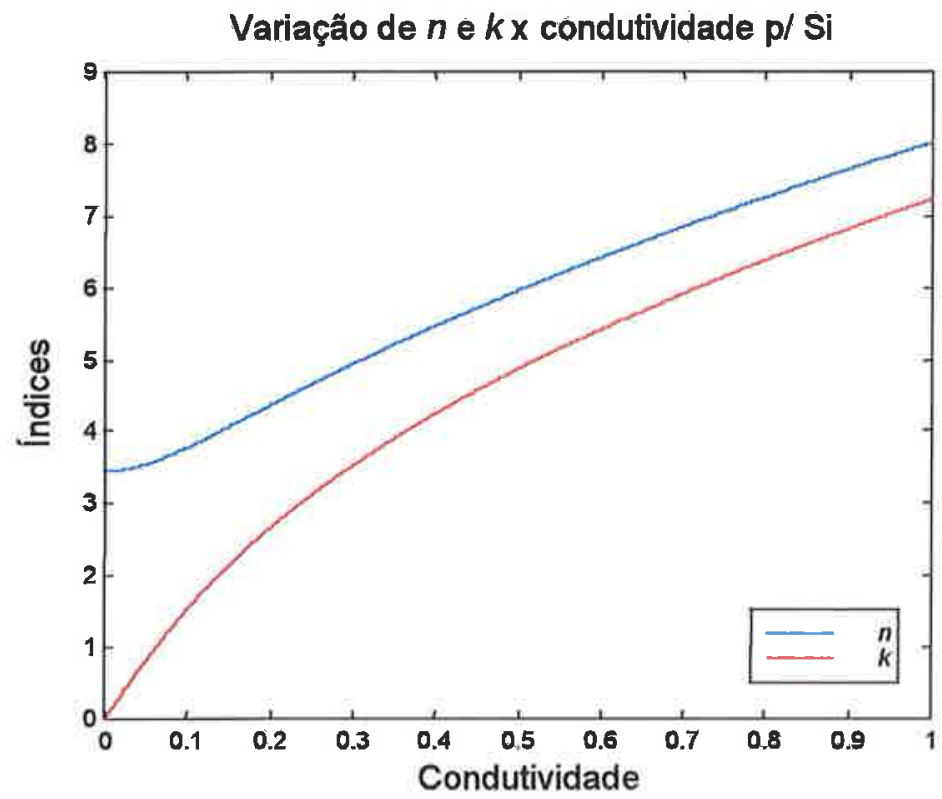

Fig. A-5: Variação dos coeficientes $n$ e $k$ em função de $\sigma$ para $\omega=1 \cdot 10^{5} \mathrm{rad} / \mathrm{s}$ 


\section{A.2 - O Vetor de Poynting}

Toda onda eletromagnética transporta energia armazenada em seus campos elétrico e magnético de forma que quando a amplitude de um deles é nula, a energia permanece armazenada completamente no outro campo.

O vetor de Poynting é um vetor perpendicular tanto ao campo elétrico quanto ao magnético, ou seja, é paralelo à direção de propagação da onda e representa a energia transportada pela mesma.

Matematicamente é dado pela expressão:

$$
\vec{N}=\operatorname{Re}\left[\vec{E}^{\wedge} \vec{H}^{*}+\vec{E}^{\wedge} \vec{H} \cdot e^{i 2 \omega \cdot r}\right]
$$

onde $\operatorname{Re}[\cdot]$ é o operador parte real e o símbolo ${ }^{*}$ indica complexo conjugado.

O valor médio de $n$ sobre um ciclo é dado por:

$$
\overrightarrow{N_{\text {med }}}=\frac{1}{2} \cdot \operatorname{Re}\left[\vec{E}^{\wedge} \vec{H}^{*}\right]
$$

Com isso terminamos nossa análise introdutória sobre as ondas eletromagnéticas, sob o ponto de vista clássico.

Sob a óptica quântica, todos os fenômenos eletromagnéticos podem ser explicados por meio da troca, entre as partículas que possuem carga elétrica e portanto são sensíveis às interações eletromagnéticas, de partículas "virtuais" mediadoras, no nosso caso os fótons.

Como o fóton não possui massa, sua ação pode ser sentida ao infinito, sendo que a intensidade da mesma decai com o quadrado da distância.

Nas secções seguintes estaremos analisando o comportamento de ondas eletromagnéticas na interface entre dois meios distintos, a sua absorção por materiais 
semicondutores e alguns fenômenos interessantes relacionados à presença de campos elétricos.

\section{A.3 - Niveis de energia em um átomo e num sólido}

No começo do século um problema instigava os físicos de todo o mundo: sendo o elétron uma partícula de carga negativa e o próton portador de carga positiva, por que o elétron não era atraído para dentro do núcleo do átomo destruindo-se assim a estabilidade atômica, e portanto, a de toda a matéria conhecida?

A resposta para esse dilema é que o elétron, enquanto onda, (seguindo as proposições de de Broglie), só pode existir em níveis discretos de energia, o que quer dizer, em outras palavras, que o mesmo só pode estar em orbitais de distância definida em relação ao núcleo do átomo, são as camadas atômicas.

Para um sólido, a aproximação dos átomos para a formação da estrutura cristalina acaba por fundir os níveis de energia discretos de cada átomo numa faixa de estados permitidos, conforme se vê na figura A-6.

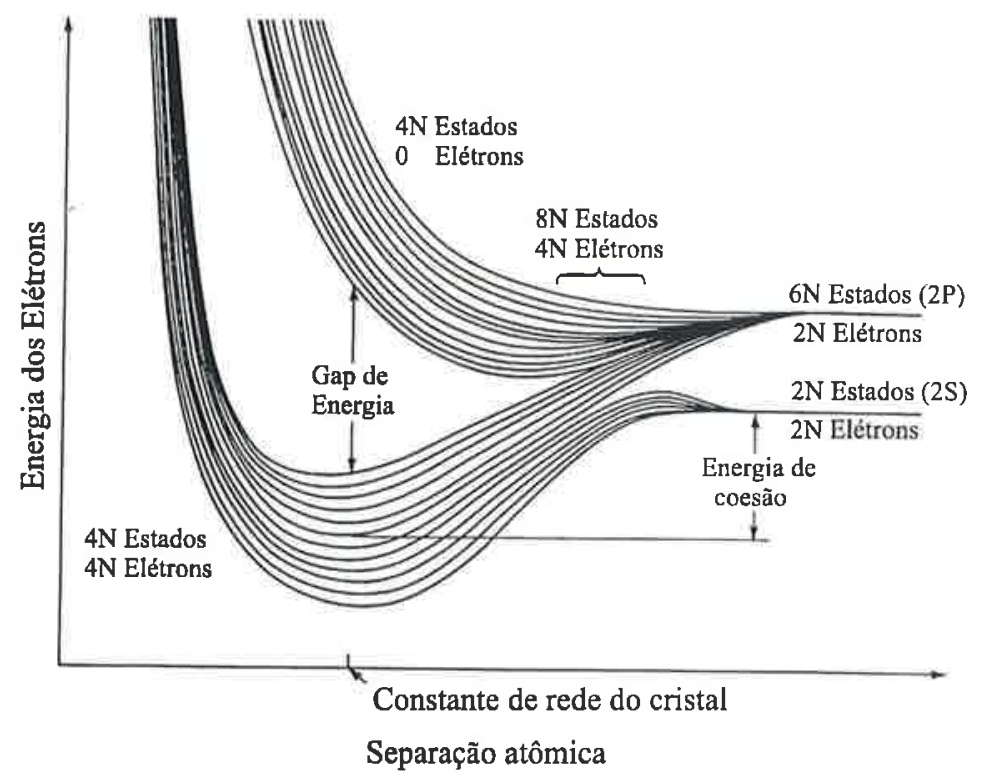

Fig. A-6: Formação da estrutura de faixas de energia no diamante como função da separação entre os átomos 
Isso se dá pois, pelo princípio de exclusão de Pauli, que diz que somente um elétron pode ocupar um dado nível de energia em um sólido, sempre existe uma pequena diferença entre o valor da energia para cada nível discreto entre os diferentes átomos que compõem a rede cristalina. Assim, ao ajuntá-los essas pequenas diferenças acabam por criar uma verdadeira banda de energia, onde têm-se estados permitidos para elétrons.

Num cristal semicondutor, haverá um intervalo de energia, conhecido como "faixa proibida", que separa a faixa de valência, que é a faixa onde ficam os átomos mas externos do material, e a faixa de condução, onde os átomos ficam livres pela rede contribuindo com a condução de corrente.

Em outras palavras, essa faixa de energia implica a existência de uma energia mínima necessária para ionizar os átomos do material, desprendendo os seus elétrons de valência e deixando-os livres para a condução de corrente.

No entanto, para cada elétron ionizado, haverá um espaço vago deixado na faixa de valência. Tal "lacuna" também é um portador de carga elétrica já que "desloca-se" de átomo a átomo da rede conforme elétrons da camada de condução são atraídos pelos átomos ionizados.

Esse efeito é tanto maior quanto menor for a diferença de mobilidade entre elétrons e lacunas.

Assim, para o caso do silício, temos efetivamente um processo de condução bipolar, com um portador de carga negativa, o elétron, e um de carga positiva, a lacuna.

\section{A.4 - Absorção de ondas eletromagnéticas}

O estudo da absorção de ondas eletromagnéticas pode ser levado a efeito quer considerando-se apenas o átomo isoladamente, como num gás por exemplo, ou num 
sólido, onde teremos a participação dos elétrons das camadas de valência e de condução.

De uma forma ou de outra a absorção se dá sempre que a energia do fóton incidente for suficiente para levar um elétron de um nível inicial de energia a um nível final conservando-se nesse processo tanto a energia total do sistema quanto o seu momento.

Num semicondutor, há vários mecanismos pelos quais quântuns de energia das ondas eletromagnéticas incidentes são absorvidos.

Nas próximas secções apresentaremos alguns desses mecanismos.

\section{A.4.1 Transição direta permitida}

Ocorre em materiais de gap direto, isto é, naqueles em que o mínimo da faixa de condução coincide com o máximo da faixa de valência para um valor nulo do vetor de onda. Isso quer dizer que numa transição da banda de valência para a de condução (geração de um par elétron-lacuna) não há necessidade de alteração no valor do momento do elétron.

A figura A-7 ilustra o diagrama de bandas de energia para três semicondutores: $\mathrm{Ge}$, silício e GaAs, onde somente o GaAs possui gap direto. 


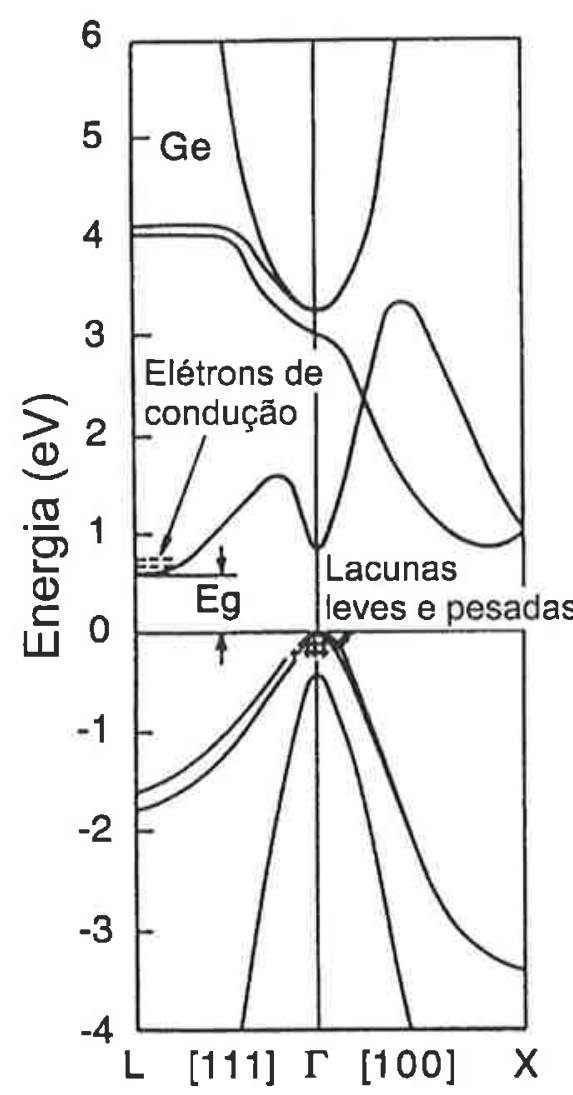

(a)

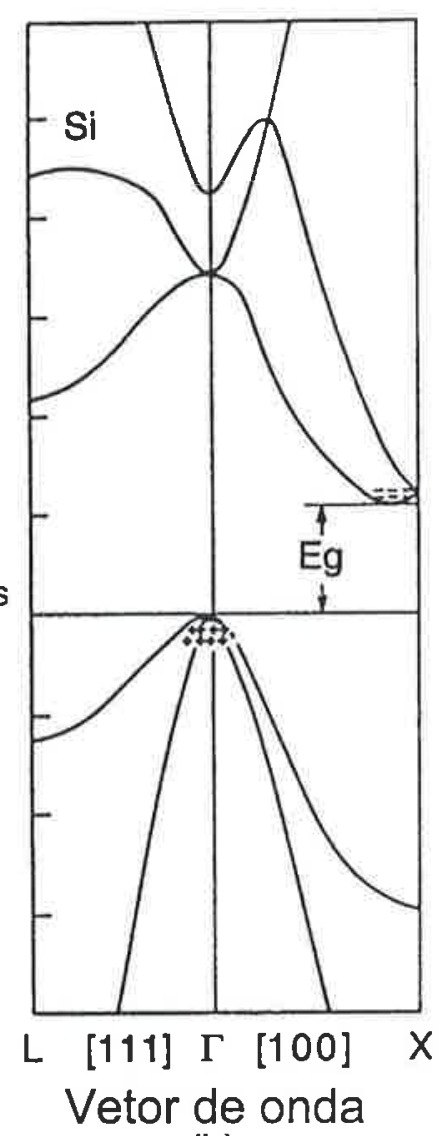

(b)

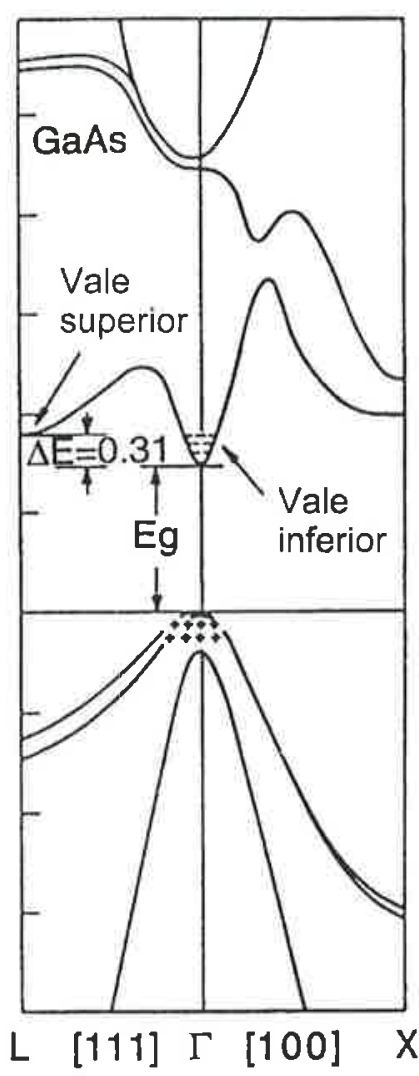

(c)

Fig. A-7: Diagrama de bandas de energia para Ge (a), silício (b) e GaAs (c)

\section{A.4.2 Transição indireta entre vales indiretos}

Ocorre em materiais de gap indireto como o Si. Nela o fóton deve prover a energia necessária para a transição, mas a mesma só ocorrerá se houver interação com algum fónon da rede, com energia $E_{P}$, para providenciar a mudança de momento necessária, já que o fóton não possui momento suficiente para tal.

A figura A-8 a seguir ilustra o processo. 


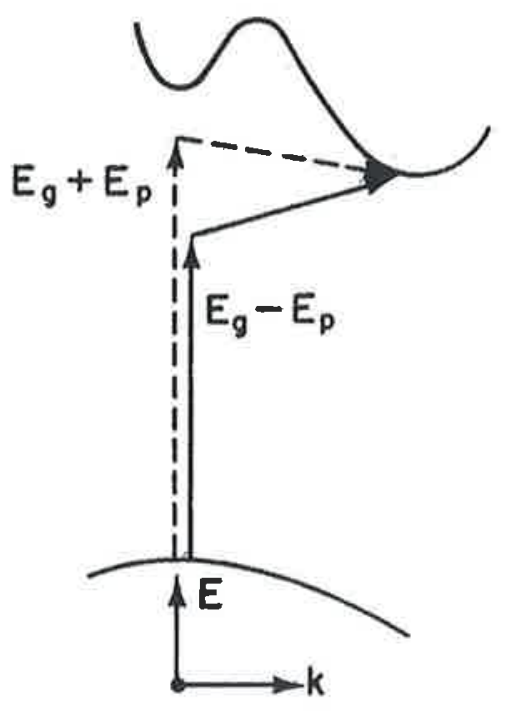

Fig. A-8: Transição indireta

\section{A.4.3 Transições entre prolongamentos de banda}

Pode ser direta ou indireta, como já delineado acima. A diferença ocorre por conta de um prolongamento das bandas de energia (valência e/ou condução) devido à variações nos próprios níveis de energia. A figura A-9 ilustra a formação desses prolongamentos.
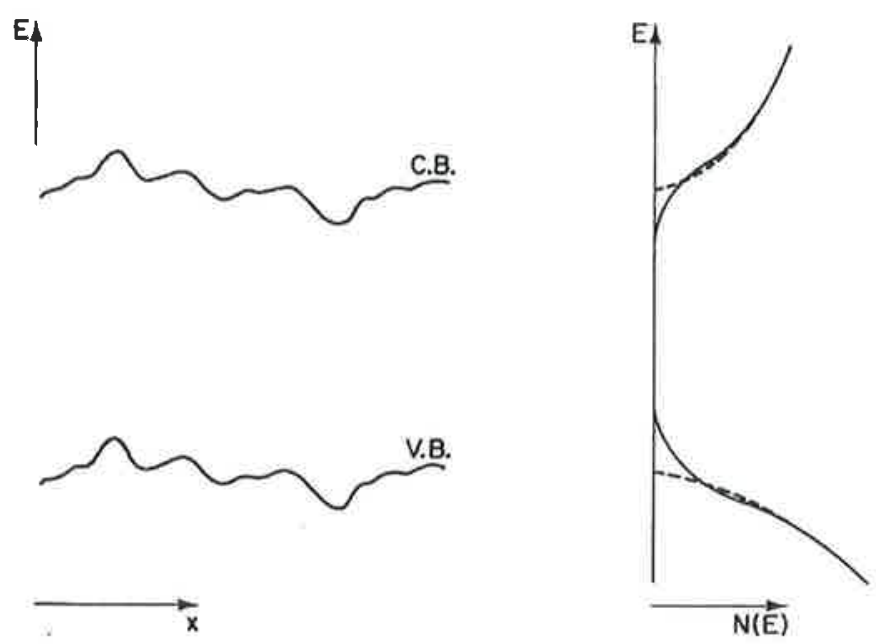

Fig. A-9: Formação de prolongamentos das bandas de energia 


\section{A.4.4 Absorção fundamental em presença de campo elétrico forte}

Ocorre de forma similar ao já descrito com a diferença que, em presença de um campo elétrico forte, a probabilidade de tunelamento aumenta, aumentado assim a probabilidade de tal fenômeno ocorrer assistido por um fóton que seja absorvido.

O efeito global disso é um deslocamento do espectro de absorção para energias mais baixas.

\section{A.4.5 Transições de alta energia}

Ocorrem quando fótons de energia muito alta são absorvidos criando pares elétrons-lacunas de forma direta mesmo em materiais de gap indireto, já que a energia do fóton é suficiente para levar o elétron de qualquer ponto da banda de valência para qualquer ponto da banda de condução (veja a figura A-7 e apêndice A, onde para silício, podemos ter transições diretas para energias de $\sim 3.4 \mathrm{eV}$ ).

\section{A.4.6 Transições entre bandas e níveis de impureza}

Ocorrem para energias menores do que o gap do material já que o fóton só precisa levar o elétron de um nível de energia dentro do gap (nível de energia da impureza) até a banda de condução.

\section{A.4.7 Absorção por portadores livres}

É um tipo de transição que ocorre dentro de uma mesma faixa de energia, sendo necessário uma interação com fónons ou espalhamento com outros portadores livres para conservar o momento total do sistema.

\section{A.4.8 - Coeficiente de absorção}

O coeficiente de absorção de um material é dado pela somatória dos efeitos de cada processo de absorção que ocorre para o referido material. 
O seu comportamento global é começar abruptamente em um nível de energia que é função do gap do material e a partir daí crescer até atingir o seu valor máximo, como pode ser visto na figura A-10.

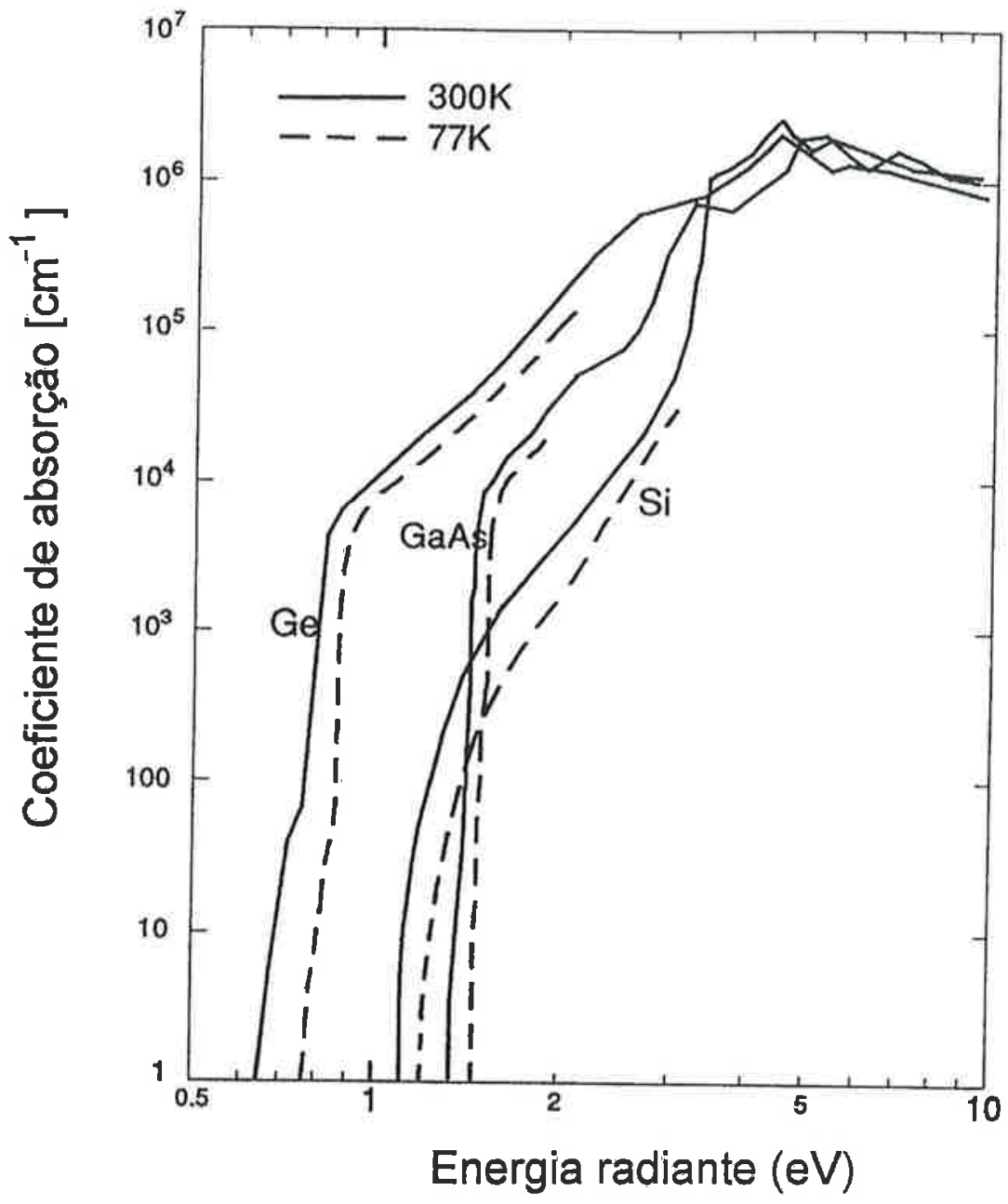

Fig. A-10: Coeficiente de absorção para Ge, silício e GaAs 


\section{Bibliografia}

[AUDE'89] AUDET, S. A.; SCHOONEVELD, E. M. AND MDDELHOEK, S. Highpurity silicon sensor array for imaging soft X-Ray and infrared radiation. International Electron Devices Meeting 1989. Technical Digest, p. 177$180,1989$.

[BAKO'95] BAKOWSKI, A.; CZERWINSKI, A. A.; TOMASZEWSKI, D. AND GIBKI, J. A novel approach to generation lifetime determination from gate-controlled diode characteristics. Electron Technology, 28 (4), p. 241 $250,1995$.

[BRUG'69] BRUGLER, J. S. AND JESPERS, P. G. A. Charge pumping in MOS devices. IEEE Transactions on Electron Devices, ED-16 (3), March 1969.

[CHEN'97] CHEN, T. P.; LO, K. F. AND FUNG, S. Instabilities in gate-controlleddiode characteristics of n-MOSFETs following hot-carrier injection. Semiconductor Science and Technology, 12, p. 1355-1368, 1997.

[CHEN'96] CHEN, T. P.; CHAN, D. S. H. AND CHIM, W. K. Determination of substrate doping, substrate carrier lifetime and density of surface recombination centres of MOSFETS by gate-controlled-diode measurements. Semiconductor Science and Technology, 11, p. 672-678, 1996.

[ÇILI'91] ÇILINGIROGLU, U. Bistable storage in pulsed gate-controlled diode. IEEE Electron Device Letters, 12 (6), p. 338-340, 1991.

[DEMA'85] DeMASSA, T. A. AND LATTIN, W. W. Small-signal analysis of the gate-controlled diode. Solid-State Electronics, 28 (4), p. 393-401, 1985. 
[DUGA'91] DUGAS, J.; JÉRISIAN, R.; QUALID, J.; LABRUNYS, D. AND MIRABEL, J. M. Extraction of the interfacial generation velocity in MOSFET's. Proc. IEEE 1991 International Conference on Microelectronic Test Structures, 4 (1), p. 11-15, March 1991.

[GROV'67] GROVE, A. S., Physics and technology of semiconductors devices. New York, ed. John Wiley \& Sons, 1967.

[GROV'66] GROVE, A. S. AND FITZGERALD, D. J., Surface effects on PN junctions: characteristics of surface space-charge regions under nonequilibrium conditions. Solid-state Electronics, 9, p. 783-806, March 1966.

[HIRA'96] HIRAYAMA, Y. Gate-controlled lateral diodes formed in undoped heterostructure. Japanese Journal of Applied Physics, 35 (10A), p. L1245L1248, Part II, October 1996.

[JACO'83] SWART, J. W. AND CHARRY, E. Interpretation of a non-conventional reverse-current curve of a depletion-type gate-controlled diode. SolidState Electronics, 26 (8), p. 801-803, 1983.

[JELLI'82] JELLISON, G. E., Jr; AND MODINE, F. A. Optical absorption of silicon between 1.6 and $4.7 \mathrm{eV}$ at elevated temperatures. Applied Physical Letters, $41(2)$, p. 180-182, 1982.

[KLAA'90] KLAASEN, W. A. AND NEUDECK, G. W. Sidewall gate controlled diode for the measurement of silicon selective epitaxial growth-SiO $\mathrm{S}_{2}$ interface defects. IEEE Transactions on Electron Devices, 37 (1), p. 273279, January 1990.

[KOLT'88] KOLTUN, M. M. Solar cells, Their optics and metrology. Allerton Press, Inc., 1988. 
[LAN'91] LAN, W. H.; TU, S. L.; CHERNG, Y. T.; PANG, Y. M.; YANG, S. J. AND HUANG, K. F. Field-induced junction in InSb gate-controlled diodes. Japanese Journal of Applied Physics, 30 (1A), p. L1-L3, January 1991.

[LARI'68] LARIN, F. Radiation effects in semiconductor devices. John Wiley \& Sons, Inc., 1968.

[LIOU'94] LIOU, J. J. Advanced semiconductor device physics and modeling. Artech House, 1994.

[LIU'96] LIU, W. Charge trapping in thin gate oxides of nMOSFETs at $77 \mathrm{~K}$ during uniform Fowler-Nordheim electron injection. Internation Journal of Electronics, 80 (1), p. 47-55, 1996.

[MATS'81] MATSUOKA, Y. AND IKUTA, K. Electrical characterization of crystal defects and oxygen in Czochralski silicon using a gate-controlled diode. Solid-State Electronics, 24 (11), p. 1015-1023, 1981.

[MOHS'75] MOHSEN, A. M. AND MORRIS, F. J. Measurements on depletion-mode field effect transistors and buried channel MOS capacitors for the characterization of bulk transfer charge-coupled devices. Solid-State Electronics, 18, p. 407-416, 1975.

[MOSS'73] MOSS, T. S.; BURRELL, G. J. AND ELLIS, B. Semiconductor optoelectronics, Butterworth \& Co., 1973.

[MURA'85] MURAKAMI, S.; MISAWA, Y. AND MOMMA, N. Investigation of leakage currents in a zinc borosilicate glass passivated p-n junction using a gate-controlled diode. Journal of the Electrochemical Society, 132 (9), p. 2198-2201, 1985. 
[NICO'82] NICOLLIAN, E. H. AND BREWS, J. R. MOS (Metal Oxide Semiconductor) physics and technology. John Wiley \& Sons, 1982.

[PANK'71] PANKOVE, Jacques I. Optical process in semiconductors. Prentice-Hall Inc. Englewood Cliffs, New Jersey, 1971.

[PAUL'89] HEREMANS, P.; WITTERS, J.; GROESENEKEN, G. AND MAES, H. E. Analysis of the charge pumping technique and its application for the evaluation of MOSFET degradation. IEEE Transactions on Electron Devices, 36 (7), p. 1318-1335, 1989.

[PIER'74] PIERRET, R. F. The gate-controlled diode $s_{0}$ measurement and steadystate lateral current flow in deeply depleted MOS structures. Solid-State Electronics, 17, p. 1257-1269, 1974.

[SEBA'84] SANTOS FILHO, S. G. DOS; MARTINO, J. A. AND WALDMAN, B. Influência da resistência série na curva característica capacitância-tensão de capacitores MOS. IV Simpósio Brasileiro de Microeletrônica, anais, p. 105-115, 1984.

[SELB'84] SELBERHER, S. Analysis and simulation of semiconductor devices. Springer-Verlag, Wien, NewYork, 1984.

[SHEP'94] SHEPPARD, S. T.; COOPER, J. A. AND MELLOCH, M. R. Nonequilibrium characteristics of hte gate-controlled diode in 6H-SiC. Journal of Applied Physics, 75 (6), p. 3205-3207, March 1994.

[SNOW'67] SNOW, E. H.; GROVE, A. S. AND FITZGERALD, D. J. Effects on ionizing radiation on oxidized silicon surfaces and planar devices. 55 (7), p. 1168-1185, July 1967.

[STRE'95] STREETMAN, B. G. Solid state electronic devices. Prentice-Hall, Inc., $4^{\mathbf{a}}$. ed., 1995. 
[SULL'57] SULLIVAN, M. V. AND EIGLER, J. H. Electroless nickel plating for making ohmic contacts to silicon. Journal of the Electrochemical Society, v. 104 , n. 4 , p. $226-230$.

[SZE'94] SZE, S. M. Semiconductor sensors. New York, ed. John Wiley \& Sons, 1994.

[SZE'83] SZE, S. M. VLSI Technology, McGraw-Hill Book Company, Murray Hill, New Jersey, 1983.

[SZE'81] SZE, S. M. Physics of semiconductor devices. New York, ed. John Wiley \& Sons, $2^{\mathbf{a}}$. ed., 1981.

[VISW'93] VISWANATHAN, C. R.; HSU, J.; AUM, P. AND CHAN D. Enhanced gate-controlled-diode current (EGCDC) measurement. Proc. IEEE International Conference on Microelectronic Test Structures, 6, p. 45-49, March, 1993.

[WALD'85] WALDMAN, B. AND SANTOS FILHO, S. G. DOS Interpretação rápida do transitório $C-t$ do capacitor MOS. V Simpósio Brasileiro de Microeletrônica, anais, p. 79-88, 1985.

[WOLF'69] WOLF, H. F. Silicon semiconductor data. Pergamon Press, 1969.

[YATE'92] YATES, G. J.; SMITH, G. W.; ZAGARINO, P. AND THOMAS, M. C. Measuring neutron fluences and gamma/X-Ray fluxes with CCD cameras. IEEE Transactions on Nuclear Science, 39 (5), p. 1217-1225, October 1992.

[ZIOC'91] ZIOCK, H. J.; MILNER, C.; SOMMER, W. F.; CARTIGLIA, N.; DeWITT, J.; DORFAN, D.; HUBBARD, B.; LESLIE, J.; O'SHAUGHENESSY, K. F.; PITZL, D.; ROWE, W. A.; SADROZINSKI, H. F. -W.; SEIDEN, A.; SPENCER, E.; TENNENBAUM, P.; ELLISON, 
J.; JERGER, S.; LIETZKE, C.; WIMPENNY, S. J.; FERGUSON, P. AND GIUBELLINO, P. Tests of the radiation hardness of VLSI integrated circuits and silicon strip detectors for the SSC under neutron, proton and gamma irradiation. IEEE Transactions on Nuclear Science, 38 (2), p. 269 276, April 1991.

[ZUPA'94] ZUPAC, D.; ANDERSON, S. R.; SCHRIMPF, R. D. AND GALLOWAY, K. F. Determining the drain doping in DMOS transistors using the pump in the leakage current. IEEE Transactions on Electron Devices, 41 (12), p. 2326-2335, 1994. 


\section{Apêndice A - Propriedades físicas do Silício ${ }^{8}$}

\begin{tabular}{|c|c|c|c|}
\hline Propriedade & Símbolo & Valor & unid. \\
\hline N. ${ }^{\circ}$ Atômico & $Z$ & 14 & - \\
\hline Peso Atômico & $W_{a t}$ & 28,09 & u.m.a. \\
\hline Densidade Atômica & - & $5,00 \cdot 10^{22}$ & $\mathrm{~cm}^{-3}$ \\
\hline Estrutura Cristalina & - & Diamante & - \\
\hline Constante de Rede & $a$ & 5,4309 & $\AA$ \\
\hline Ponto de fusão & $T_{f}$ & 1412 & ${ }^{\circ} \mathrm{C}$ \\
\hline Densidade efetiva de estados na banda de condução & $N_{C}$ & $2,8 \cdot 10^{19}$ & $\mathrm{~cm}^{-3}$ \\
\hline Densidade efetiva de estados na banda de condução & $N_{V}$ & $1,04 \cdot 10^{19}$ & $\mathrm{~cm}^{-3}$ \\
\hline $\begin{array}{r}\text { Massa efetiva para elétrons }(4 \mathrm{~K}) \\
\qquad(300 \mathrm{~K})\end{array}$ & $m_{n}$ & $\begin{array}{r}1,1 \cdot \mathrm{m}_{0} \\
0,98 \cdot \mathrm{m}_{0}\end{array}$ & - \\
\hline $\begin{array}{r}\text { Massa efetiva para lacunas (4 K) } \\
\qquad(300 \mathrm{~K})\end{array}$ & $m_{p}$ & $\begin{array}{l}0,59 \cdot \mathrm{m}_{0} \\
0.49 \cdot \mathrm{m}_{0}\end{array}$ & - \\
\hline $\begin{aligned} \text { Energia do Gap: }(0 \mathrm{~K}) \\
(300 \mathrm{~K})\end{aligned}$ & $E_{G}$ & $\begin{array}{l}1,153 \\
1,106 \\
\end{array}$ & $\mathrm{eV}$ \\
\hline Energia de ionização & $E_{i}$ & 3,61 & $\mathrm{eV}$ \\
\hline Energia p/ transição direta & - & 3.4 & $\mathrm{eV}$ \\
\hline Eletro-afinidade & $\chi$ & 4,05 & $\mathrm{~V}$ \\
\hline Emissão predominante & $\lambda_{E}$ & 1,27 & $\mu \mathrm{m}$ \\
\hline Concentração intrínseca de portadores & $n_{i}$ & $1,45 \cdot 10^{10}$ & $\mathrm{~cm}^{-3}$ \\
\hline Comprimento intrínseco de Debye & $L_{D}$ & 24 & $\mu \mathrm{m}$ \\
\hline Tempo de vida médio dos portadores minoritários & $\tau$ & $2,5 \cdot 10^{-3}$ & $\mathrm{~s}$ \\
\hline Mobilidade p/ elétrons & $\mu_{n}$ & 1350 & $\begin{array}{c}\mathrm{cm}^{2} / \mathrm{V} \\
\cdot \mathrm{s}\end{array}$ \\
\hline Mobilidade $\mathrm{p} /$ lacunas & $\mu_{p}$ & 480 & $\begin{array}{c}\mathrm{cm}^{2} / \mathrm{V} \\
\cdot \mathrm{s}\end{array}$ \\
\hline Constante de difusão p/ elétrons & $D_{n}$ & 34.6 & $\mathrm{~cm}^{2} / \mathrm{s}$ \\
\hline Constante de difusão $\mathrm{p} /$ lacunas & $D_{p}$ & 12.3 & $\mathrm{~cm}^{2} / \mathrm{s}$ \\
\hline $\begin{array}{l}\text { Livre caminho médio de fónons: } e^{-} \\
\qquad h^{+}\end{array}$ & $\lambda_{0}$ & $\begin{array}{l}76 \\
55\end{array}$ & $\AA$ \\
\hline Energia óptica de fónons & - & 0,063 & $\mathrm{eV}$ \\
\hline Resistividade intrínseca & $\rho_{i}$ & $2,3 \cdot 10^{5}$ & $\Omega \cdot \mathrm{cm}$ \\
\hline Função trabalho & $\phi$ & 5,05 & $\mathrm{eV}$ \\
\hline Constante dielétrica & $\varepsilon$ & 11,9 & - \\
\hline Campo crítico p/ elétrons & $E_{\text {crit.n }}$ & 2500 & $\mathrm{~V} / \mathrm{cm}$ \\
\hline Campo crítico p/ lacunas & $E_{\text {crit.p }}$ & 7500 & $\mathrm{~V} / \mathrm{cm}$ \\
\hline Campo de ruptura & $E_{b r}$ & $3 \cdot 10^{5}$ & $\mathrm{~V} / \mathrm{cm}$ \\
\hline Densidade & $d$ & 2,329 & $\mathrm{~g} / \mathrm{cm}^{3}$ \\
\hline Índice de refração $(\lambda=6 \mu \mathrm{m})$ & $n^{*}$ & 3,42 & - \\
\hline
\end{tabular}

\footnotetext{
${ }^{8}$ Dados extraídos de [WOLF'69] e [SZE'94] e válidos para $300 \mathrm{~K}$, substrato levemente dopado.
} 


\section{Apêndice B - Constantes físicas}

\begin{tabular}{l|ccc}
\hline \multicolumn{1}{c|}{ Descrição } & Símbolo & Valor & unidade \\
\hline Carga eletrônica & $q$ & $1,602177 \cdot 10^{-19}$ & $\mathrm{C}$ \\
Constante de Boltzmann & $k$ & $8,617386 \cdot 10^{-5}$ & $\mathrm{eV} / \mathrm{K}$ \\
Constante dielétrica do Si & $\varepsilon_{S i}$ & 11,9 & - \\
Constante dielétrica do $\mathrm{SiO}_{2}$ & $\varepsilon_{o x}$ & 3,9 & - \\
Constante de Dirac (h/2 $\pi)$ & $\hbar$ & $6,582122 \cdot 10^{-16}$ & $\mathrm{eV} \cdot \mathrm{s}$ \\
Constante de Planck & $h$ & $4,135669 \cdot 10^{-15}$ & $\mathrm{eV} \cdot \mathrm{s}$ \\
Massa de repouso do elétron & $m_{O}$ & $0,91095 \cdot 10^{-30}$ & $\mathrm{~kg}$ \\
Massa de repouso do próton & $M_{P}$ & $1,67264 \cdot 10^{-27}$ & $\mathrm{~kg}$ \\
Permeabilidade do vácuo & $\mu_{0}$ & $1,256637 \cdot 10^{-6}$ & $\mathrm{H} / \mathrm{m}$ \\
Permitividade do vácuo & $\varepsilon_{0}$ & $8,854188 \cdot 10^{-18}$ & $\mathrm{~F} / \mu \mathrm{m}$ \\
Raio de Bohr & $a_{B}$ & 0,52917 & $\AA$ \\
Tensão térmica ${ }^{9}$ & $\beta, k T / q$ & 0,025852 & $\mathrm{~V}$ \\
Velocidade da luz no vácuo & $c$ & 299.792 .458 & $\mathrm{~m} / \mathrm{s}$ \\
Zero absoluto & $O K$ & $-273,16$ & ${ }^{\circ} \mathrm{C}$ \\
\hline
\end{tabular}

${ }^{9}$ Para temperatura de $300 \mathrm{~K}$. 


\section{Apêndice C - Identidades vetoriais}

$$
\begin{gathered}
\left(\overrightarrow{A^{\wedge}} \vec{B}\right) \times \vec{C}=\left(\overrightarrow{B^{\wedge}} \vec{C}\right) \times \vec{A}=\left(\overrightarrow{C^{\wedge}} \vec{A}\right) \times \vec{B} \\
\vec{A}^{\wedge}\left(\overrightarrow{B^{\wedge}} \vec{C}\right)=(\vec{A} \times \vec{C}) \cdot \vec{B}-(\vec{A} \times \vec{B}) \cdot \vec{C} \\
\vec{\nabla} \times(\vec{A}+\vec{B})=\vec{\nabla} \times \vec{A}+\vec{\nabla} \times \vec{B} \\
\nabla(\psi+\varphi)=\nabla \psi+\nabla \varphi \\
\vec{\nabla} \wedge(\vec{A}+\vec{B})=\vec{\nabla} \wedge \vec{A}+\vec{\nabla} \wedge \vec{B} \\
\vec{D} \times \nabla \psi=\psi \cdot \vec{\nabla} \times \vec{D}-\vec{\nabla} \times(\psi \cdot \vec{D}) \\
\nabla(\psi \cdot \varphi)=\psi \cdot \nabla \varphi+\varphi \cdot \nabla \psi \\
\vec{\nabla} \wedge(\psi \cdot \vec{A})=(\nabla \psi)^{\wedge} \vec{A}+\psi \cdot \vec{\nabla} \wedge \vec{A} \\
\vec{\nabla} \times\left(\overrightarrow{A^{\wedge}} \vec{B}\right)=\vec{B} \times \vec{\nabla} \wedge \vec{A}-\vec{A} \times \vec{\nabla} \wedge \vec{B} \\
\vec{\nabla} \wedge \vec{\nabla} \wedge \vec{A}=\nabla(\vec{\nabla} \times \vec{A})-\overrightarrow{\nabla^{2}} \vec{A} \\
\vec{\nabla} \times(\psi \cdot \vec{A})=\vec{A} \times \nabla \psi+\psi \cdot \vec{\nabla} \times \vec{A} \\
\vec{\nabla} \times \vec{\nabla} \wedge \vec{A}=0 \\
\vec{\nabla} \wedge \nabla \psi
\end{gathered}
$$

